\title{
Untersuchungen zu Auftreten von Clostridium botulinum, betriebsspezifischen Risikofaktoren und Symptomen beim Krankheitsbild des viszeralen Botulismus
}

\author{
Dissertation \\ zur Erlangung des Doktorgrades \\ der Fakultät für Agrarwissenschaften \\ der Georg-August-Universität Göttingen
}

vorgelegt von

Stefanie Engels, geb. Beykirch

geboren in Leinefelde

Göttingen, Februar 2012 
D7

1. Referent: PD Dr. Frank Gessler

2. Korreferent: Prof. Dr. Dr. Matthias Gauly

Tag der mündlichen Prüfung: 9. Februar 2012 
Meiner Familie 


\section{Inhaltsverzeichnis}

$1 \quad$ Einleitung

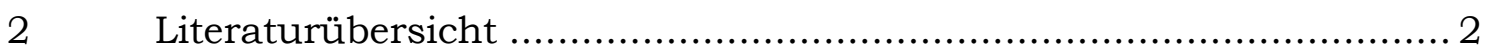

2.1 Ätiologie und Pathogenese des Botulismus ……............................. 2

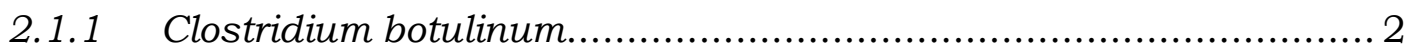

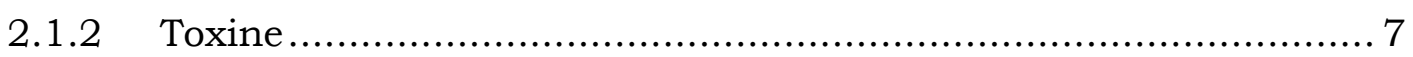

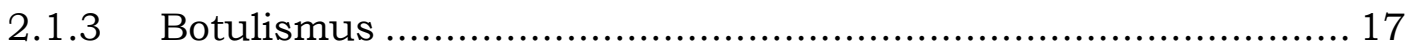

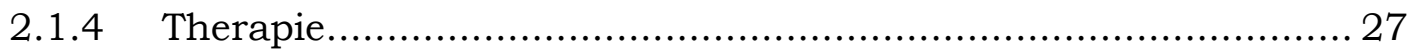

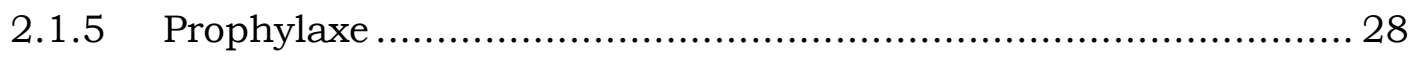

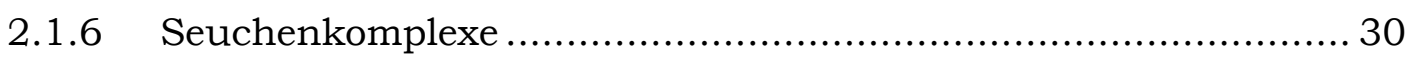

2.2 Nachweis von C. botulinum und BoNT ............................................ 30

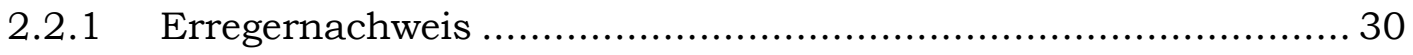

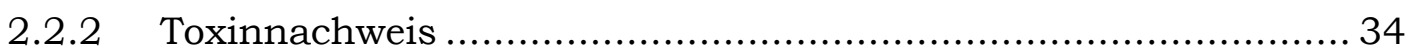

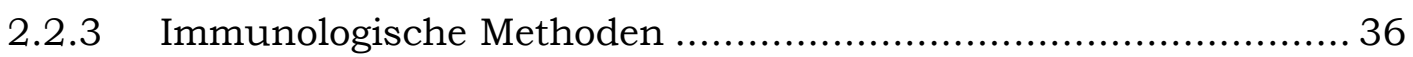

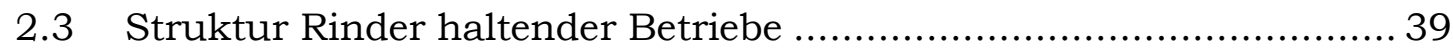

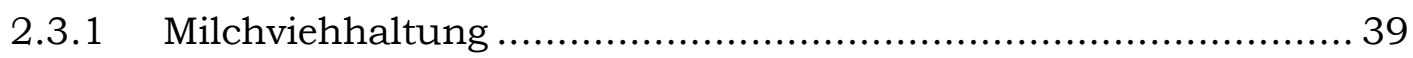

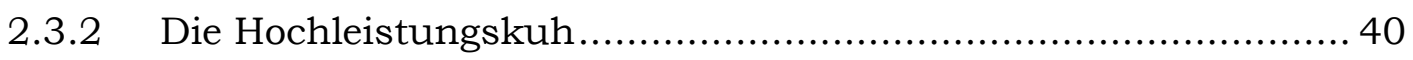

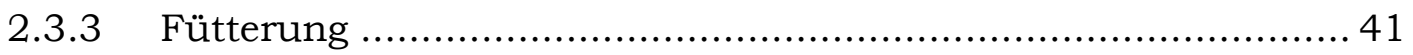

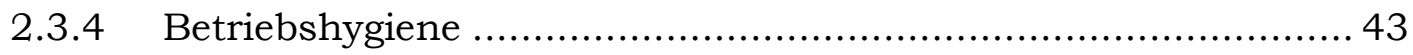

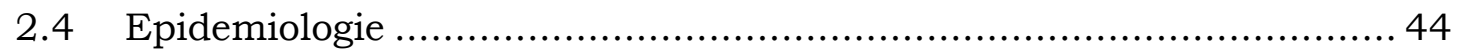

2.4.1 Epidemiologische Studien zur Ermittlung von Risikofaktoren .... 44

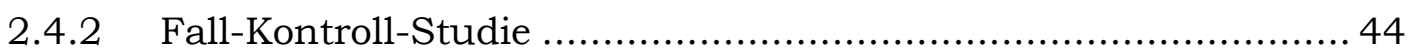

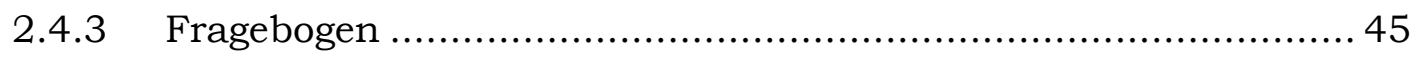

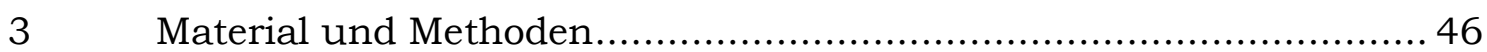







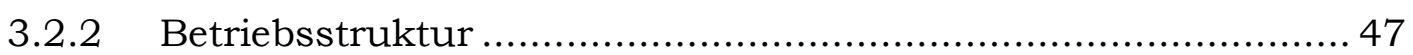

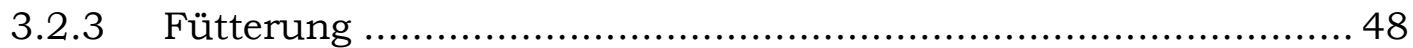

3.2.4 Tiergesundheit ................................................................ 48

3.2.5 Auswertung und Beurteilung der erhobenen Daten .................. 49



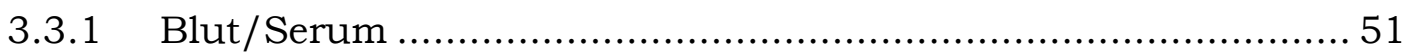

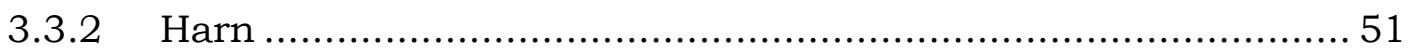

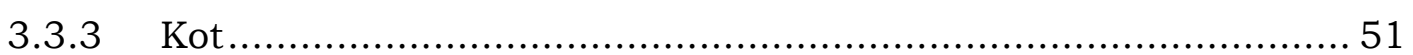

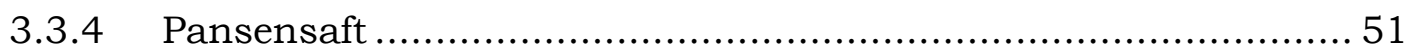

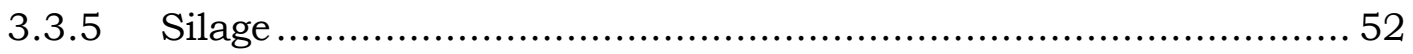

3.4 Bestandsdiagnostik / Herdengesundheit ….................................... 52 


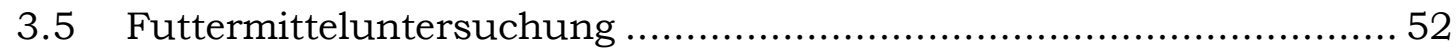

3.6 Clostridiendiagnostik .................................................... 52

3.6.1 Probenvorbereitung............................................. 52

3.6.2 Clostridium botulinum.............................................. 53

3.6.3 Clostridium perfringens .......................................... 62



4.1 Struktur der Studienpopulation.......................................... 66

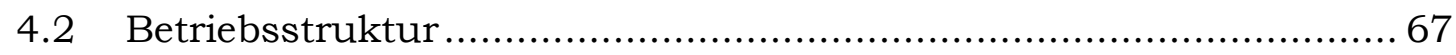

4.2.1 Bestand Milchvieh ...................................................... 67

4.2.2 Weitere Tierhaltung...................................................... 68

4.2.3 Haltung und Reproduktion ......................................... 68

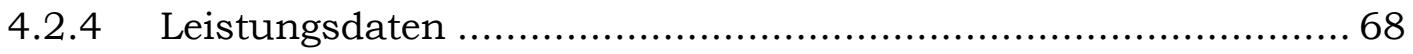

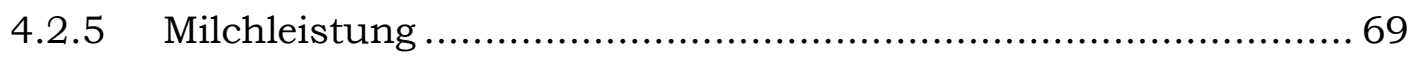

4.2.6 Jährliche Verlustdaten................................................. 77

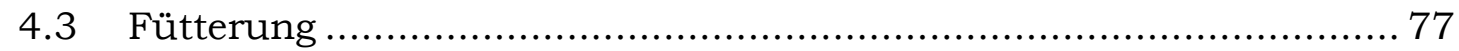

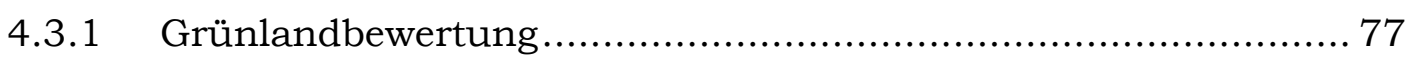

4.3.2 Bewertung der Silierung (Grassilage) ............................... 81

4.3.3 Futtermitteluntersuchung der Grassilage ........................... 86

4.3.4 Wasserversorgung................................................ 90

4.3.5 Fütterung ........................................................... 90

4.4 Tiergesundheit.............................................................. 92

4.4.1 Pflege der Tiere und Sanierungsstatus der Herde .................... 92

4.4.2 Klinische Untersuchung.......................................... 94

4.4.3 Bestandsdiagnostik.................................................. 97

4.4.4 Toxikologische Untersuchung von Organmaterial .................. 104

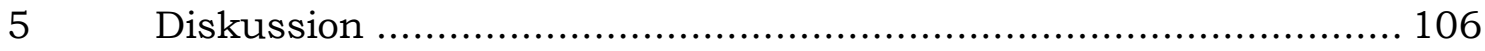

5.1 Entwicklung neuer PCR-Methoden ...................................... 106



5.3 Betriebsstrukturen ............................................................. 109

5.4 Milchleistung ........................................................... 112

5.5 Bewertung des Grünlandes.......................................... 116

5.6 Bewertung der Silierung ....................................................... 119

5.7 Futtermitteluntersuchung der Grassilage ............................. 121

5.8 Bewertung weiterer Futtermittel ..................................... 125

5.9 Wasserversorgung ......................................................... 125

5.10 Tiergesundheit im Bestand .............................................. 126

5.11 Klinisches Erscheinungsbild des viszeralen Botulismus ............... 128

5.12 Bewertung von Maus-Bioassay und PCR anhand der Bestandsdiagnostik 


\begin{tabular}{|c|c|}
\hline 5.14 & 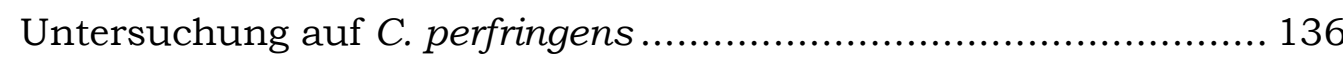 \\
\hline 5.15 & BoNT-Antikörper.... \\
\hline 5 & Schlussfolgerung ....... \\
\hline & Zusammenfassung ............ \\
\hline & Summary...... \\
\hline & Literaturverzeichnis ..... \\
\hline & Anhang.. \\
\hline 10.1 & biologisches Material .... \\
\hline 10.2 & Medien, Puffer und Lösungen .... \\
\hline 10.3 & Geräte..... \\
\hline 10.4 & BoNT/CD-Multiplex-qPCR . \\
\hline 10.5 & Kreuzreaktionen PCR......... \\
\hline 10.6 & Laborwerte der Einzeltiere ........... \\
\hline 10.7 & Anti-BoNT-Titer der Einzeltiere... \\
\hline 10.8 & Fragebogen. \\
\hline
\end{tabular}




\section{Abkürzungsverzeichnis}

\begin{tabular}{|c|c|}
\hline a.p. & ante partum \\
\hline $\mathrm{AK}$ & Antikörper \\
\hline AS & Aminosäure \\
\hline ASAT & Aspartat-Aminotransferase \\
\hline BHB & $\beta$-Hydroxybuttersäure \\
\hline BoNT & Botulinum-Neurotoxin \\
\hline $\mathrm{bp}$ & Basenpaare \\
\hline C. & Clostridium \\
\hline $\mathrm{CDC}$ & Center für Disease Control \\
\hline DNA & Desoxyribonukleinsäure \\
\hline EDTA & Ethylendiamintetraacetat \\
\hline ELISA & Enzyme Linked Immunosorbent Assay \\
\hline ELISA & Enzyme-linked immunosorbent assay \\
\hline FFS & freie Fettsäuren \\
\hline GLDH & Glutamatdehydrogenase \\
\hline GPP & Gelatine-Phosphat-Puffer \\
\hline $\mathrm{H}_{2} \mathrm{O}$ dest. & Aqua destillatum \\
\hline HA & Hämagglutinin \\
\hline $\mathrm{HC}$ & heavy chain \\
\hline HST & Harnstoff \\
\hline i.p. & intraperitoneal \\
\hline i.v. & intravenös \\
\hline IBT & Institut für angewandte Biotechnologie der Tropen, \\
\hline & Göttingen \\
\hline $\mathrm{KbE}$ & Koloniebildende Einheiten \\
\hline $\mathrm{LC}$ & light chain \\
\hline $\mathrm{LD}_{50}$ & 50 \% Letale Dosis \\
\hline LKV & Landeskontrollverband \\
\hline M & molare Masse \\
\hline MJ & Megajoule \\
\hline MLD & Mäuse Letale Dosis \\
\hline MLP & Milchleistungsprüfung \\
\hline NEL & Netto-Energie-Laktation \\
\hline NSBA & Netto-Säure-Basen-Ausscheidung \\
\hline
\end{tabular}


NTNH

OD

p.p.

PBS

PCR

qPCR

$\mathrm{RCM}$

RGD MV

SNAP

SNARE

ssp.

TBE

$\mathrm{TE}$

TM

TMB

TMR

VAMP non-toxic-non-haemagglutinin

optische Dichte

post partum

Phosphate buffered saline

Polymerase-Kettenreaktion

Real-time PCR

Reinforced Clostridial Medium

Rindergesundheitsdienst Mecklenburg-Vorpommern

Synaptosomal-associated protein

soluble N-ethylmaleimide-sensitive-factor

attachment receptor

subspecies

Tris-Borat-EDTA

Tris-EDTA

Trockenmasse

Tetramethylbenzemidin

Total-Mischration

Vesicle associated membrane protein 


\section{Einleitung}

Die klassische Form des Botulismus wurde vor fast 200 Jahren von Justinus Kerner als „Wurstvergiftung“ beschrieben (Kerner, 1820). Es handelt sich ursprünglich um eine sporadisch vorkommende, akute Intoxikation mit durch Clostridium (C.) botulinum gebildetem Botulinum-Neurotoxin (BoNT), die meist tödlich verläuft. Diese anaeroben Sporenbildner sind ubiquitär und in der Lage, hochgiftige Toxine freizusetzen, die in die Reizweiterleitung der Nervenzellen eingreifen. Sie sind pathogen für Säugetiere, Vögel und Fische. Inzwischen sind vier verschiedene klinische Formen des Botulismus anerkannt.

Seit Mitte der 1990er Jahre häufen sich Berichte aus verschiedenen Bundesländern über chronisch verlaufende und mit erheblichen Verlusten einhergehende Bestandserkrankungen bei Hochleistungsmilchrindern und Kälbern. Als Hauptsymptome wurden Lahmheit, Verdauungsstörungen, mangelhafte Futterverwertung und damit verbunden Leistungsrückgang und Abmagerung sowie Kreislaufstörungen und Abgänge nach therapieresistentem Festliegen beobachtet (Schwagerick und Böhnel, 2001). Da im Zuge einer umfassenden Diagnostik sowohl freie BoNTe im Kot von erkrankten Kälbern als auch Antikörper gegen die BoNTe nachgewiesen wurden, bezeichnete Böhnel diese bisher unbekannte Art der Erkrankung als viszeralen Botulismus (Böhnel et al., 2001b).

Da die ätiologische Zuordnung dieses Krankheitsbildes bisher konträr diskutiert wurde, die Definition des viszeralen Botulismus laut Kritikern weder einheitlich noch eindeutig war und nicht endgültig geklärt werden konnte, welche Faktoren am Krankheitsgeschehen beteiligt sind (BfR, 2004; BfR, 2010), wurde im Rahmen dieser Arbeit ein bereits vorhandenes Diagnoseschema (Schwagerick, 2004b) überarbeitet, um im Rahmen einer Fall-Kontroll-Studie in Mecklenburg-Vorpommern die ausschlaggebenden Faktoren für diese Herdenerkrankung zu ermitteln und anschließend das Erkrankungsrisiko beim Tier vermindern zu können.

Parallel dazu wurden immunologische und molekularbiologische diagnostische Verfahren zum Nachweis von $C$. botulinum entwickelt und/oder optimiert und im Rahmen der Fall-Kontroll-Studie angewandt. 


\section{Literaturübersicht}

\section{1 Ätiologie und Pathogenese des Botulismus}

\subsubsection{Clostridium botulinum}

\subsubsection{Taxonomie}

Für die taxonomische Einordnung von Clostridium botulinum ist das Bergey's Manual ${ }^{\circledR}$ of Systematic Bacteriology (2009) bindend. Mit Hilfe dieses Standardwerkes ist es möglich, die Bakterien aufgrund ihres phylogenetischen Stammbaumes, ihrer morphologischen und physiologischen Eigenschaften einer Spezies zuzuordnen. Dabei spielte ab der 2. Auflage des Handbuches die Übereinstimmung der 16S-rRNA-Sequenz durch die Entwicklung neuer Analysemethoden eine entscheidende Rolle, so dass aufgrund neuer Erkenntnisse Umbenennungen oder Neuzuordnungen von Arten möglich waren (Wayne et al., 1987).

Erst 1924 wurde nach einem Vorschlag von Bengtson der Gattungsname Clostridium für anaerob wachsende Sporenbildner eingeführt.

Die Gattung Clostridium gehört zur Familie der Clostridiaceae und besteht aus anaeroben, Endosporen bildenden grampositiven Stäbchen (siehe Abb. 1). Die hervorstechendste Eigenschaft von C. botulinum ist die Produktion von Botulinum-Neurotoxin (BoNT).

Die durch C. botulinum hervorgerufene Symptomatik des Botulismus wird wahrscheinlich so lange beobachtet, wie Menschen Lebensmittel bearbeiten und versuchen, sie durch Konservierung haltbar zu machen. Smith (1977) beschrieb, dass bereits im zehnten Jahrhundert der byzantinische Herrscher Leo VI. (886-911) Verbote für die Herstellung von Blutwurst erließ. Ebenso scheinen einige Fälle einer diagnostizierten Vergiftung mit Atropa belladonna im Nachhinein aufgrund ihrer Symptomatik eher auf lebensmittelbedingten Botulismus hinzudeuten. Nachdem in Wildbad in Württemberg 1793 ein Ausbruch sechs von dreizehn Erkrankten das Leben kostete und in kurzer Abfolge weitere Fälle auftraten, erkannte der Arzt Justinus Kerner, dass diese Lebensmittelvergiftung durch den Verzehr von Wurst (lat. botulus) hervorgerufen wurde (Kerner, 1820). Van Ermengem gelang es schließlich 1895 erstmals, den Erreger aus verdorbenem Schinken zu isolieren und nannte ihn 


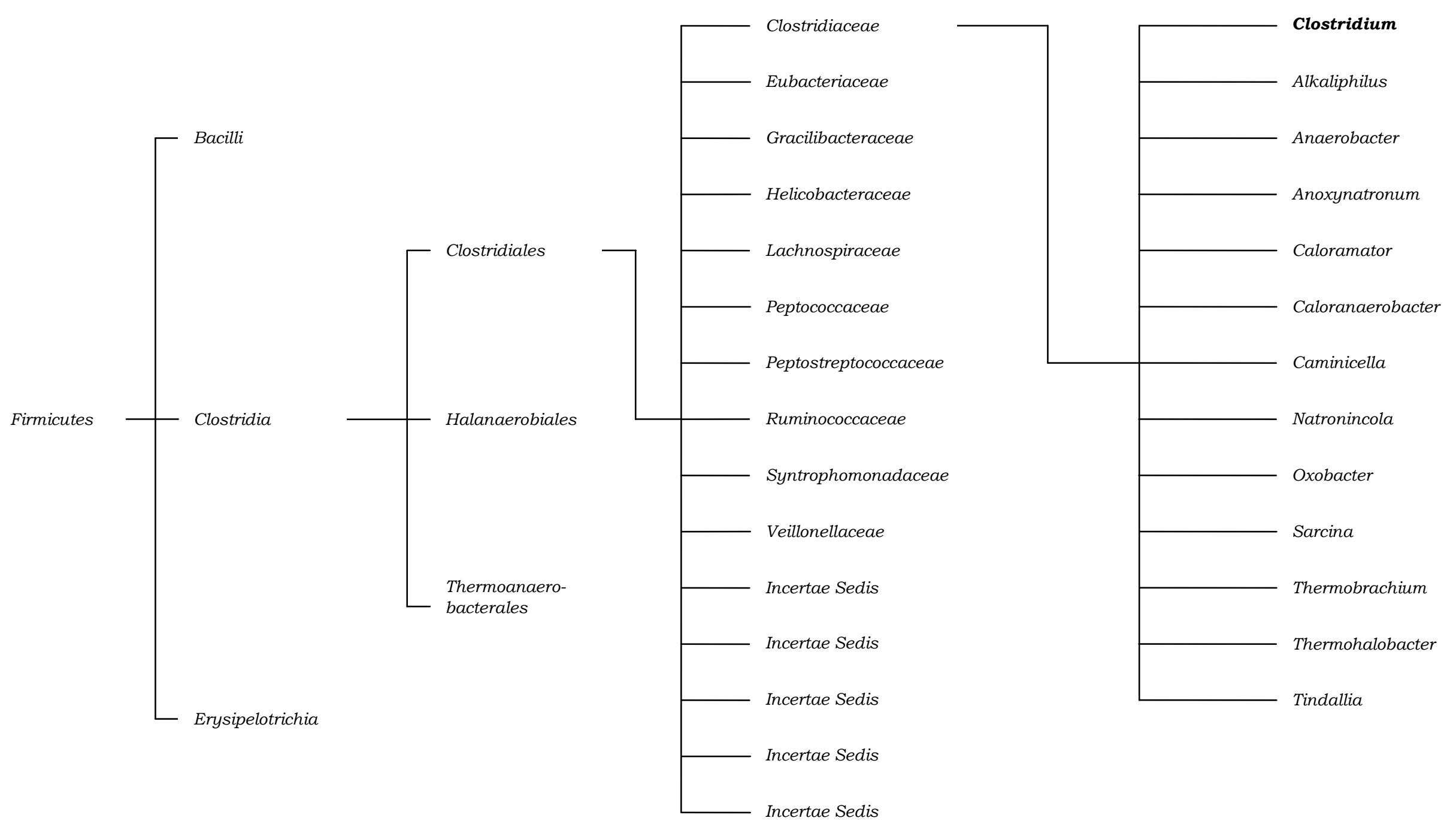

Abb. 1: phylogenetischer Stammbaum (nach Bergey's Manual, 2009) 
Bacillus botulinus (1897). Durch die Isolierung eines zweiten Stammes aus grünen Bohnen widerlegte Landmann (1904) die Annahme, dass das Bakterium nur in Fleisch vorkommt. Leuchs (1910) verglich beide Stämme und konnte feststellen, dass sie sich nicht nur in ihren Wachstumseigenschaften und ihrem Toxinbildungsvermögen, sondern auch in der Neutralisierbarkeit der gebildeten Toxine unterschieden. Nachdem Burke (1919) zwölf verschiedene Stämme untersucht hatte und sie aufgrund ihres verschiedenen Toxin-Antitoxin-Verhaltens in zwei Gruppen einteilen konnte, ordnete er diesen beiden Gruppen die Buchstaben A und B zu.

Kurze Zeit später isolierten Bengtson (1922) in den Vereinigten Staaten und parallel dazu Seddon (1922) in Australien weitere Stämme, die nicht den Typen A oder B zuzuordnen waren. Dieser neue Toxintyp wurde aufgrund der alphabetischen Reihenfolge in der angewandten Nomenklatur als Toxintyp C bezeichnet. Es folgten rasch weitere neue Stämme, die sich in ihren Eigenschaften von den bisher bekannten unterschieden und alphabetisch fortlaufend benannt wurden; so der Typ D aus Südafrika (Meyer und Gunnison, 1928) und der aus Fisch isolierte Typ E (Gunnison et al., 1935). 1960 wurde ein weiterer Typ, F, aus Leberpastete isoliert (Møller und Scheibel). Der anschließend entdeckte C.-botulinum-Typ G (Gimenez und Ciccarelli, 1970a), der sich völlig von den bisher entdeckten Stämmen unterschied, wurde später in C. argentinense umbenannt (Suen et al., 1988b). Einige C.-botulinumStämme sind in der Lage zwei Toxine parallel zu exprimieren, z. B. A und B, A und F oder B und F (Gimenez und Ciccarelli, 1970b; Hatheway et al., 1981; Santos-Buelga et al., 1998).

Die sieben C.-botulinum-Typen A bis G werden nach dieser Nomenklatur ausschließlich auf Basis ihrer Fähigkeit BoNT zu bilden (Prévot, 1953) und ihrer serologischen Spezifität benannt und unterteilt (Dodds, 1994). Nicht toxigene Stämme, die ansonsten die gleichen biochemischen Eigenschaften wie das toxigene $C$. botulinum aufweisen, werden als $C$. sporogenes bezeichnet (Olsen et al., 1995). Dadurch ergeben sich allerdings Probleme in der Zuordnung. Häufig zeigt sich bei den Typen $\mathrm{C}$ und $\mathrm{D}$ die Instabilität der Toxinbildung und/oder der Verlust des Toxingens durch Kultivierung (Oguma, 1976), da sich bei diesen Typen das Toxingen auf einem Bakteriophagen befindet. Eklund et al. (1974) zeigten, dass die Umwandlung eines C.-botulinum- 
Stammes vom Typ C in einen C.-novyi-Typ-A-Stamm durch Verlust des Prophagen ohne Weiteres möglich und auch umkehrbar ist.

Zusätzlich zu C. botulinum wurden einige Stämme von C. baratii und C. butyricum identifiziert, die ebenfalls in der Lage sind, BoNTe zu produzieren (Hall et al., 1985; Aureli et al., 1986; McCroskey et al., 1986).

Heute werden die Stämme nicht nur aufgrund ihres Toxintyps, sondern auch aufgrund ihrer Stoffwechselleistungen, insbesondere der Fähigkeit Proteine verwerten zu können, unterteilt. Genetische Analysen haben gezeigt, dass nur durch die zusätzliche Einteilung in die verschiedenen Stoffwechselgruppen eine eindeutige Zuordnung hinsichtlich des Verwandtschaftsgrades möglich ist (Collins und East, 1998; Hunter und Poxton, 2002).

\subsubsection{Morphologie und Stoffwechselleistungen}

C. botulinum und verwandte Clostridienarten sind gerade oder leicht gekrümmte, grampositive Stäbchen mit einer Länge von 1,6-22 $\mu \mathrm{m}$ und einer Breite von 0,5-2 $\mu \mathrm{m}$. Sie kommen einzeln oder paarweise vor und bilden überwiegend opake, runde bis ausgefranste Kolonien, die vereinzelt schwärmen können (Cato, 1986). Das Gramverhalten der Bakterien ist vom Alter der Kulturen abhängig und kann mit zunehmender Inkubation gramnegativ erscheinen (Bengtson, 1922). Die beweglichen Formen sind peritrich begeißelt. Der Großteil der C. botulinum, C. baratii und C. butyricum wächst obligat anaerob, einige Spezies besitzen eine größere Sauerstofftoleranz. Die Enzyme Katalase, Peroxidase und Cytochrom-Oxidase, die im aeroben Stoffwechsel eine wichtige Rolle spielen, fehlen. Endosporen liegen meist subterminal und lassen die Bakterienzelle anschwellen, so dass sie die charakteristische Form eines Tennisschlägers bekommt. Die optimalen Wachstumsvoraussetzungen herrschen bei einer Temperatur von $30-37{ }^{\circ} \mathrm{C}$ und einem $\mathrm{pH}$-Wert zwischen 6,5 und 7, sind aber vom jeweiligen Typ abhängig (Segner et al., 1971; Hinderink et al., 2009; Brooks et al., 2011; Derman et al., 2011).

Die Einteilung von $C$. botulinum nach ihren biochemischen Leistungen geht auf Holdeman und Brooks (1968) zurück. Sie teilten die C.-botulinum-Typen A bis $F$ in drei metabolische Gruppen. Stämme vom Typ G wurden in einer vierten Gruppe platziert. C. baratii und C. butyricum, die ebenfalls BoNT der 
Typen $\mathrm{E}$ und $\mathrm{F}$ produzieren können, bilden die fünfte Gruppe. In der Gruppe I befinden sich alle Stämme vom Typ A, die proteolytischen Stämme der Typen $\mathrm{B}$ und $\mathrm{F}$, sowie die bivalenten Toxintypen AB, Ab, Af, Ba und Bf. Sie wachsen bei einem Temperaturoptimum von $37^{\circ} \mathrm{C}$ und bilden Sporen von hoher Hitzeresistenz $\left(112{ }^{\circ} \mathrm{C} / \mathrm{D}\right.$-Wert 1,23$)$. Zur Gruppe II gehören alle Stämme vom Typ E, sowie die nichtproteolytischen bzw. saccharolytischen Stämme der Typen B und F. Die Vertreter dieser Gruppe sind psychrotroph und haben ihr Temperaturoptimum bei $30^{\circ} \mathrm{C}$ oder weniger. Ihre Sporen besitzen eine geringere Hitzeresistenz $\left(80^{\circ} \mathrm{C} /\right.$ D-Wert $\left.0,6-1,25\right)$. Die C.-botulinum-Stämme der Gruppe III produzieren Toxine vom Typ C oder D und sind generell saccharolytisch. Sie wachsen optimal bei Temperaturen um $40{ }^{\circ} \mathrm{C}$. Die Hitzeresistenz der Sporen beträgt $104{ }^{\circ} \mathrm{C}$ bei einem D-Wert von 0,1-0,9). Die C.-argentinense-Typ-G-Stämme sind ebenfalls saccharolytisch und bilden die Gruppe IV. Im Gegensatz zu den C.-botulinum-Stämmen bilden sie keine Lipase und können keine Glucose verwerten (alle Parameter nachCollins und East, 1998).

Tab. 1: Charakteristika BoNT-bildender Clostridien (modif. nach Hatheway, 1990)

\begin{tabular}{|c|c|c|c|c|c|c|}
\hline & \multicolumn{4}{|c|}{$\begin{array}{c}\text { C. botulinum } \\
\text { Gruppe }\end{array}$} & \multirow[t]{2}{*}{$\begin{array}{c}C . \\
\text { butyricum }\end{array}$} & \multirow[t]{2}{*}{$\begin{array}{c}C . \\
\text { baratii }\end{array}$} \\
\hline & I & II & III & IV & & \\
\hline Toxintypen & $\mathrm{A}, \mathrm{B}, \mathrm{F}$ & $\mathrm{B}, \mathrm{E}, \mathrm{F}$ & C, D & $\mathrm{G}$ & $\mathrm{E}$ & $\mathrm{F}$ \\
\hline \multicolumn{7}{|l|}{$\begin{array}{l}\text { Produktion } \\
\text { von: }\end{array}$} \\
\hline Lecithinase & - & - & + & - & + & - \\
\hline Lipase & + & + & + & - & - & - \\
\hline Proteolyse & + & - & \pm & + & - & - \\
\hline $\begin{array}{l}\text { Fermentation } \\
\text { Kohlenhydrate }\end{array}$ & + & + & + & - & + & + \\
\hline $\begin{array}{l}\text { Hydrolyse } \\
\text { Gelatine }\end{array}$ & + & + & + & + & - & - \\
\hline $\begin{array}{l}\text { nichttoxische } \\
\text { Variante }\end{array}$ & $\begin{array}{c}C . \\
\text { sporogenes }\end{array}$ & & C. novyi & $\begin{array}{l}\text { C. sub- } \\
\text { terminale }\end{array}$ & & \\
\hline
\end{tabular}


2005 wurde außerdem ein Clostridium sp. RKD aus Fisch in Indien isoliert, das zwar ein BoNT/B-ähnliches Toxin bildet, aber 1t. 16S-rDNA-Analyse eine 99\%ige Übereinstimmung mit C. tetani zeigt und bzgl. seiner Stoffwechselleistungen zwischen $C$. tetani und C. botulinum einzuordnen ist (Dixit et al., 2005).

\subsubsection{Toxine}

\subsubsection{Botulinum-Neurotoxine (BoNTe)}

\subsection{Toxizität}

Bei den sieben bisher bekannten BoNTen handelt es sich um die giftigsten biologischen Toxine. Die Sensitivität variiert je nach Spezies und Applikationsverfahren (Lamanna, 1959). So sind die Toxinkomplexe, die neben den Toxinen aus nichttoxischen Komponenten bestehen, oral verabreicht wesentlich toxischer als die Toxine allein, da der schützende Komplex die Inaktivierung im Magen-Darm-Trakt reduziert (Gill, 1982). So kann die orale Toxizität um $10^{4} \log _{10}$ steigen, wie Ohishi et al. (1977) zeigten. Im Intestinum gelangen die Toxine durch Bindung an spezifische Rezeptoren an der mukosalen Seite der Epithelzellen und aktiven Transport, durch Porenbildung (Hoch et al., 1985; Maksymowych und Simpson, 1998; Simpson, 2004) oder durch transepithelialen Durchtritt in den Körper (Matsumura et al., 2008).

Bivalente C.-botulinum-Stämme sind in der Lage mehr als ein BoNT zu bilden. Wird das Toxin in gleichem Maße produziert, werden die beiden Buchstaben großgeschrieben (z. B. AB). Wird eines der Toxine in weit geringerem Maße gebildet oder ist als stilles Gen nur in der PCR nachweisbar, wird der Buchstabe dieses BoNTs kleingeschrieben (z. B. Ba, Af). 
Tab. 2: LD50 bzw. MLD der BoNTe (modif. nach Gill, 1982)

\begin{tabular}{|c|c|c|c|c|}
\hline BoNT-Typ & Maus & Affe & Rind & Mensch \\
\hline A & $(1,2 \text { ng i.p. })^{1}$ & $(0,5-0,7 \mathrm{ng})^{\mathrm{a}}$ & \multirow{6}{*}{$(0,388 \mathrm{ng})^{5}$} & \multirow[t]{6}{*}{$(\text { ca. } 1 \mathrm{ng})^{\mathrm{c}}$} \\
\hline B & \multicolumn{2}{|l|}{$1,2-2$ ng i.p..$^{2,3}$} & & \\
\hline $\mathrm{C} 1$ & $1,1 \mathrm{ng}$ i.v. ${ }^{4}$ & (ca. 0,4 ng)c & & \\
\hline $\mathrm{D}$ & 0,4 ng i.p. ${ }^{6}$ & 40 ngc & & \\
\hline $\mathrm{E}$ & $1,1 \mathrm{ng}^{7}$ & \multirow[t]{2}{*}{$1,1 \mathrm{ngc}^{\mathrm{c}}$} & & \\
\hline $\mathrm{F}$ & 2,5 ng i.v. ${ }^{8}$ & & & \\
\hline \multicolumn{5}{|c|}{$\begin{array}{l}\text { Werte in Klammern: Minimale Letale Dosis (MLD), } \\
\text { 1(Lamanna et al., 1946); }{ }^{2} \text { (Duff et al., 1957); }{ }^{3}\left(\text { Lamanna und Glassman, 1947); }{ }^{4} \text { (Syuto und }\right. \\
\text { Kubo, 1977); } 5 \text { (Moeller et al., 2003); }{ }^{6} \text { (Cardella et al., 1960); }{ }^{7} \text { (Gerwing et al., 1965); } 8 \text { (Ohishi und } \\
\text { Sakaguchi, 1974) } \\
\text { a-c: anhand der Mäusetoxizität geschätzte Werte; a(Herrero et al., 1967); b(Meyer und Eddie, } \\
\text { 1951); c(Prévot und Brygoo, 1953) }\end{array}$} \\
\hline
\end{tabular}

2.1.2.1.2 Struktur des BoNTs und seine Wirkungsweise an und in der Zielzelle

BoNTe werden als $150 \mathrm{kDa}$ Polypeptidkette gebildet und durch die Bakterien oder den Wirt proteolytisch in zwei Ketten gespalten, in eine schwere Kette (HC) von $100 \mathrm{kDa}$ und in eine leichte Kette (LC) von $50 \mathrm{kDa}$, die durch eine Disulfidbrücke verbunden sind (Montecucco und Schiavo, 1994). Sie können durch Polyacrylamid-Gelelektrophorese (PAGE) aufgetrennt werden (Sugiyama, 1980). Die Aufnahme des Toxins aus der Lymphe oder dem Blut in die Nervenzelle geschieht in einem vierstufigen Prozess (Montecucco et al., 1994). Er besteht aus der Bindung an die Zelle, der Internalisierung, der Membrantranslokation und der Zielmodifikation.

Die leichte Kette repräsentiert die aktive Komponente. Sie agiert als Zink-abhängige Endopeptidase mit einer strikten Substratspezifität (Schiavo et al., 1992b; Schiavo et al., 1994b). Die schwere Kette setzt sich aus einer jeweils $50 \mathrm{kDa} \mathrm{N}$-terminalen $\left(\mathrm{HC}_{\mathrm{N}}\right)$ und $\mathrm{C}$-terminalen $\left(\mathrm{HC}_{\mathrm{C}}\right)$ Domäne zusammen. Die $\mathrm{HC}_{\mathrm{C}}$-Domäne wiederum besteht aus zwei je $25 \mathrm{kDa}$ Subdomänen (Swaminathan, 2011). Mit der $\mathrm{HC}_{\mathrm{C}}$-Domäne der schweren Kette bindet das 
BoNT an den präsynaptischen Nervenendigungen der cholinergen Neuronen. Anschließend bildet das $\mathrm{HC}_{\mathrm{N}}$-Fragment in der präsynaptischen Membran Kanäle, die den Durchtritt der LC in das Zytosol der Zielzelle ermöglichen (Black und Dolly, 1986b; Black und Dolly, 1986a; Blaustein et al., 1987; Koriazova und Montal, 2003; Fischer und Montal, 2007).

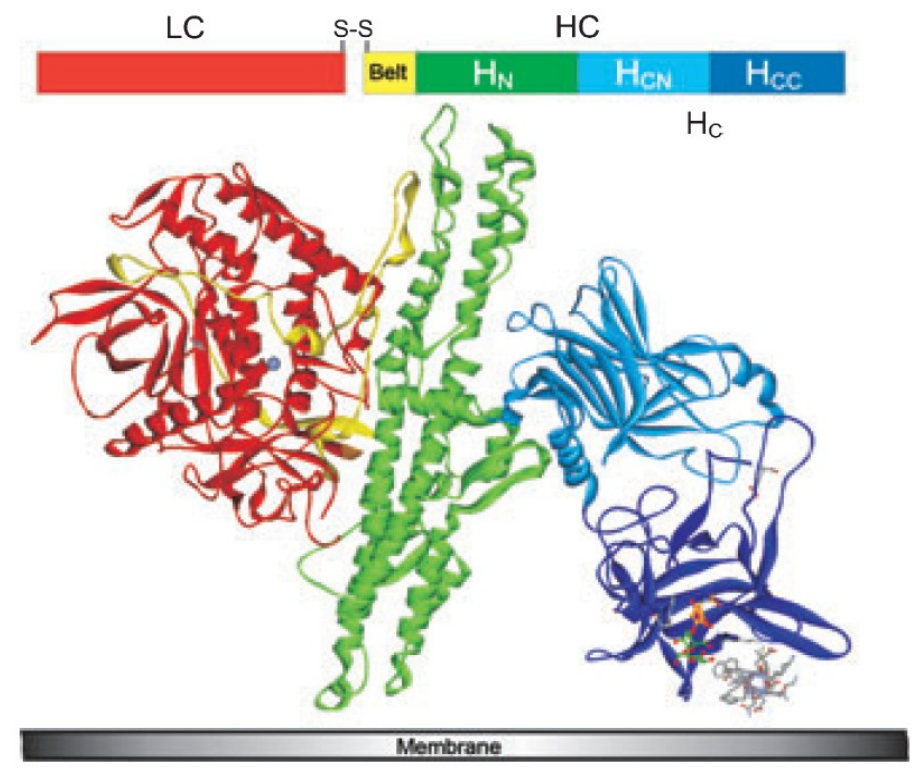

Abb. 2: Struktur der Domänen und Rezeptorbindungstaschen von BoNT/B (Binz und Rummel, 2009)

In der Nervenzelle hat jedes BoNT ein spezifisches Ziel am SNARE-Komplex. BoNT/A und E spalten eine spezifische Peptidbrücke in SNAP-25 (Binz et al., 1994), BoNT/B, D, F und G (genauso wie das Tetanustoxin) setzen am Synaptobrevin (VAMP) an (Schiavo et al., 1992a; Schiavo et al., 1993a; Schiavo et al., 1993b; Yamasaki et al., 1994; Schiavo et al., 1994a). BoNT/C kann sowohl SNAP-25 als auch Syntaxin spalten (Schiavo et al., 2000). Da diese Proteine für die Verschmelzung der Acetylcholinvesikel mit der präsynaptischen Membran verantwortlich sind, wird auf diesem Wege die Ausschüttung von Acetylcholin gehemmt und ein Ausfall in den cholinerg innervierten Muskelfasern hervorgerufen (Kao et al., 1976; Simpson, 1980). 

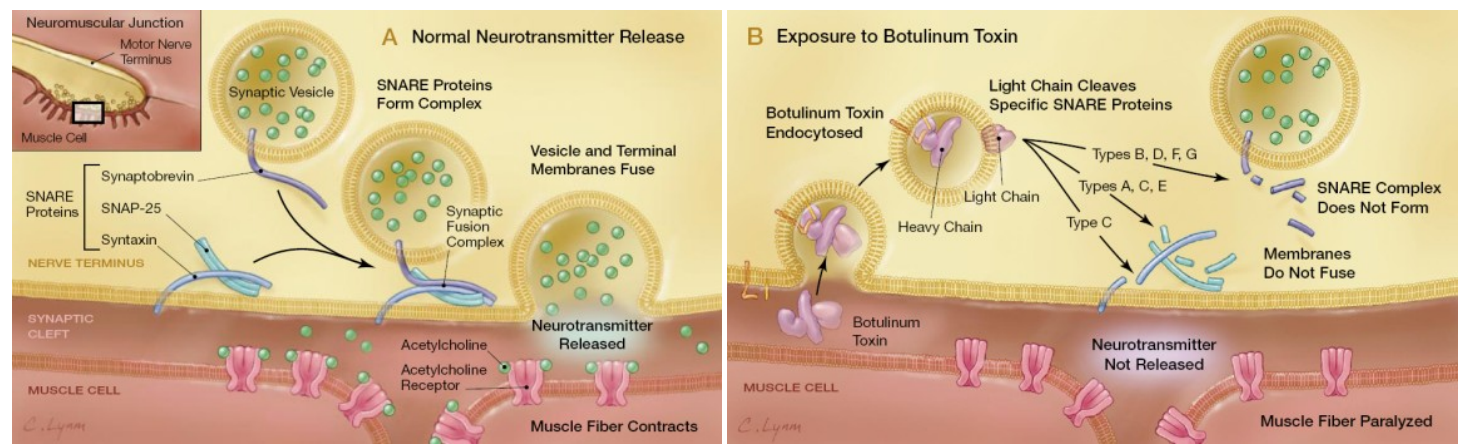

Abb. 3: Wirkungsweise der BoNTe (Arnon et al., 2001)

Die kristallinen Strukturen der Holotoxine BoNT/A, B und E geben einen Einblick in den Mechanismus und die Funktionen der einzelnen Domänen, die in den vierstufigen Prozess der Zellinvasion involviert sind (Lacy et al., 1998; Swaminathan und Eswaramoorthy, 2000; Kumaran et al., 2009). Die BoNTe zeigen eine signifikante Sequenzhomologie (Lacy und Stevens, 1999), allerdings unterscheiden sich ihre dreidimensionalen Strukturen in der Organisation ihrer Domänen. So stehen bei BoNT/E Binde-, katalytische und Translokationsdomäne in viel engerem Kontakt und können an der präsynaptischen Membran wesentlich schneller agieren als das toxischere BoNT/A (Kumaran et al., 2009). BoNT/E wird als nichttoxisches Präcursor-Toxin exprimiert und erst durch den Einsatz von Proteasen aktiviert (Duff et al., 1956).

\subsection{Genetische Grundlagen}

Die ersten Beweise für das Vorkommen von Plasmiden in C. botulinum und ihnen ähnlichen Stämmen wurden 1978 von Scott und Duncan geliefert. Sie lassen sich in den Bakterien aller vier metabolischen Gruppen nachweisen (Strom et al., 1984; Weickert et al., 1986), lange Zeit war aber nur für BoNT/G die Toxinbildung durch ein $81 \mathrm{MDa}$ Plasmid bestätigt (Eklund et al., 1988). Ebenso wurden in allen C.-botulinum-Typen Bakteriophagen nachgewiesen (Inoue und Iida, 1968), aber nur für die BoNT-Typen C und D ist die genetische Information zur Toxinbildung auf diesen Phagen gespeichert (Eklund et al., 1971; Eklund et al., 1972; Skarin et al., 2011). Durch sein pseudolysogenes Verhalten und die geringe Größe erklärt sich der mögliche Verlust des Bakteriophagen während der Laborpassage. Dies erschwert die Isolierung und den Nachweis von C.-botulinum-Typ C und D. 
Das BoNT-Molekül ist in Abhängigkeit vom Toxintyp zwischen 1251 und 1309 Aminosäuren (AS) groß. Die Serotypen unterscheiden sich in ihrer Nukleotidbzw. AS-Sequenz zwischen 35 und 70 \% voneinander.

Tab. 3: Aminosäurenlänge verschiedener BoNT-Typen

\begin{tabular}{cll}
\hline BoNT-Typ & AS-Länge & Quelle \\
\hline A & 1296 & (Binz et al., 1990b) \\
nonprot. B & 1291 & (Whelan et al., 1992; Hutson et al., 1994) \\
prot. B & 1309 & (DasGupta und Woody, 1984) \\
C & 1291 & (Hauser et al., 1990) \\
D & 1276 & (Binz et al., 1990a) \\
E & 1251 & (Poulet et al., 1992) \\
nonprot. F & 1274 & (East et al., 1992) \\
prot. F & 1279 & (Raphael et al., 2010) \\
G & 1297 & (Campbell et al., 1993a) \\
\hline
\end{tabular}

prot - proteolytisch, nonprot. - nichtproteolytisch

Vergleicht man die inzwischen veröffentlichten Nukleotid- bzw. AS-Sequenzen der verschiedenen Serotypen der BoNTe, wird eine Variabilität innerhalb der Serotypen deutlich, die von $2,6 \%$ bis $32 \%$ reichen kann und zur Untergliederung in Subtypen führt (Smith et al., 2007). Diese Vielfalt ist der Grund für signifikante Unterschiede bei der Wirkung von Vakzinen und therapeutischen Agenzien (Kozaki et al., 1995; Smith et al., 2005), da sie einen großen Einfluss auf die Bindung und die Neutralisationskapazität der monoklonalen Antikörper hat. Zurzeit sind für sechs der sieben Serotypen Subtypen bekannt (siehe Tab. 4). Durch Untersuchungen zu den Subtypen fanden Marshall et al. (2007) und Franciosa et al. (2009) heraus, dass bei einigen C.-botulinum-Stämmen der Subtypen BoNT/A3 und A4, genauso wie bei BoNT/B- und bivalenten Stämmen wie $\mathrm{Ba}, \mathrm{Ab}$ und $\mathrm{Bf}$ das BoNT-Gen ebenfalls auf einem Plasmid lokalisiert sein kann (Hill et al., 2009). Dadurch wird ein Transfer von BoNT-Genen mindestens innerhalb der C.-botulinum-Spezies möglich (Marshall et al., 2010). 
Tab. 4: bisher bekannte Subtypen der BoNT-Serotypen

\begin{tabular}{|c|c|c|}
\hline $\begin{array}{l}\text { BoNT- } \\
\text { Serotyp }\end{array}$ & Subtypen & Quelle \\
\hline $\mathrm{A}$ & A1-A5 (inkl. Ab, Af, AB) & $\begin{array}{l}\text { (Gimenez und Ciccarelli, } \\
\text { 1970b; Fujinaga et al., 1995; } \\
\text { Hutson et al., 1996; Dineen et } \\
\text { al., 2004; Arndt et al., 2006; } \\
\text { Hill et al., 2007; Carter et al., } \\
\text { 2009) }\end{array}$ \\
\hline $\mathrm{B}$ & B1-B3, nonprot.B, bv B (Ba, Bf) & $\begin{array}{l}\text { (Gimenez und Ciccarelli, } \\
\text { 1970a; Hatheway et al., 1981; } \\
\text { Santos-Buelga et al., 1998; } \\
\text { Barash und Arnon, 2004; Hill } \\
\text { et al., 2007) }\end{array}$ \\
\hline $\mathrm{C}$ & $\mathrm{C}, \mathrm{C} / \mathrm{D}$ & $\begin{array}{l}\text { (Hauser et al., 1990; Kimura et } \\
\text { al., 1990; Moriishi et al., } \\
\text { 1996a; Moriishi et al., 1996b) }\end{array}$ \\
\hline $\mathrm{D}$ & $\mathrm{D}, \mathrm{D} / \mathrm{C}$ & $\begin{array}{l}\text { (Binz et al., 1990a; Sunagawa } \\
\text { et al., 1992; Moriishi et al., } \\
\text { 1996a; Moriishi et al., 1996b) }\end{array}$ \\
\hline $\mathrm{E}$ & E1-E6 & $\begin{array}{l}\text { (Chen et al., 2007; Hill et al., } \\
\text { 2007) }\end{array}$ \\
\hline $\mathrm{F}$ & F1-F7 & $\begin{array}{l}\text { (Hill et al., 2007; Raphael et } \\
\text { al., 2010) }\end{array}$ \\
\hline
\end{tabular}

nonprot. - nichtproteolytisch, bv - bivalent

Einen besonderen Platz innerhalb der BoNT-Subtypen nehmen die Mosaikformen der BoNT/C und D ein. Sie sind keine Subtypen im eigentlichen Sinne, denn sie unterscheiden sich nicht durch eine Sequenzvariation, sondern durch einen Austausch ganzer Sequenzabschnitte. Oguma et al. verglichen das Neutralisationsvermögen von BoNT/C- und -D-Antiseren in Bezug auf verschiedene C.-botulinum-Typ-C- und -D-Stämme und entdeckten in manchen Fällen eine Kreuzreaktivität zwischen BoNT/C-Antiserum und BoNT/D bzw. BoNT/D-Antiserum und BoNT/C (Oguma et al., 1980; Oguma et al., 1981; Oguma et al., 1984). Moriishi et al. (1989) bemerkten ebenfalls, dass sich innerhalb der BoNT/D-Gruppe die Neurotoxine in ihrer molekularen Struktur und ihrer Antigenität stark voneinander unterschieden. Sie stellten 1996 fest, dass das BoNT des BoNT/D-Stammes South African sowohl die antigenetischen Strukturen der LC von BoNT/D als auch der HC von BoNT/C besaß und bezeichneten BoNTe dieser Art als Mosaikformen (1996b; Moriishi et al., 1996a). Je nach Zusammensetzung der $\mathrm{LC} / \mathrm{HC}_{\mathrm{N}}$ und des $\mathrm{HC}_{\mathrm{C}}$-Fragments werden die Toxintypen als BoNT/C/D oder als BoNT/D/C bezeichnet (Sunagawa et al., 1992; Tsukamoto et al., 2005). 
Diese chimären BonT-Subtypen wirken bei Geflügel toxischer als BoNT/C oder BoNT/D (Takeda et al., 2005).

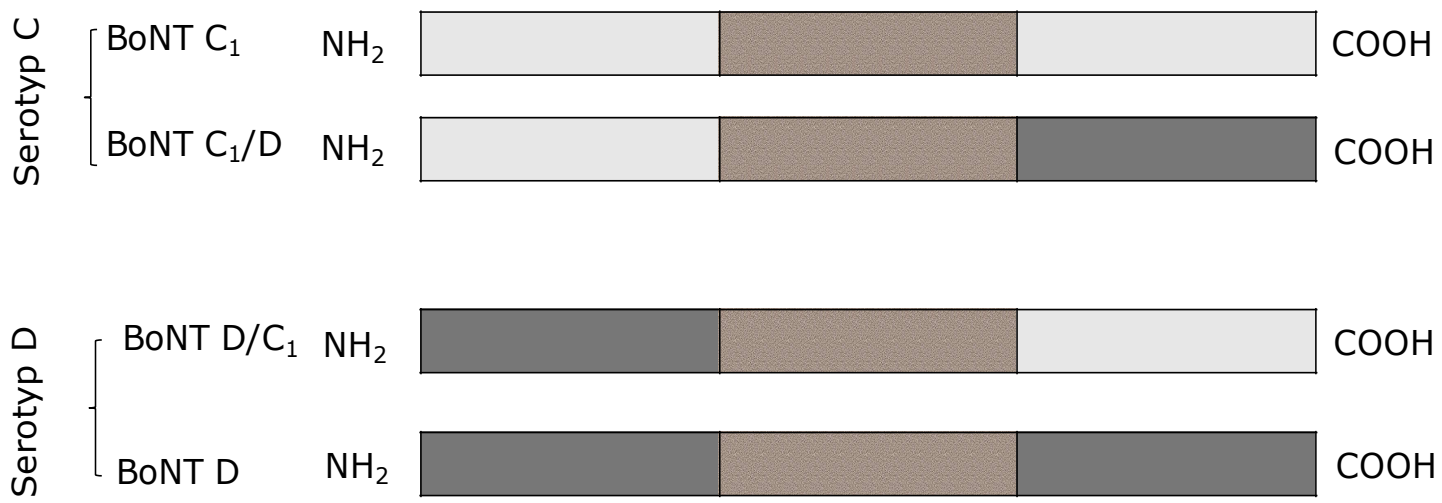

Abb. 4: Mosaikformen von BoNT/C und D (modif. nach Curran et al., 2009)

Die Kenntnis von ihnen ist enorm wichtig, um diagnostische Ergebnisse angemessen bewerten zu können, neue immundiagnostische Verfahren zu entwickeln, aber auch bei der Immunprophylaxe bzw. der Therapie von Botulismus.

\subsection{Struktur und Funktion der Progenitortoxine}

Alle BoNTe werden als Bestandteil eines Enzymkomplexes (Progenitortoxin) gebildet, zu dem auch eine nichttoxische Komponente gehört (Lamanna und Sakaguchi, 1971). Diese kann aus Hämagglutininen (HA) und Nicht-toxischem-nicht-Hämagglutinin (NTNH) bestehen. Die Gene dafür liegen im Genom vor dem Gen für das BoNT. Aufgabe dieser Komponente ist es, das BoNT im Magen vor dem Einwirken von Säure und Proteasen zu schützen. Erst im Dünndarm dissoziieren unter den dort vorherrschenden alkalischen Bedingungen die Proteinkomplexe in die toxischen und nichttoxischen Komponenten (Lowenthal und Lamanna, 1951; Lowenthal und Lamanna, 1953). Das BoNT gelangt nun über die Lymphe und die Blutbahnen zu den Zielorganen. Dementsprechend ist die orale Toxizität der Progenitortoxine um einiges größer als die der BoNTe allein (Ohishi et al., 1977; Ohishi und Sakaguchi, 1980). 
Die Komplexe können, je nach Toxintyp, als verschieden große Progenitortoxine vorliegen. In Abhängigkeit von ihrer Molekülgröße werden sie in drei Gruppen eingeteilt, 12S (M, ca. $300 \mathrm{kDa}$ ), 16S (L, $500 \mathrm{kDa})$ und 19S (LL, 900 kDa) (Kozaki et al., 1974; Sugii und Sakaguchi, 1975). Alle drei Formen existieren bei Typ A (Sugii und Sakaguchi, 1977). 12S und 16S sind bei Typ B (Kozaki et al., 1974), genauso wie bei den Typen C (Iwasaki und Sakaguchi, 1978) und D (Miyazaki et al., 1977) zu finden. Die Typen E und F werden nur als 11,6S bzw. 10,3S-Molekül gebildet (Kitamura et al., 1968; Ohishi und Sakaguchi, 1975). Das eigentliche (Derivat-)Toxin ist $7 \mathrm{~S}$ groß (S, $150 \mathrm{kDa})$ (DasGupta und Sugiyama, 1977). Die HA werden ebenfalls in Abhängigkeit von ihrer Molekülgröße als HA-17, -33, -22 23, -53 und -70 benannt (Tsuzuki et al., 1990; Fujinaga et al., 1994).

Inzwischen wurde entdeckt, dass die nichttoxischen Komponenten mehr Funktionen haben als nur den Schutz des BoNTs. Je eine Region in der ASSequenz von HA-22 23 und -53 zeigt eine signifikante Übereinstimmung mit der gleichen Region des C.-perfringens-Typ-A-Enterotoxins, die wichtig für die Aufnahme des Toxins in die Zelle ist. Es gibt bei HA-22 23 außerdem eine Sequenz, die auch im Fibronektin, einem Glykoprotein der extrazellulären Matrix, gefunden wurde, und die ausschlaggebend für die Interaktion mit dem Zelloberflächenrezeptor ist (Fujinaga et al., 1994). HA zerstört die Diffusionsbarriere zwischen den intestinalen Epithelzellen und begünstigt so den transepithelialen Durchtritt von BoNT (Matsumura et al., 2008). Bei einer Intoxikation durch Inhalation haben die nichttoxischen Proteine keinen Einfluss auf die Toxizität (Park und Simpson, 2003). In vitro zeigt Typ-A-HA eine größere Wirksamkeit als Typ-B-HA, während Typ-C-HA nur einen äußerst geringen Effekt auf humane Zelllinien zu haben scheint. Dagegen hat es einen größeren Einfluss auf MDCK-I-Zellen, wo Typ-C-HA zur Zerstörung der Diffusionsbarriere zwischen den Zellen führt und zytotoxisch wirkt. Dies könnte erklären, warum beim Menschen Botulismus eher durch die Toxintypen A, B, $\mathrm{E}$ oder $\mathrm{F}$ verursacht wird und Typ $\mathrm{C}$ dagegen häufiger bei Botulismus im Tier zu finden ist (Jin et al., 2009). 


\subsubsection{C2-Toxin}

Die meisten BoNT/C- oder BoNT/D-Stämme sind in der Lage, weitere Toxine zu bilden, die sich in ihren Eigenschaften von den BoNTen unterscheiden. Nach Neutralisationsstudien mit Antiseren benannte Jansen (1971) die antigenetisch verschiedenen Toxine als C1, C2 und D. Das C2-Toxin-Gen ist nicht auf einem Phagen, sondern auf chromosomaler DNA lokalisiert (Fujii et al., 1996) und kann auch exprimiert werden, wenn das BoNT-Bildungsvermögen verloren gegangen ist (Eklund et al., 1971). Es wird zunächst als Protoxin gebildet und erst durch Trypsin aktiviert (Eklund und Poysky, 1972). Bei dem C2-Toxin handelt es sich um ein binäres Toxin, das zur Gruppe der MonoADP-Ribosyltransferasen gehört (Simpson, 1986) und Aktin als Substrat verwendet (Ohishi und Tsuyama, 1986). Es unterscheidet sich von den BoNTen durch das Fehlen der kovalenten Bindung zwischen der leichten und der schweren Kette (Komponente I und II) und erlangt seine Toxizität nur als Gemisch von beiden Komponenten (Iwasaki et al., 1980; Ohishi et al., 1980a). Die Ribosyltransferase-Aktivität ist mit der monomeren Komponente I (50 kDa, C2I) assoziiert, während die heptamere Komponente II (100 kDa, C2II) für die Bindung am Oberflächenrezeptor der Zielzelle verantwortlich ist (Ohishi et al., 1980a; Ohishi, 1983b; Ohishi, 1986; Aktories et al., 1986; Mauss et al., 1990). Nach der Stärke ihrer biologischen Aktivität können die C2-Toxine in drei Gruppen eingeteilt werden (Ohishi und Sakaguchi, 1980; Ohishi und Okada, 1986). Die C2II-Komponente des C.-botulinum-Stammes 2300 besitzt zusätzlich eine 129-AS-lange Erweiterung, die die Bindung an die Zelloberflächenrezeptoren unterstützt und so zu einer effektiveren Toxinwirkung führt (Sterthoff et al., 2010).

Eine hydrophobe Schleife jeder C2II-Untereinheit wird in die endosomale Membran eingebracht und formt eine Pore, die den Durchtritt der C2I in das Zytosol erlaubt (Simpson, 1989; Barth et al., 2000). Dort führt die ADPRibosylierung des Aktins zu einer Dysfunktion der Aktinpolymerisation (Aktories et al., 1986; Wegner und Aktories, 1988; Lang et al., 2008). Daraus resultiert eine Umverteilung des Zytoskeletts und es entstehen runde Zellen (Reuner et al., 1987). Des Weiteren induziert C2-Toxin die Bildung neuer Mikrotubuli-Strukturen, die über die Zelloberfläche der Darmepithelzellen hinausragen und so die Anhaftung der Clostridien begünstigen (Schwan et al., 2009). 




Abb. 5: Wirkung des C2-Toxins (Aktories et al., 2011)

In vivo verursacht das C2-Toxin Hypotonie, nekrotische Veränderungen und ruft Flüssigkeitsansammlungen in der Lunge und dem Intestinum hervor (Ohishi et al., 1980b; Simpson, 1982; Ohishi, 1983b; Ohishi, 1983a; Miyake und Ohishi, 1987; Ermert et al., 1995). Es spielt für die Wirkung keine Rolle, ob das Darmepithel nur 15 min oder einen dauerhaften Kontakt hat. Das C2-Toxin ist in der Lage, sehr schnell an epitheliale Zellen zu binden, entfaltet seine enterotoxische Aktivität aber verzögert. Eine Bildung von C2-Toxin durch C. botulinum ist direkt im Darm möglich (Ohishi, 1983b).

\subsubsection{C3-Toxin}

Das C3-Toxin gehört ebenfalls zur Gruppe der ADP-Ribosyltransferasen. Es ist ein ca. $25 \mathrm{kDa}$ Protein (Aktories et al., 1987) und im Phagengenom der C.botulinum-Typen C und D lokalisiert (Matsuoka et al., 1987). Seine Sequenz ist 211 AS lang (Popoff et al., 1990). In diesem Fall ist nicht direkt das Aktin das Substrat, sondern die GTP-bindenden Proteine Rho und andere Proteine der 
Ras-Familie (Rösener et al., 1987; Rubin et al., 1988; Chardin et al., 1989). Mit ihrer entscheidenden Rolle in Migration, Zytokinese, Phagozytose und ZellMatrix-Kontakten führen auch sie zu einer Veränderung der Mikrofilamente in Zellen von Säugetieren (Wilde und Aktories, 2001).

\subsubsection{Clostridiolysin S}

Im Zuge der Genomsequenzierung des Hall-A-C.-botulinum-Stammes und einer vergleichenden Analyse mit Genomen anderer Bakterien bemerkten Sebaihia et al. (2007) ein Gencluster, das große Übereinstimmung mit dem Streptolysin-S-(SLS)-biosynthetic-Operon des Streptococcus spp. aufwies. Bei SLS handelt es sich um ein Zytolysin, das dem Organismus seinen hämolytischen Charakter verleiht und einen bedeutenden Virulenzfaktor darstellt (Datta et al., 2005). Gonzalez et al. (2010) zeigten, dass das analog benannte Clostridiolysin $\mathrm{S}$ tatsächlich für die hämolytischen Eigenschaften von C. botulinum verantwortlich ist und bei der Gewebeverletzung des Wirtes und als Bakteriozin bei der Bildung einer ökologischen Nische eine Rolle spielen kann.

Das Clostridiolysin S wird als Präpropeptid gebildet und erst posttranslational zu einem Propeptid modifiziert (Gonzalez et al., 2010).

\subsubsection{Botulismus}

\subsubsection{Epidemiologie}

Botulismus ist eine natürlich auftretende Erkrankung, die durch Exposition gegenüber BoNT hervorgerufen wird. Unabhängig vom auslösenden Toxintyp und dem betroffenem Wirt zeigt sich bei allen Formen des Botulismus eine übereinstimmende Wirkungsweise auf die Nervenzelle. Durch die Blockade der Acetylcholinfreisetzung in den postsynaptischen Spalt wird die Reizleitung blockiert. Diese Blockade führt zu einer schlaffen Lähmung der motorischen und autonomen Muskulatur, die auch die Lähmung der Atemmuskulatur und den Tod bedeuten kann. 


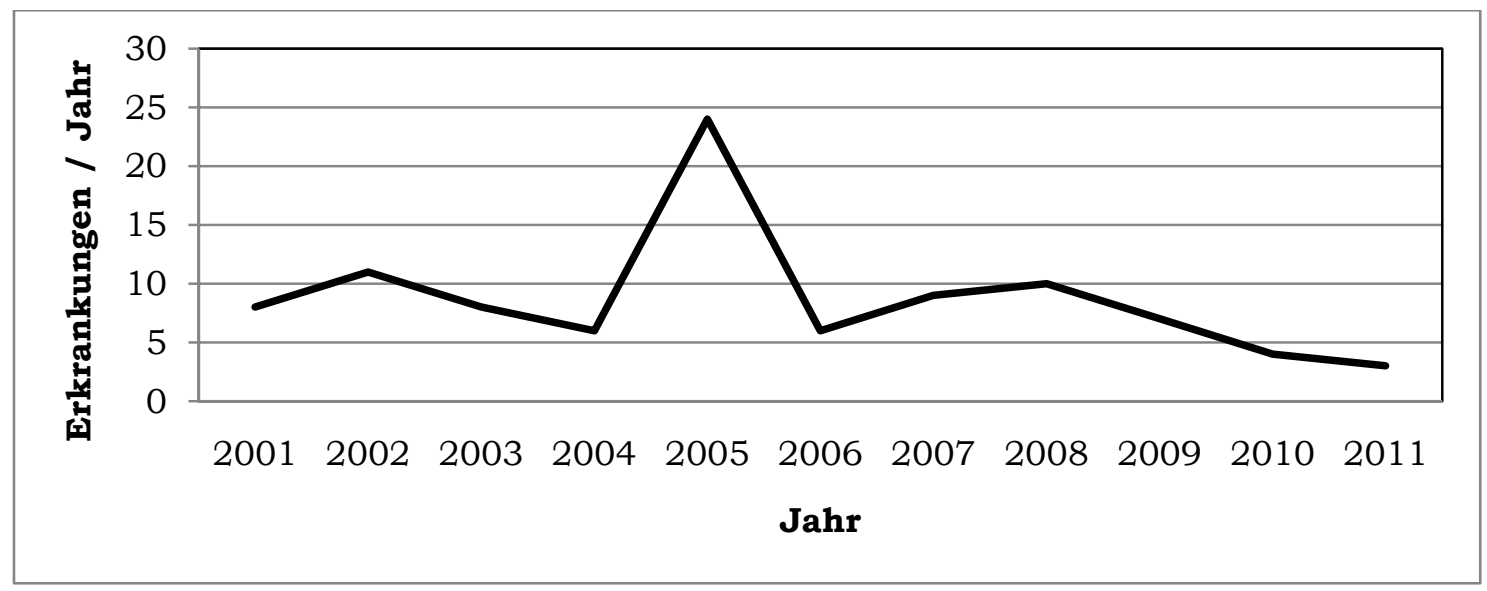

Abb. 6: Fälle von Botulismus beim Menschen in Deutschland 2001-2011 (RKI, 2011)

Beim Menschen sind der Krankheitsverdacht, die Erkrankung an und der Tod durch Botulismus nach $\S 6$ Abs. I Nr. I Buchst. a IfsG in Deutschland meldepflichtig (IfSG, 2000; RKI, 2007). Während in der Lebensmittelindustrie aufgrund der Kenntnisse über C. botulinum und die darauf folgenden verbesserten Herstellungsprozesse der Nahrungsmittel lebensmittelbedingter Botulismus nur noch selten diagnostiziert wird, zeigen sich in Ländern mit traditioneller Nahrungsmittelzubereitung und -konservierung weiterhin hohe Prävalenzraten beim Auftreten des lebensmittelbedingten Botulismus.

Bei Erkrankungen von Tieren bestehen in Deutschland weder Anzeige- noch Meldepflicht. Durch die in der Literatur beschriebenen Fälle lässt sich selbst global nur ein unvollständiges Bild aufzeichnen, da diese Publikationen oft in der jeweiligen Landessprache für eine nationale Zeitschrift verfasst wurden und für die internationale Fachwelt kaum zugänglich sind. Fälle von Botulismus in Rindern wurden in Australien, Brasilien, Kanada, Finnland, Deutschland, Irland, Israel, den Niederlanden, Norwegen, Schweden, der Schweiz, Südafrika, Großbritannien und den USA beschrieben (Theiler und Robinson, 1927; Simmons und Tammemagi, 1964; Lindström et al., 2010) und waren meist mit der Aufnahme von Geflügeleinstreu, Kadaverteilen oder konservierten Futtermitteln verbunden (Jean et al., 1995; Wilson et al., 1995; Yeruham et al., 2003; Böhnel et al., 2005; Myllykoski et al., 2009). 


\subsubsection{Intoxikation}

\subsection{Mensch}

Beim Menschen erscheinen die frühesten klinischen Symptome des akuten Botulismus ca. 18 bis 36 Stunden nach der Exposition und zeigen sich als Mundtrockenheit, verschwommenes Sehen und/oder Doppeltsehen. Diesen initialen Anzeichen folgen Sprach-und Schluckstörungen und eine Lähmung der peripheren Muskulatur, beginnend mit den oberen Extremitäten, dann der respiratorischen Muskulatur und abschließend den unteren Extremitäten (Cherington, 1998). Der lebensmittelbedingte Botulismus (foodborne botulism) tritt nach dem Verzehr von Nahrung auf, die BoNTe enthält. Das betroffene Gemüse, Obst, Fleisch oder der Fisch wurde in diesen Fällen ungenügend erhitzt, falsch bearbeitet oder gelagert. Besonders selbst konservierte Lebensmittel sind die häufigsten Quellen einer Intoxikation (CDC, 1998). Hier kommen zu den beschriebenen Symptomen Übelkeit, Erbrechen, Bauchkrämpfe, im frühen Stadium Diarrhö und später Obstipation hinzu (Shapiro et al., 1998). Die meisten Erkrankungen beim Menschen werden durch die Toxintypen A, B und E hervorgerufen. Typ-E-Botulismus wird besonders mit dem Verzehr von Fisch und Krustentieren in Verbindung gebracht. Durch BoNT/F wurden nur wenige Fälle von lebensmittelbedingtem Botulismus verursacht (McCroskey et al., 1991). Aber auch der Typ D, der in der Literatur häufig im Zusammenhang mit Botulismus beim Tier genannt wird oder der Typ G sind durchaus in der Lage, Botulismus beim adulten Menschen hervorzurufen (Demarchi et al., 1958; Sonnabend et al., 1981).

Neben der Vergiftung durch Lebensmittel gab es durch Laborunfälle auch schon Vergiftungen durch Inhalation (Holzer, 1962; Park und Simpson, 2003), ebenso wie die Form des iatrogenen Botulismus, wo Vergiftungen durch Behandlungsfehler bei der Applikation von BoNT gegen Muskelerkrankungen oder bei Schönheitskorrekturen auftraten (Bakheit et al., 1997).

Durch die Verbesserung von intensivmedizinischen Maßnahmen und der Bereitstellung von Antitoxinen konnte die hohe Sterblichkeit von 60 \% während der 50er Jahre auf 3-10\% vermindert werden (Shapiro et al., 1998; Cherington, 1998; CDC, 1998). 


\subsection{Monogastrier}

Das Pferd reagiert von allen Monogastriern am empfindlichsten auf alle Typen der BoNTe (Kinde et al., 1991). Der akute Botulismus entsteht durch die Aufnahme von toxinhaltigen Futtermitteln (Ricketts et al., 1984) und führt durch die Lähmung der Muskulatur zu einem schwankenden Gang, Schluckstörungen und einer heraushängenden Zunge bis hin zum Tremor. Die Todesursache ist gewöhnlich Atemlähmung oder Herzversagen (Galey, 2001). Die am häufigsten nachgewiesenen C.-botulinum-Toxintypen beim Pferd sind BoNT/B, C und D (Kinde et al., 1991; Galey, 2001; Camargo et al., 2008).

Dagegen scheint das Schwein relativ widerstandsfähig gegen BoNTe zu sein, es wurden nur wenige Krankheitsfälle beschrieben (Beiers und Simmons, 1967). Auch hier war die Ursache kontaminiertes Futtermittel.

Fleischfresser sind ebenfalls relativ unempfindlich gegen BoNTe. Nur bei Nerzen und Füchsen werden regelmäßig schwere Verluste gemeldet (Kriek und Odendaal, 1994; Lindström et al., 2004). Bei Katzen wurde C.-botulinum-Typ C nachgewiesen (Elad et al., 2004).

\subsection{Geflügel}

Bei Vögeln wurde erstmals 1930 Botulismus als Todesursache ermittelt (Giltner und Couch, 1930) und gilt besonders bei wildlebendem Wassergeflügel als klassischer Grund für Massensterben (Western duck sickness). In erster Linie wird bei solchen Ausbrüchen C.-botulinum-Typ C nachgewiesen, durch die Aufnahme von toxinhaltigem Fisch oder GoldfliegenLarven spielen aber auch die BoNT-Typen A und E eine Rolle (Bengtson, 1922; Giltner und Couch, 1930; Hubálek und Halouzka, 1991; Sandler et al., 1993; Hannett et al., 2011).

Die Erkrankung zeigt sich durch eine fortschreitende Lähmung der Beine und der Flügel, die zur Flugunfähigkeit führt, und später auch der Halsmuskulatur. Durch das Abknicken des Halses tritt meist der Tod durch Ersticken, bei Wasservögeln durch Ertrinken ein. 
Vögel reagieren verschieden empfindlich auf das Typ-C-Toxin. Während Wachteln noch einmal deutlich empfindlicher als Pekingenten sind, führen beim Huhn erst sehr hohe Dosen des Toxins zu klinischen Symptomen (Schettler, 1979). Aasvögel zeigen eine Immunität gegenüber BoNTen. Sie scheinen durch zirkulierende Antikörper geschützt zu sein, die unter anderem auf eine aktive Immunisierung durch im Darm befindliches C. botulinum zurückzuführen sein könnten (Ohishi et al., 1979). Ohishi sieht diese Symbiose auch als mögliche Erklärung für die geografische Verbreitung von C. botulinum.

\subsection{Wiederkäuer}

Schon 1922 stellte Seddon einen Zusammenhang zwischen Intoxikationen bei Rindern, Pferden und Schafen und der Aufnahme von mit Toxin verseuchtem Futtermittel her. Es ist eine hauptsächliche Belastung durch die BoNT-Typen C und D erkennbar (Simmons und Tammemagi, 1964; Davies et al., 1974; Smart et al., 1987; Heider et al., 2001), aber auch Toxine der ABE-Gruppe konnten bei erkrankten Rindern, Zebus oder Alpensteinböcken nachgewiesen werden (Schocken-Iturrino et al., 1990; Bruckstein und Tromp, 2001; Dahlenborg et al., 2003; Böhnel, 2005).

Im Allgemeinen geht man davon aus, dass die Kontamination der Futtermittel durch das Einbringen von Tierkadavern oder Bodenteilen während der Futterwerbung zustande kommt (Böhnel, 1999; Galey et al., 2000; Myllykoski et al., 2009), aber auch ohne tierische Proteine ist eine Vermehrung von C. botulinum in Heu, Stroh und Silage möglich (Notermans et al., 1979b; Wilson et al., 1995). Eine besondere Rolle spielt auch die Verfütterung von Einstreu aus der Geflügelhaltung. Es wird als Stickstoffquelle genutzt, enthält aber häufig C. botulinum (-Sporen), die von dem Geflügel ausgeschieden wurden oder infizierte Kadaver. Das kontaminierte Futter löst im Tier Botulismus aus (Appleyard und Mollison, 1985; Smart et al., 1987; McLoughlin et al., 1988; Jean et al., 1995; Wobeser, 1997). In Deutschland ist die Verfütterung von Geflügeleinstreu verboten. Weitere mögliche Eintragsquellen von C. botulinum ergeben sich durch Wildvogelkot, die Düngung von Weideflächen mit Hühnermist/-gülle oder der Verteilung des 
Aushubs der Weidegräben auf den Weideflächen (Smith und Turner, 1989; Böhnel, 1999). Durch die Beweidung mit (kranken) Tieren kann ein Kreislauf der Re-Infektion entstehen (Notermans et al., 1981; Dahlenborg et al., 2003; Böhnel und Gessler, 2010).

Die klinischen Symptome beim Rind variieren in Abhängigkeit der aufgenommenen Toxinmenge beachtlich, aber auch der Toxintyp hat einen großen Einfluss auf die Dauer und den Verlauf der Erkrankung, so dass zwischen perakuten, akuten, subakuten und chronischen Formen unterschieden werden kann (Theiler und Robinson, 1927; Simmons und Tammemagi, 1964). Das diagnostische und epidemiologische Wissen über den Rinderbotulismus ist sehr begrenzt, da bei $60 \%$ der publizierten Botulismusfälle beim Rind kein Toxintyp bestimmt werden konnte. In $43 \%$ der Fälle handelte es sich um die C.-botulinum-Typen $\mathrm{C}$ und D, bei weiteren $5 \%$ um den Typ B und bei $1 \%$ der Fälle war der C.-botulinum-Typ A verantwortlich für das Krankheitsgeschehen (Lindström et al., 2010). Die Mortalitätsraten betragen zwischen $8 \%$ und $64 \%$ (Galey et al., 2000).

Wird der Botulismus durch die C.-botulinum-Typen C und D verursacht, beträgt die Inkubationszeit zwischen achtzehn Stunden und sechzehn Tagen. Die Tiere sind fieberfrei. Die Parese, die sich zu einer Paralyse entwickelt, beginnt in den hinteren Gliedmaßen und weitet sich dann auf die Vordergliedmaßen und die Muskulatur von Hals und Kopf aus. Die Lähmung der Kauund Schluckmuskulatur zeigt sich durch ein sichtbares Heraushängen der Zunge und erhöhten Speichelfluss. Reflexe sind vermindert oder fehlen völlig. Die Nahrungsaufnahme ist bis zum Zeitpunkt der Lähmung von Kau- und Schluckmuskulatur nicht vermindert. Beim Typ-B-Botulismus entwickeln sich die Symptome innerhalb von drei Tagen nach der Exposition des Toxins. Die ersten Anzeichen sind eine reduzierte Milchleistung und die Entwicklung einer Diarrhö. Es folgt eine verminderte Nahrungsaufnahme, übermäßiger Speichelfluss, Regurgitation und Dehydrierung. Die Tiere weisen einen schwächeren Tonus der Skelettmuskulatur auf, sie sind aber nicht ataktisch und auch der Schwanz und die Zunge sind nicht gelähmt. Durch die Inhalation des regurgitierten Materials ist eine Pneumonie möglich (Kriek und Odendaal, 1994; Böhnel, 1999). 
Ziegen und Schafe sind seltener von Botulismus betroffen, zeigen aber ähnliche Symptome, wie Lähmungen der Gliedmaßen und Halsmuskulatur sowie Schluckstörungen (Kriek und Odendaal, 1994).

\subsubsection{Infektion}

Wundbotulismus wird durch die Kontamination einer Wunde mit C.-botulinum-Sporen verursacht. Unter anaeroben Bedingungen keimen sie aus und geben das gebildete BoNT in die Blutbahn ab. Es entwickeln sich die beschriebenen neurologischen Symptome, die Inkubationszeit verlängert sich allerdings auf durchschnittlich sieben Tage (Merson und Dowell, 1973).

Während beim Menschen Wundbotulismus früher eine seltene Erkrankung war und bei Laborunfällen auftrat (Cherington, 1998), häufen sich seit den 1990er Jahren die Fälle in Verbindung mit Drogenmissbrauch (Swedberg et al., 1987; CDC, 1995; Werner et al., 2000).

Eine Form von Wundbotulismus beim Tier ist das „Shaker Foal Syndrome“. Dort kommt es nach Aufnahme von sporenhaltigem Futter, Kot oder über den Nabelstrang zur Besiedlung von Geschwüren und nekrotischen Läsionen im Gastrointestinaltrakt durch C.-botulinum-Typ B (Rooney und Prickett, 1967; Kriek und Odendaal, 1994; Galey, 2001).

\subsubsection{Toxikoinfektion}

2.1.3.4.1 Säuglingsbotulismus (infant botulism) und „infant like botulism“ beim Erwachsenen

Nachdem Botulismussymptome bei Säuglingen beschrieben wurden, aber keine Toxinquelle ermittelt werden konnte, gelang 1976 erstmals der Nachweis von BoNT und C. botulinum in Fäzes (Midura und Arnon, 1976). Es erwies sich die Annahme als richtig, dass mit der Nahrung oder durch die Umgebung Sporen von Clostridien aufgenommen werden, die den Darm des Säuglings aufgrund seiner besonderen Darmflora besiedeln können, dort in vivo BoNTe bilden, die durch die Blutzirkulation zu den peripheren Nerven gelangen (Arnon 
et al., 1978; Arnon, 1995). Anhaltende Obstipation ist ein erster Hinweis. Ein Nachweis von Toxin im Serum ist nicht möglich.

In den meisten Fällen konnten C.-botulinum-Typ A und -Typ B als Ursache ermittelt werden, es gelang aber auch der Nachweis von Typ C (Oguma et al., 1990), Typ E (Lúquez et al., 2010) und Typ Bf (Barash und Arnon, 2004), außerdem von C.-butyricum-Typ E (Aureli et al., 1986; McCroskey et al., 1986; Suen et al., 1988a) oder C.-baratii-Typ F (Hall et al., 1985; Paisley et al., 1995). Die Sporen konnten zum großen Teil in Honig, aber auch in der Umgebung, z. B. in Staubsaugerbeuteln, nachgewiesen werden (Arnon et al., 1979; Fenicia et al., 1993; Nevas et al., 2005). Säuglingsbotulismus gilt auch als eine Ursache für den plötzlichen Kindstod (Sudden Infant Death Syndrome, SID) (Arnon et al., 1981; Böhnel et al., 2001a).

Ähnlich dem Säuglingsbotulismus gibt es auch beim Erwachsenen die Form der intestinalen Kolonisation mit anschließender Toxinbildung (McCroskey und Hatheway, 1988). Als Voraussetzung hierfür wird eine bereits erfolgte Schädigung des Darmes oder eine Antibiotika-Behandlung angesehen (Sonnabend et al., 1987; McCroskey et al., 1991; Griffin et al., 1997; Fenicia et al., 1999). Desweiteren wird beim Menschen von einer chronischen Form des Botulismus berichtet, die im Zusammenhang mit einem engen Kontakt zu Rindern, die an chronischem Botulismus erkrankt sind, steht. Durch die systemische Verbreitung des BoNT sind eindeutige Wirkungen auf das autonome Nervensystem messbar (Dressler und Benecke, 2003; Dressler und Saberi, 2009).

\subsection{Geflügel}

Während bei Wildgeflügel die Intoxikation durch die Aufnahme von toxinbelasteten Kadavern und Insektenlarven im Vordergrund steht, stellt in der Geflügelhaltung auch die Toxikoinfektion mit C.-botulinum-Typ C ein Problem dar, bei dem die eigentliche Toxinquelle nicht ermittelt werden konnte. Im Caecum der Tiere kommt es bei günstigen Milieuverhältnissen zu einer massiven Vermehrung von C. botulinum mit Toxinbildung (Schettler, 1979; Trampel et al., 2005). 


\subsection{Equine Grass Sickness (EGS)}

Die Equine Grass Sickness (EGS) ist eine polyneuropathische Erkrankung des zentralen, peripheren und enteralen Nervensystems bei Pferden, die perakut, akut, subakut oder chronisch verlaufen kann. Sie wurde erstmals 1907 in Schottland beobachtet und durch Tocher et al. (1923) beschrieben. Die Erkrankung tritt vorwiegend in Großbritannien und sporadisch auf dem europäischen Festland, den Falkland-Inseln und in Australien auf (Cottrell et al., 1999), es wurde aber auch eine Verbindung zu der in Argentinien vorkommenden „Mal seco“ hergestellt (Uzal und Robles, 1993).

Betroffen sind vor allem zwei bis sieben Jahre alte Pferde oder solche, die unter besonderer Belastung stehen. Bei den verschiedenen akuten Verlaufsformen sind Hypovolämie, Tachykardie, Ptosis, Muskeltremor, Schluckstörungen, Reflux durch die Nüstern, das Fehlen von Darmgeräuschen, Koliken und Verstopfung zu beobachten. In der überwiegenden Anzahl der Fälle führt die Schädigung der Nervenzellen nach $48 \mathrm{~h}$ bis sieben Tagen zum Tod (Cottrell et al., 1999).

In der chronischen Form der EGS magern die Pferde innerhalb kurzer Zeit stark ab, zeigen eine hochgezogene Bauchdecke und eine enge Beinstellung. Die Herzfrequenz ist leicht erhöht, es treten Muskeltremor und Ptosis sowie ungleichmäßiges Schwitzen, Appetitlosigkeit und Schluckstörungen auf. In diesen Fällen lebt das Tier länger als sieben Tage und eine Rehabilitation ist möglich (Uzal und Robles, 1993).

Als Ursache der EGS gilt die Besiedlung von Gras mit verschiedenen C.-botulinum-Typen (Tocher et al., 1923; Tocher, 1924; Böhnel et al., 2003), in manchen Fällen ist auch C.-perfringens-Typ A beteiligt (Cottrell et al., 1999). Durch die Aufnahme von kontaminiertem Gras kann eine Besiedlung des Verdauungstraktes mit Clostridien und eine Toxinbildung stattfinden. Die Wirkungsweise der dort vom Typ C gebildeten Toxine C1, C2 und C3 geben eine eindeutige Erklärung für die Zellläsionen, die in Obduktionen gefunden wurden. 


\subsection{Viszeraler (chronischer) Botulismus beim Rind}

Seit ca. 1995 wird bei Rindern neben dem klassischen Botulismus ein weiteres Krankheitsgeschehen beobachtet, das mit hohen wirtschaftlichen Verlusten für die betroffenen Landwirte einhergeht. Es wird als chronische Erkrankung mit schleichendem Leistungsabfall, Lähmungen und Verdauungsstörungen bei vorwiegend frisch laktierenden Kühen beschrieben. Pupillen-, Lid-, Ohr-, sowie Haut- und Analreflex sind fast immer deutlich eingeschränkt oder fallen ganz aus (Schwagerick, 2011b). Die Beeinträchtigung der autonomen Muskulatur führt zu verringertem Wiederkauen, mukösem Speichel, nur tropfenweisem Absetzen des Harns und Durchfall im Wechsel mit Obstipation (Schwagerick und Böhnel, 2001).

Da Stoffwechselanalysen keine Ergebnisse brachten und in mikrobiologischen Untersuchungen häufig C. botulinum oder BoNTe nachgewiesen werden konnte, obwohl kein akuter Krankheitsverlauf zu beobachten war, gingen Böhnel und Schwagerick (2001b) von einer Toxikoinfektion beim Rind aus, die sie als „viszeralen Botulismus“ beschrieben. Danach ist ähnlich wie beim Säuglingsbotulismus (Midura und Arnon, 1976), der Toxikoinfektion beim Erwachsenen (Sonnabend et al., 1987) oder der EGS (Tocher et al., 1923) im Falle einer Dysbiose eine Besiedlung des bovinen Verdauungstraktes oder der Tonsillen mit C. botulinum möglich (Böhnel et al., 2008). Die intestinale Toxinbildung führt zu den oben beschriebenen systemischen, motorischen und neurologischen Ausfallerscheinungen. Durch den nur langsamen Abbau des BoNTs im Körper bleibt eine Supplementation von $\mathrm{Ca}^{2+}$, Glucose und Kortisol, die bei ähnlich verlaufenden Erkrankungen wie dem Milchfieber bzw. der Ketose Wirkung zeigen, ohne Erfolg (Böhnel et al., 2001b) und kann als Ausschlusskriterium dienen.

Zusätzlich werden im Serum der Rinder hohe Antikörpertiter gegen meist mehrere BoNT-Typen gefunden, was untypisch für den klassischen Botulismus ist (Böhnel und Gessler, 2003).

Hygienerechtlich ist die Verwendung von Milch oder Fleisch von erkrankten Tieren nicht zulässig. Zwar steht fest, dass Produkte von sichtbar kranken Tieren nicht verarbeitet und in den Handel gelangen dürfen, im Fall des viszeralen Botulismus werden die Tiere in den betroffenen Betrieben nach der 
ersten Zeit aber meist schon vor Auftreten deutlicher klinischer Symptome wegen Leistungsabfall geschlachtet. Da das Toxin nur selten im Serum erkrankter Rinder nachweisbar ist, wird der Transfer in die Milch für unwahrscheinlich gehalten, ebenso in das Fleisch (Cobb et al., 2002). Durch das permanente Ausscheiden von C. botulinum mit dem Kot ist trotzdem das Risiko einer Kontamination von Milch und Fleisch gegeben (Böhnel, 2004). Experimentelle Daten haben gezeigt, dass durch Pasteurisierung 99,99\% von BoNT/A und B und 99,5 \% ihrer Komplexe inaktiviert werden (Weingart et al., 2010).

Entsprechend den genetischen und funktionellen Eigenschaften des C. botulinums gestaltet sich der Nachweis der Ursache-Wirkungs-Beziehung zwischen C. botulinum bzw. BoNT und dem Rind äußerst schwierig und genügt in vielen Fällen nicht den Ansprüchen der Henle-Koch-Postulate. Die daraus resultierenden Unstimmigkeiten hinsichtlich der Nachweisverfahren von BoNT, C.-botulinum-Sporen und vegetativen Zellen bieten Spielraum für kontroverse Diskussionen.

Eine weitere Hypothese zur Erklärung der Entstehung des oben beschriebenen Krankheitsbildes, das auch als „Faktorenerkrankung Milchviehherde“ bezeichnet wird, sieht die Hauptursache in der Verfütterung von Grassilage verminderter Qualität bezogen auf die Parameter Reineiweiß, Vitamin E und freie Aminosäuren (Scholtz et al., 2010; Eicken et al., 2010). Dies konnte in Untersuchungen von Gresner (2011) und Theermann (2011) bisher nicht bestätigt werden.

\subsubsection{Therapie}

Die Kernbereiche der Therapie umfassen beim Botulismus bei Menschen zum einen die sofortige Gabe von Botulinum-Antitoxin, zum anderen die intensivmedizinische Betreuung unter besonderer Berücksichtigung der Atemfunktion (CDC, 1998). Die Gabe von equinem Antitoxin beim adulten Menschen muss möglichst schnell erfolgen, da bereits an die Nervenzellen gebundenes BoNT bisher nicht neutralisiert werden kann (Sugiyama, 1980). Zurzeit wird ein Medikament entwickelt, dessen Wirkstoff die Kaliumkanäle der Synapsen blockiert, was zu einem Einstrom von Calcium führt und die Wiederherstellung 
der Aktionspotentiale fördert (Zakhari et al., 2011). Im Falle einer Kolonisation des Darmes mit C. botulinum wird die Einnahme probiotischer Präparate empfohlen. Von einer Antibiotika-Gabe ist abzusehen, da durch die Lyse der Clostridien die Menge an BoNT im Darm ansteigen kann (Black und Gunn, 1980). Bei durch die C.-botulinum-Typen A und B verursachtem infant botulism steht BabyBIG $^{\circledR}$, ein humanes Immunglobulinpräparat, das intravenös appliziert wird, zur Verfügung (Arnon et al., 2006).

Beim Tier verhält sich die Lage bei akutem Botulismus ebenso wie beim Menschen, eine Neutralisation von gebundenem BoNT ist nicht möglich. Nur in frühen Stadien der Erkrankung ist eine Antitoxingabe nach einer ToxintypBestimmung erfolgreich. Sie ist allerdings sehr teuer und darf bei der Verwendung von ausländischen Antiseren nur mit einer Ausnahmegenehmigung verabreicht werden.

Im Fall des viszeralen Botulismus kann man versuchen, die Darmflora durch die Gabe von prä-und probiotischen Substanzen positiv zu beeinflussen um so ein weiteres massives Vermehren von C. botulinum und die Toxinbildung zu verhindern (Krüger und Schrödl, 2004). Durch den therapeutischen Einsatz von Toxoid-Impfstoff konnte ein einigen Fällen eine Verbesserung der Symptome erzielt werden, in einigen schweren Fällen verschlimmerte sich die Krankheit allerdings (Böhnel, 2004).

\subsubsection{Prophylaxe}

Das Hauptaugenmerk in Bezug auf die Prophylaxe sollte auf der Verhinderung der Weiterverbreitung der Sporen von C. botulinum liegen. Einen Schwerpunkt bildet die Abfallwirtschaft, die durch die Erzeugung bzw. Wiederverwendung von Biokompost, Klärschlamm und Biogasgärsubstrat einen Kreislauf schafft, der die Streuung und Anreicherung von Sporen begünstigt (Böhnel und Gessler, 2004).

Zur Prophylaxe sind theoretisch Toxoid-Impfstoffe verfügbar. Eine Impfung gestaltet sich bei Mensch und Tier allerdings schwierig, da aufgrund der großen Anzahl verschiedener BoNT-Subtypen ein umfassender Schutz momentan nicht möglich ist. Für den Mensch sind ein pentavalenter Toxoid-Impfstoff, der 
gegen die BoNT-Typen A bis E schützt, und ein monovalenter Toxoid-Impfstoff gegen BoNT/F verfügbar. Aufgrund der zahlreichen Nebenwirkungen der Toxoid-Impfstoffe werden inzwischen aber auch rekombinante, nichttoxische HC-Fragmente der BoNTe für den Einsatz als Impfstoff entwickelt (Siegel, 1988; Byrne und Smith, 2000; Nowakowski et al., 2002; Park und Simpson, 2003; Xu et al., 2009).

Für Rinder sind verschiedene kommerzielle Toxoid-Impfstoffe für die Typen C und D auf dem internationalen Markt verfügbar (Ultravac ${ }^{\circledR}$ Botulinum Vaccine von Pfizer Australia und Onderstepoort Botulism Vaccine aus Südafrika). Der Einsatz in Deutschland darf nur mit einer Ausnahmegenehmigung in den Beständen erfolgen, in denen bereits $C$. botulinum oder das Toxin nachgewiesen wurde (TierSG, 2010). Bei Tieren würde sich auch ein bestandsspezifischer Impfstoff anbieten, durch den der Kreislauf der Re-Infektion durchbrochen werden könnte. Zum einen ist aber die Isolierung des zur Impstoffherstellung benötigten $C$. botulinum aus dem Rind nahezu unmöglich, zum anderen ist durch den Zukauf von Futtermitteln ein Eintrag „fremder“ Sporen möglich und der Impfschutz nicht gewährleistet.

Die für die Darmsanierung eingesetzten Pro- und Präbiotika sind prophylaktisch sogar noch wesentlich wirkungsvoller (Krüger und Schrödl, 2004). Laktobazillen und Streptokokken sind die am häufigsten verwendeten Mikroorganismen beim Einsatz von Probiotika. Sie bilden eine Konkurrenzflora zu zahlreichen pathogenen Erregern und verhindern so deren Ansiedlung im Magen-Darm-Trakt, erhöhen die Aktivität nützlicher Enzyme und stimulieren die Bildung von Antikörpern (Snoeyenbos et al., 1983; Fuller, 1989). Präbiotika wie z. B. Inulin, Fructo-Oligosaccharide oder Lactulose sind für den Wirt unverdauliche Kohlenhydrate, die als Nährstoffe das Wachstum und die Aktivität der Darmflora fördern, aber auch zur gleichzeitigen Reduzierung von Clostridien beitragen und auf diese Weise das Tier schützen (Kleessen et al., 2001; Krüger et al., 2002; Blaut, 2002; Kleessen et al., 2003). Das zusätzliche Angebot von Laktose und Galaktose im Dünndarm verdrängt die HA-Komponente des BoNT-Komplexes von den Galaktoserezeptoren und verhindert so die Aufnahme des Toxins in den Körper und die darauf folgende Intoxikation (Böhnel et al., 2001b; Krüger und Schrödl, 2004). 


\subsubsection{Seuchenkomplexe}

Der Nachweis von C. botulinum und/oder BoNT kann sich labordiagnostisch problematisch gestalten. Neben den angesprochenen Schwierigkeiten gerade die C.-botulinum-Typen C und D zu kultivieren, kommen nicht interpretierbare Ergebnisse vor, die aus dem Vorhandensein anderer pathogener Bakterien resultieren können. So berichteten Popoff und Lecoanet 1987 vom parallelen Auftreten von C. botulinum und C.perfringens im Schaf. Erst durch eine Mischung von BoNT/D-Antitoxin und C.-perfringens-Enterotoxin-Antitoxin ließ sich die mäuseletale Substanz neutralisieren. In einem anderen Fall konnte neben C.-botulinum-Typ B auch Salmonella typhimurium isoliert werden (Wilson et al., 1995).

\subsection{Nachweis von C. botulinum und BoNT}

\subsubsection{Erregernachweis}

\subsubsection{Anreicherung, Isolierung und biochemische Differenzierung}

Obwohl C. botulinum ubiquitär ist, erweist es sich unter Laborbedingungen als anspruchsvoll. Da fast alle Vertreter dieser Spezies obligat anaerob wachsen, ist für die Anzucht eine sauerstoffarme bzw. -freie Umgebung vonnöten. Das Wachstumsmedium sollte zusätzlich sauerstoffreduzierende Substanzen enthalten. Die Fähigkeit von C. botulinum Sporen zu bilden, bietet eine gute Möglichkeit unerwünschte Begleitflora zu eliminieren. Man kann entweder durch den Zusatz von Ethanol (Cato, 1986; Klarmann, 1989) oder durch Erhitzung Nichtsporenbildner reduzieren. Allerdings ist die unterschiedliche Hitzeresistenz der Sporen zu beachten. So wird für die Selektion von Sporen der Gruppe I eine Erhitzung auf $80^{\circ} \mathrm{C}$ für $10 \mathrm{~min}$ empfohlen, während für die hitzeempfindlicheren Sporen der Gruppe II eine Erhitzung auf $60^{\circ} \mathrm{C}$ für 10-20 min nicht überschritten werden sollte (Smith, 1977). Routinemäßig werden für die Anreicherung der Probe in Flüssigmedium HackfleischGlucose-Stärke-Medium (CDC, 1998), Kochfleisch-Medium mit verschiedenen Kombinationen von Trypton, Pepton, Glucose, Hefeextrakt und Trypsin (Robertson, 1915; Dezfulian et al., 1981; Mills et al., 1985; Hall et al., 1985; Sonnabend et al., 1987; Hatheway und McCroskey, 1987; Yamakawa und 
Nakamura, 1992) oder Reinforced Clostridia Medium (RCM) (Campbell et al., 1993b; Kirchner et al., 2010) verwendet und bei $30-37^{\circ} \mathrm{C}$ für $4-7$ d bebrütet. Diese Medien sind nicht selektiv und erlauben das Wachstum aller Arten von Bakterien. Der Ausstrich und eine erste Differenzierung erfolgen anschließend auf Eigelb-Laktose-Agar. Durch die Lipasebildung zeigt C. botulinum einen perlmuttartigen Hof (McClung und Toabe, 1947). Durch den Zusatz verschiedener Antibiotika lässt sich die Begleitflora hemmen und kann im Nährboden zur Isolierung von C. botulinum eingesetzt werden (Dezfulian et al., 1981; Glasby und Hatheway, 1985; Mills et al., 1985; Hall et al., 1985; Hatheway und McCroskey, 1987). Da diese Medien aber auch das Wachstum von C. botulinum der Gruppe II unterdrücken, ist ihr Einsatz in der Diagnostik begrenzt (Whitmer und Johnson, 1988; Loch, 2000).

Reinkulturen können anhand ihrer Stoffwechselleistungen identifiziert werden. In kommerziell erhältlichen Schnelltestsystemen (API ${ }^{\circledR} 20$ A, Rapid ID 32A oder RapID ${ }^{\mathrm{TM}}$ ANA II) wird das System der Kombination verschiedener Nährstoffe vereinfacht und erlaubt eine visuelle Differenzierung, auch bekannt als „Bunte Reihe“. Eine einwandfreie Identifizierung von C. botulinum nur aufgrund seiner biochemischen Eigenschaften ist nicht möglich, da die proteolytischen C.-botulinum-Stämme in ihrer DNA-Sequenz eine hohe Übereinstimmung mit $C$. sporogenes oder nichtproteolytischen $C$. botulinum aufweisen und gleiche phänotypische Charakteristika zeigen (Lee und Riemann, 1970b; Lee und Riemann, 1970a; Nakamura et al., 1977; Hatheway, 1992). Die Systeme können meist nur proteolytische oder nur nichtproteolytische C. botulinum erkennen, die Zuordnung von C. sporogenes und C.-botulinumähnlichen Stämmen versagt in den meisten Fällen ebenfalls (Lindström et al., 1999).

Eine andere Methode, um biochemische Leistungen zu erfassen ist die Gaschromatografie. Durch die jeweils spezifische Flüchtigkeit von gebildeten kurzkettigen Fettsäuren, Alkoholen und zellulären langkettigen Fettsäuren lässt sich für jede Bakterienspezies ein charakteristisches Spektrum aufzeigen. Auf diese Weise ist es möglich, die vier metabolischen Gruppen und sogar einzelne Serotypen von C. botulinum zu differenzieren (Moss und Lewis, 1967; Seifert et al., 1986; Böhnel, 1995). Die ermittelten Spektren sind allerdings immer stark abhängig von den Anzuchtbedingungen und der Fettsäureextrak- 
tion, so dass eine Vergleichbarkeit nur bedingt möglich ist (Ghanem et al., 1991).

Zusätzlich stark abhängig von den Reaktionsgefäßen ist die Identifikation von C. botulinum durch die kombinierte Matrix-gestützte Laser-Desorption/Ionisation und Flugzeitanalyse (engl. matrix-assisted laser desorption and time-of-flight mass spectrometry, MALDI-TOF). Durch einen Laser wird die Probe ionisiert und in einem elektrischen Feld beschleunigt. Die detektierten Ionen mit spezifischer Ladung und Flugzeit werden in ein elektrisches Signal umgewandelt. So ergibt sich für jede Spezies ein spezifisches Spektrum, das zur Identifikation der Reinkultur herangezogen werden kann (GrosseHerrenthey et al., 2008).

\subsubsection{Polymerase-Kettenreaktion (PCR)}

\subsubsection{1 konventionelle PCR}

Die Polymerase-Kettenreaktion (engl. polymerase chain reaction, PCR) zählt zu den wichtigsten Methoden der modernen Molekularbiologie und bietet die Möglichkeit, DNA in vitro zu vervielfältigen (nach einem Patent von Mullis, Saiki et al., 1988). Durch zwei spezifische Oligonukleotide (Primer), die an der Original-DNA den Startpunkt der DNA-Synthese festlegen und den zu vervielfältigenden Bereich von beiden Seiten begrenzen, und eine hitzestabile DNAPolymerase lässt sich ein festgelegter Bereich eines Genoms replizieren. Die PCR-Produkte haben eine spezifische Länge und können in einem Agarosegel durch Gelelektrophorese aufgetrennt und sichtbar gemacht werden.

Durch die Entschlüsselung der BoNT-Gene und teilweise auch der Progenitortoxinkomplexe lassen sich auch für diese Nukleotid-Sequenzen spezifische Primer entwickeln. Die meisten Veröffentlichungen beziehen sich auf die Detektion einzelner Toxingene (Szabo et al., 1992; Ferreira et al., 1993; Franciosa et al., 1994; Takeshi et al., 1996; Franciosa et al., 1996; Fujii et al., 1996; Moriishi et al., 1996b; Fach et al., 1996; Franciosa et al., 1998; Williamson et al., 1999; Nevas et al., 2002). Durch eine geeignete Primerwahl lassen sich aber auch mehrere BoNT-Gene in einer sog. Multiplex-PCR parallel amplifizieren und anhand ihrer unterschiedlichen spezifischen Fragment- 
größen einwandfrei detektieren (Ferreira und Hamdy, 1995; Lindström et al., 2001; Joshy et al., 2008; De Medici et al., 2009). In der Routinediagnostik werden inzwischen BoNT/A, B, E und F meist gemeinsam erfasst, während BoNT/C und D bzw. deren Mosaiktoxine separat amplifiziert werden.

Ein wesentlicher Einflussfaktor auf das Gelingen der PCR ist die Probenmatrix und das Isolieren der dort eingeschlossenen bakteriellen DNA. Durch das gleichzeitige Herauslösen von Stoffen, die inhibierend wirken, kann die Amplifikation wesentlich beeinträchtigt werden (Bessetti, 2007). Bei einem direkten Ansatz werden außerdem tote Bakterien oder ruhende Sporen mit erfasst. Dies kann man über einen Anreicherungsschritt umgehen.

Der Nachweis von C. botulinum mit Hilfe einer PCR ist kein Nachweis von gebildetem Toxin.

\subsection{Real-time PCR}

Eine Weiterentwicklung der PCR-Technologie stellt die Real-time PCR dar, die neben der Echtzeitanalyse der PCR auch eine Quantifizierung des DNAAmplifikates durch Fluoreszenzmessung erlaubt. Zusätzlich zu den spezifischen Primern werden dem Ansatz entweder ein Fluoreszenzfarbstoff oder sequenzspezifische fluoreszenzmarkierte Sonden zugegeben (Higuchi et al., 1992; Heid et al., 1996). Farbstoffe wie Ethidiumbromid oder SYBR ${ }^{\circledR}$ Green interkalieren in die doppelsträngige DNA, wodurch die Fluoreszenz dieser Farbstoffe ansteigt. Spezifischer ist jedoch der Einsatz von Sonden, die sich zwischen den Primern an die Zielsequenz anlagern. Durch die Markierung mit unterschiedlichen Donor- bzw. Akzeptorfarbstoffen wird bei Anregung der Sonde mit Licht einer bestimmten Wellenlänge durch Fluoreszenz-Resonanzenergietransfer (FRET) ein Fluoreszenzsignal erzeugt, dass durch räumliche Nähe der antagonistischen Farbstoffe entweder unterdrückt oder emittiert wird. Der Anstieg des Signals ist proportional zur gebildeten DNA. Durch die Verwendung von verschiedenen Farbstoffen ist eine gleichzeitige Detektion unterschiedlicher Zielsequenzen möglich.

Auch für den Nachweis von C. botulinum sind eine Reihe von Real-time PCRMethoden entwickelt wurden, die entweder als Single- oder Multiplex-PCR 
konstruiert wurden (siehe auch Tab. 5). Eine universellere Methode zur C.-botulinum-Detektion entwickelten Raphael und Andreadis (2007), indem sie sich statt auf das BoNT-Gen auf das ntnh-Gen konzentrierten, da dieses größere Homologien durch alle Serotypen hindurch aufweist. Eine Kombination aus beiden Varianten verwenden Hill et al. (2010).

Tab. 5: Übersicht verschiedener Real-time PCR- Methoden

\begin{tabular}{|c|c|c|c|c|c|c|c|c|}
\hline & \multicolumn{8}{|c|}{ Zielsequenz der verwendeten Primer } \\
\hline & A & $\mathrm{B}$ & $\mathrm{C}$ & $\mathrm{D}$ & $\mathrm{E}$ & $\mathrm{F}$ & $\mathrm{G}$ & $n t n h$ \\
\hline (Campbell et al., 1993b) & & $\mathrm{x}$ & & & $\mathrm{x}$ & $\mathrm{x}$ & & \\
\hline (Fach et al., 1995) & $\mathrm{x}$ & $\mathrm{x}$ & & & $\mathrm{x}$ & $\mathrm{x}$ & $\mathrm{x}$ & \\
\hline (Kimura et al., 2001) & & & & & $\mathrm{x}$ & & & \\
\hline (Akbulut et al., 2004) & $\mathrm{x}$ & $\mathrm{x}$ & & & $\mathrm{x}$ & & & \\
\hline (Yoon et al., 2005) & $\mathrm{x}$ & & & & & & & \\
\hline (Artin et al., 2007) & & & & & $\mathrm{x}$ & & & \\
\hline (Fenicia et al., 2007) & $\mathrm{x}$ & & & & & & & \\
\hline (Raphael und Andreadis, 2007) & & & & & & & & $\mathrm{x}$ \\
\hline (Fach et al., 2009) & $\mathrm{x}$ & $\mathrm{x}$ & & & $\mathrm{x}$ & $\mathrm{x}$ & & \\
\hline (Hill et al., 2010) & $\mathrm{x}$ & $\mathrm{x}$ & $\mathrm{x}$ & $\mathrm{x}$ & $\mathrm{x}$ & $\mathrm{x}$ & $\mathrm{x}$ & $\mathrm{x}$ \\
\hline (Kirchner et al., 2010) & $\mathrm{x}$ & $\mathrm{x}$ & $\mathrm{x}$ & $\mathrm{x}$ & $\mathrm{x}$ & $\mathrm{x}$ & & \\
\hline (Lindberg et al., 2010) & & & $\mathrm{x}$ & & & & & \\
\hline
\end{tabular}

\subsubsection{Toxinnachweis}

\subsubsection{Maus-Bioassay}

Nach wie vor gilt der Maus-Bioassay als Goldstandard zum Nachweis von C. botulinum und BoNT. Denn obwohl zahlreiche tierversuchsfreie Methoden entwickelt wurden, bleibt der Maus-Bioassay aufgrund seiner hohen Empfindlichkeit gegenüber BoNT im Bereich von wenigen Pikogramm unübertroffen (Kozaki et al., 1974; Gill, 1982). Für die Untersuchung von Lebensmitteln auf C. botulinum und dessen Toxine ist die Verwendung des Maus-Bioassay und seine Durchführung in der Amtlichen Methodensammlung nach § 64 LFGB vorgeschrieben. Diese bezieht sich auf die DIN 10102.

Man unterscheidet zwischen dem direkten und dem indirekten Toxinnachweis bzw. dem Toxinbildungsvermögen. Nach der Extraktion des Toxins aus der Probenmatrix mit Hilfe eines geeigneten Puffers wird ein Teil der Pufferlösung 
mit Trypsin versetzt (entspr. Duff et al., 1956; Eklund und Poysky, 1972), $30 \mathrm{~min}$ bei $37^{\circ} \mathrm{C}$ inkubiert und jeweils $0,5 \mathrm{~mL}$ der untrypsinierten und der trypsinierten Probe intraperitoneal in je zwei Mäuse gespritzt. Parallel dazu wird ein Extrakt, in dem durch zehnminütiges Kochen evtl. vorhandenes BoNT zerstört wurde, als Erhitzungskontrolle in jeweils zwei Mäuse injiziert.

Enthält die Probe Toxin, zeigen die Mäuse innerhalb der nächsten 96 h die typischen Symptome für Botulismus - Muskellähmung und Respirationsstörungen, die in der sog. Wespentaille deutlich werden können, während die Mäuse der Erhitzungskontrolle symptomlos bleiben. Mit spezifischem Antitoxin, das mit der positiven Probe vermischt und in weitere Mäuse injiziert wird, lässt sich der Serotyp des BoNTs ermitteln. Erst nach einer erfolgreichen Neutralisation der mäusetoxischen Substanz gilt der BoNT-Nachweis als erbracht.

Für den indirekten Nachweis wird ein Teil der Pufferlösung zusätzlich in Nährmedium überimpft, $4 \mathrm{~d}$ bei $30-37^{\circ} \mathrm{C}$ anaerob inkubiert und der Überstand nach dem Zentrifugieren entsprechend dem direkten Toxinnachweis verwendet.

Nicht eindeutige Ergebnisse können durch zu hohe Toxinkonzentrationen, Toxingemische, nicht neutralisierbare BoNTe oder andere Komponenten der Probenmatrix verursacht werden (Gessler und Böhnel, 2004). Aufgrund verschiedener Erfahrungswerte variieren die verwendeten Probenpuffer und Kulturmedien (DIN10102; CDC, 1998; AOAC, 2000).

\subsubsection{Hemidiaphragma-Test}

Zum Zweck des BoNT-Nachweises wird bei dieser Methode das Zwerchfell aus Ratten oder Mäusen präpariert. Nach dem Kontakt mit BoNT wird der Nervus phrenicus gereizt und die darauf folgenden Muskelkontraktionen aufgezeichnet. Enthält die Probe BoNT, kann man eine Lähmung des Zwerchfells beobachten (Simpson, 1971; Simpson, 1973; Simpson, 1974). 


\subsubsection{Immunologische Methoden}

\subsubsection{Enzyme linked Immunosorbent Assay (ELISA)}

Für die Detektion von BoNT wurden eine Reihe immunologischer Verfahren wie z. B. der Radioimmunoassay (Boroff und Shu-Chen, 1973; Ashton et al., 1985), der Geldiffusionsassay (Vermilyea et al., 1968; Miller und Anderson, 1971; Ferreira et al., 1981) oder auch der passive Hämagglutinationsassay (Johnson et al., 1966) entwickelt. Da diese jedoch entweder eine geringe Sensitivität oder Spezifität gegenüber dem Maus-Bioassay aufwiesen, setzte sich letzten Endes der ELISA durch.

Im ELISA werden spezifische Antikörper eingesetzt, die in der Lage sind, den nachzuweisenden Stoff (Antigen) zu binden. Durch eine enzymvermittelte Farbreaktion, deren Intensität mit einem Photometer bestimmt werden kann, lässt sich der Gehalt des nachzuweisenden Antigens sogar quantitativ ermitteln. Im sog. Sandwich-ELISA werden zwei Antikörper verwendet. Nachdem der erste, an eine feste Phase gekoppelte (coating) Antikörper das Antigen gebunden hat, wird ein zweiter, der Detektionsantikörper, hinzugegeben, der an einer zweiten Stelle des Antigens bindet. Da dieser wiederum mit einem Enzym wie der Meerrettichperoxidase oder der alkalischen Phosphatase gekoppelt ist, wird nach Abwaschen überschüssiger Detektionsantikörper und dem Zugeben einer passenden chromogenen Substanz ein Reaktionsprodukt gebildet, das durch Farbumschlag oder Fluoreszenz messbar ist.

In der Botulismus-Diagnostik sind ELISAs für reines BoNT (Ekong et al., 1995; Szilagyi et al., 2000; Poli et al., 2002), toxische C.-botulinum-Kulturen (Dezfulian und Bartlett, 1984; Dezfulian und Bartlett, 1985; Shone et al., 1985; Schrödl et al., 2007), Lebensmittel (Doellgast et al., 1993; Rodriguez und Dezfulian, 1997; Ferreira und Crawford, 1998), Serum (Poli et al., 2002) oder Fäzes (Dezfulian et al., 1984) entwickelt worden. Durch Lebensmittelinhaltsstoffe wie auch durch Fäzeskomponenten kann die Sensitivität empfindlich beeinträchtigt werden. Diese ist außerdem stark abhängig von der Wahl der verwendeten Antikörper, die durch Kreuzreaktionen auch falsch-positive Ergebnisse verursachen können. Besonders die Mosaiktoxine von BoNT/C und D schränken die Spezifität ein (Curran et al., 2009). Bei den Toxinen BoNT/A, $\mathrm{B}, \mathrm{E}$ und $\mathrm{F}$ dagegen konnte die Weiterentwicklung der ELISAs, gerade im Be- 
reich der poly- und monoklonalen Antikörper, Kreuzreaktionen weitestgehend eliminieren. Aber auch wenn der ELISA eine gute Möglichkeit bietet, den Maus-Bioassay als Screening-Methode zu ersetzen, kann er diesen derzeit nicht in der Sensitivität übertreffen.

Tab. 6: Sensitivität und Spezifität verschiedener ELISAs

\begin{tabular}{lccc}
\hline & BoNT-Typ & $\begin{array}{c}\text { Empfindlichkeit } \\
{[\text { MLD50 / mL] }}\end{array}$ & $\begin{array}{c}\text { Kreuz- } \\
\text { reaktionen }\end{array}$ \\
\hline (Notermans et al., 1978) & A & $50-100$ & A \\
(Kozaki et al., 1979) & B & 5000 & A, B \\
(Notermans et al., 1979a) & E & 80 & C, D \\
(Lewis et al., 1981) & G & $<1$ i.p. & \\
(Notermans et al., 1982) & C, D & $<10$ & \\
(Dezfulian und Bartlett, 1984; & A, B & $5-10$ & \\
Dezfulian et al., 1984) & A & & \\
(Shone et al., 1985) & & & \\
\hline
\end{tabular}

\subsubsection{Lateral Flow Assay (LFA)}

Eine andere Form der antikörpervermittelten Botulismus-Diagnostik ist der Nachweis des BoNTs mit Hilfe des Lateral Flow Assays. Da sie schnell, einfach und ohne besondere Hilfsmittel durchzuführen sind, eignen sie sich hervorragend für das Screening von verdächtigen Proben und spielen eine besondere Rolle im Katastrophenschutz.

Auf einer Nitrozellulosemembran ist der spezifische Rezeptor für BoNTe, das Trisialogangliosid GT1b fixiert, an dem vorhandenes BoNT aus der Probe gebunden wird. Durch die Kopplung mit Goldkolloid erscheint eine farbige Bande auf dem Teststreifen. Der Test ist rein optisch qualitativ, mit einem entsprechenden Auslesegerät sogar semi-quantitativ auswertbar. Die Nachweisgrenze beträgt $3 \mathrm{MLD}_{50} / \mathrm{mL}$ (Ahn-Yoon et al., 2004). Durch Interferenzen mit der Probenmatrix, insbesondere von Fettsäuren, können allerdings bei ungenügender Probenaufarbeitung falsch-negative Ergebnisse entstehen (AhnYoon et al., 2004; Hörman et al., 2005; Sharma et al., 2005; Gessler et al., 2007). 


\subsubsection{Endopeptidase-Assay}

Dieser Test basiert auf der Zink-Endopeptidase-Aktivität der BoNTe im synaptischen Spalt und kombiniert die spezifische Spaltung der SNARE-KomplexProteine mit einer immunologischen oder fluoreszenzbasierenden Detektion der Spaltprodukte (Hallis et al., 1996; Wictome et al., 1999a; Schmidt et al., 2001).

Er weist eine sehr hohe Sensitivität von im Durchschnitt 0,04-0,8 MLD 50 auf (Ekong et al., 1997; Boyer et al., 2005; Ferracci et al., 2005; Moura et al., 2011). Durch die ebenso hohe Spezifität bietet sich der Endopeptidase-Assay als Ersatz für den Maus-Bioassay an, da er ebenfalls nur freies BoNT detektiert. Da allerdings eine entsprechende Laborausstattung und -kompetenz benötigt wird, bietet sich der Test nicht für viele Laboratorien an.

Durch die Verwendung ungeeigneter monoklonaler Antikörper können falschnegative Ergebnisse entstehen (Wictome et al., 1999b), der Einsatz von EDTA als Antikoagulans in Serumproben kann den Assay inhibieren (Ekong et al., 1997). Es ist kein Nachweis der gesamten biologischen Aktivität des Gesamttoxins möglich. 


\subsection{Struktur Rinder haltender Betriebe}

\subsubsection{Milchviehhaltung}

Die Milcherzeugung in Deutschland ist durch ständig optimierte Produktionstechniken und eine intensive züchterische Steigerung von Leistungsmerkmalen geprägt. Dieses System bringt Hochleistungskühe hervor, deren Stoffwechselleistungen den Organismus immer nah an die Grenzen von pathophysiologischen Zuständen führt.

Tab. 7: Entwicklung der Milchleistung aller Kühe von 1995-2010 (nach ADR, 2005-2010)

\begin{tabular}{ccccc}
\hline Jahr & Milchkühe (Mio) & Milch [kg] & Fett [\%] & Eiweiß [\%] \\
\hline 1995 & - & 5.427 & 4,25 & 3,25 \\
$:$ & $:$ & $:$ & $:$ & $:$ \\
2005 & $4.163,4$ & 7.915 & 4,14 & 3,45 \\
2006 & $12.676,7$ & 8.033 & 4,13 & 3,43 \\
2007 & $4.087,3$ & 8.138 & 4,12 & 3,44 \\
2008 & $4.229,1$ & 8,153 & 4,12 & 3,43 \\
2009 & 4,2 & 8.255 & 4,11 & 3,43 \\
\hline
\end{tabular}

Eine stetig absinkende Zahl an Betrieben und Rindern erbringt jedoch eine nahezu konstant bleibende Milchproduktion.

Tab. 8: Rinderproduktion in Mecklenburg-Vorpommern - Tierzahlen (SIS-OnlineMV, 2011)

\begin{tabular}{ccccc}
\hline Jahr & $\begin{array}{c}\text { Betriebe mit } \\
\text { Rindern }\end{array}$ & Rinder & $\begin{array}{c}\text { Betriebe mit Milch- } \\
\text { kühen }\end{array}$ & Anteil Milchkühe \\
\hline 1996 & 4.007 & 636.135 & 1.519 & 231.237 \\
1999 & 2.718 & 611.055 & 1.239 & 203.291 \\
2001 & 2.606 & 591.948 & 1.104 & 190.103 \\
2003 & 2.408 & 565.079 & 1.019 & 182.210 \\
2007 & 2.310 & 543.885 & 846 & 173.026 \\
\hline
\end{tabular}


In Deutschland wurden 2011 4,2 Mio. Milchkühe gehalten, davon stehen ca. 4,2 \% in Milchviehbetrieben in Mecklenburg-Vorpommern (GENESIS-Online, 2011). Dort betrug ihre durchschnittliche Milchleistung $8.835 \mathrm{~kg}, 362 \mathrm{~kg}$ Fett und $316 \mathrm{~kg}$ Eiweiß pro Kuh und Jahr.

Tab. 9: Struktur der Milchviehhaltung in Mecklenburg-Vorpommern 2010

(Landeskontrollverband, 2010)

\begin{tabular}{lllll}
\hline $\begin{array}{l}\text { Bestandsgröße } \\
\text { (Milchkühe) }\end{array}$ & Anzahl Betriebe & Milch $[\mathrm{kg}]$ & Fett $[\mathrm{kg}]$ & Eiweiß $[\mathrm{kg}]$ \\
\hline $1-9$ & 6 & 6.755 & 322 & 238 \\
$10-19$ & 10 & 6.620 & 287 & 224 \\
$20-29$ & 13 & 6.972 & 308 & 235 \\
$30-39$ & 11 & 7.459 & 316 & 249 \\
$40-59$ & 35 & 6.509 & 282 & 220 \\
$60-79$ & 62 & 7.607 & 323 & 259 \\
$80-99$ & 40 & 8.088 & 340 & 276 \\
$100-199$ & 172 & 8.342 & 348 & 284 \\
$200-499$ & 235 & 8.867 & 363 & 301 \\
$500-999$ & 63 & 9.133 & 374 & 309 \\
$>1000$ & 9 & 9.625 & 382 & 324 \\
\hline
\end{tabular}

\subsubsection{Die Hochleistungskuh}

„Hochleistung“ ist kein feststehender Begriff, sondern umfasst immer die Kühe, deren Leistung oberhalb der durchschnittlichen Leistung einer vergleichbaren Population liegt. Diese hohen Milchleistungen wirken sich positiv auf betriebswirtschaftliche und nährstoffökonomische Aspekte aus, denn obwohl sich der Nährstoffbedarf der Tiere erhöht, senkt sich insgesamt aufgrund des konstant bleibenden Erhaltungsbedarfes der Futterbedarf pro Kilogramm erzeugter Milch (Rossow, 2004). Mit steigender Herdenleistung wächst allerdings das Risiko von Erkrankungen und Fruchtbarkeitsstörungen. Dadurch sinkt die Nutzungsdauer (Lotthammer, 1999).

Voraussetzungen für hohe Leistungen einer Milchkuh sind ein stabiles HerzKreislaufsystem, eine hohe Gluconeogeneserate in der Leber und eine tägliche Futtertrockenmasseaufnahme von bis zu $25 \mathrm{~kg}$ mit einer Energiedichte von 7,2 MJ NEL/kg. Die Pansenbakterien und -infusorien müssen über optimale Milieubedingungen und Nährstoffangebote verfügen und der Übergang von der Trockenstehperiode zur Laktation muss mit einer möglichst hohen Futterauf- 
nahme einhergehen, damit die Kuh zu Beginn der Laktation nicht in eine negative Energie- und Proteinbilanz gerät und in Folge dessen Körperenergiebzw. Körperproteinreserven mobilisiert. Dafür müssen adäquate Fütterungsund Haltungsbedingungen geschaffen werden (Rossow, 2004).

\subsubsection{Fütterung}

\subsubsection{Grundfuttermittel}

Grundlage für eine optimale Fütterung ist eine möglichst gute Qualität der Grundfuttermittel. Sie basiert auf der chemischen Zusammensetzung, physikalischen und physiologischen Eigenschaften und dem hygienischen Zustand. Als Grundfuttermittel gelten überwiegend Silagen und Heu, Rüben und zunehmend auch geschnittenes Grünfutter (Drochner, 2004). Da das Futteraufnahmevermögen einer Milchkuh bei gleichzeitig hohem Energiebedarf begrenzt ist, können qualitativ hochwertige und leicht verdauliche Silagen zu einer erhöhten Futter- und damit Energieaufnahme beitragen (Höner, 2001).

Silage ist ein durch Milchsäuregärung haltbar gemachtes Futtermittel. Generell können alle Grünfuttermittel, wie Gras, Mais, Klee, Luzerne, Ackerbohnen oder Getreide als Grundlage dienen, aber auch „Abfälle“ wie Rübenblätter oder Biertreber können siliert werden. Das Siliermaterial wird vor dem Einbringen in das Silo zerkleinert, um eine bessere Verfügbarkeit der zellulären Kohlenhydrate zu gewährleisten. Anschließend wird das Silo verdichtet und luftdicht abgeschlossen, um unerwünschte aerobe bzw. fakultativ anaerobe Bakterien, Hefen und Schimmelpilze zu unterdrücken. Milchsäurebakterien wandeln die vorhandenen Kohlenhydrate unter Sauerstoffabschluss in Milchsäure und kurzkettige Fettsäuren um, wodurch der pH-Wert auf 4,0-4,5 sinkt (Archibald, 1953). Dies hemmt wiederum die Vermehrung anderer Anaerobier, wie Listerien oder Clostridien, die negativ auf die Futterqualität wirken würden (Kalac und Woolford, 1982). Zur Verbesserung der Silierqualität können biologische oder chemische Silierhilfsmittel eingesetzt werden (DLG-Ausschuss Futterkonservierung (2006)). Eine gute Hemmwirkung auf C. botulinum besitzt Natriumnitrit (Weißbach, 2004). 
Tab. 10: Anzustrebende Gehalte in Gras- und Maissilagen (DLG-Ausschuss Futterkonservierung (2006))

\begin{tabular}{lcc}
\hline & Grassilage & Maissilage \\
\hline Trockenmassse (TM) [\%] & $30-40$ & $28-35^{1}$ \\
Rohasche [\% der TM] & $<10$ & $<4,5$ \\
Rohfaser [\% der TM] & $22-25$ & $17-20$ \\
Netto-Energie Laktation (NEL) [MJ/kg TM] & $\geq 6,4$ bzw. $\geq 6,0^{2}$ & $\geq 6,5$ \\
Stärke [\% der TM] & Keine & $>30$ \\
Rohprotein [g/kg TM] & $>135$ & $>130$ \\
\hline
\end{tabular}

1: in Abhängigkeit vom Kornanteil, ${ }^{2}:$ 1. Schnitt bzw. Folgeschnitte

Für eine schnelle Beurteilung der Silage genügt eine Einschätzung des Trockenmassegehaltes, eine pH-Wert-Bestimmung, die Beurteilung des Gärverlaufes und eventueller Verschmutzungen (Nussbaum et al., 2004).

Für Heu oder Dürrfutter hat die DLG ebenfalls einen Bewertungsschlüssel zur Qualitätsprüfung erstellt. Danach sollte das Heu eine hellgrüne bis dunkelgrüne Farbe aufweisen, aromatisch riechen und Blattanteile entsprechend dem Ausgangsmaterial enthalten (Nussbaum et al., 2004). Es ist sehr gut getrocknet und zeigt nur geringe Verschmutzungen.

Durch mangelnde Futterhygiene gibt es jährlich Einbußen. Aufgrund einer erhöhten Ausgangskeimbelastung oder ungünstiger Lagerbedingungen kann das Futter an Wert verlieren und zusätzlich zur Quelle von mikrobiellen Intoxikationen werden. Bei ungenügender Verdichtung vermehren sich Schimmelpilze und belasten das Futter mit Mykotoxinen (Bauer et al., 2000), bei zu langsamer Silierung besteht die Gefahr der Vermehrung von Clostridien und der Bildung von BoNT (Kalac und Woolford, 1982; Weißbach, 2004; Myllykoski et al., 2009).

\subsubsection{Mischration}

Da das Grundfutter allein in der Regel nicht ausreicht, um den Energiebedarf einer Milchkuh zu decken, werden diesem energiereiche, rohfaserarme Komponenten beigemischt. Dieses sog. Kraftfutter besitzt einen TM-Gehalt von mehr als $55 \%$ und einen Energiegehalt von mehr als 7 MJ NEL/kg TM. Die Ration kann je nach Energie-, Mineralstoff- und Vitaminbedarf des Trocken- 
stehers oder der laktierenden Kuh berechnet werden. Ziel ist es, das Nährstoffangebot aus dem Futter auf den Nährstoffbedarf der angestrebten Leistung abzustimmen. Neben industriell gefertigten Produkten ist die Zumischung von energiereichem Getreide und eiweißreichen Leguminosen üblich (Gruber Tabelle, (Institut für Tierernährung und Futterwirtschaft, 2010)). Bei der Total-Misch-Ration (TMR) enthält die vorgelegte Ration sowohl Grund- als auch Kraftfutter, es wird keinem Tier Futter individuell zugeteilt. Dadurch werden besonders Futterkosten gespart, da auch Komponenten eingemischt werden können, die sich als Einzelfutter schwierig handhaben lassen. Aufgrund gleichbleibender Fermentation im Pansen lässt sich so die Futteraufnahme, Milchleistung und Tiergesundheit steigern. Da die TMR der Laktation angepasst wird, werden innerhalb des Viehbestandes Gruppen mit gleichem Leistungsniveau gebildet (Nussbaum, 2010). Durch die Verwendung von Transpondern ist eine individuelle Anpassung des Kraftfutters an den Energiebedarf des Einzeltieres möglich.

\subsubsection{Betriebshygiene}

Um gesunde Tiere zu halten und qualitativ hochwertige Milch zu produzieren, spielen eine Vielzahl von Einflussfaktoren eine Rolle. Dazu zählen neben Haltung, Fütterungs- und Weidetechnik auch die Reinigung und Desinfektion. Gerade durch die Sporenbildung von Clostridien kann ein Infektionskreislauf entstehen, der nur schwer zu durchbrechen ist (Notermans et al., 1981; Dahlenborg et al., 2003; Weißbach, 2004).



Abb. 7: Risikofaktoren für die Kontamination mit Clostridien (modif. nach Weißbach, 2004) 


\subsection{Epidemiologie}

\subsubsection{Epidemiologische Studien zur Ermittlung von Risikofaktoren}

Die Epidemiologie ist die Lehre von der Verteilung von Krankheiten und den Faktoren, die diese Verteilung beeinflussen. Sie beruht auf der Herstellung einer hypothetischen Verbindung zwischen zwei scheinbar beziehungslosen Ereignissen (Halpin, 1981). Man kann dabei zwischen rein deskriptiven Verfahren und Verfahren zur Zusammenhangsanalyse wählen (Kreienbrock und Schach, 2005). Bei den Beobachtungsstudien wird im Gegensatz zu den experimentellen Studien kein Einfluss auf die Risikofaktoren genommen. Man unterscheidet je nach Art der Datenerfassung zwischen einer QuerschnittsErhebung, einer Kohortenstudie und einer Fall-Kontroll-Studie.

\subsubsection{Fall-Kontroll-Studie}

In der Fall-Kontroll-Studie stellt man eine Gruppe von Erkrankten (den Fällen) einer Gruppe von Nicht-Erkrankten (den Kontrollen) gegenüber und vergleicht deren zurückliegende Exposition durch einen Risikofaktor. Lassen sich unterschiedliche Expositionen bezüglich des vermuteten Risikofaktors ermitteln, gilt dies als Hinweis auf einen ätiologischen Zusammenhang. Um eine Vergleichbarkeit der Studiengruppen zu gewährleisten, sollten beide Gruppen aus exakt der gleichen Zielgesamtheit stammen. Daher muss beim Design der Studie viel Wert auf die Rekrutierung der Studienpopulationen gelegt werden (Kreienbrock und Schach, 2005).

Diese Art der Studie ist mit geringem Kostenaufwand und in einem kurzen zeitlichen Rahmen durchzuführen, manchmal ist sie auch die einzig praktisch durchführbare. Sie eignet sich zur gleichzeitigen Untersuchung mehrerer Risikofaktoren in Bezug auf eine Krankheit, allerdings lässt sich oft nur in begrenztem Maße bestimmen, ob ein Faktor der Krankheit vorausgeht oder durch sie bestimmt wird. Weitere Nachteile sind der Beobachtungsunterschied bei bestehenden Erwartungshaltungen oder die retrospektive Expositionsbestimmung, wenn die Exposition durch einen Risikofaktor der Krankheit weit voraus ging. Angaben aus dem Gedächtnis heraus können zu Verzerrungen führen (Kreienbrock und Schach, 2005). 


\subsubsection{Fragebogen}

Fragebögen sind neben den klinischen und den Laboruntersuchungen ein gebräuchliches Untersuchungsinstrument zur Erfassung von Daten in der Veterinärepidemiologie. Die Beantwortung der Fragen kann telefonisch oder in einem Interview erfolgen. Durch die Standardisierung mit einheitlich formulierten Fragen und vorgegebenen Antworten lassen sich die erhobenen Daten besser kategorisieren und auswerten.

Die Fragen sollten präzise und verständlich formuliert sein und nach Möglichkeit geschlossen gestaltet werden, so dass der Befragte mit „ja/nein“ bzw. durch „multiple choice“ antworten kann. Die Antwortmöglichkeiten sollten in den meisten Fällen einander ausschließen und in ihrer Gesamtheit erschöpfend sein (Noordhuizen et al., 2001). Zu Beginn werden allgemeine Fragen gestellt, dann folgen detaillierte.

Vor dem Studienbeginn wird der Fragebogen in einem Test auf seine Verständlichkeit geprüft. Im Rahmen einer Pilotstudie kann geklärt werden, ob die erhobenen Daten zur Prüfung der Hypothese dienen oder korrigiert werden müssen. 


\section{Material und Methoden}

\subsection{Auswahl der Betriebe}

Die Untersuchungen zum Auftreten von Clostridium botulinum und betriebsspezifischen Risikofaktoren beim Krankheitsbild des viszeralen Botulismus waren als Fall-Kontroll-Studie angelegt. Sowohl die Fall- als auch die Kontrollbetriebe wurden durch ihren Erkrankungsstatus definiert. Die Expositionen wurden retrospektiv erfasst. Dieser Studientyp eignete sich aufgrund des langwierigen und schleichenden Krankheitsverlaufes besonders für die Untersuchungen bei dieser Erkrankung.

Als Studienregion wurde das Bundesland Mecklenburg-Vorpommern ausgewählt, da dort diese Art der Bestandserkrankung erstmalig beschrieben wurde (Böhnel et al., 2001b; Schwagerick und Böhnel, 2001) und durch die langjährigen Erfahrungen in der Beurteilung der klinischen Symptomatik durch den Rindergesundheitsdienst Mecklenburg-Vorpommern (RGD MV) eine aussagekräftige Auswahl der Betriebe und deren Betreuung möglich war.

Aufgrund der Vergleichbarkeit in Betriebsstruktur und Exposition durch verschiedene Risikofaktoren konnten im Rahmen dieser Pilotstudie zunächst nur drei Fallbetriebe jeweils drei Kontrollbetrieben gegenüber gestellt werden. Laut persönlicher Mitteilung von Dr. Schwagerick gestaltete sich die Suche nach Kontrollbetrieben schwierig, da es kaum noch „gesunde Betriebe“ in ihrem Zuständigkeitsbereich gab. Als Fallbetriebe wurden Betriebe ausgewählt, die in einer Voruntersuchung gemäß der Definition aus den Veröffentlichungen von 2001 dem Krankheitsbild des viszeralen Botulismus entsprachen. In den Kontrollbetrieben waren in den Voruntersuchungen keine Tiere mit diesen Symptomen zu finden. 


\subsection{Fragebogen}

\subsubsection{Entwicklung}

Der 22-seitige Fragebogen zur Erhebung von Daten im Rahmen der Fall-Kontroll-Studie wurde in Anlehnung des BMBF-geförderten Zoonose-Verbundprojektes „Botulinom“ unter dem Arbeitstitel „Fall-Kontroll-Studie Botulinom in Milchviehbetrieben“ erstellt. Er basiert auf der 30-seitigen Anleitung „Leitlinien und Prüfliste für das Vorgehen in Milchviehbeständen mit dem Krankheitsbild einer Faktorenerkrankung“, die vom Ministerium für Ernährung, Landwirtschaft, Forsten und Fischerei Mecklenburg-Vorpommern herausgegeben wurde (Schwagerick, 2004b). In Zusammenarbeit mit Dr. Schwagerick vom RGD MV, PD Dr. Gessler und Prof. Dr. Dr. Böhnel vom IBT Göttingen und Dr. Merle und Frau Schneider vom Institut für Biometrie, Epidemiologie und Informationsverarbeitung der Tierärztlichen Hochschule Hannover wurde aus diesen Leitlinien ein Fragebogen konstruiert, der sowohl Betriebsdaten als auch mögliche Einflussfaktoren auf die Herdengesundheit erfasste.

Vor dem Studienbeginn wurde der Fragebogen auf seine Verständlichkeit und Stimmigkeit geprüft. Nach einem Test in zwei Betrieben wurden Fragen teilweise verständlicher formuliert und zusätzliche Antwortmöglichkeiten aufgenommen.

Fall- und Kontrollbetriebe erhielten jeweils den gleichen Fragebogen.

\subsubsection{Betriebsstruktur}

Der erste Teil des Fragebogens beinhaltet allgemeine Fragen zum untersuchten Betrieb, wie Bestandsgröße, Rassen, weitere Tierhaltung, sowie Daten zur Haltung und Reproduktion, Leistungsdauer, Milchleistung 1t. monatlicher Milchleistungsprüfung und dem Herdenprogramm, jeweils bezogen auf die letzten zwölf Monate. 


\subsubsection{Fütterung}

Im zweiten Teil des Fragebogens wurden die Art der Futterwerbung, -herstellung, -lagerung und die -qualität untersucht. Ein Teilbereich umfasste die Grünlandbewertung mit der Bedeutung möglicher Überschwemmungen und dem Wildbesatz, Fragen zur Nutzung als Schnitt- bzw. Weideland und zu dessen Düngung, mit vertiefenden Fragen bei der Verwendung von Biogasoutput. Zur Bewertung der Grassilage wurden Daten zur Lagerungsform, Schnitt- und Häckselhöhe, dem Verschmutzungsgrad, Silierzusätzen und leicht erkennbaren sensorischen Abweichungen erfragt. Ein weiterer Punkt war die Art der Wasserversorgung und der Fütterung. Mehrere Futter waren zur Auswahl aufgelistet und mit einer Möglichkeit zur sensorischen Beurteilung versehen. Zusätzlich befand sich am Ende des zweiten Teils des Fragebogens eine Tabelle für die Laborergebnisse der Futtermitteluntersuchung. Darin enthalten waren die Bewertungsparameter der DLG zur Futtermittelbewertung wie TS-Gehalt, Rohasche, Rohprotein, Rohfaser und Energiegehalt, aber auch der $\mathrm{NH}_{3}$-Anteil am Gesamtstickstoff zur Beurteilung der Proteolyse. Weiterhin wurde die mikrobielle Belastung mit Enterobakterien, aeroben und anaeroben Sporenbildnern, sowie Schimmelpilzen und Hefen erfasst, genauso wie die Belastung mit verschiedenen Mykotoxinen und C.-botulinum-Toxinen.

\subsubsection{Tiergesundheit}

Im dritten Teil des Fragebogens wurden Daten zur Tiergesundheit erhoben, die klinische Bewertung von Tieren mit Botulismusverdachtssymptomen erfasst und die Laborwerte von fünf symptomatisch unauffälligen Tieren als Bestandsuntersuchung tabellarisch aufgeführt. Im allgemeinen Teil wurde nach der tierärztlichen Betreuung, der Klauenpflege und dem Sanierungsstatus bzgl. BHV-1, BVD/MD, Paratuberkulose und Salmonellose sowie nach Clostridienschutzimpfungen gefragt.

Zur klinischen Untersuchung wurde die Art der begutachteten Leistungsgruppe, die Anzahl der beurteilten Tiere und die Anzahl der Tiere mit Botulismusverdachtssymptomen erfasst. Von drei ausgewählten Tieren wurden die Ohrmarkennummern notiert. Die eingehende klinische Untersuchung umfasste eine Bewertung des Allgemeinzustandes des Tieres, die Bewertung 
der Verdauung und eine Begutachtung unter systemischen und neuromotorischen Gesichtspunkten. Durch eine Kotuntersuchung bei den drei klinisch untersuchten Tieren wurde das Vorhandensein von C. perfringens, C. botulinum, Clostridien allgemein, Salmonellen und Mykobakterien bzw. säurefesten Stäbchen überprüft.

Zur Erfassung der Herdengesundheit wurden von fünf symptomatisch unauffälligen Tieren ebenfalls die Ohrmarkennummern erfasst und Blut und Harn auf verschiedene Laborparameter untersucht. Diese Parameter wurden zu drei verschiedenen Zeitpunkten bestimmt, 7-0 Tage a.p., 0-7 Tage p.p. und 6-8 Wochen p.p. Im Blut wurden zur Beurteilung des Leberstoffwechsels die Aktivitäten der Leberenzyme Aspartat-Aminotransferase (ASAT) und Glutamatdehydrogenase (GLDH), die Gehalte an Bilirubin und Cholesterol herangezogen, zur Bewertung des Energiestoffwechsels der Gehalt an freien Fettsäuren (FFS) bzw. $\beta$-Hydroxybuttersäure (BHB), als Nierenparameter der Harnstoffgehalt (HST), zur Mineralstoffversorgung die Mengen an Calcium (Ca), Phosphor (P) und zur Vitaminversorgung die Mengen an Vitamin B12. Im Harn wurden die Netto-Säure-Basen-Ausscheidung (NSBA) und die Ausscheidung von $\mathrm{Ca}, \mathrm{P}$ und Kalium $(\mathrm{K})$ erfasst. In einer toxikologischen Untersuchung von Organmaterial wurde das Vorhandensein von BoNT und C.perfringens-Toxin in Pansensaft, Leber, Dünndarm und Kot geprüft.

\subsubsection{Auswertung und Beurteilung der erhobenen Daten}

Angesichts der geringen Anzahl an Fall- und Kontrollbetrieben war in dieser Arbeit nur eine vergleichende und deskriptive Analyse möglich, aufgrund dessen gegebenenfalls ein Trend bzgl. des Einflusses verschiedener Risikofaktoren auf die Problematik des viszeralen Botulismus erkennbar ist. Gleiches gilt für klinische Symptome, die zukünftig als charakteristische Anhaltspunkte für das Krankheitsbild des viszeralen Botulismus in der veterinärmedizinischen Diagnostik zur Verfügung stehen sollen.

Zur Auswertung der gesammelten Daten wurden diese in eine, für diese Studie entwickelte, ACCESS ${ }^{\circledR}$-Datenbank eingegeben, Abfragen erstellt und durch die Verknüpfung mit dem Tabellenkalkulationsprogramm EXCEL ${ }^{\circledR}$ tabellarisch 
dargestellt. Dabei wurde die Summe der Fallbetriebe der Summe der Kontrollbetriebe gegenübergestellt, und bei Bedarf differenziert betrachtet.

Die Daten zur Betriebsstruktur und zur Milchleistung wurden zur allgemeinen Gegenüberstellung genutzt. Ebenso wurde der Einfluss von weiterer Tierhaltung, die Totgeburtenrate und Kälbermortalität auf das Krankheitsgeschehen geprüft und die Ergebnisse der Milchleistungsprüfung in den Zusammenhang mit klinischen Symptomen bzw. den Laborparametern gestellt.

Die erhobenen Daten zur Fütterung in der Art der Futterwerbung, -herstellung, -lagerung und -qualität wurden besonders ausführlich beleuchtet. Betrachtet wurde die Beziehung von Leistung und Herdengesundheit zu Faktoren wie Überschwemmungen, Wildtierbesatz, der Nutzung des Grünlandes, die Art der Düngung mit besonderem Fokus auf der Verwendung von Gülle, Mist oder Biogasoutput, der Herstellung und Qualität der Silage und der Wasserversorgung.

Die Tiergesundheit in Fall- und Kontrollbetrieben wurde anhand der klinischen Untersuchungen und der Laborparameter als Instrument der Herdengesundheit verglichen. Im klinischen Bereich wurde ein Score über die jeweils drei untersuchten Tiere für die Kriterien Allgemeinzustand, Verdauung, systemische Symptome, neuro-motorische Symptome und das Ergebnis der Kotuntersuchung erstellt. Die Laborparameter der klinisch unauffälligen Tiere wurden auf Über- oder Unterschreitungen entsprechender Grenzwerte, die einen Hinweis auf Erkrankungen geben können, überprüft. Die Klinik wurde des Weiteren der Herdengesundheit und der mikrobiologischen Diagnostik gegenübergestellt.

\subsection{Probenahme}

Alle Proben wurden aus versicherungsrechtlichen Gründen bei den Bestandsbesuchen durch die Hoftierärzte selbst oder durch Tierarzt Jongmans im Beisein der Hoftierärzte entnommen. 


\subsubsection{Blut/Serum}

Zur Gewinnung von Serum aus Blut für die Antikörper- bzw. Toxindiagnostik wurden Monovetten ${ }^{\circledR}$ verwendet. Mit Hilfe einer Einmalkanüle wurde das Blut aus der Schwanzvene (Vena caudalis mediana) des Rindes entnommen. Dies garantierte eine möglichst stressfreie Gewinnung des Blutes für das Rind und die geringstmögliche Beeinflussung der Blutparameter (Schulze, 2008).

Das Vollblut für die Bestimmung der Blutparameter wurde gekühlt und in ein Auftragslabor eingeschickt. Die Serumproben wurden für die immunologische Diagnostik zunächst zur Denaturierung von Enzymen im Wasserbad bei $56{ }^{\circ} \mathrm{C}$ 30 min inaktiviert und anschließend bis zum Zeitpunkt der Untersuchungen bei $-20{ }^{\circ} \mathrm{C}$ gelagert.

\subsubsection{Harn}

Der Harn wurde per Katheter entnommen, in wenigen Fällen auch direkt im Röhrchen aufgefangen, und gekühlt verschickt.

\subsubsection{Kot}

Der Kot wurde mit Hilfe eines Veterinär-Handschuhs rektal entnommen und bis zum Zeitpunkt der Untersuchung bei $-20{ }^{\circ} \mathrm{C}$ gelagert.

\subsubsection{Pansensaft}

Die Pansensaftentnahme erfolgte über die Punktion des ventralen Pansenblindsacks auf der Verbindungslinie zwischen dem Übergang der knöchernen zur knorpeligen Verbindung der letzten Rippe und dem Knie durch Tierarzt Jongmans (Budras et al., 2007). Mit Hilfe einer Einmalkanüle und einer 50-mL-Spritze wurde die Probe in zwei 15-mL-Röhrchen überführt und teilweise bei $37^{\circ} \mathrm{C}$ für die direkt anschließende Untersuchung der Infusorien und teilweise bei $-20{ }^{\circ} \mathrm{C}$ für die mikrobiologische Diagnostik gelagert. 


\subsubsection{Silage}

Die Entnahme der Silageprobe für die Untersuchung auf Clostridien erfolgte mit Hilfe eines sterilen Handschuhs. Sie wurde ca. $20 \mathrm{~cm}$ hinter dem Anschnitt entnommen.

\subsection{Bestandsdiagnostik / Herdengesundheit}

Die Untersuchungen der Blut- und Harnparameter wurden routinemäßig durch das Auftragslabor METABOVET, Rostock geleistet.

In dem entnommenen Pansensaft wurde der $\mathrm{pH}$-Wert mittels $\mathrm{pH}$-Teststreifen gemessen und optisch ausgewertet. Sowohl Farbe als auch Geruch der Pansensaftproben wurden aufgezeichnet. Mit Hilfe eines Lichtmikroskops wurde die Zahl der Infusorien, deren Zusammensetzung und Beweglichkeit erfasst.

\subsection{Futtermitteluntersuchung}

Die Untersuchung der Silagen fand im Rahmen der Beratung des RGD Mecklenburg-Vorpommern durch die Landwirtschaftliche Untersuchungs- und Forschungsanstalt (LUFA) der LMS Landwirtschaftsberatung MecklenburgVorpommern statt.

\subsection{Clostridiendiagnostik}

\subsubsection{Probenvorbereitung}

Vor der eigentlichen Aufarbeitung wurden die tiefgefrorenen Proben über Nacht bei $+4{ }^{\circ} \mathrm{C}$ aufgetaut. Anschließend wurden sie je nach Beschaffenheit auf dem Vortex $^{\circledR}$ (Pansensaft, Serum) oder mit einem sterilen Spatel (Kot, Silage) homogenisiert.

Während der gesamten Diagnostik wurde unter sterilen Bedingungen mit sterilen Materialien und Medien (s. Anhang) gearbeitet. 


\subsubsection{Clostridium botulinum}

\subsubsection{Maus-Bioassay}

\subsection{Probenaufarbeitung}

Aus den homogenisierten Proben wurden jeweils $25 \mathrm{~g}$ Kot bzw. Silage in einen Kolben eingewogen und mit $50 \mathrm{~mL}$ Gelatine-Phosphat-Puffer (GPP) versetzt und mittels Schwenken durchmischt. Zur Auswaschung des Toxins aus der Probe wurde der Probenansatz über Nacht bei $+4{ }^{\circ} \mathrm{C}$ inkubiert. Nach ca. $12 \mathrm{~h}$ wurden die Proben erneut geschwenkt und die Flüssigkeit mit Hilfe einer Pipette entnommen und in verschiedene Röhrchen gegeben.

Tab. 11: Pipettierschema für den Toxinnachweis im Maus-Bioassay

\begin{tabular}{ccl}
\hline Zugabe $[\mathrm{mL}]$ & Röhrcheninhalt & Verwendung \\
\hline 10 & leer & Bearbeitungsprobe für direkten Toxinnachweis \\
$2-10$ & leer & $\begin{array}{l}\text { Rückstellprobe } \\
4 \text { d-Probe für den Bakteriennachweis (indirekter } \\
\text { Toxinnachweis) } \\
7\end{array}$ \\
$20 \mathrm{~mL} \mathrm{RCM}$ & $\begin{array}{l}4 \mathrm{~d} / 60^{\circ} \mathrm{C}-P r o b e \text { für den Bakteriennachweis (indi- } \\
\text { rekter Toxinnachweis) }\end{array}$ \\
\hline
\end{tabular}

RCM: Reinforced Clostridia Medium

\subsubsection{2 direkter Toxinnachweis}

Die Bearbeitungsprobe wurde mit $100 \mu \mathrm{L}$ Trypsin-Lösung (1:200) versetzt, durchmischt und im Wasserbad bei $37^{\circ} \mathrm{C} 30 \mathrm{~min}$ inkubiert. Anschließend wurden 0,5 mL dieser Probe einer NMRI-Maus injiziert und diese über $96 \mathrm{~h}$ beobachtet. Verendete das Tier in diesem Zeitraum, wurde der Nachweis von BoNT durch eine Neutralisationsreaktion mit BoNT-Antiseren geführt.

\subsubsection{3 indirekter Toxinnachweis / Bakteriennachweis}

Parallel wurde eines der beimpften RCM-Röhrchen zur Abtötung der vegetativen Begleitflora im Wasserbad auf $60^{\circ} \mathrm{C}$ für $30 \mathrm{~min}$ erhitzt. Beide RCMRöhrchen wurden unter anaeroben Bedingungen bei $37{ }^{\circ} \mathrm{C} 4 \mathrm{~d}$ inkubiert und anschließend bei 620 x g 20 min zentrifugiert. $10 \mathrm{~mL}$ des Überstandes wurden in leere Röhrchen überführt und analog zur Bearbeitungsprobe trypsiniert, in eine Maus injiziert und im Falle eines positiven Ergebnisses neutralisiert. 


\subsection{Neutralisation}

Zur Neutralisation möglicherweise vorhandener BoNTe in einer Probe wurden jeweils drei 1,5-mL-Reagiergefäße mit je $600 \mu \mathrm{L}$ der zu prüfenden Probenflüssigkeit versehen. $\mathrm{Zu}$ je einem der Gefäße wurde entweder ein Gemisch der Antiseren für die Typen A/B/E oder ein Gemisch der Antiseren für die Typen $\mathrm{C}$ und $\mathrm{D}$ gegeben. Die eingesetzte Menge richtete sich jeweils nach dem, bei der Gewinnung dieser Antiseren ermittelten Neutralisationspotential, das im Maus-Bioassay jeweils zwei neutralisierende Einheiten betragen sollte. In diesen Untersuchungen wurden $18 \mu \mathrm{L}$ Anti-A, $12 \mu \mathrm{L}$ Anti-B und $12 \mu \mathrm{L}$ Anti-E bzw. $18 \mu \mathrm{L}$ Anti-C und $30 \mu \mathrm{L}$ Anti-D eingesetzt. Die dritte Probe diente als Kontrolle und wurde äquivalent zu den Neutralisationsproben mit $48 \mu \mathrm{L}$ GPP versetzt. Nach einer gründlichen Durchmischung wurden die Proben im Wasserbad bei $37^{\circ} \mathrm{C} 30 \mathrm{~min}$ inkubiert und anschließend analog zum Toxinnachweis in eine Maus injiziert und diese dann 96 h beobachtet. Verendete die Kontrollmaus, während eine oder beide Neutralisationsmäuse überlebten, galt der BoNT-Nachweis als erbracht. Verendeten dagegen alle drei Versuchstiere war der Versuch mit Verdünnungen der Probe in GPP 1:2, 1:4, 1:8 und 1:10 nacheinander zu wiederholen, um ein eindeutiges Ergebnis zu erhalten.

\subsubsection{Antikörper-ELISA}

\subsection{Vorbereitung}

Der Sandwich-ELISA wurde auf 96er-Mikrotiterplatten (PolySorp ${ }^{\circledR}$, Nunc) durchgeführt. Diese Platten wurden vor Beginn des Versuchs mit den Antigenen belegt (engl. Coating), deren Antikörper im Serum der Rinder nachgewiesen werden sollten. Da im verwendeten ELISA nur ein spezifischer Nachweis von Antikörpern gegen BoNT/A, B, C und D möglich war, wurden Kulturüberstände dieser C.-botulinum-Typen 1:40 mit Bicarbonat-Beschichtungspuffer verdünnt und in jede der Vertiefungen jeweils $100 \mu \mathrm{L}$ dieser Lösung gegeben. Anschließend wurde die Platte mit einer Plastikfolie verschlossen und über Nacht im Kühlschrank inkubiert. 
Tab. 12: Übersicht über die beim ELISA eingesetzten Antigene

\begin{tabular}{ccc}
\hline IBT-Stamm-Nr. & Bezeichnung & Herkunft \\
\hline 2298 & C.-botulinum-Typ A & 62 A, Japan \\
2299 & C.-botulinum-Typ B & Okra, Japan \\
3291 & C.-botulinum-Typ C1 & unbekannt \\
2301 & C.-botulinum-Typ D & CB-16, Japan \\
\hline
\end{tabular}

Am darauffolgenden Tag wurden die Platten je drei Mal mit Wasser und drei Mal mit PBS-Tween20 mit jeweils $200 \mu \mathrm{L} /$ Vertiefung automatisiert gewaschen, um nicht gebundene Antigene zu entfernen. Zur Blockierung freier Bindungsstellen wurde die Platte nun mit $200 \mu \mathrm{L} /$ Vertiefung miproBLOCK $\mathrm{C}$ für $1 \mathrm{~h}$ inkubiert. Abschließend wurden sie, wie oben beschrieben, erneut gewaschen.

\subsection{Nachweis der BoNT-spezifischen Antikörper aus Rinderserum}

Das bei $-20{ }^{\circ} \mathrm{C}$ gelagerte Serum wurde im Wasserbad zügig aufgetaut, 1:10 mit PBS-Tween20 verdünnt und je $100 \mu \mathrm{L} /$ Vertiefung und BoNT-Typ auf die Platte gegeben. Parallel dazu wurden Negativ- und Positivkontrollen aufgebracht. Die Platten wurden unter sanftem Schütteln bei $37^{\circ} \mathrm{C} 1 \mathrm{~h}$ inkubiert, erneut automatisiert gewaschen und zusätzlich ausgeschlagen, um alle Reste des Waschpuffers zu entfernen. Anschließend wurden Phosphatase-markierte tierspezifische Anti-Antikörper hinzugegeben, $1 \mathrm{~h}$ bei $37^{\circ} \mathrm{C}$ auf dem Schüttler inkubiert und ungebundene Anti-Antikörper durch automatisiertes Waschen entfernt. Durch die Zugabe des entsprechenden Phosphatase-Substrates ließ sich nach einer Inkubation von $10 \mathrm{~min}$ bei Raumtemperatur die Intensität einer Farbreaktion im Photometer bei einer Wellenlänge von $655 \mathrm{~nm}$ als Absorption ermitteln. Die enzymatische Reaktion wurde mit 25\%iger Schwefelsäure gestoppt und die Farbintensität nun bei $450 \mathrm{~nm}$ gemessen. Entsprechend der Auswertbarkeit wurden die 450-nm-Messungen als Ergebnisse herangezogen. Die Photometer-Software SoftMax Pro 5.4 wandelte diese Ergebnisse anhand einer im System hinterlegten Kalibrierreihe mit definierten Seren direkt in einen vierstufigen Score von „-, und „+“ bis „+++“ um. 


\subsubsection{PCR}

\subsection{Anreicherung}

Beim Einwiegen der Proben für den Maus-Bioassay wurden parallel die Anreicherungsproben für die PCR eingewogen. Dafür wurden jeweils 0,5 g Probe auf zwei 4,5-mL-RCM-Röhrchen eingewogen, gevortext und eines davon bei $60{ }^{\circ} \mathrm{C}$ für $30 \mathrm{~min}$ erhitzt. Anschließend wurden beide Röhrchen unter einer kontrollierten anaeroben Atmosphäre in Vakuumplexiglastöpfen bei $37^{\circ} \mathrm{C} 3 \mathrm{~d}$ bebrütet.

\subsection{DNA-Isolierung}

Die inkubierten RCM-Röhrchen wurden zu Beginn der Isolierung gevortext. Aus den Röhrchen wurde jeweils $1 \mathrm{~mL}$ der Flüssigkeit entnommen und in ein 2-mL-SafeLock-Reagiergefäß überführt. Diese wurden bei 2400 x g für 5 min zentrifugiert. Dieser Überstand wurde verworfen, das Pellet in $1 \mathrm{~mL}$ TE-Puffer resuspendiert und erneut bei $2400 \mathrm{x} g$ für 5 min zentrifugiert. Der erhaltene Überstand wurde erneut verworfen, das Pellet in 0,5 mL TE-Puffer resuspendiert und im Wasserbad für $10 \mathrm{~min}$ bei $100{ }^{\circ} \mathrm{C}$ aufgeschlossen. Der nach der Zentrifugation ( $2400 \mathrm{x} \mathrm{g} / 5 \mathrm{~min}$ ) erhaltene Überstand wurde in ein 1,5-mL-Reagiergefäß überführt und bis zur weiteren Verwendung bei $-20{ }^{\circ} \mathrm{C}$ gelagert.

\subsection{BoNT/ABEF-Multiplex-PCR}

Von dem im Wasserbad bei $37{ }^{\circ} \mathrm{C}$ aufgetauten und gevortexten DNA-Überstand wurden $3 \mu \mathrm{L}$ in ein PCR-Reagiergefäß gegeben und mit $47 \mu \mathrm{L}$ des frisch hergestellten PCR-Mastermixes versetzt. Parallel zur Probe wurde eine Positivkontrolle aus den Stämmen C. botulinum A (IBT 2298), C. botulinum B (IBT 2299), C. botulinum E (IBT 2626) und C. botulinum F (IBT 2303) als Poolprobe analysiert.

Die Bestimmung der BoNT-Gene für BoNT/A, B, E und F geschah nach einer abgeänderten und auf die vorhandenen Laborgeräte optimierten Multiplex- 
Methode von Lindström (2001) und De Medici (2009). Da in vorhergehenden Untersuchungen festgestellt wurde, dass die Primer für das BoNT/A-Gen mindestens einen Subtyp von C.-botulinum-Typ A nicht detektieren, wurden diese Primer gegen parallel selbst entwickelte Primer ausgetauscht.

Tab. 13: Primer für die BoNT/ABEF-Multiplex-PCR

\begin{tabular}{cllc}
\hline BoNT & Primer & Sequenz (5‘3) & $\begin{array}{c}\text { Produktgröße } \\
(\mathrm{bp})\end{array}$ \\
\hline \multirow{2}{*}{ A } & bontA6 F & CAT CAC AGG CAG GCG TAG & 350 \\
& bontA6 R & TGG ATG TTT ACA GAA AAT TCT TGA C & \\
B & CBML B1 & CAG GAG AAG TGG AGC GAA AA & 205 \\
& CBML B2 & CTT GCG CCT TTG TTT TCT TG & 389 \\
E & CBML E1 & CCA AGA TTT TCA TCC GCC TA & \\
& CBML E2 & GCT ATT GAT CCA AAA CGG TGA & \\
F & CBML F1 & CGG CTT CAT TAG AGA ACG GA & 543 \\
& CBML F2 & CTC CCC TAG CCC CGT AT & \\
\hline
\end{tabular}

Pro Probe wurde ein 50- $\mu$ L-Reaktionsansatz hergestellt. Die Einzelkomponenten wurden zu diesem Zweck bei $37^{\circ} \mathrm{C}$ im Wasserbad aufgetaut, gründlich durchmischt und bis zur Verwendung kühl gelagert. Die BoNT/A-, B-, E- und F-Primer lagen in einer Konzentration von $100 \mathrm{pmol} / \mathrm{L}$ und die BoNT/A-Primer in einer Konzentration von $10 \mathrm{pmol} / \mathrm{L}$ vor. Der Reaktionsansatz wurde nach dem Pipettieren ebenfalls gründlich durchmischt und kühl gelagert.

Tab. 14: Zusammensetzung eines 50- $\mu$ L-Reaktionsansatzes einer BoNT/ABEF-Multiplex-PCR

\begin{tabular}{ll}
\hline Komponenten & Volumen \\
\hline SuperHOT Mastermix (2x) & $25 \mu \mathrm{L}$ \\
$\mathrm{MgCl}_{2}(100 \mathrm{mM})$ & $1,65 \mu \mathrm{L}$ \\
Primer & je $0,5 \mu \mathrm{L}$ bontA6 F und bontA6 R \\
& je $0,5 \mu \mathrm{L}$ CBML B1 und B2 \\
& je $0,5 \mu \mathrm{L}$ CBML E1 und E2 \\
& je $1,0 \mu \mathrm{L}$ CBML F1 und F2 \\
steriles Wasser & $18,35 \mu \mathrm{L}$ \\
\hline
\end{tabular}


Folgende Reaktionsbedingungen wurden für die PCR gewählt:

Tab. 15: Thermocycler-Programm für die BoNT/ABEF-Multiplex-PCR

\begin{tabular}{ll}
\hline Programmschritt & Temperatur / Zeit \\
\hline initiale Denaturierung & $94{ }^{\circ} \mathrm{C} / 5$ min \\
Denaturierung & $94{ }^{\circ} \mathrm{C} / 1 \mathrm{~min}$ \\
Annealing & $55{ }^{\circ} \mathrm{C} / 1 \mathrm{~min}$ \\
Elongation & $72{ }^{\circ} \mathrm{C} / 1 \mathrm{~min}$ \\
Zyklenanzahl & 30 \\
abschließende Elongation & $72{ }^{\circ} \mathrm{C} / 10 \mathrm{~min}$ \\
\hline
\end{tabular}

Nach Beendigung des Programms wurden die Proben automatisch im Gerät auf $4{ }^{\circ} \mathrm{C}$ abgekühlt, direkt zum Nachweis der PCR-Produkte in die Gelelektrophorese gegeben oder höchstens über Nacht im Kühlschrank aufbewahrt.

\subsection{BoNT/CD-Multiplex-PCR}

Von dem aufgetauten und gevortexten DNA-Überstand wurden $3 \mu \mathrm{L}$ in ein PCR-Reagiergefäß gegeben und mit $47 \mu \mathrm{L}$ des frisch hergestellten PCRMastermixes versetzt. Parallel zur Probe wurde eine Positivkontrolle aus den Stämmen C. botulinum C1 (IBT 3291), C. botulinum C1/D (IBT 2300), C. botulinum D (IBT 2301) und C. botulinum D/C1 (IBT 3828) als Poolprobe untersucht.

Entsprechend der Mosaiktoxin-Problematik, die im Literaturteil erläutert wurde, wurde im Zuge dieser Arbeit eine PCR-Multiplex-Methode entwickelt, die auf Basis einer geeigneten Platzierung der Primer und vier verschieden großen Produkte zusätzlich zur allgemeinen Detektion eine Zuordnung in die BoNT/C- und D-Subtypen erlaubte. 
Tab. 16: Primer für die BoNT/CD-Multiplex-PCR

\begin{tabular}{llll}
\hline $\begin{array}{l}\text { Platzierung } \\
\text { auf BoNT- } \\
\text { Sequenz }\end{array}$ & Primer & Sequenz (5`3`) & $\begin{array}{c}\text { Produktgröße } \\
\text { (bp) }\end{array}$ \\
\hline C (vorn) & IBTSB F1 & TCC TCG AGT TAC AAG CCC TAA & 706 \\
& IBTSB R1 & ATC CAA TGC CTT TTC CTC AA & \multirow{4}{*}{ T62 } \\
& IBTSB F2 & TGG TTC ACC TTT TAT GGG AGA & \\
& IBTSB R2 & TGT ACG TTG GGT CCA TCT TG & 287 \\
C (hinten) & IBTSB F3 & AAA TTA GGT AGT TCA GGG GAK GA & \\
& IBTSB R3 & TTR TAT CCM GSA GCA TTM TTT & 128 \\
\hline
\end{tabular}

Diese Primer wurden auf Kreuzreaktionen mit anderen C.-botulinumStämmen, verschiedenen Clostridien und anderen Keimen, die als Begleitflora im Verdauungstrakt zu finden sein können, negativ getestet (siehe Anhang). Die Methode wurde bezüglich Temperatur, Primerkonzentration und $\mathrm{MgCl}_{2}$ Konzentration optimiert.

Pro Probe wurde ein 50- $\mu$ L-Reaktionsansatz hergestellt. Die Einzelkomponenten wurden zu diesem Zweck aufgetaut, gründlich durchmischt und bis zur Verwendung kühl gelagert. Die Primer lagen in einer Konzentration von $100 \mathrm{pmol} / \mathrm{L}$ vor. Der Reaktionsansatz wurde nach dem Pipettieren ebenfalls gründlich durchmischt und kühl gelagert.

Tab. 17: Zusammensetzung eines 50- $\mu$ L-Reaktionsgemisches einer BoNT/CD-Multiplex-PCR

\begin{tabular}{ll}
\hline Komponenten & Volumen \\
\hline SuperHOT Mastermix (2x) & $25 \mu \mathrm{L}$ \\
$\mathrm{MgCl}_{2}(100 \mathrm{mM})$ & $1,75 \mu \mathrm{L}$ \\
Primer & je $0,5 \mu \mathrm{L}$ IBT SB F1 IBT SB R1 \\
& je $0,5 \mu \mathrm{L}$ IBT SB F2 und IBT SB R2 \\
& je $0,5 \mu \mathrm{L}$ IBT SB F3 und IBT SB R3 \\
& je $0,5 \mu \mathrm{L}$ IBT SB F4 und IBT SB R4 \\
steriles Wasser & $19,25 \mu \mathrm{L}$ \\
\hline
\end{tabular}

Das Probe-Mastermix-Gemisch wurde in einen Thermocycler gestellt und mit dem folgenden Programm prozessiert. 
Tab. 18: Thermocycler-Programm für die BoNT/CD-Multiplex-PCR

\begin{tabular}{ll}
\hline Programmschritt & Temperatur / Zeit \\
\hline initiale Denaturierung & $94{ }^{\circ} \mathrm{C} / 5 \mathrm{~min}$ \\
Denaturierung & $94{ }^{\circ} \mathrm{C} / 30 \mathrm{~s}$ \\
Annealing & $56{ }^{\circ} \mathrm{C} / 30 \mathrm{~s}$ \\
Elongation & $72{ }^{\circ} \mathrm{C} / 1 \mathrm{~min} 30 \mathrm{~s}$ \\
Zyklenanzahl & 30 \\
abschließende Elongation & $72{ }^{\circ} \mathrm{C} / 10 \mathrm{~min}$ \\
\hline
\end{tabular}

Nach Beendigung des Programms wurden die Proben automatisch im Gerät auf $4{ }^{\circ} \mathrm{C}$ abgekühlt, direkt zum Nachweis der PCR-Produkte in die Gelelektrophorese gegeben oder höchstens über Nacht im Kühlschrank aufbewahrt.

\subsection{C2-PCR}

Von dem aufgetauten und gemischten DNA-Überstand wurden $3 \mu \mathrm{L}$ in ein PCR-Reagiergefäß gegeben und mit $47 \mu \mathrm{L}$ des frisch hergestellten PCRMastermixes versetzt. Parallel zur Probe wurde eine Positivkontrolle aus dem Stamm C. botulinum C1/D C2 (IBT 3291) analysiert.

Die C2-PCR-Methode wurde im Haus entwickelt, getestet und optimiert (Dr. Große-Herrenthey, persönl. Mitteilung).

Tab. 19: Primer der C2-PCR

\begin{tabular}{llc}
\hline Primer & Sequenz $\left(5^{`}-3^{`}\right)$ & $\begin{array}{c}\text { Produktgröße } \\
(\mathrm{bp})\end{array}$ \\
\hline CbotC2-P1 & AAG GAA GAT AAA ACA AAA AT & 311 \\
CbotC2-P2 & CCT AAT GAT ACA AAT GAA AA & 311 \\
\hline
\end{tabular}

Pro Probe wurde ein 50- $\mu$ L-Reaktionsansatz hergestellt. Die Einzelkomponenten wurden zu diesem Zweck aufgetaut, gründlich durchmischt und bis zur Verwendung kühl gelagert. Die Primer lagen in einer Konzentration von $100 \mathrm{pmol} / \mathrm{L}$ vor. Der Reaktionsansatz wurde nach dem Pipettieren ebenfalls gründlich durchmischt und kühl gelagert. 
Tab. 20: Zusammensetzung eines 50- $\mu$ L-Reaktionsgemisches einer C2-PCR

\begin{tabular}{ll}
\hline Komponenten & Volumen \\
\hline SuperHOT Mastermix $(2 \mathrm{x})$ & $25 \mu \mathrm{L}$ \\
Primer & je $2,0 \mu \mathrm{L}$ Cbot C2 P1 und P2 \\
steriles Wasser & $21 \mu \mathrm{L}$ \\
\hline
\end{tabular}

Das Probe-Mastermix-Gemisch wurde in einem Thermocycler mit dem folgenden Programm prozessiert. Annealing und Elongation erfolgten in einem Schritt.

Tab. 21: Thermocycler-Programm für die C2-PCR

\begin{tabular}{ll}
\hline Programmschritt & Temperatur / Zeit \\
\hline initiale Denaturierung & $94{ }^{\circ} \mathrm{C} / 5 \mathrm{~min}$ \\
Denaturierung & $94{ }^{\circ} \mathrm{C} / 45 \mathrm{~s}$ \\
Annealing & $55^{\circ} \mathrm{C} / 2 \mathrm{~min}$ \\
Zyklenanzahl & 34 \\
\hline
\end{tabular}

Nach Beendigung des Programms wurden die Proben automatisch im Gerät auf $4{ }^{\circ} \mathrm{C}$ abgekühlt, direkt zum Nachweis der PCR-Produkte in die Gelelektrophorese gegeben oder höchstens über Nacht im Kühlschrank aufbewahrt.

\subsection{Nachweis der PCR-Produkte durch Gelelektrophorese}

Es wurde ein $2 \%$ iges Agarosegel mit TBE-Puffer vorbereitet und vor dem Gießen mit $50 \mu \mathrm{L}$ UV-aktivem Ethidiumbromid/100mL Gel auf einem Magnetrührer gemischt. Entsprechend der Probenanzahl wurden 0,5 mLReagiergefäße mit $2 \mu \mathrm{L}$ blauem Ladepuffer versetzt und darin $18 \mu \mathrm{L}$ der PCRProbe suspendiert. Aus diesem Gemisch wurden $18 \mu \mathrm{L}$ in die Taschen eines Agarosegels pipettiert, das bereits in eine mit TBE-Puffer gefüllten Pufferschale überführt worden war. Je nach Größe des Gels wurde eine entsprechende Spannung angelegt.

Tab. 22: Spannung und Laufzeit bei verschiedenen Gelgrößen

\begin{tabular}{lcc}
\hline & $125-\mathrm{mL}-\mathrm{Gel}$ & $300-\mathrm{mL}-\mathrm{Gel}$ \\
\hline Spannung & $90 \mathrm{~V}$ & $120 \mathrm{~V}$ \\
Laufzeit & $60 \mathrm{~min}$ & $90 \mathrm{~min}$ \\
\hline
\end{tabular}


Anschließend wurde das Gel der Schale entnommen, in der Fotokammer unter UV-Licht fotografiert und das Bild zur Dokumentation und späteren Auswertung gespeichert. Die Methode galt als erfolgreich durchgeführt, wenn die Positivkontrollen als Banden sichtbar waren und die Negativkontrolle keine Banden aufwies. Eine Probe wurde als positiv definiert, wenn eine oder mehrere Banden zu erkennen waren, die die gleichen Höhen und damit Fragmentgrößen wie die Banden der Positivkontrollen aufwiesen. Durch die Zuordnung zu den Banden der Positivkontrolle ließ sich der Toxintyp eindeutig bestimmen.

\subsubsection{Clostridium perfringens}

\subsubsection{Probenvorbereitung}

Beim Einwiegen der Proben für den Maus-Bioassay wurden parallel auch die Proben zum Nachweis von C. perfringens eingewogen. Dafür wurden jeweils 0,5 g Probe auf zwei 4,5-mL-RCM-Röhrchen und ein 4,5-mL-GPP-Röhrchen eingewogen, gemischt und eines der beiden RCM-Röhrchen bei $60{ }^{\circ} \mathrm{C}$ für 30 min erhitzt. Anschließend wurden beide Röhrchen unter einer kontrollierten, anaeroben Atmosphäre in Vakuumplexiglastöpfen bei $37^{\circ} \mathrm{C}$ über Nacht bebrütet. Das beimpfte GPP-Röhrchen wurde über Nacht im Kühlschrank inkubiert. Bis zur weiteren Verwendung wurden alle Röhrchen bei $-20{ }^{\circ} \mathrm{C}$ gelagert.

\subsubsection{Toxin-ELISA}

Bei dem C.-perfringens-ELISA handelt es sich um einen kommerziell erhältlichen Enterotoxämie ELISA Kit, in dem auf vorbereiteten Mikrotiterplatten mit Hilfe der mitgelieferten Reagenzien der Nachweis von Alpha-, Beta- und Epsilontoxin von $C$. perfringens sowie der semiquantitative Nachweis des Bakterium aus biologischen Proben und Kulturüberständen möglich ist. In den Vertiefungen der Reihen A (Alpha), C (Beta), E (Epsilon) und G (anti-C.perfringens-Antikörper) sind spezifische poly- und monoklonale Antikörper gegen die C.-perfringens-Toxine gebunden, während die Reihen $\mathrm{B}, \mathrm{D}, \mathrm{F}$ und $\mathrm{H}$ 
mit nichtspezifischen Antikörpern beschichtet sind und so als Negativkontrolle fungieren.

Alle Reagenzien wurden vor Gebrauch auf Raumtemperatur gebracht. Nach dem Auftauen der Proben wurde die GPP-Probe 1:2 mit Verdünnungspuffer verdünnt, während die RCM-Proben 10 min bei 2500 x g zentrifugiert wurden. Je Reihe, die alle C.-perfringens-Toxine und die dazugehörigen Negativkontrollen abdeckt, und je Vertiefung wurden je $100 \mu \mathrm{L}$ einer Probe aufgetragen. Parallel dazu wurde eine Positivkontrolle mitgeführt.

Die Platte wurde bei Raumtemperatur 1 h auf dem Horizontalschüttler inkubiert und anschließend mit dem Plattenwascher (Programm M/ELI) mit Waschpuffer gewaschen.

Nach der Durchführung des Toxin-ELISAs entsprechend des HerstellerProtokolls erfolgte eine photometrische Messung des Substratumsatzes bei $450 \mathrm{~nm}$ im Plattenphotometer.

Der Nachweis eines Toxins galt als gesichert, wenn neben der Positivkontrolle auch das Probenmaterial bei der photometrischen Messung die Differenz zwischen Antitoxin-Vertiefung und Kontroll-Vertiefung mehr als 0,100 erreicht.

\subsubsection{C. perfringens-Multiplex-PCR}

\subsection{DNA-Isolierung}

Den beiden RCM-Röhrchen als 1-d- und 1-d-60 ${ }^{\circ} \mathrm{C}$-Probe wurden zur DNAIsolierung jeweils $1 \mathrm{~mL}$ der gemischten Flüssigkeit entnommen und in 2-mL-SafeLock-Reagiergefäße überführt. Es folgte die DNA-Isolierung (siehe 3.6.2.3.2). 


\subsection{PCR}

Von dem im $37{ }^{\circ} \mathrm{C}$-Wasserbad aufgetauten und gemischten DNA-Überstand wurden $3 \mu \mathrm{L}$ in ein PCR-Reagiergefäß gegeben und mit $47 \mu \mathrm{L}$ des frisch hergestellten PCR-Mastermixes versetzt. Parallel zur Probe wurde eine Positivkontrolle aus den Stämmen C. perfringens B mit den Toxinen a, $\beta$ und $\varepsilon$ (IBT 1038), C.perfringens $\mathrm{E}$ mit Enterotoxin und í-Toxin (IBT 76), und C. perfringens mit den Toxinen $\alpha$ und $\beta_{2}$ (IBT 3785) als Poolprobe analysiert.

Die Bestimmung der Toxingene für $\alpha-, \beta-, \beta_{2^{-}}, \varepsilon^{-}$, Entero- und i-Toxin beruhte auf einer von Baums et al. (2004) entwickelten und auf die vorhandenen Laborgeräte optimierten Multiplex-Methode.

Tab. 23: Primer für die C.-perfringens-Multiplex-PCR

\begin{tabular}{|c|c|c|c|}
\hline Toxin & Primer & Sequenz (5‘-3) & $\begin{array}{c}\text { Produktgröße } \\
(\mathrm{bp})\end{array}$ \\
\hline \multirow{2}{*}{ a } & CPA5 L & AGT CTA CGC TTG GGA TGG AA & \multirow{2}{*}{900} \\
\hline & CPA5 R & TTT CCT GGG TTG TCC ATT TC & \\
\hline \multirow[b]{2}{*}{$\beta$} & CPB L & TCC TTT CTT GAG GGA GGA TAA A & \multirow{2}{*}{611} \\
\hline & CPB R & TGA ACC TCC TAT TTT GTA TCC CA & \\
\hline \multirow[b]{2}{*}{$\beta_{2}$} & CPB2 L & CAA GCA ATT GGG GGA GTT TA & \multirow{2}{*}{200} \\
\hline & CPB2 R & GCA GAA TCA GGA TTT TGA CCA & \\
\hline \multirow[b]{2}{*}{$\varepsilon$} & CPETX L & TGG GAA CTT CGA TAC AAG CA & \multirow{2}{*}{396} \\
\hline & CPETX R & TTA ACT CAT CTC CCA TAA CTG CAC & \\
\hline \multirow{2}{*}{ Entero } & CPE L & GGG GAA CCC TCA GTA GTT TCA & \multirow{2}{*}{233} \\
\hline & CPE R & ACC AGC TGG ATT TGA GTT TAA TG & \\
\hline \multirow{2}{*}{$i$} & CPI L & AAA CGC ATT AAA GCT CAC ACC & \multirow{2}{*}{293} \\
\hline & CPI R & CTG CAT AAC CTG GAA TGG CT & \\
\hline
\end{tabular}

Pro Probe wurde ein 50- $\mu$ L-Reaktionsansatz hergestellt. Die Einzelkomponenten wurden zu diesem Zweck aufgetaut, gründlich durchmischt und bis zur Verwendung kühl gelagert. Die Primer lagen in einer Konzentration von $100 \mathrm{pmol} / \mathrm{L}$ vor. Der Reaktionsansatz wurde nach dem Pipettieren ebenfalls gründlich durchmischt und kühl gelagert. 
Tab. 24: Zusammensetzung eines 50- $\mu$ L-Reaktionsansatzes einer C.-perfringens-Multiplex-PCR

\begin{tabular}{ll}
\hline Komponenten & Volumen \\
\hline SuperHOT Mastermix (2x) & $25 \mu \mathrm{L}$ \\
$\mathrm{MgCl}_{2}(100 \mathrm{mM})$ & $1,65 \mu \mathrm{L}$ \\
Primer & je $1,0 \mu \mathrm{L}$ CPA5 L und CPA5 R \\
& je $1,0 \mu \mathrm{L}$ CPB L und CPB R \\
& je $1,0 \mu \mathrm{L} \mathrm{CPE} \mathrm{L} \mathrm{und} \mathrm{CPE} \mathrm{R}$ \\
& je $0,1 \mu \mathrm{L}$ CPETX L und CPETX R \\
& je $0,1 \mu \mathrm{L}$ CPI L und CPI R \\
steriles Wasser & je $0,1 \mu \mathrm{L} \mathrm{CPB2} \mathrm{L} \mathrm{und} \mathrm{CPB2} \mathrm{R}$ \\
\hline
\end{tabular}

Das Probe-Mastermix-Gemisch wurde im Thermocycler mit dem folgenden Programm gestartet:

Tab. 25: Thermocycler-Programm für die C.-perfringens-Multiplex-PCR

\begin{tabular}{ll}
\hline Programmschritt & Temperatur / Zeit \\
\hline initiale Denaturierung & $94{ }^{\circ} \mathrm{C} / 5 \mathrm{~min}$ \\
Denaturierung & $94{ }^{\circ} \mathrm{C} / 1 \mathrm{~min}$ \\
Annealing & $55^{\circ} \mathrm{C} / 1 \mathrm{~min}$ \\
Elongation & $72{ }^{\circ} \mathrm{C} / 1 \mathrm{~min}$ \\
Zyklenanzahl & 35 \\
abschließende Elongation & $72{ }^{\circ} \mathrm{C} / 5 \mathrm{~min}$ \\
\hline
\end{tabular}

Nach Beendigung des Programms wurden die Proben automatisch im Gerät auf $4{ }^{\circ} \mathrm{C}$ abgekühlt, direkt zum Nachweis der PCR-Produkte in die Gelelektrophorese gegeben oder höchstens über Nacht im Kühlschrank aufbewahrt.

\subsection{Gelelektrophorese}

Die Gelelektrophorese wurde anschließend analog zu dem in Abschnitt 3.6.2.3.6 dargestellten Verfahren durchgeführt und ausgewertet. 


\section{Ergebnisse}

\subsection{Struktur der Studienpopulation}

Die räumliche Verteilung der Fall- und Kontrollbetriebe erstreckte sich in Mecklenburg-Vorpommern auf die Landkreise Bad Doberan (seit 04.09.2011 Landkreis Rostock) und Nordwestmecklenburg. Die Verteilung auf die einzelnen Landkreise war zufällig. Die Betriebe wurden in der Reihenfolge ihrer Datenerhebung als Fallbetrieb (FB) oder dazugehöriger Kontrollbetrieb (KB) fortlaufend nummeriert.

Tab. 26: Einordnung der Fall- und Kontrollbetriebe in die Landkreise Mecklenburg-Vorpommerns

\begin{tabular}{lll}
\hline Fallbetriebe & Kontrollbetriebe & Landkreis MV \\
\hline FB 1 & KB 1 & Bad Doberan \\
FB 2 & KB 2 & Nordwestmecklenburg \\
FB 3 & KB 3 & Bad Doberan \\
\hline
\end{tabular}

Im Rahmen der Fall-Kontrollstudie wurden, mit einem Matching-Verhältnis von 1:1, drei Fälle und drei Kontrollen in die Erhebung einbezogen, von denen abgeschlossene Fragebögen vorlagen. Alle Daten wurden in der Zeit von August bis Dezember 2010 erhoben. Es wurden insgesamt sechs Interviews mit den betriebsverantwortlichen Personen geführt.

Die Auswertung der Fragebögen und Ausführungen zu den Ergebnissen der klinischen und bakteriologischen Untersuchungen erfolgten im Hinblick auf den Vergleich der beiden Gruppen.

Der Kontrollbetrieb KB 3 musste teilweise gesondert betrachtet werden. Obwohl er nach den vorausgesetzten Kriterien als Kontrollbetrieb eingestuft worden war, sprach das Pflegepersonal zum Zeitpunkt der Probenahme von einer kaum wahrnehmbaren „gesundheitlichen Veränderung im Bestand“. Zwar ließ sich die Beobachtung vor Ort klinisch nicht belegen, die vorliegenden Ergebnisse wurden aber auch im Hinblick auf diese Feststellung betrachtet. 


\subsection{Betriebsstruktur}

\subsubsection{Bestand Milchvieh}

In den Betrieben, in denen der Verdacht auf viszeralen Botulismus bestand, betrug die Anzahl des Milchviehs durchschnittlich 563 Tiere, während in den Kontrollbetrieben der Bestand des Milchviehs durchschnittlich 545 Tiere groß war. Davon betrug der durchschnittliche Anteil der zu melkenden Kühe bei den Fallbetrieben 246 Tiere und bei den Kontrollbetrieben 230 Tiere. Die Zahl der Trockensteher belief sich auf 35 bzw. 38 Tiere und die Zahl der Jungrinder auf 282 bzw. 277 Tiere.

Tab. 27: Anzahl an gehaltenem Milchvieh in den Fall- und Kontrollbetrieben

\begin{tabular}{|c|c|c|c|c|c|c|}
\hline & \multicolumn{2}{|c|}{ melkende Kühe } & \multicolumn{2}{|c|}{ Trockensteher } & \multicolumn{2}{|c|}{ Jungrinder } \\
\hline & Fälle & Kontrollen & Fälle & Kontrollen & Fälle & Kontrollen \\
\hline $\mathrm{N}$ & 3 & 3 & 3 & 3 & 3 & 3 \\
\hline arithm. Mittel & 246 & 230 & 35 & 38 & 282 & 277 \\
\hline Median & 274 & 242 & 29 & 43 & 335 & 310 \\
\hline$\sigma$ & 120 & 45 & 23 & 16 & 133 & 95 \\
\hline VarK [\%] & 49 & 20 & 65 & 42 & 47 & 34 \\
\hline Minimum & 114 & 180 & 16 & 20 & 130 & 170 \\
\hline $5 \%$-Quantil & 130 & 186 & 17 & 22 & 151 & 184 \\
\hline $95 \%$-Quantil & 342 & 265 & 57 & 50 & 376 & 346 \\
\hline Maximum & 350 & 268 & 60 & 51 & 380 & 350 \\
\hline
\end{tabular}

o - Standardabweichung, VarK - Variationskoeffizient

Sowohl bei den Fällen als auch bei den Kontrollen war die Rasse der HolsteinSchwarzbunten mit jeweils mindestens $95 \%$ am häufigsten vertreten.

Tab. 28: prozentuale Verteilung der Rassen bei Fällen und Kontrollen

\begin{tabular}{lcccccc}
\hline \multicolumn{7}{c}{ Anteil Rinderrasse [\%] } \\
\hline Rasse & FB 1 & KB 1 & FB 2 & KB 2 & FB 3 & KB 3 \\
\hline Holstein-Friesian & 100 & 100 & 95 & 95 & 100 & 100 \\
Rotbunt & 0 & 0 & 0 & 0 & 0 & 0 \\
Fleckvieh & 0 & 0 & 0 & 0 & 0 & 0 \\
Andere & 0 & 0 & 5 & 5 & 0 & 0 \\
Gesamt & 100 & 100 & 100 & 100 & 100 & 100 \\
\hline
\end{tabular}




\subsubsection{Weitere Tierhaltung}

In den beprobten Gruppen wurde jeweils fast ausschließlich Milchviehhaltung betrieben. Im Fallbetrieb FB 2 wurden zusätzlich 52 Mutterkühe, im Fallbetrieb FB 3 außerdem 500 Schweine gehalten. Es ist davon auszugehen, dass die Haltung weiterer Tiere neben dem Milchviehbestand nur sporadisch und gestreut vorkommt.

\subsubsection{Haltung und Reproduktion}

Die zu melkenden Tiere wurden größtenteils ausschließlich im Stall gehalten. Nur im Fallbetrieb FB 2 und dem dazugehörigen Kontrollbetrieb KB 2 fand eine Haltung im Stall und auf der Weide statt. In allen Betrieben beider Gruppen stammten die Tiere aus eigener Nachzucht.

\subsubsection{Leistungsdaten}

Die prozentuale Remontierungsrate betrug bei einer durchschnittlichen Nutzungsdauer von 2-4 Jahren überwiegend 30-40 \%. Ein Fallbetrieb lag mit einer Rate von mehr als 40 \% über dem Durchschnitt, ein Kontrollbetrieb lag mit weniger als $30 \%$ darunter. Die durchschnittliche Remontierungsrate im Bereich des Landeskontrollverbandes betrug 35,6 \%.

Tab. 29: Leistungsdaten der Fall- und Kontrollbetriebe

\begin{tabular}{lcccccc}
\hline & FB 1 & KB 1 & FB 2 & KB 2 & FB 3 & KB 3 \\
\hline Remontierung [\%] & $30-40$ & $30-40$ & $30-40$ & $<30$ & $>40$ & $30-40$ \\
Nutzungsdauer [a] & $2-4$ & $<2$ & $2-4$ & $2-4$ & $2-4$ & $2-4$ \\
Zwischenkalbezeit [d] & 430 & 397 & 420 & 400 & 422 & 403 \\
\hline
\end{tabular}

Die mittlere Zwischenkalbezeit lag in den Fallbetrieben bei 424 Tagen, in den Kontrollbetrieben dagegen deutlich darunter bei nur 400 Tagen. 


\subsubsection{Milchleistung}

Alle untersuchten Betriebe nahmen an der monatlichen Milchleistungsprüfung (MLP) des Landeskontrollverbandes Mecklenburg-Vorpommern e.V. (LKV) teil, so dass die erhobenen Daten zur Milchleistung der Herde für die Beurteilung der Betriebe genutzt werden konnten. Da im Zuge dieser Pilotstudie nur sehr wenige Betriebe betrachtet werden konnten, wurden zur Vermeidung des Einflusses von extremen Ausreißern die Medianwerte anstatt der arithmetischen Mittelwerte zur Beurteilung der Leistungsdaten herangezogen.

Tab. 30: Milchleistung pro Tier in den letzten 12 Monaten nach Fall- und Kontrollbetrieben

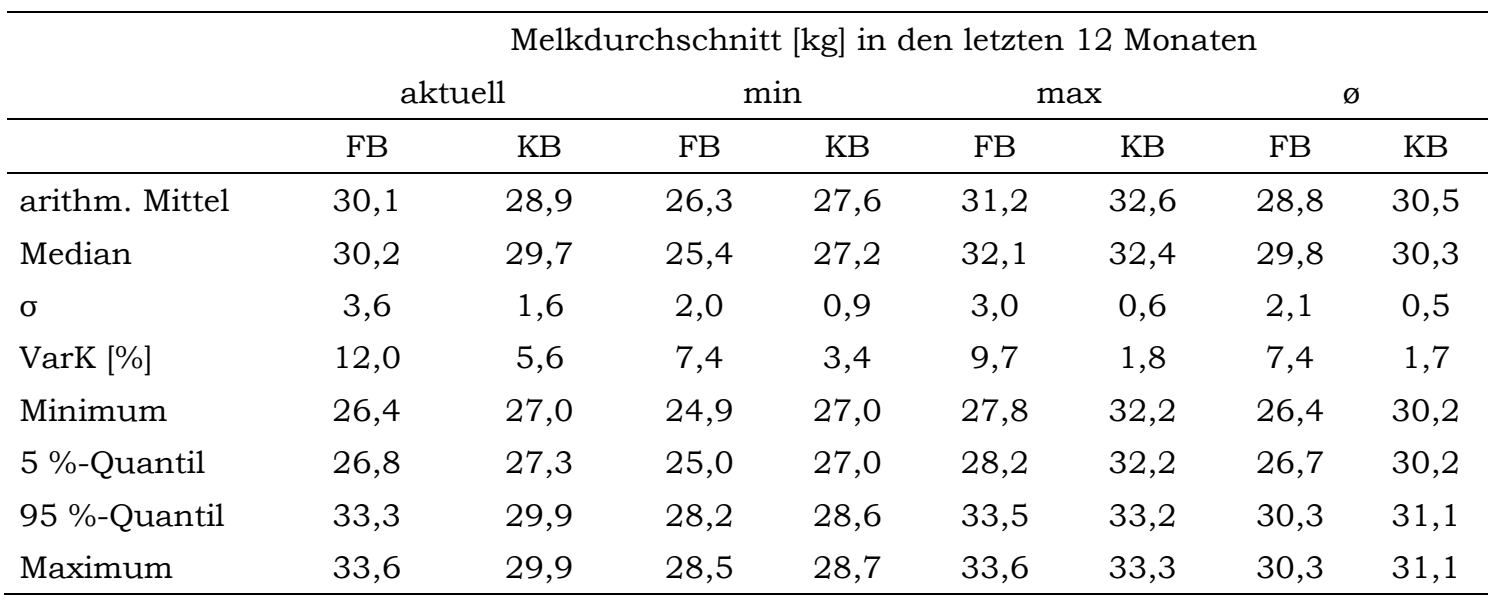

Laut Jahresbericht 2010 des zuständigen Landeskontrollverbandes betrug die durchschnittliche Milchleistung pro Kuh in Mecklenburg-Vorpommern $8.824 \mathrm{~kg} / \mathrm{Jahr}$ und speziell für Schwarzbunte $8.920 \mathrm{~kg} / \mathrm{Jahr}$. Das entspricht $28,9 \mathrm{~kg} /$ Tag bzw. 29,3 kg/Tag für Schwarzbunte bei einer angenommenen Milchleistung von 305 Tagen. Die ermittelten Daten für die untersuchten Betriebe lagen größtenteils in diesem Bereich, nur die Leistung des FB 2 lag mit 26,4 kg deutlich darunter. Während bei der Betrachtung der Medianwerte der aktuelle Melkdurchschnitt bei Fall- und Kontrollbetrieben ähnlich war und ebenso die Maximal- und Durchschnittswerte, zeigten die Minimalwerte des Fallbetriebes FB 1 mit 4,9 kg/Tag, des Kontrollbetriebes KB 3 mit 4,1 kg/Tag und des Kontrollbetriebes KB 1 mit 3,0 kg/Tag die größten Verluste zur durchschnittlichen Melkleistung, während die anderen Betriebe niedrigere Verluste aufwiesen.

Der Zellgehalt in der Milch gilt als wichtiger Indikator der Eutergesundheit. Zum einen dient dieser Parameter zur Beurteilung der Milchqualität, er hat aber auch Bedeutung als diagnostischer Wert. Bei den somatischen Zellen in 
der Milch handelt es sich überwiegend um Leukozyten und einen kleinen Anteil an epithelialen Zellen. Ein Grenzwert von 100.000 Zellen/mL wird zur Unterscheidung zwischen gesunden und erkrankten Tieren herangezogen. Hohe Zellzahlen beeinträchtigen die Milchleistung und führen $\mathrm{zu}$ Verarbeitungsschwierigkeiten durch die veränderte Milchzusammensetzung. Entsprechend Abschnitt $4 \S 14$ der Tierische Lebensmittel-HygieneVerordnung (2007 (letzte Änderung 12. November 2010)) und § 2 Absatz 10 der MilchgüteVerordnung (1981 (letzte Änderung 01.01.2011)) gilt Rohmilch mit einer Zellzahl von > 400.000 Zellen/mL als nicht verkehrsfähig.

Tab. 31: Zellzahl (nach MLP) in den letzten 12 Monaten nach Fall- und Kontrollbetrieben

\begin{tabular}{|c|c|c|c|c|c|c|c|c|}
\hline & \multicolumn{8}{|c|}{ Zellzahl [in Tausend/ml] in den letzten 12 Monaten } \\
\hline & \multicolumn{2}{|c|}{ aktuell } & \multicolumn{2}{|c|}{$\min$} & \multicolumn{2}{|c|}{$\max$} & \multicolumn{2}{|c|}{$\varnothing$} \\
\hline & FB & $\mathrm{KB}$ & $\mathrm{FB}$ & $\mathrm{KB}$ & $\mathrm{FB}$ & $\mathrm{KB}$ & FB & $\mathrm{KB}$ \\
\hline arithm. Mittel & 276 & 240 & 223 & 173 & 389 & 375 & 285 & 263 \\
\hline Median & 267 & 192 & 223 & 166 & 377 & 397 & 288 & 270 \\
\hline$\sigma$ & 22 & 137 & 27 & 66 & 55 & 146 & 36 & 114 \\
\hline VarK [\%] & 8 & 57 & 12 & 38 & 14 & 39 & 12 & 43 \\
\hline Minimum & 259 & 134 & 196 & 111 & 341 & 219 & 248 & 146 \\
\hline 5 \%-Quantil & 260 & 140 & 199 & 117 & 345 & 237 & 252 & 158 \\
\hline 95 \%-Quantil & 298 & 375 & 246 & 234 & 442 & 497 & 316 & 364 \\
\hline Maximum & 301 & 395 & 249 & 242 & 449 & 508 & 319 & 374 \\
\hline
\end{tabular}

Die Milchgüte-Verordnung sieht nach $\S 3$ eine Einordnung in die sogenannte „S-Klasse“ vor, wenn neben anderen Parametern die Zellzahl im geometrischen Mittel über drei Monate unter 300.000 Zellen/mL liegt. Das zusätzliche Gütesiegel des LKV Mecklenburg-Vorpommern wird für Milch vergeben, deren Zellzahl im geometrischen Mittel über drei Monate 250.000 Zellen/mL und in den Einzelwerten 400.000 Zellen/mL nicht überschreiten darf. Die durch die MLP ermittelten Zellzahlen unterschritten bei keinem der untersuchten Betriebe 100.000 Zellen/mL, die als Indiz für einen gesunden Betrieb gelten. Im Durchschnitt lagen die Werte allerdings knapp unter der Marke von 300.000 Zellen/mL, wodurch nach diesem Kriterium eine Einordnung in die „S-Klasse“ vorgenommen werden könnte. Die Kriterien für das Gütesiegel des LKV erfüllten diese Milchen jedoch nicht. Dort lag im Jahr 2010 die Zellzahl durchschnittlich bei $224.000 / \mathrm{mL}$. Abgesehen von den Maximalwerten lagen die Fallbetriebe mit ihren Zellzahlen 18.000-75.000 Zellen/mL höher als die 
Kontrollbetriebe. Dort wurden die stark überschreitenden Maximalwerte durch KB 3 verursacht.

Der Fettgehalt der Milch spiegelt die Versorgung mit Energie und strukturierter Rohfaser wider und bewegt sich in einem Bereich zwischen 3,5 und 5,0 \%. Unterschiede sind in der Rinderrasse und Fütterung begründet oder durch jahreszeitliche Schwankungen bedingt. Die Schwankungen sollten aber 0,5 Prozentpunkte nicht überschreiten. Die Fütterung der Tiere hat einen direkten Einfluss auf die chemische Zusammensetzung der Milch und des Fettsäuremusters (Südekum, 2010). Entsprechend dem Anteil an Fett in der Milch ist ein ausreichend energielieferndes Grund- und Kraftfutter Voraussetzung. Der jeweilige Fettgehalt ist ein maßgeblicher Bestandteil des Auszahlungspreises der Milch.

Tab. 32: Fettgehalt der Milch in den letzten 12 Monaten nach Fall- und Kontrollbetrieben

\begin{tabular}{|c|c|c|c|c|c|c|c|c|}
\hline & \multicolumn{8}{|c|}{ Fettgehalt [\%] in den letzten 12 Monaten } \\
\hline & \multicolumn{2}{|c|}{ aktuell } & \multicolumn{2}{|c|}{$\min$} & \multicolumn{2}{|c|}{$\max$} & \multicolumn{2}{|c|}{$\varnothing$} \\
\hline & $\mathrm{FB}$ & $\mathrm{KB}$ & $\mathrm{FB}$ & $\mathrm{KB}$ & $\mathrm{FB}$ & $\mathrm{KB}$ & FB & $\mathrm{KB}$ \\
\hline arithm. Mittel & 4,05 & 3,85 & 4,02 & 3,51 & 4,87 & 4,29 & 4,35 & 3,90 \\
\hline Median & 3,89 & 3,82 & 3,89 & 3,62 & 4,86 & 4,30 & 4,30 & 3,88 \\
\hline$\sigma$ & 0,28 & 0,25 & 0,23 & 0,35 & 0,12 & 0,07 & 0,10 & 0,18 \\
\hline $\operatorname{VarK}[\%]$ & 6,98 & 6,40 & 5,74 & 9,92 & 2,47 & 1,66 & 2,40 & 4,51 \\
\hline Minimum & 3,89 & 3,62 & 3,89 & 3,12 & 4,75 & 4,21 & 4,28 & 3,74 \\
\hline $5 \%$-Quantil & 3,89 & 3,64 & 3,89 & 3,17 & 4,76 & 4,22 & 4,28 & 3,75 \\
\hline $95 \%$-Quantil & 4,33 & 4,08 & 4,25 & 3,77 & 4,98 & 4,35 & 4,45 & 4,07 \\
\hline Maximum & 4,38 & 4,11 & 4,29 & 3,79 & 4,99 & 4,35 & 4,47 & 4,09 \\
\hline
\end{tabular}

Im Prüfbereich des LKV Mecklenburg-Vorpommern betrug im Jahr 2010 der durchschnittliche Fettgehalt der Rohmilch aller Rassen 4,11\%. Insgesamt produzierten schwarzbunte Kühe, die auch in den hier untersuchten Betrieben zu 95-100 \% gehalten wurden, Milch mit einem durchschnittlichen Fettgehalt von 4,09 \%. Der Median der aktuellen Fettgehalte beider untersuchten Gruppen lag mit 3,89 bzw. 3,82 \% deutlich unter 4,00 \%. Die Durchschnittsfettgehalte der letzten zwölf Monate betrugen in den Fallbetrieben 4,30 \%, in den Kontrollbetrieben aber nur 3,88 \%. Es ließ sich feststellen, dass im Vergleich zu den durchschnittlichen Werten der letzten zwölf Monate die prozentualen Fettgehalte in den Fallbetrieben grundsätzlich gesunken sind, während die Fettgehalte in den Kontrollbetrieben, bis auf eine Ausnahme, im gleichen 
Zeitraum angestiegen sind. Das ließ auf einen Einbruch der Fettsyntheserate bei den Milchkühen der Fallbetriebe schließen.

Das Milcheiweiß ist der zweite qualitäts- und preisbestimmende Inhaltsstoff der Milch. Seine Bedeutung steigt durch die Vielzahl der Verwendungsmöglichkeiten und neuer Produkte in der Lebensmittelindustrie und wird in immer stärkerem Maße ausschlaggebend für den Wert der abgelieferten Milch. Der Anteil an Milcheiweiß beträgt zwischen 3,0 und 3,8 \%. Die Gehalte in der Rohmilch variieren wie auch der Fettgehalt je nach Rasse, Fütterung und Jahreszeit. Bei einem niedrigen Eiweißgehalt steht den Mikroorganismen nicht genügend Energie für die Proteinsynthese im Pansen zur Verfügung. In solchen Fällen sollte die Proteinverdaulichkeit und die Versorgung mit leicht verdaulichen Kohlenhydraten überprüft werden.

Tab. 33: Eiweißgehalt der Milch in den letzten 12 Monaten nach Fall- und Kontrollbetrieben

\begin{tabular}{|c|c|c|c|c|c|c|c|c|}
\hline & \multicolumn{8}{|c|}{ Eiweißgehalt [\%] in den letzten 12 Monaten } \\
\hline & \multicolumn{2}{|c|}{ aktuell } & \multicolumn{2}{|c|}{$\min$} & \multicolumn{2}{|c|}{$\max$} & \multicolumn{2}{|c|}{ ø } \\
\hline & FB & $\mathrm{KB}$ & $\mathrm{FB}$ & $\mathrm{KB}$ & FB & $\mathrm{KB}$ & FB & KB \\
\hline arithm. Mittel & 3,36 & 3,30 & 3,26 & 3,21 & 3,58 & 3,51 & 3,41 & 3,38 \\
\hline Median & 3,32 & 3,41 & 3,31 & 3,31 & 3,58 & 3,50 & 3,43 & 3,39 \\
\hline$\sigma$ & 0,21 & 0,26 & 0,08 & 0,18 & 0,05 & 0,06 & 0,05 & 0,08 \\
\hline VarK [\%] & 6,18 & 7,97 & 2,48 & 5,67 & 1,26 & 1,59 & 1,38 & 2,23 \\
\hline Minimum & 3,17 & 3,00 & 3,17 & 3,00 & 3,53 & 3,46 & 3,36 & 3,30 \\
\hline $5 \%$-Quantil & 3,19 & 3,04 & 3,18 & 3,03 & 3,54 & 3,46 & 3,37 & 3,31 \\
\hline 95 \%-Quantil & 3,55 & 3,48 & 3,31 & 3,32 & 3,62 & 3,56 & 3,45 & 3,44 \\
\hline Maximum & 3,58 & 3,49 & 3,31 & 3,32 & 3,62 & 3,57 & 3,45 & 3,45 \\
\hline
\end{tabular}

Der durchschnittliche Eiweißgehalt der Milch aller Rinderrassen betrug in mecklenburgischen Betrieben 3,40 \% und unterschied sich damit nicht von den 3,39 \% Milcheiweiß bei den schwarzbunten Milchkühen (MöcklinghoffWicke und Zieger, 2005). Auch die im Rahmen dieser Studie untersuchten Betriebe lieferten Milch, die durchschnittlich 3,43 \% Eiweiß für die Fallbetriebe und 3,39 \% Eiweiß für die Kontrollbetriebe aufwies. Es waren keine Unterschiede zwischen den Fall- und Kontrollbetrieben auszumachen. Allerdings lag der Durchschnittswert der letzten zwölf Monate in den Fallbetrieben ca. 0,1 Prozentpunkte über dem aktuellen Wert, während sich diese beiden Werte in den Kontrollbetrieben kaum unterschieden. Betrachtete man den Kontrollbetrieb KB 3 separat, wurde ersichtlich, dass der aktuelle Gehalt an 
Milcheiweiß in diesem Betrieb von durchschnittlich 3,30\% auf 3,00\% stark gesunken war.

Der Fett/Eiweiß-Quotient gibt eine erste Auskunft über die Stoffwechselsituation der Herde und sollte im Idealfall zwischen 1,1 und 1,5 liegen (Möcklinghoff-Wicke und Zieger, 2005). Ein Quotient über 1,5 deutet auf einen hohen Abbau von Körperfett hin, was eine enorme Belastung des Stoffwechsels darstellt und die Gefahr einer Ketose birgt. Ein Quotient unter 1,1 deutet auf eine unzureichende Versorgung mit strukturreichem Grundfutter hin, wodurch der Stoffwechsel in eine azidotische Schieflage geraten kann. In den untersuchten Fallbetrieben befanden sich die aktuellen und durchschnittlichen Fett/Eiweiß-Quotienten komplett im mittleren Idealbereich. In den Kontrollbetrieben lagen sie, mit der Ausnahme des aktuellen Wertes für $\mathrm{KB} 2$, ebenfalls im Idealbereich und gaben in beiden Gruppen keinen Hinweis auf eine veränderte Stoffwechsellage. Im KB 2 sollte dem Hinweis auf eine azidotische Stoffwechsellage nachgegangen werden.

Tab. 34: Fett/Eiweiß-Quotienten der aktuellen und durchschnittlichen Fett- und Eiweißgehalte

\begin{tabular}{lcccccc}
\hline & FB 1 & KB 1 & FB 2 & KB 2 & FB 3 & KB 3 \\
\hline aktuell & 1,17 & 1,23 & 1,22 & 1,06 & 1,23 & 1,27 \\
$\varnothing$-Werte & 1,25 & 1,27 & 1,30 & 1,14 & 1,27 & 1,13 \\
\hline
\end{tabular}

Aussagekräftiger für die Tiergesundheit wird der Eiweißgehalt in Kombination mit dem Harnstoffgehalt der Milch, denn dieser spiegelt deutlich das Proteinangebot im Verhältnis zur Energieversorgung wider. Bei einer Über- oder Unterversorgung der Pansenmikrobiota mit leichtverdaulichen Kohlenhydraten akkumuliert das nicht verstoffwechselte Protein und erhöht den Harnstoffgehalt der Milch. Er sinkt dagegen bei ausreichender Energieversorgung und gleichzeitigem Proteinmangel. Der Harnstoffgehalt sollte im Bereich von 150-300 mg/L liegen, im Optimalfall sogar in den engeren Grenzen von 200-250 mg/L (Möcklinghoff-Wicke und Zieger, 2005). 
Tab. 35: Harnstoffgehalte der Milch in den letzten 12 Monaten nach Fall- und Kontrollbetrieben

\begin{tabular}{|c|c|c|c|c|c|c|c|c|}
\hline & \multicolumn{8}{|c|}{ Harnstoffgehalt der Milch [mg/L] in den letzten 12 Monaten } \\
\hline & \multicolumn{2}{|c|}{ aktuell } & \multicolumn{2}{|c|}{$\min$} & \multicolumn{2}{|c|}{$\max$} & \multicolumn{2}{|c|}{$\varnothing$} \\
\hline & FB & $\mathrm{KB}$ & FB & $\mathrm{KB}$ & FB & $\mathrm{KB}$ & FB & $\mathrm{KB}$ \\
\hline arithm. Mittel & 268 & 221 & 219 & 155 & 281 & 291 & 252 & 237 \\
\hline Median & 275 & 261 & 238 & 194 & 297 & 277 & 269 & 239 \\
\hline$\sigma$ & 26 & 84 & 41 & 91 & 37 & 27 & 40 & 9 \\
\hline VarK [\%] & 10 & 38 & 19 & 59 & 13 & 9 & 16 & 4 \\
\hline Minimum & 239 & 123 & 172 & 51 & 239 & 274 & 206 & 228 \\
\hline 5 \%-Quantil & 243 & 138 & 179 & 65 & 245 & 274 & 212 & 229 \\
\hline 95 \%-Quantil & 289 & 275 & 246 & 218 & 307 & 318 & 280 & 244 \\
\hline Maximum & 290 & 277 & 238 & 221 & 308 & 322 & 381 & 245 \\
\hline
\end{tabular}

Zog man die engeren Grenzwerte für die Beurteilung des Harnstoffgehaltes der Milch heran, so fanden sich kaum Ergebnisse, die innerhalb dieses Bereiches lagen. Benutzte man allerdings die etwas weiter gefassten Grenzwerte, befanden sich alle Gruppenresultate im Normbereich. Auffällig war der starke Unterschied zwischen dem arithmetischen Mittel und dem Median der aktuellen Werte in der Kontrollgruppe, der durch sehr geringe Werte im Kontrollbetrieb KB 3 zustande kam. Dort betrugt der aktuelle Harnstoffgehalt $124 \mathrm{mg} / \mathrm{L}$ und über die letzten zwölf Monate der minimalste Wert $51 \mathrm{mg} / \mathrm{L}$ und der maximalste Wert $322 \mathrm{mg} / \mathrm{L}$, so dass sich ein durchschnittlicher Wert von $228 \mathrm{mg} / \mathrm{L}$ ergab, der die großen Schwankungen des Stoffwechsels in keinster Weise widerspiegelte.

Bei gleichzeitiger Betrachtung von Eiweißgehalt und Harnstoffgehalt der Milch lassen sich Rückschlüsse auf das Fütterungsmanagement und evtl. vorliegende Erkrankungen ziehen. Zu diesem Zweck werden die Betriebe nachfolgend einzeln betrachtet.

Tab. 36: Aktuelle und ø-Werte der Eiweiß- und Harnstoffgehalte der Milch pro Betrieb

\begin{tabular}{lcccccc}
\hline & FB 1 & KB 1 & FB 2 & KB 2 & FB 3 & KB 3 \\
\hline Eiweiß aktuell [\%] & 3,32 & 3,41 & 3,58 & 3,49 & 3,17 & 3,00 \\
HST aktuell [mg/L] & 239 & 277 & 275 & 261 & 290 & 124 \\
\hline Eiweiß ø-Wert [\%] & 3,45 & 3,39 & 3,43 & 3,45 & 3,36 & 3,30 \\
HST ø-Wert [mg/L] & 206 & 245 & 281 & 239 & 269 & 228 \\
\hline
\end{tabular}


Im Fallbetrieb FB 1 befanden sich sowohl Eiweiß- als auch Harnstoffgehalt aktuell und über die letzten zwölf Monate im optimalen Bereich, so dass davon auszugehen ist, dass die Fütterung bzgl. Energie- und Proteingehalt optimal angepasst war. Im Fallbetrieb FB 2 fanden sich ebenfalls sehr gute Eiweißwerte, allerdings waren die Harnstoffwerte leicht erhöht, so dass evtl. ein Rohproteinüberhang im Futter vorliegen könnte. Zusätzlich könnte es ein Anzeichen für eine erhöhte Leberbelastung oder Ovarialzysten sein. Der Fallbetrieb FB 3 wies sehr niedrige Eiweißgehalte bei gleichzeitig erhöhten Harnstoffwerten knapp unter $300 \mathrm{mg} / \mathrm{L}$ auf. Hier bestand der Verdacht auf Futtermangel, vielleicht auch Energiemangel bei gleichzeitigem Proteinüberschuss. Mögliche Ursachen neben dem Futter könnten Klauenprobleme neben einer vermutlich starken Leberbelastung sein. Ein Milchleistungsrückgang konnte aufgrund der stabilen Werte ausgeschlossen werden. Gleichzeitig waren in diesem Betrieb die Zellzahlen mit durchschnittlich 288.000 Zellen/mL so erhöht, dass die Milch nicht mehr das Gütesiegel des LKV Mecklenburg-Vorpommern erhalten würde. Eine Einordnung in die „S-Klasse“ nach der Milchgüte-Verordnung wäre dennoch möglich. Das Gleiche traf für die Kontrollbetriebe KB 1 und KB 2 zu. Beide wiesen normale Eiweißgehalte im Bereich von 3,30-3,80 \% auf, während die Harnstoffwerte im Rahmen lagen oder minimal erhöht waren. Die Fütterung war gut angepasst, es sollte auf einen möglichen Rohproteinüberhang geachtet werden. Die Ergebnisse für den Eiweißgehalt im Kontrollbetrieb KB 3 lagen aktuell mit 3,00 \% unter den üblichen Werten und auch im Mittel über zwölf Monate erreichte der Eiweißgehalt nur 3,30 \%. In Kombination mit dem aktuellen, zu niedrigen Harnstoffgehalt bestand der Verdacht auf Energie- und Rohproteinmangel und könnte neben einem schlecht eingestellten Futter auf eine Leberbelastung, (sub)klinische Ketose oder Fruchtbarkeitsstörungen hindeuten. Selbst die Durchschnittswerte sprachen für einen Versorgungsmangel. Die erhöhten Zellzahlen von 374.000 Zellen/mL und der starke Milchleistungsrückgang von $31,14 \mathrm{~kg}$ auf $27,00 \mathrm{~kg}$ bestätigten diese Werte. Insgesamt war festzustellen, dass bei gleichzeitiger Betrachtung der angenommenen Normalwerte für Eiweiß von 3,3-3,8 \% und Harnstoff von 150-300 mg/L Milch alle drei Fallbetriebe und zwei der Kontrollbetriebe ein zufriedenstellendes Fütterungsmanagement betrieben. 
Betrachtete man zusätzlich den Kontrollbetrieb KB 3 gegenüber der Fall- und der Kontrollgruppe, zeigte sich dessen Sonderstellung.

Tab. 37: Milchleistungsdaten von KB 3 im Vergleich zu Fall- und Kontrollbetrieben

\begin{tabular}{lccc}
\hline & Fallbetriebe & KB 3 & Kontrollbetriebe \\
\hline Melkdurchschnitt aktuell [kg] & 30,2 & 27,0 & 29,8 \\
Melkdurchschnitt min [kg] & 25,4 & 27,0 & 27,9 \\
Melkdurchschnitt max [kg] & 32,1 & 33,3 & 32,3 \\
Melkdurchschnitt ø [kg] & 29,8 & 31,1 & 30,2 \\
\hline Zellzahlgehalt aktuell [in Tausend/mL] & 267 & 395 & 163 \\
Zellzahlgehalt min [in Tausend/mL] & 223 & 242 & 138 \\
Zellzahlgehalt max [in Tausend/mL] & 377 & 508 & 308 \\
Zellzahlgehalt ø [in Tausend/mL] & 288 & 374 & 208 \\
\hline Fett aktuell [\%] & 3,89 & 3,82 & 3,87 \\
Fett min [\%] & 3,89 & 3,12 & 3,71 \\
Fett max [\%] & 4,86 & 4,21 & 4,33 \\
Fett durch [\%] & 4,3 & 3,74 & 3,99 \\
\hline Eiweiß aktuell [\%] & 3,32 & 3,00 & 3,45 \\
Eiweiß min [\%] & 3,31 & 3,00 & 3,32 \\
Eiweiß max [\%] & 3,58 & 3,50 & 3,52 \\
Eiweiß ø [\%] & 3,43 & 3,30 & 3,42 \\
\hline Harnstoff aktuell [mg/L] & 275 & 124 & 269 \\
Harnstoff min [mg/L] & 238 & 207 \\
Harnstoff max [mg/L] & 297 & 322 \\
Harnstoff ø [mg/L] & 269 & 228 & 245 \\
\hline
\end{tabular}

Während keine Unterschiede in der Melkleistung erkennbar waren, waren die Zellzahlen sehr hoch und überstiegen teilweise auch die Werte der Fallbetriebe. Die Fettgehalte waren gering, entsprachen aber den Werten der anderen Kontrollbetriebe. Dagegen waren die aktuellen Eiweißwerte sehr gering, genauso wie die Harnstoffwerte. 


\subsubsection{Jährliche Verlustdaten}

Die jährlichen Verlustdaten wurden dem Herdenprogramm über den Zeitraum der letzten zwölf Monate entnommen. Der Anteil der Abgänge wegen Krankheit umfasste auch das Verenden und die Krankschlachtung.

Tab. 38: jährliche Verlustdaten (Herdenprogramm) der Fall- und Kontrollbetriebe

\begin{tabular}{lcccccc}
\hline & FB 1 & KB 1 & FB 2 & KB 2 & FB 3 & KB 3 \\
\hline Totgeburtenrate [\%] & 1,00 & 7,85 & 9,00 & 7,00 & 6,00 & 7,10 \\
Kälbermortalität [\%] & 1,00 & 5,49 & 6,00 & 1,00 & 8,20 & 1,10 \\
Abgänge Kühe gesamt & 30 & 104 & 138 & 57 & 122 & 140 \\
$\quad$ Krankheit & 20 & 91 & 110 & 30 & 94 & 14 \\
$\quad$ mangelnde Leistung & 10 & 13 & 28 & 27 & 28 & 106 \\
Zuchtviehverkauf & 0 & 20 & 0 & 0 & 0 & 20 \\
\hline
\end{tabular}

Mit der Ausnahme des Fallbetriebs FB 1 traten in beiden Gruppen Totgeburtenraten zwischen 6 und $9 \%$ auf. Auch bei der Kälbermortalität wich FB 1 von den anderen Fallbetrieben ab, die eine durchschnittliche Mortalität von $7,1 \%$ aufwiesen. Die Kontrollbetriebe hatten, von KB 1 mit einem vergleichsweise hohen Wert abgesehen, eine mittlere Kälbermortalität von 1,05\%. Bei der absoluten Anzahl der Abgänge durch Krankheit oder Leistungsmangel ließ sich keine Gruppierung in Fall- und Kontrollbetriebe feststellen. Auch bei der Einbeziehung des Verhältnisses zur Bestandsgröße bewegte sich die Menge aller Abgänge zwischen 23 und $42 \%$ ohne die Möglichkeit einer Einordnung in Fälle oder Kontrollen auf Basis dieser Werte.

\subsection{Fütterung}

\subsubsection{Grünlandbewertung}

Eine besondere Aufmerksamkeit musste der Fütterung und der Futterwerbung in den Fall- und Kontrollbeständen gewidmet werden, da sie sowohl von den Befürwortern als auch von den Gegnern als mögliche oder wahrscheinliche Ursache für das Vorhandensein des Krankheitsbildes des viszeralen Botulismus oder der sog. Multifaktorenerkrankung, wenn auch unter konträren Gesichtspunkten, angesehen werden. 
Bei Wiederkäuern fungiert Grobfutter als Basis der Fütterung, die je nach gesetztem Leistungsanspruch durch Kraftfutter ergänzt wird.

Grünland wird direkt als Weideland oder zur Futterwerbung und Herstellung von Silage genutzt. Um eine gute Silage $\mathrm{zu}$ erzeugen, ist neben dem Silierprozess bereits die Beschaffenheit, Pflege und die Schnittreife des Grünlandes von enormer Bedeutung. Ein qualitativer Einfluss wird der Überschwemmung des Grünlandes oder dem Besatz mit anderen Tieren zugesprochen.

Tab. 39: Belastung des Grünlandes mit Überschwemmungen oder Wildtieren

\begin{tabular}{lcccccc}
\hline & FB 1 & KB 1 & FB 2 & KB 2 & FB 3 & KB 3 \\
\hline Überschwemmungen & regel- & nein & $\begin{array}{c}\text { unregel- } \\
\text { mäßig }\end{array}$ & nein & nein & nein \\
mäßig & letztmalig & 03/2010 & $/$ & $/$ & $/$ \\
starke Maulwurf- & ja & nein & nein & ja & nein & nein \\
belastung & nein & nein & ja & nein & nein & nein \\
Beweidung mit Schafen & ja & ja & ja & ja & ja & nein \\
hoher Wildtierbesatz & $/$ & $/$ & ja & ja & $/$ & $/$ \\
Schalenwild & $/$ & $/$ & ja & ja & $/$ & $/$ \\
Schwarzwild & $/$ & $/$ & ja & $/$ & $/$ & $/$ \\
Niederwild & $/$ & $/$ & ja & $/$ & $/$ & $/$ \\
Schadnager & ja & ja & $/$ & $/$ & ja & $/$ \\
Stare & $/$ & $/$ & $/$ & ja & $/$ & $/$ \\
andere Wildvögel & & & & & \\
\hline
\end{tabular}

Im März 2010 kam es in zwei Fallbetrieben zu Überschwemmungen des Grünlandes, während die Flächen der Kontrollbetriebe nicht betroffen waren. Dies deutete auf einen Einfluss der Überschwemmungen auf die Qualität des zur Futterwerbung genutzten Grünlandes hin. Die höhere Feuchtigkeit könnte neben den Inhaltsstoffen auch die mikrobiologische Fauna des Grünlandes beeinflussen. Zum einen kann durch den Verschluss des Bodens eine anaerobe Atmosphäre entstehen, zum anderen sind in überschwemmungsreichen Gebieten meist Entwässerungsgräben vorhanden, deren Aushub wieder auf die Felder verbracht wird und so zu einer Kontamination mit unerwünschten Mikroorganismen führen kann. Eine Maulwurfbelastung wurde nur in einem Fall- und in einem Kontrollbetrieb angegeben, ebenso fand nur in einem Fallbetrieb die Beweidung des Grünlandes mit Schafen statt. Von hohem Wildtierbesatz ihres Grünlandes waren mit Ausnahme des Kontrollbetriebes KB 3 alle Betriebe betroffen, wenn auch in 
unterschiedlichem Maße. Während die Betriebe FB 1 und der dazugehörige KB 1, vermutlich auch wegen der räumlichen Nähe, einen hohen Besatz mit Staren angaben, waren in den Betrieben FB 2 und KB 2 Schalenwild und Schwarzwild, im Fallbetrieb FB 2 zusätzlich Niederwild und Schadnager und nur im Kontrollbetrieb KB 2 verschiedene Wildvögel vorzufinden. Auch der Fallbetrieb FB 3 gab einen hohen Besatz mit Staren an. Im Rahmen der Vorversuche wurde Vogelkot aus dem Fallbetrieb FB 3 und ein toter Star aus dem Fallbetrieb FB $1 \mathrm{im}$ Toxin-ELISA positiv auf $C$. perfringens getestet.

Das Grünland kann für den Schnitt von Frischfutter, die Herstellung von Heu oder Silage oder als Weideland genutzt werden. Oft geschieht das auf separaten Flächen; eine Doppelnutzung ist aber ebenso gebräuchlich und birgt durch das eventuelle Ausscheiden von Krankheitserregern auf später als Siliergut genutztem Gras das Risiko von Re-Infektionen.

Tab. 40: Nutzung des Grünlandes als Schnitt, Weide oder in Kombination

\begin{tabular}{lcccccc}
\hline & FB 1 & KB 1 & FB 2 & KB 2 & FB 3 & KB 3 \\
\hline Schnitt & ja & ja & ja & nein & ja & ja \\
Fläche Schnitt [ha] & 35 & 90 & 140 & $/$ & 140 & 100 \\
Anzahl Schnitte /Jahr & 3 & 4 & 3 & $/$ & 3 & 4 \\
Weide & ja & nein & ja & ja & ja & ja \\
Fläche Weide [ha] & 20 & $/$ & 20 & 6 & 40 & 8 \\
Schnitt \& Weide & nein & nein & ja & ja & nein & ja \\
Fläche Schnitt \& & $/$ & $/$ & 60 & 80 & $/$ & 120 \\
Weide [ha] & $/$ & $/$ & 2 & 3 & $/$ & 1 \\
Anzahl Schnitte /Jahr & & & & & & \\
\hline
\end{tabular}

Bis auf den Kontrollbetrieb KB 2 nutzten alle Betriebe separates Grünland für den Schnitt. KB 2 nutzte für den Schnitt nur Land, das parallel auch als Weide diente und der dazugehörige Fallbetrieb FB 2 bediente sich beider Formen. Bis auf den Kontrollbetrieb KB 1 gaben alle Betriebe an, separates Grünland als Weideland zu nutzen. Bis auf FB 2 und KB 2 wurde für die melkenden Kühe eine reine Stallhaltung angegeben. Bei der reinen Schnittnutzung wurden drei bis vier Schnitte pro Jahre durchgeführt.

Die organische Düngung umfasst das Ausbringen von zumeist Gülle oder Mist auf die zu düngenden Flächen und ist bezüglich des Stickstoffeintrages und der Ausbringungstermine streng reglementiert (DüV, 2006 (letzte Änderung vom 31. Juli 2009)). Mineralische Dünger sind synthetische Dünger, dessen 
Wirkstofffreisetzung wesentlich schneller als bei organischem Dünger erfolgt und eine rasche Verfügbarkeit der fehlenden Nährstoffe bei Mangelerscheinungen garantiert. Vergorenes Gärsubstrat (engl. output) aus Biogasanlagen ist ein Abfallprodukt bei der Fermentation von organischen Stoffen zur Methan- bzw. Energiegewinnung. Da der Gärprozess unter Luftabschluss stattfindet, bieten sich anaeroben Bakterien gute Voraussetzungen zur Vermehrung. Durch die Fähigkeit der Clostridien Sporen zu bilden, besteht durch die Düngung von Feldern mit Biogasoutput die Möglichkeit und Gefahr Clostridiensporen in den Boden und auf die Pflanzen zu verbringen. Durch den Eintrag in das Siliergut ergibt sich für Clostridiensporen bei fehlerhafter Silierung die Möglichkeit zum Auskeimen, Vermehren und zur Toxinbildung. Gelangen Sporen andererseits direkt in den Verdauungstrakt eines Hochleistungsrindes ohne ausreichende Konkurrenzflora, sind hier ebenfalls optimale Auskeimungs-, Vermehrungsund Toxinbildungsbedingungen denkbar (McLoughlin et al., 1988; Böhnel et al., 2001b), wie sie bereits für Geflügel nachgewiesen wurde (Schettler, 1979; Trampel et al., 2005).

Tab. 41: Düngung des Grünlandes in Fall- und Kontrollbetrieben

\begin{tabular}{|c|c|c|c|c|c|c|}
\hline & FB 1 & KB 1 & FB 2 & KB 2 & FB 3 & KB 3 \\
\hline Art der Düngung & $\min$ & org. / $\min$. & org. / $\min$. & org. / $\min$. & org. / $\min$. & $\min$. \\
\hline Einsatz Gülle/Kot & nie & gelegentl & gelegentl & immer & gelegentl & nie \\
\hline Schwein & / & nein & nein & nein & nein & nein \\
\hline Rind & / & ja & ja & ja & ja & nein \\
\hline Geflügel & / & nein & nein & nein & nein & nein \\
\hline Einsatz Fremdgülle & nie & nie & nie & nie & nie & nie \\
\hline Schwein & / & / & / & / & / & / \\
\hline Rind & / & / & / & / & / & / \\
\hline Geflügel & / & / & / & / & / & / \\
\hline $\begin{array}{l}\text { Düngung mit Bio- } \\
\text { kompost }\end{array}$ & nie & nie & nie & nie & nie & nie \\
\hline $\begin{array}{l}\text { Düngung mit Bio- } \\
\text { gasoutput }\end{array}$ & nein & nein & nein & nein & nein & nein \\
\hline
\end{tabular}

min. - mineralisch; org. - organisch

Die Düngung erfolgt organisch, mineralisch oder in einer Kombination aus beiden Arten. In dieser Studie düngten nur der Fallbetrieb FB 1 und der Kontrollbetrieb KB 3 ausschließlich mineralisch. Alle anderen Betriebe verwandten eine Kombination aus mineralischer und organischer Düngung, wobei zu Letzterem ausschließlich eigene Rindergülle verwendet wurde. Laut Fragebogen wurde in den beprobten Beständen weder mit Biokompost noch mit 
Biogasoutput gedüngt, die durch die Art ihrer Erzeugung besonders im Verdacht stehen, die Vermehrung von Clostridien, deren Sporenbildung und demzufolge die Entstehung von viszeralen Botulismus zu begünstigen. Die vorgegebene Antwortmöglichkeit „nein“ suggerierte in der Auswertung, dass zu keinem Zeitpunkt eine Düngung mit Biogasoutput stattgefunden hätte. Tatsächlich wurden aber im Fallbetrieb FB 3 bis vor zwei Jahren Gärreste einer mit Schlachtabfällen betriebenen Biogasanlage auf die Ackerkulturen verbracht. Ein Einsatz von Schweine-, Geflügel- oder Fremdgülle fand nicht statt.

\subsubsection{Bewertung der Silierung (Grassilage)}

Durch die Haltbarmachung von Futter ergibt sich die Möglichkeit Nutztiere im Stall über das ganze Jahr hinweg zu versorgen. Unter den Methoden zur Futterkonservierung hat sich besonders die Fermentation verschiedener Futtermittel (Silierung) etabliert. Besondere Bedeutung kommt neben der Optimierung des Konservierungsprozesses auch der Bestimmung des bestmöglichen Erntezeitpunktes des Siliergutes zu, da sich die Veränderungen im Nährstoffgehalt und der Energiekonzentration mengenmäßig stärker auswirken als die Reduzierung der Verluste durch den Silierprozess, der im Wesentlichen durch die Einlagerungstechnik bestimmt wird (Richter et al., 2009). Der optimale Schnittzeitpunkt liegt kurz vor dem Rispenschieben der Hauptgräser, die zu diesem Zeitpunkt einen Rohfasergehalt von unter $25 \%$ in der Trockenmasse aufweisen. Anschließend würden Lignineinlagerungen die Verdaulichkeit und die Futteraufnahme beeinträchtigen (Anonym, 2011).

Die Schnitthöhe sollte zwischen 5-7 cm gewählt werden. Zwar steigt der Ertrag mit sinkender Schnitthöhe an, durch das tiefere Mähen kommt es allerdings zu einem größeren Eintrag von Schmutz in das Siliergut und damit zu einem höheren Asche- und sinkendem Energiegehalt in der Silage. Durch die Einhaltung der Mindestschnitthöhe wird der Eintrag von unerwünschten Sporen reduziert. Zusätzlich sorgt die Stoppelhöhe für eine gute Durchlüftung und unterstützt das Vorwelken auf dem Feld. Die Häcksellänge sollte bei Grassilage 2,5-5 cm betragen. Kurze Partikel wirken sich positiv auf die Silierbarkeit, Verdichtbarkeit und die Mischbarkeit aus, andererseits wird 
durch die Häcksellänge auch die Strukturwirkung der Ration bestimmt (Spiekers, 2004).

Die luftdichte Abdeckung des Silos mit Folie ist von zentraler Bedeutung, da nur unter anaeroben Bedingungen eine adäquate Fermentation stattfinden kann und Hefen und Schimmelpilzen keine Wachstumsmöglichkeit geboten wird. Das Benutzen einer Unterziehfolie hat sich in der Praxis ebenfalls bewährt. Zum Beschweren der Abdeckfolien werden Silosäcke, Reifen oder Netze verwendet. Durch den Einsatz der heutigen Ernte- und Einlagerungstechnik sind Silobreiten von 6-7 $\mathrm{m}$ erforderlich. Geringere Breiten ermöglichen aber einen schnelleren Vorschub, der dem Wachstum von Hefen und Schimmelpilzen an der Oberfläche der Silage zuvorkommt. Durch ein optimiertes Silomanagement kann einer Beeinträchtigung der Leistung der Tiere, der Tiergesundheit und der Qualitätsminderung tierischer Lebensmittel begegnet werden.

Die Mehrzahl der untersuchten Betriebe benutzte ausschließlich ein Fahrsilo. Nur der Fallbetrieb FB 2 und der Kontrollbetrieb KB 3 stellten auch Ballensilage her. Zwar zeichnet sich diese Lagerungsform durch bessere Handhabbarkeit und geringere Verluste aus, das Auftreten von Kondenswasser könnte die Gärsäuren in diesem kleinem Volumen aber stärker verdünnen und Schadorganismen Vorschub leisten. In den Fahrsilos lagen die Schnittlängen durchschnittlich im empfohlenen Bereich zwischen 5-7 cm, nur der Kontrollbetrieb KB 2 schnitt sein Gras auf einer Höhe von $4 \mathrm{~cm}$. Auch die angeratenen Häcksellängen wurden mit 4-5 cm meist beachtet. Der Fallbetrieb FB 3 lag mit $2 \mathrm{~cm}$ etwas darunter, der Kontrollbetrieb $\mathrm{KB} 1 \mathrm{mit} 10 \mathrm{~cm}$ weit darüber. Dies könnte sich negativ auf die Verdichtbarkeit auswirken. Für die Ballensilage wurde die vorgeschlagene Schnitthöhe von 5-6 cm verwendet, die Häckellänge betrug hier 25-30 cm. Zur Abdeckung des Fahrsilos und zur Herstellung einer anaeroben Atmosphäre nutzten alle Betriebe eine einfache gasdichte Folie, eine zusätzliche Unterziehfolie und beschwerten die Folien. Im Kontrollbetrieb KB 1 kamen dazu auch Netze zum Einsatz. Alle Fahrsilos waren mit einer Bodenplatte ausgestattet. In den Fallbetrieben FB 1, FB 2 und FB 3 und dem Kontrollbetrieb KB 1 waren keine Seitenwände vorhanden, der FB 2 besaß aber ein zusätzliches Silo mit Seitenwänden, während die Kontrollbetriebe KB 2 und KB 3 nur Fahrsilos mit Seitenwänden aufwiesen. Diese Seitenwände ermöglichen eine bessere Verdichtung und könnten sich positiv auf die Gär- 
qualität auswirken. Die Silobreite variierte zwischen 8 und $18 \mathrm{~m}$ und ermöglichte bedingt durch die unterschiedliche Bestandsgröße einen durchschnittlichen Vorschub von ca. $2 \mathrm{~m} /$ Woche. So konnte dem Befall mit Hefen und Schimmelpilzen vorgebeugt werden. Nur im Kontrollbetrieb KB 3 betrug der Vorschub der Grassilage nur 0,4 m/Woche, wodurch ein Verderb begünstigt wurde. In zwei Fallbetrieben und dem Kontrollbetrieb KB 3 wurde die Silage mit einem Blockschneider entnommen. Durch die sehr geringe Lockerung bei dieser Entnahmetechnik kommt es zu einem geringeren Sauerstoffeintritt, der mit Nacherwärmung und Schimmelbildung verbunden wäre (Anonym, 2011). In den anderen Betrieben kamen entweder Fräse oder Greifzange zum Einsatz.

Tab. 42: Art und Aufbau der Silos in Fall- und Kontrollbetrieben

\begin{tabular}{|c|c|c|c|c|c|c|}
\hline & FB 1 & KB 1 & FB 2 & KB 2 & FB 3 & KB 3 \\
\hline Lagerungsform & Fahrsilo & Fahrsilo & $\begin{array}{l}\text { Ballen, } \\
\text { Fahrsilo }\end{array}$ & Fahrsilo & Fahrsilo & $\begin{array}{l}\text { Ballen, } \\
\text { Fahrsilo }\end{array}$ \\
\hline \multicolumn{7}{|l|}{ Schnitthöhe [cm] } \\
\hline Ballen & / & / & 5 & / & / & 6 \\
\hline Fahrsilo & 6 & 6 & 5 & 4 & 7 & 6 \\
\hline \multicolumn{7}{|l|}{ Häcksellänge [cm] } \\
\hline Ballen & / & / & 30 & / & / & 25 \\
\hline Fahrsilo & 5 & 10 & 5 & 5 & 2 & 4 \\
\hline \multicolumn{7}{|l|}{ Abdeckung Silo } \\
\hline einfache Folie & ja & ja & ja & ja & ja & ja \\
\hline Unterziehfolie & ja & ja & ja & ja & ja & ja \\
\hline Beschwerung & ja & ja & ja & ja & ja & ja \\
\hline anderes & / & Netze & / & / & / & / \\
\hline \multicolumn{7}{|l|}{ Silogeometrie } \\
\hline $\begin{array}{l}\text { ohne BP, ohne } \\
\text { SW }\end{array}$ & nein & nein & nein & nein & nein & nein \\
\hline $\begin{array}{l}\text { mit BP, ohne } \\
\text { SW }\end{array}$ & ja & ja & ja & nein & ja & nein \\
\hline $\begin{array}{l}\text { mit BP, mit SW, } \\
\text { plan }\end{array}$ & / & / & ja & ja & / & ja \\
\hline $\begin{array}{l}\text { mit BP, mit } \\
\text { SW," Berg" }\end{array}$ & / & / & / & / & / & / \\
\hline \multicolumn{7}{|l|}{ Silomaße } \\
\hline Länge Silo [m] & 60 & 50 & 20 & 42 & 25 & 40 \\
\hline Breite Silo [m] & 8 & 14 & 18 & 13 & 15,5 & 12 \\
\hline Höhe Silo [m] & 2,4 & 2 & 1 & 2 & 1,8 & 3 \\
\hline Entnahmetechnik & Blockschn. & Fräse & Blockschn. & Greifzange & Fräse & Blockschn. \\
\hline $\begin{array}{l}\text { Silovorschub } \\
\text { [m/Woche] }\end{array}$ & 2,5 & 2 & 2 & 2 & 2 & 0,4 \\
\hline
\end{tabular}

BP - Bodenplatte, SW - Seitenwände, Blockschn. - Blockschneider 
Durch eine Probenahme und die sensorische Beurteilung der Silage bezüglich Farbe und Geruch lässt sich bereits vor Ort der Siliererfolg und die Gärqualität beurteilen. Die Verschmutzung der Ernte ist meist von der Schnitthöhe des Grases abhängig, da durch tiefes Mähen Boden, Fremdkörper und Schaderreger in das Schnittgut gelangen. Der Verschmutzungsgrad gibt oftmals schon Auskunft über die Qualität der daraus entstehenden Silage. Bei der Einsilierung selbst können aerobe Gärschädlinge wie Essigsäurebakterien, Schimmel- und Fäulnispilze die Futterqualität beeinflussen. Neben enormen Nährstoffverlusten kann das Futter geschmacklich beeinflusst werden und Mykotoxine können dem Tier schaden. Durch eine Verdichtung mit Schleppern, Radladern oder Walzen werden Lufteinschlüsse herausgearbeitet, die durch ihren Sauerstoffgehalt den Verderb der Silage begünstigen können. Dies ist wichtig für die Gärqualität, aber auch die Haltbarkeit der Silage nach dem Öffnen des Silos. Die Verdichtbarkeit ist abhängig vom Siliergut und dessen Trockenmassegehalt (TM). So sollte Grassilage mit einem TM-Gehalt von $20 \%$ eine Dichte von $160 \mathrm{~kg} \mathrm{TM} / \mathrm{m}^{3}$ erreichen und eine 40\%ige Grassilage sogar $240 \mathrm{~kg} \mathrm{TM} / \mathrm{m}^{3}$. Besondere Beachtung ist den Randbereichen zu widmen, da diese meist nur ungenügend verdichtet sind.

Grundsätzlich ist es bei Einhaltung der Silierregeln möglich, eine Silage ohne Hilfsmittel zu erzeugen. Inzwischen werden Silierzusätze aber auch strategisch eingesetzt um den Gärverlauf, die Haltbarkeit unter Lufteinfluss, die Futteraufnahme und Verdaulichkeit zu verbessern, den Gärsaftverlust zu reduzieren und/oder das Vermehren von Clostridien zu verhindern. Die Siliermittel basieren entweder auf Bakterienkulturen (biologische Siliermittel) oder chemischen Verbindungen (chemische Siliermittel), die besonders unter erschwerten Bedingungen für eine gute Silagequalität sorgen sollen. Die durchschnittliche Silierdauer beträgt sechs Wochen. Der Zeitpunkt, an dem das Silo geöffnet wird, bestimmt die aerobe Stabilität. Je länger ein Silo geschlossen bleibt, umso ausgereifter ist die Silage und umso geringer ist das Risiko der Nacherwärmung. Wird das Silo früher geöffnet, ist mit einer geringeren Haltbarkeit zu rechnen, was bei zügigem Verbrauch unproblematisch ist (Thaysen, 2011a). Eine Methode um den Vorschub zu beschleunigen, ist der Gebrauch von Sandwichsilos. Dort werden Mais und Gras in Schichten übereinander einsiliert, wodurch sich das Problem der Nacherwärmung verringert, weil nur ein Silo im Anschnitt sein muss (Richter et al., 2009). 
Sensorisch lässt sich die Silage auf optische Abweichungen wie Verfärbungen oder Schimmel und auf geruchliche Abweichungen, die auf einen Schimmel(muffig) oder Clostridienbefall (ranzig) hindeuten, prüfen. Eine visuelle Überprüfung der Folie auf eventuelle Beschädigungen kann Silierfehler aufdecken. Verschimmelte Bereiche finden sich besonders häufig an Silowänden, da an dieser Stelle durch Luft- und Feuchtigkeitszutritt ein geeignetes Klima für das Wachstum von Schimmelpilzen herrscht (Richter et al., 2009).

Tab. 43: Bewertung der Silierung

\begin{tabular}{|c|c|c|c|c|c|c|}
\hline & FB 1 & KB 1 & FB 2 & KB 2 & FB 3 & KB 3 \\
\hline $\begin{array}{l}\text { Verschmut- } \\
\text { zung }\end{array}$ & mittel & $\begin{array}{l}\text { unauf- } \\
\text { fällig }\end{array}$ & $\begin{array}{l}\text { unauf- } \\
\text { fällig }\end{array}$ & $\begin{array}{l}\text { unauf- } \\
\text { fällig }\end{array}$ & mittel & $\begin{array}{l}\text { unauf- } \\
\text { fällig }\end{array}$ \\
\hline Silierzusatz & chemisch & biologisch & bio/chem & chemisch & biologisch & biologisch \\
\hline Sandwichsilo & nein & nein & nein & nein & nein & nein \\
\hline Verdichtung & $\begin{array}{l}\text { ausrei- } \\
\text { chend }\end{array}$ & $\begin{array}{l}\text { ausrei- } \\
\text { chend }\end{array}$ & $\begin{array}{l}\text { ausrei- } \\
\text { chend }\end{array}$ & $\begin{array}{l}\text { ausrei- } \\
\text { chend }\end{array}$ & $\begin{array}{c}\text { nicht } \\
\text { ausreichend }\end{array}$ & $\begin{array}{l}\text { ausrei } \\
\text { chend }\end{array}$ \\
\hline $\begin{array}{l}\text { Silierdauer } \\
\text { (Wochen) }\end{array}$ & 12 & 8 & 6 & 6 & 1 & 16 \\
\hline $\begin{array}{l}\text { optische } \\
\text { Abweichung }\end{array}$ & ja & nein & nein & nein & nein & nein \\
\hline Verfärbung & ja & / & / & / & / & / \\
\hline Schimmel & nein & / & / & / & / & / \\
\hline $\begin{array}{l}\text { geruchliche } \\
\text { Abweichung }\end{array}$ & ja & nein & nein & nein & nein & nein \\
\hline muffig & nein & / & / & / & / & / \\
\hline ranzig & ja & / & / & / & / & / \\
\hline $\begin{array}{l}\text { beschädigte } \\
\text { Abdeckung }\end{array}$ & nein & nein & nein & nein & nein & nein \\
\hline sonstiges & / & / & $\begin{array}{c}\text { hohe } \\
\text { Feuchtigkeit }\end{array}$ & / & Nacherwärmung & / \\
\hline Bemerkungen & / & / & $\begin{array}{l}\text { Feldgras } \\
\text { sehr nass, } \\
\text { fast } \\
\text { geruchlos }\end{array}$ & / & / & / \\
\hline
\end{tabular}

Die Verschmutzung der Ernte wurde in den Fallbetrieben FB 1 und FB 3 mit "mittel“ angegeben. In den anderen Betrieben wurde die Verschmutzung der Ernte als unauffällig eingestuft. Silierhilfsmittel kamen sowohl in den Fall- als auch in den Kontrollbetrieben zum Einsatz. In den Kontrollbetrieben KB 1, KB 3 und im Fallbetrieb FB 3 wurden rein biologische Zusätze verwendet, der Fallbetrieb FB 2 verwendete eine Kombination aus biologischen und chemischen Siliermitteln und die Betriebe FB 1 und KB 2 benutzten rein chemische Zusätze. Dies wird von der DLG nur für schwer silierbares Futter empfohlen, was Rückschlüsse auf die Beschaffenheit des Siliergutes zuließ. Die Verdichtung wurde nur im Fallbetrieb FB 3 als nicht ausreichend beschrieben. Die 
Silierdauer lag in den meisten Betrieben zwischen 6 und 16 Wochen, nur der Fallbetrieb FB 3 öffnete bereits nach einer Woche das Silo und setzte so die aerobe Stabilität herab, die zusammen mit der ungenügenden Verdichtung zur Nacherwärmung der Silage führte. Optische und geruchliche Abweichungen allerdings wurden nur im Fallbetrieb FB 1 beschrieben. Dort waren Verfärbungen und ein ranziger Geruch wahrnehmbar. Im Fallbetrieb FB 2 wurde zusätzlich angegeben, dass die Silage eine hohe Feuchtigkeit besaß, die aus dem sehr nassen Feldgras resultierte. Dies könnte eine Buttersäuregärung begünstigen, da der Silierverlauf abgepuffert wird.

\subsubsection{Futtermitteluntersuchung der Grassilage}

Parallel zu den sensorischen Prüfungen vor Ort wurde die Grassilage für Frischmelker und Hochleistungstiere im Labor chemisch und mikrobiologisch analysiert.

Der Trockenmasseanteil (TM) einer hochwertigen Silage wird mit 30-45 \% angegeben. An ihm orientieren sich alle weiteren Parameter, wie z. B. der pHWert. Dieser sollte für eine Grassilage mit weniger als $30 \% \mathrm{TM}$ unter 4,0 liegen, bei einer TM von 30-35\% weniger als 4,5 und bei mehr als $45 \%$ TM weniger als 5,0 betragen (DLG, 2006). Der Rohaschegehalt beschreibt den Anteil an anorganischen Mineralstoffen und sollte nicht über $10 \%$ liegen, da er auch Auskunft über den Grad der Verschmutzung und unverdauliche Sandanteile gibt. Mit steigendem Rohaschegehalt sinkt der Energiegehalt der Silage. Der Rohproteingehalt ist abhängig von Standortbedingungen, der Pflanzenzusammensetzung, der Düngung und dem Nutzungszeitpunkt und sollte in Abhängigkeit vom TM-Gehalt zwischen 15 und $20 \%$ liegen. Beim Rohprotein von Gräsern und Leguminosen wird die ruminale Abbaubarkeit mit $85 \%$ angegeben (Thaysen, 2011b). Der Rohfasergehalt beschreibt den Strukturwert der Silage und ist auch der Maßstab für das Alter der Pflanzen zum Zeitpunkt der Ernte. Im Pansen wird daraus Essigsäure gebildet, die für den Aufbau von Milchfett benötigt wird. Der Gehalt an Rohfaser sollte 22-25 \% der Trockensubstanz betragen. Aus diesen Inhaltsstoffen sollte sich im Optimalfall ein Energiegehalt von 6,0-6,4 MJ NEL/kg TM ergeben. Der Anteil von Ammoniak-Stickstoff am Gesamtstickstoff ist ein Maß für den Proteinabbau in der Silage und sollte $10 \%$ nicht übersteigen. 
Für die Beurteilung der Zusammensetzung der mikrobiellen Fauna einer Silage finden sich in den DLG-Leitlinien zur Grobfutterbewertung keine Anhaltspunkte. In der Broschüre des „aid infodienst Ernährung, Landwirtschaft, Verbraucherschutz" werden für Clostridiensporen, Kahmhefen und Schimmelpilze jeweils Grenzwerte von $10^{4} \mathrm{KbE} / \mathrm{g}$ TM angegeben. Der folgenden Einschätzung der ermittelten Keimzahlen werden Erfahrungswerte von Dr. Schwagerick zugrunde gelegt. Es wurde die maximale mesophile aerobe Keimzahl auf $10^{6} \mathrm{KbE} / \mathrm{g}$ festgelegt. Enterobakterien sollten einen Wert von $10^{4} \mathrm{KbE} / \mathrm{g}$ nicht überschreiten, aerobe und anaerobe Sporenbildner jeweils unter $10^{5} \mathrm{KbE} / \mathrm{g}$, Schimmelpilze unter $10^{2} \mathrm{KbE} / \mathrm{mL}$ und Hefen unter $10^{5} \mathrm{KbE} / \mathrm{mL}$ liegen. Der optimale Gehalt an Milchsäurebakterien, die für die energetisch günstiger verlaufende Milchsäuregärung verantwortlich sind, sollte $10^{7} \mathrm{KbE} / \mathrm{mL}$ betragen.

Besonders wichtig war auch die Ermittlung der Mykotoxingehalte in den Silagen, denn die Symptome einer Mykotoxikose zeigen Ähnlichkeiten zum klinischen Erscheinungsbild des viszeralen Botulismus. Die Fusarientoxine Deoxynivalenol (DON) und Zearalenon (ZEA) kommen am häufigsten vor und gelten gleichzeitig als Indikatoren für das Auftreten weiterer Mykotoxine, die die Giftwirkung verstärken könnten. Vom BMVEL (2000) wurden für Milchrinder Grenzwerte in Höhe von $5,0 \mathrm{mg} / \mathrm{kg}$ bei $88 \% \mathrm{TM}$ für DON und $0,5 \mathrm{mg} / \mathrm{kg}$ für ZEA empfohlen, bei deren Unterschreitung die Gesundheit und Leistungsfähigkeit der Milchrinder nicht beeinträchtigt werden soll. Dies entsprach der Empfehlung der Europäischen Kommission (2006/576/EC), die zusätzlich für Ochratoxin A einen Grenzwert von 0,25 mg/kg Futtermittel empfahl. Da die für das Rind tolerierbaren Mykotoxingehalte in der Literatur voneinander abwichen (Hult et al., 1976; Kiessling et al., 1984; Sreemannarayana et al., 1988), wurden für diese Fall-Kontroll-Studie geringere Grenzwerte zur Beurteilung der Mykotoxinbelastung der Silage definiert. Für DON wurden $500 \mu \mathrm{g} / \mathrm{kg}$, für ZEA $250 \mu \mathrm{g} / \mathrm{kg}$ und für Ochratoxin $20 \mu \mathrm{g} / \mathrm{kg}$ festgelegt. 
Tab. 44: Futtermitteluntersuchungen der Grassilage aus Fall- und Kontrollbetrieben

\begin{tabular}{|c|c|c|c|c|c|c|}
\hline & FB 1 & KB 1 & FB 2 & KB 2 & FB 3 & KB 3 \\
\hline TM-Gehalt [g/kg] & 324 & 326 & 341 & 321 & 741 & 339 \\
\hline pH-Wert & 4,2 & 4,3 & 4,2 & 4,6 & 3,7 & 3,8 \\
\hline Rohasche [g/kg TM] & 139 & 94 & 80 & 97 & 103 & 104 \\
\hline Rohprotein [g/kg TM] & 204 & 138 & 167 & 188 & 161 & 175 \\
\hline Rohfaser [g/kg TM] & 241 & 307 & 217 & 207 & 292 & 200 \\
\hline $\begin{array}{l}\text { Energiegehalt } \\
{[\mathrm{MJ} \text { NEL/kg TM] }}\end{array}$ & 6,0 & 5,6 & 6,2 & 6,7 & 6,2 & 6,9 \\
\hline $\mathrm{NH}_{3}-\mathrm{N} \%$ ges. $\mathrm{N}$ & 12 & 15 & 4,88 & k.A. & 3,65 & 4,68 \\
\hline $\begin{array}{l}\text { aerobe Keimzahl } \\
{[\mathrm{KbE} / \mathrm{g}]}\end{array}$ & $1,5 \times 10^{3}$ & $5,5 \times 10^{7}$ & $1,0 \times 10^{8}$ & $1,5 \times 10^{3}$ & $1,0 \times 10^{4}$ & $1,5 \times 10^{3}$ \\
\hline Enterobakterien & 0 & 0 & 5 & 5 & 100 & $5,0 \times 10^{3}$ \\
\hline aerobe Sporenbildner & $1,5 \times 10^{3}$ & $3,5 \times 10^{3}$ & $5,0 \times 10^{3}$ & 500 & 0 & $5,0 \times 10^{3}$ \\
\hline $\begin{array}{l}\text { anaerobe } \\
\text { Sporenbildner (MPN) }\end{array}$ & 40 & $4,5 \times 10^{3}$ & 5 & 5 & 5 & $5,0 \times 10^{3}$ \\
\hline Milchsäurebakterien & $1,8 \times 10^{4}$ & $3,0 \times 10^{7}$ & $9,0 \times 10^{5}$ & $8,4 \times 10^{6}$ & $1,0 \times 10^{5}$ & $5,0 \times 10^{3}$ \\
\hline Schimmelpilze & 0 & $1,5 \times 10^{3}$ & 500 & 500 & 100 & $5,0 \times 10^{3}$ \\
\hline Hefen & $4,4 \times 10^{4}$ & 0 & $5,5 \times 10^{5}$ & 500 & 100 & $1,0 \times 10^{3}$ \\
\hline $\begin{array}{l}\text { Deoxynivalenol } \\
(\mathrm{DON})[\mu \mathrm{g} / \mathrm{kg}]\end{array}$ & 134 & 134 & k.A. & 100 & k.A. & k.A. \\
\hline Zearalenon $[\mu \mathrm{g} / \mathrm{kg}]$ & 20,1 & 130,5 & k.A. & 10 & k.A. & k.A. \\
\hline Ochratoxin $[\mu \mathrm{g} / \mathrm{kg}]$ & 12,6 & 26,5 & k.A. & 1 & k.A. & k.A. \\
\hline BoNT & neg. & neg. & neg. & neg. & neg. & neg. \\
\hline
\end{tabular}

Abgesehen vom Fallbetrieb FB 3 mit einem TM-Gehalt der Silage von $741 \mathrm{~g} / \mathrm{kg}$, produzierten alle Betriebe Silagen mit einem TM-Gehalt von 321-341 g/kg. Die entsprechenden $\mathrm{pH}-$ Werte wurden für fast alle Silagen, inklusive der Silage aus FB 3, eingehalten, die laut dem DLG-Bewertungsschema damit 10 Punkte erreichten. Nur der Kontrollbetrieb KB 2, der aber in der sensorischen Beurteilung der Silage keine Auffälligkeiten aufwies, verfütterte eine Silage mit einem etwas erhöhten $\mathrm{pH}$ von 4,6 und würde nach dem DLG-Bewertungsschema nur 6,67 Punkte erreichen. Der Gehalt an Rohasche lag in den Betrieben FB 3 und KB 3 knapp über $10 \%$, im FB 1 mit 13,9\% deutlich darüber. Für die Fallbetriebe FB 1 und FB 3 spiegelte dies auch die vorher beobachtete Verschmutzung des Siliergutes wider. Die Rohproteingehalte lagen mit 161-204 g/kg TM im optimalen Bereich, nur der Kontrollbetrieb KB 1 lag mit 138 g/kg TM knapp darunter. Dagegen streuten die Rohfasergehalte der verschiedenen Silagen sehr stark und lagen nur in den Fallbetrieben FB 1 und FB 2 im Rahmen. In dem Kontrollbetrieb KB 1 und im Fallbetrieb FB 3 waren sie erhöht, in den Kontrollbetrieben KB 2 und KB 3 dagegen erniedrigt. Der Energiegehalt zur Milchbildung lag in allen drei Fall- 
betrieben im optimalen Bereich, der Kontrollbetrieb KB 1 lag mit 5,59 MJ NEL/kg TM darunter, KB 2 und KB 3 mit 6,7 bzw. 6,9 MJ NEL/kg TM darüber. Der Ammoniakanteil am Gesamtstickstoff lag für die Betriebe FB 2, FB 3 und KB 3 deutlich unterhalb des Grenzwertes von $10 \%$. Der Fallbetrieb FB 1, der bereits sensorische Abweichungen festgestellt hatte, verzeichnete einen erhöhten Proteinabbau in seiner Silage, ebenso wie der dazugehörige Kontrollbetrieb. Für den KB 2 war kein Ammoniakanteil bestimmt worden.

Innerhalb der mikrobiologischen Untersuchungen zeigte sich ein sehr heterogenes Bild. Die mesophile aerobe Keimzahl lag im KB 1 mit 5,5 x $10^{7} \mathrm{KbE} / \mathrm{mL}$ und im FB 2 mit 1,0 x $10^{8} \mathrm{KbE} / \mathrm{mL}$ oberhalb des festgelegten Grenzwertes. Die Zahl der Enterobakterien bewegte sich in allen Betrieben im akzeptablen Bereich, wobei der KB 3 die höchsten Werte aufwies. Die Zahl der aeroben Sporenbildner betrug im Höchstfall 5,0 x $10^{3} \mathrm{KbE} / \mathrm{mL}$, während bei den anaeroben Sporenbildnern nur im KB 1 und im KB 3 erhöhte, aber noch vertretbare, Keimzahlen bestimmt wurden. Die ebenfalls schädigenden Schimmelpilze waren nur in den Fallbetrieben FB 1 und FB 3 innerhalb der Norm, während die Hefen im Fallbetrieb FB 2 zusätzlich in starkem Maße vertreten waren. Dem entgegen standen nur relativ geringe Mengen an Milchsäurebakterien, die im Minimum in der Silage des KB $35,0 \times 10^{3} \mathrm{KbE} / \mathrm{mL}$ betrugen und nur im Kontrollbetrieb KB 1 einen Maximalwert von 3,0 x 107 KbE/mL erreichten. So bot sich den Sporenbildnern eine Konkurrenzflora.

Die Beurteilung der Mykotoxingehalte in den Futtermitteln war nahezu unmöglich, da diese Werte in den LUFA-Untersuchungen der Betriebe FB 2, FB 3 und KB 3 fehlten. In den drei anderen Betrieben wurden DON und ZEA nachgewiesen, allerdings noch in den vertretbaren Grenzen. Ochratoxin überschritt dagegen in der Silage des KB 1 die zulässige Höchstgrenze mit 26,5 $\mu \mathrm{g} / \mathrm{kg}$ Silage. Keine der untersuchten Silagen wurde positiv auf Botulinum-Neurotoxine getestet. 


\subsubsection{Wasserversorgung}

Durch die Art der Wasserversorgung ergeben sich ebenfalls mögliche Eintragsquellen für Krankheitserreger. Oberflächenwasser beispielsweise ist einer Kontamination durch Vögel oder Wildtiere besonders ausgesetzt. Brunnenwasser kann durch Tierkadaver verseucht werden.

Tab. 45: Wasserversorgung der Tiere im Stall und auf der Weide

\begin{tabular}{lcccccc}
\hline & FB 1 & KB 1 & FB 2 & KB 2 & FB 3 & KB 3 \\
\hline Stall & Leitung & Brunnen & Leitung & Brunnen & Brunnen & Brunnen \\
Weide & Leitung & k.A. & Oberfläche & Brunnen & k.A. & Brunnen \\
\hline
\end{tabular}

Während die Kontrollbetriebe ihre Tiere ausschließlich mit Brunnenwasser versorgten, verwendete der Fallbetrieb FB 1 nur Wasser aus dem öffentlichen Wasserleitungsnetz, das der ständigen Überwachung unterliegt. Der Fallbetrieb FB 2 nutzte für die Versorgung im Stall Leitungswasser und auf der Weide Oberflächenwasser. Der FB 3 besaß ebenfalls einen eigenen Brunnen. Dass die Betriebe KB 1 und FB 3 keine Wasserversorgung für die Weide angaben, ist irrelevant, da die betroffenen Kühe ausschließlich im Stall gehalten wurden.

\subsubsection{Fütterung}

Im verwendeten Fragebogen wird weiterhin die Art des Fütterungsverfahrens beschrieben und ob bei der TMR der geprüften Gruppe sensorische Abweichungen zu erkennen waren. Alle verwendeten Futter wurden inklusive einer sensorischen Beurteilung angegeben, da neben der als Hauptursache des Krankheitsbildes „viszeraler Botulismus“ von beiden Parteien angesehenen Grassilage auch bereits andere Futtermittel für den Ausbruch von akutem Botulismus verantwortlich waren (Notermans et al., 1981; Wilson et al., 1995; Yeruham et al., 2003). 
Tab. 46: Fütterungsverfahren und verwendete Futtermittel

\begin{tabular}{|c|c|c|c|c|c|c|}
\hline & FB 1 & KB 1 & FB 2 & KB 2 & FB 3 & KB 3 \\
\hline Fütterungsverfahren & $\begin{array}{c}\text { TMR + } \\
\text { Transp. }\end{array}$ & TMR & TMR & $\begin{array}{c}\text { TMR + } \\
\text { Transp. }\end{array}$ & TMR & TMR \\
\hline $\begin{array}{l}\text { sensorische Abwei- } \\
\text { chung TMR }\end{array}$ & Nein & Nein & Nein & Nein & Nein & Nein \\
\hline Maissilage & $\mathrm{X}$ & $\mathrm{X}$ & $\mathrm{X}$ & $\mathrm{X}$ & $\mathrm{X}$ & $\mathrm{X}$ \\
\hline Grassilage & $\mathrm{X}$ & $\mathrm{X}$ & $\mathrm{x}$ & $\mathrm{X}$ & $\mathrm{X}$ & $\mathrm{X}$ \\
\hline Pressschnitzel & / & / & $\mathrm{X}$ & / & / & / \\
\hline Biertreber & / & l & / & / & / & / \\
\hline Pülpe & / & / & / & / & / & / \\
\hline $\mathrm{Heu}$ & $\mathrm{X}$ & / & / & / & / & $\mathrm{X}$ \\
\hline Stroh & $\mathrm{X}$ & $\mathrm{X}$ & $\mathrm{X}$ & $\mathrm{X}$ & $\mathrm{X}$ & $\mathrm{X}$ \\
\hline Eigengetreide & $\mathrm{X}$ & / & $\mathrm{X}$ & / & $\mathrm{X}$ & / \\
\hline Zukauf Kraftfutter & $\mathrm{X}$ & $\mathrm{X}$ & $\mathrm{X}$ & $\mathrm{X}$ & $\mathrm{X}$ & $\mathrm{X}$ \\
\hline sonstiges Futter & / & $\mathrm{X}$ & $\mathrm{X}$ & $\mathrm{X}$ & / & $\mathrm{X}$ \\
\hline
\end{tabular}

In den untersuchten Betrieben wurden weder Einzelvorlagen noch Mischrationen, sondern ausschließlich Teilmischrationen, in FB 1 und KB 2 über Transponder, gefüttert. Dadurch war eine leistungsgerechte Zudosierung von Kraftfutter möglich. Die Qualität der TMR war insgesamt sensorisch nicht zu beanstanden. Die als risikoreich geltenden Biertreber und Kartoffelpülpe wurden in keinem der Betriebe verfüttert. In den Fallbetrieben FB 1 und FB 3 und im KB 3 wurden sensorische Abweichungen der Grassilage angegeben. Der FB 3 gab als Abweichung Nacherwärmung an, der KB 3 besaß eine sehr feuchte und feste Silage mit verdorbener Anschnittfläche. Dahinter hatte die Silage allerdings eine gute Qualität. Im KB 2 war das zugefütterte Stroh nicht von einwandfreier Qualität. Eigengetreide wurde nur in den Fallbetrieben zugefüttert. Im Fall von FB 1 wurde Mais verwendet. In den anderen beiden Fallbetrieben wurde Weizen als Eigengetreide zugefüttert. Als Kraft- und sonstiges Futter waren Soja, Raps, 20IVer KF, Luzerne, Mais, Leinsamen, Rohglyzerin, Fett, Mineralstoffe, Säuren zum Konservieren der TMR und Lebendhefen im Einsatz. 


\subsection{Tiergesundheit}

\subsubsection{Pflege der Tiere und Sanierungsstatus der Herde}

Die Tier- bzw. Herdengesundheit wird im Rahmen des Tierarztbesuches überwacht. Je öfter ein Besuch stattfindet, umso größer ist die Chance, Krankheiten schnell $\mathrm{zu}$ entdecken und $\mathrm{zu}$ intervenieren. In einer Rinderherde kommt der Klauenpflege eine große Bedeutung zu und sie muss regelmäßig stattfinden, um die optimale Funktion der Klauen zu erhalten bzw. wiederherzustellen. Klauenerkrankungen können zu Leistungseinschränkungen führen, sind ihrerseits aber auch ein Indiz für Azidosen, starke Fettmobilisation oder ein Mangel an Antioxidantien. Mögliche Rückschlüsse auf Haltung und Fütterung machen die Klauenbetrachtung zu einem unverzichtbaren Instrument bei der klinischen Untersuchung eines Tieres.

Das Bovine Herpesvirus 1 (BHV-1) verursacht eine hochansteckende VirusErkrankung, die zu den anzeigepflichtigen Tierseuchen zählt (TierSeuchAnzV, 1991 (Neufassung vom 19.07.2011); TierSG, 2010). Sie kann als respiratorische und genitale Entzündung auftreten und verursacht hohe wirtschaftliche Verluste. Die Virusinfektion Bovine Virusdiarrhoe/Mucosal Disease (BVD/MD) zählt ebenfalls zu den wirtschaftlich bedeutendsten Erkrankungen des Rindes, da Morbidität und Letalität bis zu 100 \% betragen können. Infektionen während der Trächtigkeit führen zu Fehlbildungen bzw. Aborten der Frucht. Sie ist ebenfalls anzeigepflichtig. Die Paratuberkulose ist hingegen „nur“ meldepflichtig. Es handelt sich hierbei um eine chronische Darmerkrankung bei Wiederkäuern, die zunächst trotz guten Appetites zu Abmagerung bis hin zur Kachexie führt und sich schließlich in Form von wässrigen Durchfällen bemerkbar macht. Salmonellose ist eine von Salmonellen verursachte infektiöse Gastroenteritis und führt in der akuten Form zu Durchfall. In der seltenen chronischen Variante wurden Fehlgeburten, Gelenks- und Euterentzündungen beobachtet. Sie gehört, nur bei Rindern, ebenfalls zu den anzeigepflichtigen Tierseuchen.

Eine wichtige Rolle bei der Bewertung der Laborergebnisse spielt auch die Kenntnis über den Impfstatus. Da in dieser Pilotstudie der Fokus auf durch Clostridien verursachten Problemen lag, wurden in dem Fragebogen nur die Botulism Vaccine ${ }^{\circledR}$ von Onderstepoort gegen die C.-botulinum-Typen C und D, 
Bravoxin ${ }^{\circledR}$ von Intervet und Covexin ${ }^{\circledR}$ von Pfizer (beide enthalten Toxoide von C.-perfringens -Typ A, B, C und D, C. novyi, C. septicum, C. tetani, C. sordellii, C. haemolyticum und eine inaktivierte C.-chauvoei-Vollkultur) bzw. bestandsspezifische Impfstoffe aufgeführt. Als Impferfolg wurde eine Verbesserung des Krankheitsbildes und Abnahme der Krankheitssymptome bezeichnet.

Tab. 47: Pflege der Tiere und Sanierungsstatus der Betriebe

\begin{tabular}{lcccccc}
\hline & FB 1 & KB 1 & FB 2 & KB 2 & FB 3 & KB 3 \\
\hline Tierarztbesuch & wöchentl. & wöchentl. & wöchentl. & wöchentl. & wöchentl. & wöchentl. \\
Klauenpflege & $\begin{array}{c}\text { 1/2jährl. } \\
\text { zufrieden- }\end{array}$ & $1 / 2$ jährl. & monatl. & bei Bedarf & $1 / 2$ jährl. & $1 / 2$ jährl. \\
Zustand Klauen & stellend & sehr gut & mangelhaft & sehr gut & sehr gut & sehr gut \\
BHV-Status & frei & frei & frei & frei & frei & frei \\
BVD-Status & unverd. & unverd. & unverd. & unverd. & unverd. & unverd. \\
Para-Tbc & Nein & Nein & Ja & Nein & Nein & Nein \\
Salmonellose & Nein & Nein & Nein & Nein & Nein & Nein \\
\hline Impfung gg & Ja & Nein & Nein & Nein & Ja & Nein \\
Clostridien & Covexin & $/$ & $/$ & $/$ & Covexin & $/$ \\
Name & ja & $/$ & $/$ & $/$ & ja & $/$ \\
Impferfolg & & & & &
\end{tabular}

Die Tierarztbesuche fanden in allen an dieser Studie teilnehmenden Betrieben wöchentlich statt. Hinzu kam, dass zwei der Fallbetriebe und zusätzlich ein Kontrollbetrieb durch den gleichen Tierarzt betreut wurden. Dadurch scheint gesichert, dass schon der behandelnde Tierarzt und nicht erst der RGD Mecklenburg-Vorpommern in der Lage war, eine differenzierte Diagnose bezüglich der Probleme in den Fall- und Kontrollbetrieben abzugeben. Die Klauenpflege erfolgte meist halbjährlich. Da der Klauenzustand in FB 1 „nur“ zufriedenstellend war, wäre hier eine häufigere Klauenpflege zu empfehlen. Der FB 2 hatte die Pflege der Klauen auf einen monatlichen Rhythmus eingestellt, um dem mangelhaften Zustand zu begegnen. Ein Zusammenhang mit eventuell auftretenden anderen Erkrankungen muss geprüft werden. Die Bestände waren durchgängig frei von BHV und unverdächtig auf BVD/MD. Auch eine Salmonellose wurde in den letzten zwölf Monaten weder in den Fall- noch in den Kontrollbetrieben diagnostiziert. Allerdings wurde im Fallbetrieb FB 2 Paratuberkulose nachgewiesen, die bei der Auswertung der klinischen Ergebnisse berücksichtigt werden muss. In zwei der drei Fallbetriebe, FB 1 und FB 3 fand zum Zeitpunkt der Datenerhebung und Untersuchung bereits eine Impfung mit Covexin ${ }^{\circledR}$ statt, die zu einer Verbesserung der Situation beitrug. 


\subsubsection{Klinische Untersuchung}

Zur Auswahl von drei Tieren anhand der Botulismusverdachtssymptome Lähmung, Reaktionsmangel und schlechter Allgemeinzustand wurde möglichst eine Leistungsgruppe begutachtet.

Tab. 48: Herdenbeurteilung bzgl. der Problematik des viszeralen Botulismus

\begin{tabular}{lcccccc}
\hline & FB 1 & KB 1 & FB 2 & KB 2 & FB 3 & KB 3 \\
\hline Tiergruppe & 1. LG & 1. LG & 1. LG & alle & Frischm. & Frischm. \\
Anzahl begutacheter & 59 & 90 & 200 & 180 & 16 & 40 \\
Tiere & 10 & 0 & 50 & 1 & 8 & 1 \\
Tiere mit Symptomen & 10 & & &
\end{tabular}

Pro Betrieb wurden drei Tiere mit Botulismusverdachtssymptomen eingehend klinisch untersucht. Die zu beurteilenden Parameter sollen je nach Eignung als spätere Anhaltspunkte zur klinischen Diagnostik dienen und lassen sich in die Gruppen Allgemeinzustand, Verdauung, systemische Symptome und neuro-motorische Symptome unterteilen. Zusätzlich wird der Kot der begutachteten Tiere mikrobiologisch und toxikologisch untersucht. Bei der Beurteilung des Allgemeinzustandes gelten ein schlechter bis sehr schlechter Habitus und Ernährungszustand, apathisches oder gedämpftes Verhalten, Ataxien und eine untypische Beinstellung bis zum Festliegen als Symptome für das Krankheitsbild des viszeralen Botulismus. Bezüglich der Auswirkungen auf das Verdauungssystem wird die Beschaffenheit des Kotes, die Motilität des Pansens, das Wiederkauverhalten und die Motilität des Darmes beurteilt. Eventuelle systemische Effekte lassen sich in tröpfelndem Harnabsatz, gestauten Venen, Ödemen, der Atmung, Entzündungen an Klauen und Gelenken und Muskelatrophie erkennen. Da die BoNTe in die Reizleitung der Nervenzellen eingreifen, erfolgt die Beurteilung von neuro-motorischen Symptomen und Ausfallerscheinungen besonders ausführlich. Zusätzlich wurde der Kot der untersuchten Tiere auf Clostridien allgemein, C.-perfringens-Toxine, C. botulinum und BoNTe, auf Salmonellen und Mykobakterien getestet. 
Tab. 49: Anzahl der auffälligen Tiere mit Botulismussymptomatik

\begin{tabular}{|c|c|c|c|c|c|}
\hline & Symptome & $\mathrm{FB}$ & Tiere & $\mathrm{KB}$ & Tiere \\
\hline \multirow{5}{*}{  } & Habitus & 6 & 9 & 0 & 9 \\
\hline & Ernährungszustand & 6 & 9 & 4 & 9 \\
\hline & Verhalten & 4 & 9 & 1 & 9 \\
\hline & Ataxien & 8 & 9 & 1 & 9 \\
\hline & untyp. Beinstellung & 6 & 9 & 0 & 9 \\
\hline \multirow{4}{*}{$\begin{array}{l}\infty \\
\vdots \\
5 \\
5 \\
\frac{\pi}{0} \\
0 \\
0 \\
\end{array}$} & Kot & 1 & 9 & 1 & 9 \\
\hline & Pansen & 7 & 9 & 1 & 9 \\
\hline & Wiederkauverhalten & / & / & l & l \\
\hline & Darm & 3 & 9 & 1 & 9 \\
\hline \multirow{6}{*}{ 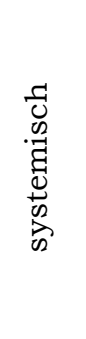 } & tröpfelnder Harnabsatz & 0 & 2 & 0 & 1 \\
\hline & gestaute Venen & 3 & 9 & 3 & 9 \\
\hline & Ödeme & 0 & 9 & 0 & 9 \\
\hline & auffällige Atmung & 4 & 9 & 1 & 9 \\
\hline & $\begin{array}{l}\text { Entzündung an Klauen und } \\
\text { Gelenken }\end{array}$ & 8 & 9 & 3 & 9 \\
\hline & Muskelatrophie & 5 & 9 & 1 & 9 \\
\hline \multirow{17}{*}{ 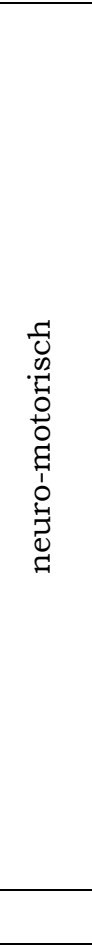 } & $\begin{array}{l}\text { fehlende Abwehrbewegung } \\
\text { Kopf }\end{array}$ & 4 & 9 & 0 & 9 \\
\hline & Mydriasis & 3 & 9 & 0 & 9 \\
\hline & fehlender Lidreflex & 4 & 9 & 0 & 9 \\
\hline & fehlender Ohrreflex & 2 & 9 & 0 & 9 \\
\hline & Schluckbeschwerden & 1 & 6 & 0 & 0 \\
\hline & auffällige Lautäußerungen & / & / & / & / \\
\hline & eingeschränkter Zungenreflex & 1 & 6 & 0 & 1 \\
\hline & muköser Speichel & 1 & 9 & 0 & 8 \\
\hline & hängende Unterlippe & 1 & 9 & 0 & 8 \\
\hline & eingeschränkter Analreflex & 2 & 9 & 0 & 8 \\
\hline & eingeschränkter Hautreflex & 2 & 9 & 1 & 9 \\
\hline & eingeschränkter Klauenreflex & 2 & 6 & 0 & 8 \\
\hline & Fibularislähmung & 1 & 9 & 0 & 9 \\
\hline & Ischiadikuslähmung & 5 & 8 & 1 & 9 \\
\hline & Obturatorislähmung & 1 & 8 & 1 & 9 \\
\hline & Radialislähmung & 1 & 9 & 0 & 9 \\
\hline & & FB & Tiere & $\mathrm{KB}$ & Tiere \\
\hline \multirow{5}{*}{ 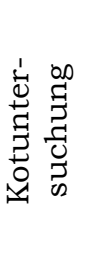 } & C. perfringens & 4 & 9 & 2 & 9 \\
\hline & C. botulinum & 5 & 9 & 2 & 9 \\
\hline & sulfitreduzierende Clostridien & / & / & 0 & 9 \\
\hline & Salmonellen & 0 & 6 & l & / \\
\hline & Mykobakterien & 3 & 6 & / & / \\
\hline
\end{tabular}


Insgesamt wurden neun Tiere in den Fallbetrieben und neun Tiere in den Kontrollbetrieben beurteilt. Tiere, bei denen Auffälligkeiten diagnostiziert wurden, sind in der Tabelle aufgeführt. Einige der Symptome konnten aus verschiedenen Gründen, wie z. B. Festliegen, nicht an allen Tieren untersucht werden. Aus diesem Grund ist hinter den Betrieben die Zahl der bezüglich dieses Symptoms beurteilten Tiere vermerkt.

In den Fallbetrieben zeigten drei Tiere ein apathisches oder gedämpftes Verhalten, ein viertes Tier reagierte nervös und reizbar. Auch im Kontrollbetrieb KB 1 war ein nervöses und reizbares Tier beobachtet worden. Eines der untersuchten Tiere lag fest, so dass die Beinstellung nicht beurteilt werden konnte. Das Wiederkauverhalten konnte bei den ausgesuchten Tieren während des Untersuchungszeitraums nicht erhoben werden. Die Tiere waren durch die Untersuchung zu ängstlich, um zu kauen. Aus dem gleichen Grund war die Beobachtung von auffälligen Lautäußerungen nicht möglich (Schwagerick, 2011a). In den Fallbetrieben lag bei zwei von neun Tieren eine Pansentympanie vor, bei weiteren fünf Tieren waren nur schwache Pansenkontraktionen auszukultieren, wohingegen in den Kontrollbetrieben insgesamt bei nur einem Tier eine Pansentympanie festzustellen war. Drei Falltiere wiesen auch Darmtympanien auf, darunter ein Tier, bei dem auch schon eine Pansentympanie diagnostiziert worden war. Bei einem weiteren Tier waren bereits schwache Pansenkontraktionen festgestellt worden, bei dem dritten Tier war der Pansen ohne besondere Beobachtung geblieben. Auch ein Kontrolltier wies eine Darmtympanie auf, es handelte sich allerdings nicht um dasselbe Tier, bei dem die Pansentympanie festgestellt worden war. Als neuromotorische Störungen kristallisierten sich besonders die fehlende Abwehrbewegung des Kopfes, der fehlende Lidreflex und die Ischiadikuslähmung heraus. Weitere Symptome traten unregelmäßiger über verschiedene kranke Tiere verteilt, auf, in ihrer Summe aber häufiger als in den Kontrolltieren.

Der Nachweis von C. perfringens im Kot der klinisch untersuchten Tiere wurde mithilfe des Toxin-ELISAs und der PCR geführt, für den Nachweis von C. botulinum wurden als Methoden der Maus-Bioassay zum direkten und indirekten Toxinnachweis und die PCR verwendet. Das Vorhandensein von Clostridien, Salmonellen und Mykobakterien wurde durch METABOVET bestimmt. 


\subsubsection{Bestandsdiagnostik}

Zur Erfassung der Herdengesundheit wurden symptomatisch unauffällige Tiere aus den beteiligten Beständen der Pilotstudie ausgewählt und auf verschiedene Parameter im Serum und im Harn untersucht. Die Bestimmung erfolgte in jeweils fünf Tieren zu drei verschiedenen Zeitpunkten; in der Trockensteherphase (I., 7-0 Tage a.p.), als Frischmelker (II., 0-7 Tage p.p.) und in der Hochlaktation (III., 6.-8. Woche p.p.). Dadurch konnten auch spezifische Veränderungen in den verschiedenen Leistungsphasen erfasst werden. Die folgenden Grenz- bzw. Optimalwerte der Laborparameter eines gesunden Tieres sind der Fachliteratur (Fürll, 2005; VUW, 2006; Wilczek und Merl, 2010) und den persönlichen langjährigen Erfahrungen von Dr. Schwagerick entlehnt. Durch diese Bestandsdiagnostik können andere Erkrankungen erkannt oder ausgeschlossen werden.

Die Aspartat-Aminotransferase (ASAT) katalysiert die Umwandlung und den Abbau von Aminosäuren und die Verwertung von Kohlenhydraten. Durch die Bestimmung der Aktivität im Serum kann man Rückschlüsse auf den Zustand der Leber ziehen. Dazu dient auch die Bestimmung der Glutamatdehydrogenase (GLDH), die im Gegensatz zur ASAT erst in das Blut gelangt, wenn Leberzellen zerstört werden. Dieses Enzym spielt im Stickstoffmetabolismus eine große Rolle bei der Freisetzung bzw. Fixierung von Ammonium. Bei Lebererkrankungen sind die Werte dieser beiden Enzyme erhöht. Der Grenzwert für ASAT beim Rind beträgt 1,33 $\mu \mathrm{kat} / \mathrm{L}$, bei Frischkalbern 1,5 $\mu \mathrm{kat} / \mathrm{L}$. Bei GLDH existieren Grenzwerte zwischen 270 und 330 nkat/L. Die Werte für beide Enzyme sind allerdings in der Diskussion, da sie auch in gesunden Hochleistungstieren häufig überschritten werden und deshalb nur bedingt aussagekräftig sind.

Als bessere Indikatoren für eine Entgleisung des Stoffwechsels gelten bei kurzfristig anhaltendem Energiemangel freie Fettsäuren (FFS) und bei länger anhaltendem Energiemangel das Level an Bilirubin, Cholesterin oder Ketonkörpern wie $\beta$-Hydroxybutyrat (BHB) im Serum des Rindes. Freie Fettsäuren steigen bei Energiemangel und reduzierter Futteraufnahme durch die Fettmobilisation stark an und liegen bei einem gesunden Tier zwischen 0,1 und 0,9 mmol/L. Bei Frischkalbern wird aufgrund der Ketosegefährdung stattdessen der Gehalt an BHB bestimmt, der zwischen 0,2 und 1,6 mmol/L 
liegen sollte. Ist dieser Wert größer als 1,0 mmol/L, deutet dies auf eine Ketose hin. Durch Leberschädigung und Hämolyse steigen die Bilirubinwerte, die im gesunden Rind unter $5,0 \mu \mathrm{mol} / \mathrm{L}$ und speziell bei Frischkalbern unter $8,5 \mu \mathrm{mol} / \mathrm{L}$ liegen sollten, an. Das Cholesterin sinkt dagegen bei eingeschränkter Futteraufnahme und Verdauung. Die Werte sollten zwischen 2,0 und 4,5 mmol/L liegen. Durch die Bestimmung des Harnstoffgehaltes (HST) im Serum lassen sich Aussagen über die Proteinversorgung durch das Futter treffen. Bei einem Defizit finden sich niedrige Werte, hohe Werte deuten auf Niereninsuffizienz, Energieunterversorgung bzw. Proteinüberschuss hin. Im gesunden Tier liegen die Werte zwischen 2,5 und 5,0 mmol HST/L.

Neben einer ausgeglichenen Energiebilanz ist auch auf eine ausreichende Versorgung mit Vitaminen und Mineralstoffen $\mathrm{zu}$ achten, da diese oft als Kosubstrate für enzymatische Reaktionen von Bedeutung sind und eine große Rolle in komplexen Interaktionen, wie z. B. Transportkanälen spielen. Das Vitamin B12 dient als Coenzym im Stoffwechsel der Aminosäuren. Damit ist es ein wichtiger Bestandteil bei der Blutbildung, Zellteilung und bei der Produktion von Neurotransmittern. In der Milchviehhaltung entstehen Probleme in der Vitamin-B12-Versorgung trotz ausreichender Cobalt-Substitution durch eine gestörte Pansenfunktion, was zu einer ungenügenden CobalaminSynthese und/oder -Resorption führt. Unspezifische Mangelsymptome sind Leistungsminderung und Abmagerung. In einer Reihenuntersuchung der METABOVET Labormedicus GmbH wurden für Milchkühe durchschnittliche Vitamin-B12-Konzentrationen von 94,4 ng/L, bei den Trockenstehern von $109,5 \mathrm{ng} / \mathrm{L}$ und bei Frischmelkern von 86,4 ng/L im Serum bestimmt (Wolf und Schütte, 2010). Der Calciumgehalt im Serum sollte zwischen 2,4 und 2,6 $\mathrm{mmol} / \mathrm{L}$ betragen, mindestens aber 2,0 $\mathrm{mmol} / \mathrm{L}$. Niedrige Werte deuten auf Hypokalzämie bis zur Gebärparese hin. Es handelt sich gleichzeitig um eine Störung des Phosphor- und Vitamin-D-Haushaltes. Der Gehalt an Phosphor im Serum des Rindes sollte zwischen 1,55 und 2,2 $\mathrm{mmol} / \mathrm{L}$ liegen, bei den Frischmelkern sind auch Werte zwischen 1,26 und 2,5 mmol/L akzeptabel.

Durch die Bestimmung von verschiedenen Parametern im Harn lassen sich zusätzlich Aussagen über die Stoffwechselleistung und den Gesundheitszustand eines Tieres, und in diesem Fall damit über den gesamten Bestand, treffen. Die Netto-Säure-Basen-Ausscheidung (NSBA) reflektiert z. B. sehr sensibel Fütterungseinflüsse bzw. -veränderungen. Pflanzenfresser haben i. d. R. 
einen positiven NSBA-Wert. Bedingt durch die Kaliumausscheidung kann er in Fastenzuständen aber stark absinken. Abnahmen der NSBA zeigen azidotische Belastungen an, Zunahmen alkalotische Zustände. Veränderungen in der Stoffwechsellage werden durch die Betrachtung der NSBA schneller sichtbar als durch den pH-Wert, da hier bereits die Beanspruchung der Pufferkapazität ersichtlich wird (Kraft et al., 2005). Je nach Literaturquelle sollte die NSBA 200-220 mmol/L nicht überschreiten. Sie korreliert eng mit der Kaliumausscheidung, dient aber auch zur Einschätzung der Gebärparesegefährdung bei hochträchtigen Kühen. Die Calciumausscheidung mit dem Harn beträgt ca. 0,3-2,5 mmol/L, bei Trockenstehern sogar bis zu 5,0 mmol/L. Die Ausscheidung von anorganischem Phosphor sollte im Bereich von 0,1-3,3 mmol/L und die von Kalium zwischen 150 und $300 \mu \mathrm{g} / \mathrm{L}$ liegen.

Die Analysewerte wurden den Referenzwerten gegenübergestellt. Da sich der Übergang von „gesund“ zu „krank“ bei den einzelnen Stoffwechselparametern fließend gestaltet, wurde bei der Beurteilung der Ergebnisse ein modifiziertes Verfahren angewandt. War der Gruppenwert außerhalb der Kontrollgrenze lag eine Gesundheits- bzw. Leistungsgefährdung vor. Überschritt der Wert außerdem die Toleranzgrenze, war davon auszugehen, dass die Gruppe nicht mehr zu einer gesunden, leistungsfähigen Population zu rechnen war (Fürll, 2005).

Tab. 50: Laboruntersuchungen zur Herdengesundheit (Medianwerte)

\begin{tabular}{|c|c|c|c|c|c|c|}
\hline & \multicolumn{3}{|c|}{ FB } & \multicolumn{3}{|c|}{$\mathrm{KB}$} \\
\hline & I. & II. & III. & I. & II. & II. \\
\hline ASAT $[\mu \mathrm{kat} / \mathrm{L}]$ & 1,18 & 1,84 & 1,59 & 1,33 & 2,88 & 1,64 \\
\hline GLDH [nkat/L] & 217 & 331 & 202 & 221 & 190 & 623 \\
\hline Bilirubin $[\mu \mathrm{M}]$ & 3,1 & 5,2 & 3,9 & 3,6 & 7,2 & 3,3 \\
\hline $\mathrm{FFS} / \mathrm{BHB}[\mathrm{mM}]$ & 0,08 & 0,70 & 0,60 & 0,23 & 1,01 & 0,64 \\
\hline $\mathrm{HST}[\mathrm{mM}]$ & 4,47 & 4,30 & 5,39 & 4,00 & 3,31 & 4,57 \\
\hline Vit. B12 [ng/L] & 93 & 105 & 105 & 122 & 121 & 99 \\
\hline Cholesterin [mM] & 2,15 & 2,40 & 5,64 & 1,96 & 2,11 & 5,20 \\
\hline Calcium [mM] & 2,38 & 2,49 & 2,52 & 2,44 & 2,40 & 2,38 \\
\hline Phosphor[mM] & 2,15 & 1,75 & 1,77 & 2,05 & 1,60 & 2,08 \\
\hline \multicolumn{7}{|c|}{ Harn } \\
\hline NSBA [mM] & 40 & 160 & 180 & 95 & 65 & 135 \\
\hline Calcium [mM] & 1,10 & 1,07 & 0,61 & 2,22 & 2,75 & 1,44 \\
\hline $\begin{array}{l}\text { Phosphor anorg. } \\
{[\mathrm{mM}]}\end{array}$ & 0,44 & 0,54 & 0,53 & 0,78 & 0,65 & 0,69 \\
\hline Kalium [mM] & 240 & 313 & 312 & 270 & 213 & 241 \\
\hline
\end{tabular}


Die Aktivitätswerte der ASAT lagen sowohl in den Fall- als auch in den Kontrollbetrieben fast ausschließlich über 1,33 $\mu \mathrm{kat} / \mathrm{L}$ und waren bei den Frischkalbern am höchsten. Die Werte in den Fallbetrieben waren allerdings etwas niedriger als in den Kontrollbetrieben. Die Werte für das Enzym GLDH befanden sich in den Tieren beider Gruppen nur während der Hochträchtigkeitsphase im Normbereich. In den Fallbetrieben stiegen die Werte direkt nach der Geburt etwas an, während sich die GLDH-Werte in der Kontrollgruppe erst in der Hochleistungsphase auf durchschnittlich 623 nkat/L steigerten. Dies deutete besonders in den Kontrollbetrieben auf eine verstärkte Leberbelastung während der Laktation hin. Die Bilirubinwerte, die auf Energiemangelzustände hinweisen könnten, waren in beiden Betriebesgruppen nur während der Frischlaktation erhöht und zeigten die Umstellung des Stoffwechsels. Die Bestimmung der FFS bzw. Ketonkörper BHB zeigte nur in der II. Phase im Kontrollbetrieb KB 3 einen $\mathrm{zu}$ hohen Wert, so dass nur dort von einem Energiemangel ausgegangen werden könnte. Auch die Harnstoffwerte im Serum befanden sich zu fast allen Phasen im optimalen Bereich. Lediglich während der Hochlaktation schien es in den Fallbetrieben zu einer Energieunterversorgung bzw. Proteinüberversorgung zu kommen. Dies spiegelte sich für die Fallbetriebe FB 2 und FB 3 auch bereits in der Betrachtung der HST-Gehalte der Milch wider. Auch die Vitamin-B12-Gehalte im Serum waren während der verschiedenen Phasen, aber in unterschiedlichen Betrieben, zu niedrig, so dass eine Substitution ratsam wäre. Die Cholesterinwerte wichen ebenfalls in der Hochlaktation sowohl in den Fall- als auch in Kontrollbetrieben nach oben ab. Die Calcium- und Phosphorkonzentrationen im Serum befanden sich während aller Phasen im jeweils optimalen Bereich.

Die NSBA im Harn war während der Hochträchtigkeit in den Fallbetrieben zu niedrig, aber grundsätzlich in allen Tieren noch im positiven Bereich, während die Werte der Kontrollbetriebe während der Frischmelkerphase zwar im Durchschnitt höher waren, aber in den Einzeltieren sogar eine negative Bilanz zu messen war. Diese niedrigen Werte deuteten auf eine azidotische Stoffwechselsituation hin. Die Ausscheidung von Calcium und anorganischem Phosphor verlief in allen Betrieben im Durchschnitt innerhalb der Grenzen, war bei den Einzeltieren aber besonders während der Hochleistungsphase zu 
niedrig. Die Kaliumausscheidung war in den Fallbetrieben in dieser Zeit erhöht.

Zusätzlich zu den Untersuchungen laut Fragebogen wurden von den für die Bestandsdiagnostik beprobten Tieren vor Ort die Sensorik, der pH-Wert des Pansensaftes und die Zusammensetzung und Beweglichkeit der Infusorien bestimmt.

Die Pansenflora und -fauna setzt sich aus verschiedenen Mikroorganismen, Bakterien, Einzellern (sog. Infusorien) und Pilzen zusammen. Sie sind an den Abbauprozessen der Nahrungspartikel zu kurzkettigen Fettsäuren und an der Aufrechterhaltung des Pansenmilieus beteiligt. Die Protozoen resorbieren leicht abbaubare Kohlenhydrate, verringern so einen zügigen Abbau und damit die Gefahr einer Pansenazidose. Gleichzeitig sind sie in der Lage, einige toxische Futterbestandteile abzubauen oder zu binden. Bei einer hohen Konzentration des Mykotoxins Trypacidin besteht allerdings die Möglichkeit einer Beeinträchtigung der Pansenfunktion hochleistender Kühe (Gutteridge et al., 1969; Richter et al., 2009). Der physiologische pH-Wert im Pansen beträgt 5,5 bis 7 . Bei niedrigen $\mathrm{pH}-$ Werten, die auf eine Pansenazidose hindeuten, werden Mikroorganismen und Infusorien in ihrer Funktion beeinträchtigt.

Tab. 51: Sensorische Beurteilung und Zusammensetzung der Infusorien des Pansensaftes

\begin{tabular}{|c|c|c|c|c|c|c|}
\hline & FB 1 & KB 1 & FB 2 & KB 2 & FB 3 & KB 3 \\
\hline Farbe & $\begin{array}{c}\text { hellgrün, } \\
\text { oliv bis } \\
\text { braun }\end{array}$ & $\begin{array}{l}\text { hellgrün, } \\
\text { oliv }\end{array}$ & $\begin{array}{l}\text { hellgrün, } \\
\text { oliv bis } \\
\text { gelb }\end{array}$ & $\begin{array}{l}\text { hellgrün, } \\
\text { oliv }\end{array}$ & $\begin{array}{l}\text { hellgrün, } \\
\text { oliv }\end{array}$ & $\begin{array}{l}\text { hellgrün, } \\
\text { gelb }\end{array}$ \\
\hline Geruch & $\begin{array}{c}\text { mild/ } \\
\text { neutral }\end{array}$ & $\begin{array}{l}\text { überw. mild, } \\
\text { aber auch } \\
\text { stechend }\end{array}$ & $\begin{array}{l}\text { sauer bis } \\
\text { faulig }\end{array}$ & $\begin{array}{c}\text { mild/ } \\
\text { neutral }\end{array}$ & $\begin{array}{l}\text { stechend } \\
\text { bis mild, } \\
\text { faulig }\end{array}$ & $\begin{array}{l}\text { überw. } \\
\text { faulig }\end{array}$ \\
\hline pH-Wert & 5,9 & 5,4 & 5,4 & 6,2 & 6,1 & 6,0 \\
\hline \multicolumn{7}{|l|}{ Infusorien } \\
\hline kleine $^{\mathrm{a}}$ & 1 & 0 & 1 & 1 & 2 & 1 \\
\hline mittlere ${ }^{a}$ & 2 & 2 & 2 & 1 & 2 & 1 \\
\hline großea & 2 & 0 & 1 & 1 & 2 & 2 \\
\hline Bewegungb & 2 & 0 & 1 & 1 & 1 & 2 \\
\hline
\end{tabular}

a Anzahl an Infusorien: 0 - keine, 1 - wenige, 2 - mittlere, 3 - viele

b Bewegung: 0 - keine, 1- gering, 2 - mittel, 3 - stark 
Nur sehr wenige Tiere besaßen Pansensaft mit einem neutralen $\mathrm{pH}$-Wert, so dass die Tiere im Durchschnitt einen niedrigen $\mathrm{pH}$-Wert im Pansen zwischen 5,4 und 6,2 aufwiesen. Die Geruchsproben der Einzelpansensäfte variierten sehr stark, auffällig war aber der faulige Geruch von sieben Pansensaftproben im Kontrollbetrieb KB 3. Die Zahl der Infusorien bewegte sich im mittleren bzw. unteren Bereich und auch deren Beweglichkeit lag nicht im optimalen Bereich. Hier stach der Kontrollbetrieb KB 1 mit sehr wenigen, leblosen Infusorien negativ hervor. Eine Zuordnung der Betriebe in die Untersuchungsgruppen ließe sich anhand dieser Ergebnisse nicht eindeutig vornehmen.

Weiterhin wurde der Kot der Tiere mit dem Maus-Bioassay auf BoNT geprüft. Pansensaft und Kot wurden außerdem mit der PCR auf C.-perfringensToxingene ( $\alpha-, \beta-, \beta_{2^{-}}, \varepsilon-$, l-, Enterotoxin) und toxinogene Bakterien der Spezies C. botulinum (BoNT/A-F), einem ELISA auf C.-perfringens- $\left(\alpha-, \beta-, \varepsilon_{-}\right)$-Toxin und die Seren der Tiere auf Antikörper gegen C. botulinum (Anti-BoNT/A, B, C und D) überprüft.

Tab. 52: Untersuchungen zur Clostridienbelastung im Bestand

\begin{tabular}{|c|c|c|c|c|c|c|c|}
\hline & & FB 1 & KB 1 & FB 2 & KB 2 & FB 3 & KB 3 \\
\hline \multirow{3}{*}{ 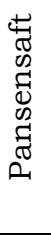 } & C. bot. PCR & $2 \times E, 1 \times C$ & $1 x F, 3 x C$ & $1 \mathrm{x} E, 1 \mathrm{x} C$ & $\begin{array}{c}4 \times E, 1 \times C \\
2 \times D\end{array}$ & $\begin{array}{c}2 \mathrm{xE}, 1 \mathrm{xF} \\
6 \mathrm{x} \mathrm{C} 2\end{array}$ & $\begin{array}{c}\text { 1x C } \\
14 \times C 2\end{array}$ \\
\hline & C. perfr. PCR & neg. & $\begin{array}{l}4 \mathrm{x} \alpha, 1 \mathrm{x} \beta \\
4 \mathrm{x} i, 2 \mathrm{x} E\end{array}$ & $4 \mathrm{x} \alpha, 2 \mathrm{x} \beta_{2}$ & $2 \mathrm{x} \alpha, 2 \mathrm{x} \beta_{2}$ & $1 \mathrm{x} \alpha$ & $\begin{array}{c}13 \mathrm{x} \alpha \\
3 \mathrm{x} \beta_{2}, 2 \mathrm{x} \varepsilon\end{array}$ \\
\hline & $\begin{array}{l}\text { C. perfr. } \\
\text { ELISA }\end{array}$ & neg. & neg. & neg. & neg. & neg. & neg. \\
\hline \multirow{4}{*}{ 苜 } & BoNT MBA & 4x ABE CD & neg. & $\begin{array}{c}3 \times \mathrm{ABE} \\
2 \mathrm{x} C D\end{array}$ & neg. & neg. & $\begin{array}{l}3 \mathrm{x} A B E \\
2 x \mathrm{CD}\end{array}$ \\
\hline & C. bot. PCR & neg. & neg. & neg. & neg. & neg. & neg. \\
\hline & C. perfr. PCR & neg. & $1 \mathrm{x} \alpha$. & neg. & $1 \mathrm{x} \alpha$ & neg. & $\begin{array}{c}13 \mathrm{x} \alpha \\
3 \mathrm{x} \beta_{2}, 2 \mathrm{x} \varepsilon\end{array}$ \\
\hline & $\begin{array}{l}\text { C. perfr. } \\
\text { ELISA }\end{array}$ & neg. & neg. & neg. & neg. & neg. & neg. \\
\hline
\end{tabular}

Bei der Beurteilung der Ergebnisse war generell zu beachten, dass mit Hilfe der PCR lediglich der Nachweis eines vorhandenen Toxingens erbracht wurde, nicht aber die Exprimierung des entsprechenden Toxins. Während in nahezu allen Betrieben der Nachweis von toxinogenen $C$. botulinum und C. perfringens im Pansensaft von einigen Einzeltieren gelang, war der Nachweis von Toxin wesentlich seltener. Auffällig war die hohe Durchseuchung des Kontrollbetriebes KB 3, wo in allen untersuchten Tieren im Pansensaft das Toxingen für das C2-Toxin gefunden wurde und außerdem in fast allen Tieren vor allem 
das Gen für das C.-perfringens- $\alpha$-Toxin nachgewiesen wurde. Mit den bekannten Wirkungen des C2-Toxins ließ sich hier vielleicht der Beginn eines chronischen Krankheitsgeschehens feststellen. Der Nachweis von BoNT per Maus-Bioassay gelang in den Fallbetrieben FB 1 und FB 2 und dem Kontrollbetrieb KB 3. Bemerkenswert war die Abnahme der BoNT/C-positiven Proben nach einer erneuten Anzucht in RCM. Die Zahl der BoNT/C-positiven Proben wurde nach unten korrigiert.

Die Ergebnisse des ELISAs zur Ermittlung der Antikörpertiter gegen BoNT/A, B, C und D waren nur bedingt aussagekräftig. Da bereits die Fallbetriebe FB 1 und FB 3 den Impfstoff Covexin ${ }^{\circledR}$ mit Erfolg einsetzten, wären Wechselwirkungen mit Antikörpern gegen C. tetani oder C. novyi, aufgrund der genetischen Übereinstimmung mit C. botulinum (Collins und East, 1998), in diesem Test möglich.

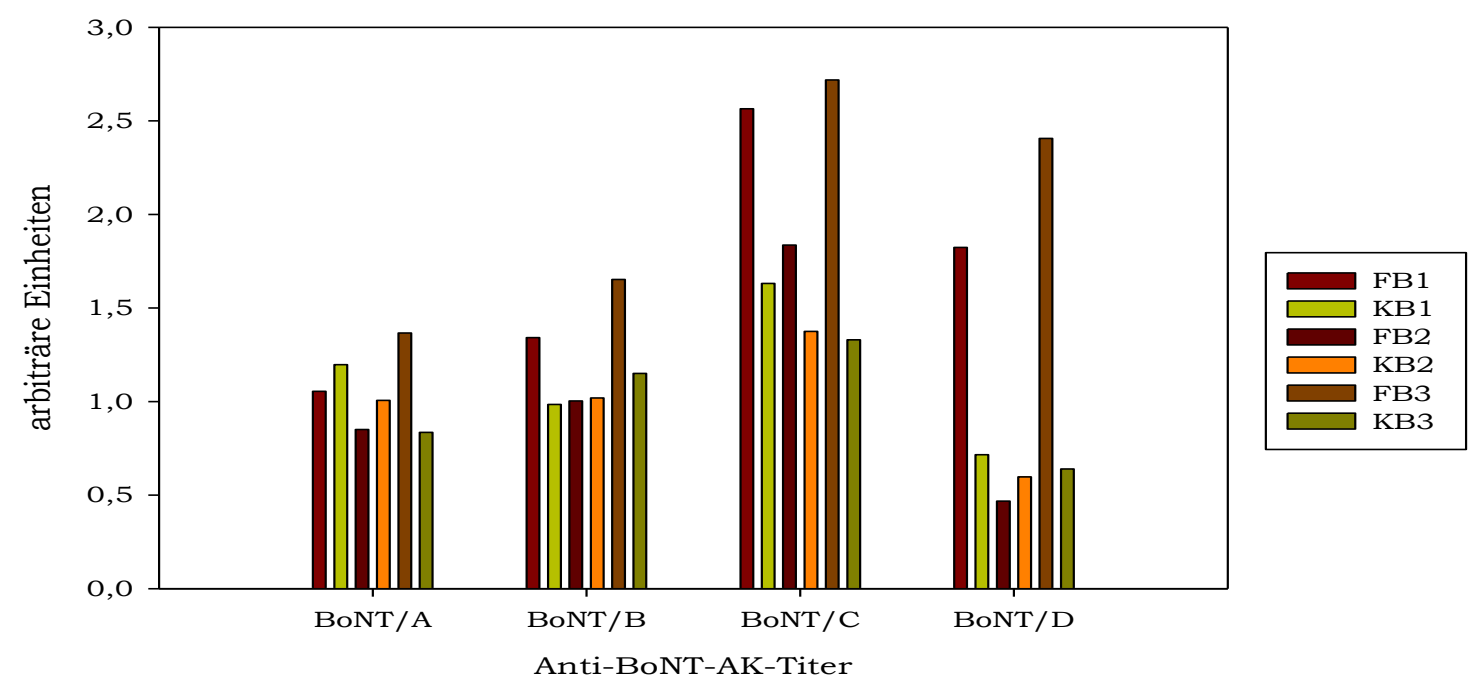

Abb. 8: Anti-BoNT-Titer der Fall- und Kontrollbetriebe

Sowohl in den Fall- als auch in den Kontrollbetrieben konnten Antikörper gegen verschiedene BoNTe nachgewiesen werden, allerdings in unterschiedlichem Maße. Grundsätzlich waren im Durchschnitt in den Fallbetrieben FB 1 und FB 3 höherer Antikörper detektiert worden als im Fallbetrieb FB 2. Für BoNT/A bewegten sich die Antikörperlevel aller untersuchten Tiere in allen Betrieben auf ca. dem gleichen Niveau. Für BoNT/B wichen die Antikörpertiter von FB 1 und FB 3 gegenüber den anderen Betrieben nach oben ab, was sich bei der Detektion von Antikörpern gegen BoNT/C und D wesentlich verstärkte. 
In den Kontrollbeständen wurden für die verschiedenen Antikörper ähnliche Titer ermittelt. Insgesamt war aber aufgrund der geringen Datenmenge keine Ermittlung von signifikanten Unterschieden möglich.

\subsubsection{Toxikologische Untersuchung von Organmaterial}

Der letzte Abschnitt des Fragebogens umfasste die toxikologische Untersuchung von Organmaterial. Dazu wurden getöteten oder verendeten Tieren Proben von Pansensaft, Leber, Dünndarm und Kot bzw. Enddarm entnommen und der Nachweis auf BoNT direkt und indirekt im Maus-Bioassay und C.-perfringens-Toxine im Toxin-ELISA geführt.

Die Entschädigungssumme für ein Rind im Rahmen einer meldepflichtigen Tierseuche beträgt $3068 €$ (TierSG, 2010). Da im Rahmen dieser Pilotstudie nur begrenzte finanzielle Mittel zur Verfügung standen und die begutachteten Tiere nicht in einem Maße erkrankt waren, die eine Tötung und pathologische Untersuchung zwingend erforderlich machten, wurde nur auf Organmaterial oder Ergebnisse von bereits getöteten Tieren bzw. auf Pansensaft und Kot von weiteren Bestandstieren zurückgegriffen.

Tab. 53: Toxikologische Untersuchung von Organmaterial

\begin{tabular}{|c|c|c|c|c|c|c|c|}
\hline & & FB 1 & KB 1 & FB 2 & KB 2 & FB 3 & KB 3 \\
\hline \multirow{3}{*}{  } & BoNT direkt & neg. & neg. & neg. & neg. & neg. & neg. \\
\hline & BoNT indirekt & $3 x \mathrm{C}, 1 \mathrm{x} \mathrm{E}$ & neg. & $2 \mathrm{x} \mathrm{C}, 1 \mathrm{xE}$ & neg. & neg. & neg. \\
\hline & C.perfr.Toxin & neg. & neg. & neg. & neg. & $1 \mathrm{x} \alpha$ & $2 \mathrm{x} \alpha, 1 \mathrm{x} \beta$ \\
\hline \multirow{3}{*}{ 崩 } & BoNT direkt & / & neg. & / & / & neg. & / \\
\hline & BoNT indirekt & / & neg. & / & / & neg. & / \\
\hline & C.perfr.Toxin & neg. & neg. & neg. & neg. & neg. & neg. \\
\hline \multirow{3}{*}{  } & BoNT direkt & neg. & neg. & / & neg. & neg. & / \\
\hline & BoNT indirekt & neg. & neg. & / & neg. & neg. & / \\
\hline & C.perfr.Toxin & neg. & neg. & / & neg. & neg. & neg. \\
\hline \multirow{3}{*}{ 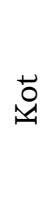 } & BoNT direkt & neg. & neg. & $2 \mathrm{xABE}$ & $1 \mathrm{x} A B D$ & neg. & $\begin{array}{c}1 \times \mathrm{ABE} \\
2 \times \mathrm{CD}\end{array}$ \\
\hline & BoNT indirekt & neg. & neg. & neg. & neg. & neg. & neg. \\
\hline & C.perfr.Toxin & neg. & neg. & neg. & $1 \times \alpha$ & $1 \mathrm{x} \alpha$ & neg. \\
\hline
\end{tabular}


Der Pansensaft wurde in drei Tieren des Fallbetriebes FB 1 positiv auf BoNT/C und in einem Tier zusätzlich auf BoNT/E getestet. Im Fallbetrieb FB 2 enthielten zwei Pansensaftproben BoNT/C und die des dritten Tieres BoNT/E. Die Pansensaftproben der entsprechenden Kontrollbetriebe waren dagegen negativ. In den Betrieben FB 3 und KB 3 wurde C.-perfringens-Toxin nachgewiesen. Während die Organproben aus Leber und Enddarm für alle Tiere negativ getestet wurden, konnten in den Kotproben der Tiere aus den Fallbetrieben FB 2 und FB 3 und den Kontrollbetrieben KB 2 und KB 3 BoNTe und/oder C.-perfringens-Toxin nachgewiesen werden. 


\section{Diskussion}

\subsection{Entwicklung neuer PCR-Methoden}

Ziel dieser Arbeit war es, durch eine Pilotstudie betriebsspezifische Risikofaktoren für das Krankheitsbild des viszeralen Botulismus zu identifizieren und spezifische Symptome am Einzeltier oder in der Herdengesamtheit zu ermitteln. Da C. botulinum und dessen Toxine als ausschlaggebender Faktor für die massive Beeinträchtigung der Herdengesundheit vermutet wurden (Böhnel et al., 2001b), spielten der Nachweis von C. botulinum und BoNT im Futter und im Tier eine wesentliche Rolle in der Ursachenforschung. Während für den Toxinnachweis der Maus-Bioassay als Goldstandard vorgeschrieben war und sich auch keine alternativen Methoden hinsichtlich ihrer Sensitivität finden ließen, standen für den Nachweis des anaeroben Bakteriums neben dem indirekten Toxinnachweis durch den Maus-Bioassay zahlreiche PCR- und Real-time-PCR-Methoden zur Verfügung, wie sie bereits unter Abschnitt 2.2.1.2 erläutert wurden. Jede dieser Methoden barg für die im Rahmen dieser Studie durchgeführten Untersuchungen allerdings Schwachstellen, die sich unterschiedlich stark auf die Spezifität und Sensitivität der Methoden auswirkten. Zum einen haben die Probenmatrix und die darin enthaltenen Stoffe einen großen Einfluss auf ein korrektes PCR-Ergebnis. Matrix und Inhaltsstoffe können sowohl bei der DNA-Isolierung als auch in der PCR selbst als Inhibitoren wirken oder durch Kreuzreaktionen mit den Primern zu falschen Resultaten führen (Bessetti, 2007). Da ein großes öffentliches Interesse an der Vermeidung von humanen Botulismusfällen besteht, war die Mehrzahl der bisher veröffentlichten Methoden nur für den Nachweis von C. botulinum in Lebensmitteln oder in menschlichem Untersuchungsmaterial geeignet (z. B. Fach et al., 1995; Lindström et al., 2001; Nevas et al., 2002; Akbulut et al., 2004; Yoon et al., 2005; De Medici et al., 2009; Fach et al., 2009; Kirchner et al., 2010). Nur wenige PCR-Methoden wurden für die Untersuchung von tierischem Material entwickelt (Dahlenborg et al., 2001; Dahlenborg et al., 2003; Skarin et al., 2010; Vidal et al., 2011; Anniballi et al., 2011). Aufgrund der tierspezifischen Unterschiede, besonders in den Verdauungsabläufen, konnten aber auch diese Methoden nicht übergreifend angewandt werden, da Interferenzen zu erwarten waren. Zum anderen ist die Entwicklung geeigneter Primer immer nur anhand bekannter Sequenzen 
möglich. Den sieben Toxintypen werden inzwischen insgesamt ca. dreißig Subtypen zugordnet (siehe Tab. 4), die sich in ihrer Nukleotidsequenz signifikant unterscheiden. Da die Zahl der Subtypen fortlaufend steigt, ist es nahezu unmöglich, universale Primer zu entwickeln. Hinzu kommt die Problematik der Mosaiktoxine, die bisher nur bei den C.-botulinum-Typen C und D bekannt ist, und die aufgrund eines einseitigen Studiendesigns zu einer falschen Zuordnung der detektierten Toxingene führen kann.

Für die Fall-Kontroll-Studie wurden im Vorfeld PCR-Methoden optimiert oder neu entwickelt, um die bis dahin bekannten Sequenzen in den Versuchen erfassen zu können. Mit Hilfe von im Vorfeld selbst entwickelten Sequenzierungsprimern gelang es, das BoNT/A-Gen eines bivalenten C.-botulinum-Ba-Stammes zu charakterisieren, das durch die Multiplex-PCR von De Medici et al. (2009) nicht erfasst wurde. Daraufhin wurde das entsprechende A-Primerpaar gegen eines der Sequenzierungsprimerpaare (bontA-6) ausgetauscht und die Methode für den Einsatz in Rinderkot optimiert und negativ auf Kreuzreaktionen mit verschiedenen Referenzstämmen getestet. Als die Methode im Rahmen der Routinediagnostik mit Feldproben überprüft wurde, konnten Kreuzreaktionen mit anaeroben Darmpathogenen, die durch eine Sequenzierung der entsprechenden PCRProdukte als enterotoxischer E. coli (ETEC), enteroaggregativer E. coli (EAEC) und Salmonella ssp. typhimurium identifiziert wurden, festgestellt werden. Dabei entstanden die Kreuzreaktionen nicht durch Reaktionen der zusammengehörenden Primerpaare, sondern vorwiegend durch die Kombination der unveränderten B- und F-Primer, die zu den eigentlichen Toxingenen nahezu identisch große Fragmente generierten. Diese Kreuzreaktionen konnten ausgeschlossen werden, wenn im Fall eines positiven Ergebnisses die Amplifikation als Einzelansatz (Singleplex) wiederholt wurde. Durch die vorherige Anwendung als Multiplex-PCR mit der Möglichkeit zur parallelen Detektion der Toxingene von BoNT/A, B, E und F ergab sich trotzdem eine enorme Zeit- und Materialersparnis.

Das Prinzip der parallelen Detektion aufgrund verschiedener PCR-Produktgrößen wurde auf die Detektion der Toxingene von BoNT/C und D übertragen. Die bisher verwendeten Labormethoden beruhten auf den Einzelnachweisen für das BoNT/C1- (Gessler und Böhnel, 2006), das BoNT/D-Gen (Takeshi et al., 1996) oder auch das ntnh-Gen mittels qPCR (Raphael und Andreadis, 
2007). Die genannten Verfahren brachten für den Nachweis der C.-botulinumTypen $\mathrm{C}$ und $\mathrm{D}$ in eigenen Untersuchungen keine befriedigenden Ergebnisse. Durch eine gezielte Platzierung neuer Primer und verschiedene Produktgrößen sollte gleichzeitig eine Unterscheidung zwischen den Mosaikformen der Toxine möglich sein. Durch die entwickelten Primer war es möglich, kultivierte C.-botulinum-Stämme eindeutig nach ihren Subtypen zu unterscheiden. Sowohl Kreuzreaktionen mit Referenzstämmen als auch mit Feldproben konnten ausgeschlossen werden. Die Sensitivität konnte im Vergleich zu den vorher eingesetzten Methoden nicht verbessert werden, wo sie ebenfalls $10^{5} \mathrm{KbE} / \mathrm{mL}$ betrug. Parallel wurde mit Hilfe einer selbst entwickelten qPCR und durch Sequenzierungsarbeiten von Sterthoff (2011) eine unterschiedlich hohe Präsenz der Toxingene für die BoNT-Typen $\mathrm{C}$ und $\mathrm{D}$ in einer C.-botulinum-Typ-C- oder -D-Kultur nachgewiesen, so dass die Menge der detektierbaren Toxingene nicht äquivalent zur eingesetzten Bakterienzahl war und sich so diese hohen Nachweisgrenzen erklären ließen. Im Hinblick auf das hohe Probenaufkommen im Rahmen dieser Studie zeigte die entwickelte CD-Multiplex-PCR aber wesentliche Vorteile bezüglich Material und Arbeitsaufwand.

\subsection{Datenmaterial}

In der Fall-Kontroll-Studie wurden die Daten zum größten Teil retrospektiv in einem Fragebogen erfasst. In den Bereichen der Tiergesundheit, der toxikologischen Untersuchung von Organmaterial und des Futtermittels konnte deshalb teilweise nur auf unvollständige Daten zurückgegriffen werden. Damit war die Interpretation des gesamten Datensatzes nur unter Vorbehalt und auf Grundlage der vorliegenden Daten möglich. Durch die insgesamt geringe Anzahl an untersuchten Betrieben und einem unzureichenden Matching-Verhältnis von 1:1, das sich durch die minimale Zahl an möglichen Kontrollen ergab, war eine umfassende statistische Auswertung mit dem Herausstellen signifikanter Unterschiede zwischen Fall- und Kontrollbetrieben bzw. eindeutiger Risikofaktoren und charakteristischer Merkmale für das Krankheitsbild des viszeralen Botulismus nicht möglich. Im Rahmen dieser Pilotstudie konnten aber Trends und Hinweise aufgezeigt werden, denen in umfassenderen Studien explizit nachgegangen werden kann. 
Da die in dieser Studie erstellten Fragebögen jeweils durch Dr. Schwagerick in Zusammenarbeit mit den jeweiligen Hofverantwortlichen bzw. Hoftierärzten ausgefüllt wurden, ließen sich zufällige Fehler bei der Interpretation von Fragen oder dem eigentlichen Ausfüllen ausschließen.

Im Zuge der teilweise seit mehreren Jahren bestehenden Betreuung der Fallbetriebe durch den RGD MV wurden bereits Maßnahmen zur Verbesserung der Tiergesundheit, wie z. B. Impfungen eingeleitet, die Erfolge zeigten und so die Interpretation der Datensätze erschwerten.

Um das Krankheitsbild des viszeralen Botulismus von anderen Erkrankungen abzugrenzen, um Einflussfaktoren zu identifizieren oder um Schnittpunkte mit Stoffwechselstörungen zu ermitteln, war eine Gegenüberstellung nahezu aller erhobenen Daten vonnöten. Die verschiedenen Parameter aus Haltung, Leistung, Fütterung und Tiergesundheit konnten sich sehr stark wechselseitig beeinflussen, was die Identifizierung der auslösenden Faktoren schwierig gestaltete. Um die Übersicht dieser komplexen Thematik zu wahren, wurde die Gliederung weitgehend entsprechend des Fragebogens beibehalten und die Einflussnahme der erhobenen Parameter aufeinander geprüft.

\subsection{Betriebsstrukturen}

Die Flächen der teilnehmenden Betriebe der Fall-Kontroll-Studie erstreckten sich auf dem Gebiet des Bundeslandes Mecklenburg-Vorpommern und waren über zwei Landkreise verteilt. Durch die jeweils räumliche Nähe eines Fallund des dazugehörigen Kontrollbetriebes zueinander konnten regionale Schwankungen bezüglich der Bodenbeschaffenheit oder saisonale Einflüsse ausgeschlossen bzw. berücksichtigt werden und führten zu keiner Verfälschung der Untersuchungsergebnisse. Außerdem besaßen die ausgewählten Betriebspaare ähnliche Bestandsgrößen und betrieben fast ausschließlich Milchviehhaltung. Alle Betriebe nutzten zu 95-100 \% die Rasse HolsteinFriesian (HF) als Milchvieh. Damit war eine Vergleichbarkeit der vorhandenen Datensätze gegeben (Kreienbrock und Schach, 2005).

Bei dem HF-Milchvieh handelt es sich um eine Hochleistungsrasse. Es ist nachgewiesen, dass die Milchleistung negativ mit der Tiergesundheit korre- 
liert. Es gilt, je höher die Leistung der Tiere liegt, umso störanfälliger sind diese (Simianer, 1988; Lotthammer, 1999; Rossow, 2004). Schon allein aufgrund ihrer Hochleistungstiere besaßen die ausgewählten Betriebe so eine erhöhte Disposition gegenüber Gesundheits- und Fruchtbarkeitsstörungen, die teilweise auch in den Kontrollbetrieben sichtbar wurde und auf die in der Diskussion der Leistungsdaten und der Bestandsdiagnostik näher eingegangen werden wird.

Im Fallbetrieb FB 2 wurden zusätzlich zum Milchvieh 52 Mutterkühe gehalten, im Fallbetrieb FB 3 zusätzlich 500 Schweine. Da es sich bei den Mutterkühen nicht um andere Tiere im eigentlichen Sinne handelt, ist nicht von einer Risikoerhöhung bezüglich des Auftretens von viszeralem Botulismus zu rechnen, diese Tiere könnten aber als Ausscheider von C. botulinum auftreten. In seiner akuten Verlaufsform wurde Botulismus bei Pferden, Eseln, Schafen und Ziegen, Schweinen, verschiedenen Arten von Vögeln und Hunden beschrieben (Kriek und Odendaal, 1994). Zwar gelten Omnivore allgemein als sehr resistent gegenüber BoNTen, es gelang allerdings der Nachweis von BoNT/C und C2-Toxin aus den Lebern gesunder Schweine, so dass diese durchaus als Träger und Ausscheider von C. botulinum in Betracht kommen (Yamakawa et al., 1992). Auch die Verbreitung von C. botulinum im Verdauungstrakt von Geflügel und infolgedessen Toxikoinfektionen sind in der Literatur mehrfach beschrieben worden (Schettler, 1979; Trampel et al., 2005), hatten in den untersuchten Betrieben allerdings keine Relevanz. Da im Rahmen dieser Studie die Haltung weiterer Tierarten allerdings nur erfasst wurde und an diesen Tieren keine weiterführenden Untersuchungen hinsichtlich des Vorhandenseins von C. botulinum durchgeführt wurden, war eine Bewertung der Relevanz zum Auftreten des Krankheitsbildes kaum möglich. Erschwerend kam hinzu, dass lediglich in einem der drei Fallbetriebe Schweine gehalten wurden. Es ist also davon auszugehen, dass neben der Haltung weiterer Tierarten hauptsächlich andere Aspekte zum Erscheinungsbild des viszeralen Botulismus beitrugen.

Der überwiegende Teil der Milchkühe wurde ausschließlich im Stall gehalten, nur im Fallbetrieb FB 2 und dem dazugehörigen Kontrollbetrieb KB 2 fand eine gemischte Haltung mit Beweidung statt. Diese kombinierte Haltung stellt in einem gesunden Bestand kein Risiko dar, in einem erkrankten Bestand besteht durch das Ausscheiden von C. botulinum oder dessen Sporen allerdings die Gefahr einer erneuten Infektion (Notermans et al., 1981; Dahlenborg et al., 
2003). Da proteolytische C.-botulinum-Stämme in der Lage sind, Gras als Substrat zu nutzen und BoNTe zu bilden (Notermans et al., 1979b), könnte auf diese Weise die Aufnahme sehr geringer Mengen von BoNTen über einen längeren Zeitraum zu einem chronischen Krankheitsgeschehen beitragen. Wie auch in anderen betroffenen Betrieben fand zusätzlich eine Überflutung des Grünlandes im Frühjahr statt, die augenscheinlich zum Auftreten der Herdenerkrankung beitrug (Schwagerick, 2004a). Die Reproduktion erfolgte in den untersuchten Betrieben ausschließlich über die eigene Nachzucht. So konnte einerseits ein Eintrag der Erkrankung in den Betrieb ausgeschlossen werden, andererseits konnten so mögliche Anpassungsschwierigkeiten und ein abweichender Immunstatus zugekaufter Tiere vernachlässigt werden (Schwagerick, 2004a).

Die jährlichen Remontierungsraten und die Nutzungsdauer bewegten sich bei allen untersuchten Betrieben im durchschnittlichen Bereich. Die hohe Remontierungsrate im Fallbetrieb FB 3 mit über $40 \%$ ließe sich durch die zahlreichen Abgänge durch Krankheit bzw. mangelnde Leistung erklären. Betrachtete man allerdings nicht die absoluten Zahlen, sondern den prozentualen Anteil der Abgänge wegen Krankheit oder mangelnder Leistung an der Gesamtheit der zu melkenden Kühe ergab sich ein einheitlicheres Bild, bei dem die Raten der Betriebspaare, mit Ausnahme von FB1 und KB 1, wo der Kontrollbetrieb eine zehn Prozentpunkte höhere Abgangsrate als sein Vergleichsbetrieb aufwies, nur unwesentlich voneinander abwichen. Die hohe Abgangsrate aufgrund mangelnder Leistung im Kontrollbetrieb KB 3 schien lediglich einem Abgang durch Krankheit zuvorzukommen, so dass sich in diesen Daten kein Hinweis speziell auf das Vorkommen von viszeralem Botulismus finden ließ.

Tab. 54: prozentuale Abgänge an Kühen bezogen auf den Gesamtbestand melkender Kühe

\begin{tabular}{ccccccc}
\hline [\%] & FB 1 & KB 1 & FB 2 & KB 2 & FB 3 & KB 3 \\
\hline Abgänge Kühe gesamt & 23,08 & 32,60 & 33,66 & 28,50 & 40,26 & 42,11 \\
Krankheit & 15,38 & 28,53 & 26,83 & 15,00 & 31,02 & 4,91 \\
mangelnde Leistung & 7,69 & 4,08 & 6,83 & 13,50 & 9,24 & 37,19 \\
\hline
\end{tabular}

Ähnlich verhielt es sich mit den Totgeburtenraten. Bis auf den Fallbetrieb FB 1 bewegten sich alle Angaben zwischen 6 und $9 \%$, so dass die Totgeburtenrate im Rahmen dieser Studie nicht als Anhaltspunkt für das 
Krankheitsbild des viszeralen Botulismus dienen konnte. Schwieriger ließ sich dagegen die Kälbermortalität bewerten. Der Fallbetrieb FB 1 wies ähnlich niedrige Werte auf wie die Kontrollbetriebe $\mathrm{KB} 2$ und $\mathrm{KB}$ 3, während der Kontrollbetrieb KB 1 augenscheinlich eher zu den Fallbetrieben FB 2 und FB 3 passte. Aufgrund der geringen Datenmenge war es schwierig, Ausreißer zu identifizieren. Unter der Annahme, dass es sich bei dem Fallbetrieb FB 1 und dem dazugehörigen Kontrollbetrieb KB 1 um Ausreißer handelte, wäre eine erhöhte Kälbersterblichkeit als Indiz für das Krankheitsgeschehen des viszeralen Botulismus denkbar. Weitaus eindeutiger zeigten sich dagegen die Unterschiede in den Zwischenkalbezeiten zwischen Fall- und Kontrollbetrieben. Eine durchschnittliche Zwischenkalbezeit von 424 Tagen in den Fallbetrieben stand in der Kontrollgruppe einer durchschnittlichen Zwischenkalbezeit von 400 Tagen gegenüber, wodurch sich eindeutige Fruchtbarkeitsstörungen in den Fallbetrieben ausmachen ließen. Diese können im komplexen Organismus des Rindes zum einen durch Energiemangel oder nicht optimale Rohfasergehalte im Futter entstehen (Lotthammer, 1999; Obermayr, 2005), zum anderen schränken aber auch C.-botulinum-Toxine durch die Beeinflussung der glatten Muskulatur und der Blutversorgung die Fruchtbarkeit einer Kuh ein (Shiokawa et al., 2000; Shiota et al., 2003; Böhnel und Gessler, 2005). Aus diesem Grund musste die Zwischenkalbezeit der Bestandsdiagnostik gegenüber gestellt werden.

\subsection{Milchleistung}

Anhand der monatlichen Milchleistungsprüfung ließen sich sehr gut aktuelle Veränderungen der Milchleistung der Betriebe erfassen und ermöglichten eine erste Einschätzung des Leistungsstatus des Betriebes und des Fütterungsmanagements. Sie gab allerdings keine Auskunft über die Gesundheit des Einzeltieres. Durch die Erhebung der jeweiligen Medianwerte war eine Berücksichtigung der Ausreißer in der geringen Datenmenge möglich.

Stellte man den aktuellen Melkdurchschnitt dem Durchschnittswert der letzten 12 Monate gegenüber, zeigte sich ein gleichbleibendes Niveau der Werte innerhalb der jeweiligen Gruppe, aber auch zwischen der Fall- und der Kontrollgruppe. Bei der Einzelbetrachtung der Minimalwerte zur durch- 
schnittlichen Melkleistung verzeichneten die Fallbetriebe geringere Verluste als die Kontrollbetriebe. Im Fall einer Fehlversorgung mit Nährstoffen und Energie würde sich zunächst die Zusammensetzung der Milchinhaltsstoffe ändern, und erst später die Gesamtmelkleistung. Dies legte einen Zusammenhang mit den erhöhten Zellzahlen und einem Krankheitsgeschehen nahe.

Die Zellzahlen aller betrachteten Betriebe lagen über 100.000 Zellen/mL, die als Grenzwert zur Unterscheidung zwischen gesunden und kranken Tieren herangezogen wurden. Auch wenn nur in dem Fallbetrieb FB 1 und in dem Kontrollbetrieb KB 3 die ermittelten maximalen Zellzahlen den gesetzlichen Grenzwert von 400.000 Zellen/mL überschritten und damit die Verkehrsfähigkeit der Milchen nicht mehr gegeben war, so waren bereits die erhöhten Zellzahlen zwischen 200.000 und 300.000 Zellen/mL ein Indiz für eine subklinische Mastitis, sowohl in den Fall- als auch in den Kontrollbetrieben. Euterentzündungen können sowohl Ausgangspunkt als auch Folgeerscheinung anderer Erkrankungen sein. Durch Euterentzündungen und Klauenerkrankungen kann im ersten Laktationsdrittel die Milchleistung sinken und der Grundstein für ein Fettmobilisationssyndrom gelegt werden. Andererseits kann auch erst eine aus Energiemangel resultierende Fettmobilisation über eine Ketose und Fettleber zu Infektionen des Euters führen. Da es sich um einen Problemkreis aus hoher Milchleistung, Gesundheit und Fruchtbarkeit handelt, gestaltet sich die Suche nach dem auslösenden Faktor schwierig.

Die aktuellen Milchfettgehalte waren in beiden Gruppen niedriger als im Landesdurchschnitt des LKV Mecklenburg-Vorpommern. Betrachtete man dazu die durchschnittlichen, die Maximal- und Minimalwerte, war festzustellen, dass die Fettgehalte in den Fallbetrieben wesentlich stärkeren Schwankungen ausgesetzt waren als in den Kontrollbetrieben, deren Milchfettgehalte auf einem gleichbleibend geringen Niveau angesiedelt waren. Dies deutete auf Mängel in der Futter- und Energieversorgung hin. In den Fallbetrieben war ein starker Abfall des Fettgehaltes zum Jahresdurchschnitt ersichtlich, der auf Pansenazidosen hinwies. Ein Abfall der Werte kann durch geringe Rohfasergehalte der Grassilage verursacht werden. Während die Rohfasergehalte der Grassilage aber nur im Fallbetrieb FB 2 zu niedrig waren, hatten in den Kontrollbetrieben gleich zwei Betriebe zu niedrige Rohfasergehalte in ihren Grassilagen, ein Umstand der sich auch in den niedrigen 
Fettgehalten der Betriebe widerspiegelte. Damit erklärte sich allerdings nicht die Tatsache, dass trotzdem in allen Fallbetrieben der Fettgehalt der Milch stark sank, so dass zusätzlich von einer Verschiebung der Bakterienflora (Dysbiose) ausgegangen werden musste.

Dies hatte keinen Einfluss auf die Milcheiweißgehalte, die in den Fallbetrieben aktuell nur geringfügig von den Durchschnittswerten abwichen, während in den Kontrollbetrieben mit Ausnahme von KB 3 gleichbleibende Werte vorlagen, die insgesamt im Rahmen lagen. Im KB 3 zeigte sich ein rapider Abfall des Milcheiweißgehaltes, der in Verbindung mit den hohen Zellzahlen dieser Milch bei gleichbleibender Milchleistung den Verdacht der dortigen Mitarbeiter erhärtete, dass in diesem Betrieb die Tiergesundheit beeinträchtigt war. Der mangelnde Rohfasergehalt der Grassilage hätte aber bei sinkendem Milchfettgehalt gleichzeitig zu einer höheren Milchleistung und zu einem höheren Eiweißgehalt führen müssen (Obermayr, 2005), die aber konstant blieben bzw. ebenfalls sanken.

Das Heranziehen der Fett/Eiweiß-Quotienten (FEQ) zur Beurteilung der Stoffwechselsituation der Herde schien im Rahmen dieser Studie kein geeignetes Instrument zur Bestandsdiagnostik zu sein, da anhand dieser Werte nur im Kontrollbetrieb KB 2 von einer Unterversorgung mit strukturreichem Grundfutter und einer darauf folgenden azidotischen Schieflage des Stoffwechsels ausgegangen werden konnte. In den drei Fallbetrieben verringerte sich der FEQ jeweils leicht und lag im optimalen Bereich, während sich der FEQ im KB 3 aktuell erhöhte und erste Hinweise auf einen steigenden Abbau von Körperfett geben könnte, der die Gefahr einer Ketose erhöhen würde. Diese Werte deckten sich zumeist nicht mit den Ergebnissen der Bestandsdiagnostik, die in den Tieren aller Betriebe Azidosen, Ketosen oder Ketoazidosen zeigten.

Bessere Rückschlüsse auf das Fütterungsmanagement ließen sich aus der Kombination von Eiweiß- und Harnstoffgehalt ziehen, die auch fast immer besser mit den Ergebnissen der Bestandsdiagnostik übereinstimmten, so dass man in den meisten Betrieben von einem aussagekräftigeren Instrument zur Steuerung der Fütterung und zur Kontrolle des Stoffwechsels auf Basis der MLP-Daten sprechen konnte. Lediglich im Fallbetrieb FB 1, dem anhand der Beurteilung von Eiweiß- und Harnstoffgehalt der Milch ein optimales 
Fütterungsmanagement zugesprochen wurde, deckte sich dieses Ergebnis nicht mit den Daten der Bestandsdiagnostik, nach denen von einer Energieunterversorgung und infolge dessen einem Fettmobilisationssyndrom ausgegangen werden musste. In den Betrieben FB 2 und KB 1 stimmten die Aussagen beider Beurteilungsverfahren überein, da die erhöhten Harnstoffwerte eng mit der ketotischen Stoffwechsellage korrelierten. Eine Leberbelastung wurde anhand der Aktivität der Leberenzyme deutlich, besonders in den Betrieben FB 3 und KB 3. Erhöhte HST-Werte werden parallel dazu auch mit Fruchtbarkeitsstörungen in Verbindung gebracht, die sich allerdings nur in den Fallbetrieben anhand der erhöhten Zwischenkalbezeiten belegen ließen und deshalb als Faktor dafür ausschieden. Allerdings führte der mittlere bis hohe Rohproteinüberschuss und der bei den Betrieben FB 3 und KB 3 nachgewiesene Energiemangel im Futter zu einer Stoffwechselschieflage, die die Immunkompetenz der betroffenen Tiere verringern und das Auftreten weiterer Erkrankungen begünstigen könnte. Gerade bei einem Überangebot an proteinreicher Nahrung und einem alkalischen $\mathrm{pH}-$ Wert im Darmlumen wirken schon geringste Mengen BoNT negativ auf die Darmmotilität, wodurch eine massive Vermehrung von Clostridien mit Toxinbildung begünstigt wird. Aber auch der entgegengesetzte Weg wäre denkbar. Das Mykotoxin Trypacidin aus Aspergillus fumigatus wirkt antiprotozoisch und zytotoxisch (Richter et al., 2009). In größeren Konzentrationen kann es in das empfindliche Gleichgewicht des Pansens eingreifen und zum Absterben von Infusorien und Pansenbakterien führen. Zum einen haben diese einen entscheidenden Anteil an der Bereitstellung von Energie für die Milchsynthese, zum anderen ist eine gesunde Pansenflora und -fauna auch in der Lage, geringe Mengen an BoNTen zu inaktivieren. Bei einer Schädigung könnten diese ungehindert in den Dünndarm gelangen und dort in den Blutkreislauf aufgenommen werden. Auf diese Weise könnten sich auch additive Effekte der Toxinwirkung ergeben.

Schon bei Betrachtung der Betriebsstruktur und der Daten der Milchleistungsprüfung zeigte sich, dass sowohl in den Fall- als auch in den Kontrollbetrieben Stoffwechselschieflagen existierten. In jedem dieser Betriebe waren deshalb auch ähnliche Werte bei den jährlichen Verlustdaten und der Fertilität zu erwarten. Es zeigte sich aber, dass bezüglich der Kälbermortalität und der Zwischenkalbezeit erhebliche Unterschiede zwischen den Fall- und Kontrollbetrieben deutlich wurden. Die Ursachen hierfür mussten in der 
Fütterung, der Herdengesundheit und einer mikrobiologischen und toxikologischen Betrachtung gesucht werden.

\subsection{Bewertung des Grünlandes}

Parallel zur Beschreibung des viszeralen Botulismus als neuer Erscheinungsform des Botulismus und in Folge der Schwierigkeiten C. botulinum und die BoNTe nachzuweisen, wurde nach weiteren Erklärungen für das neue Krankheitsbild in Rinderbeständen gesucht. Unter dem Begriff „Faktorenerkrankung Milchviehherde“ wird als Hauptursache der Einsatz von Grassilage minderer Qualität angenommen, durch den es zu massiven Einflüssen auf den Stoffwechsel mit vielfältigen Erscheinungsformen kommt (Seyboldt, 2010). Hauptsächlich betroffen sind Färsen in der Frühlaktation nach der Verfütterung von Grassilagen mit reduzierten Reineiweißgehalten, die überwiegend aus dem 1. Schnitt stammten (Scholtz et al., 2010; Eicken et al., 2010). Dem widersprechen Untersuchungen der Landesforschungsanstalten Nordrhein-Westfalen und Mecklenburg-Vorpommern, die dem 1. Schnitt das höchste Qualitätspotential zusprechen. Der richtige Erntezeitpunkt ist aber entscheidend für eine maximale Energiekonzentration im Aufwuchs (Jänicke et al., 2009; Berendonk, 2011).

Um den Einfluss von qualitativ minderwertiger Silage beurteilen zu können, wurden im Rahmen dieser Studie das zur Silageproduktion genutzte Grünland, der Silierungsvorgang selbst und die Zusammensetzung der verfütterten Silage geprüft.

Als besonders kritisch mussten die Überschwemmungen des Grünlandes betrachtet werden, da bereits im Vorfeld von Überflutungen im Zusammenhang mit chronisch erkrankten Betrieben berichtet wurde (Schwagerick, 2004a). Die regel- oder unregelmäßigen Überschwemmungen in den Fallbetrieben FB 1 und FB 2 wurden zuletzt für den März 2010 dokumentiert. Dadurch ließen sich die Überschwemmungen in einen direkten Kontext zum Auftreten des Krankheitsgeschehens bringen. C. botulinum wurde in marinen Sedimenten und Flussböden nachgewiesen (Segner et al., 1971; Yamakawa und Nakamura, 1992; Sandler et al., 1993; Williamson et al., 1999; Böhnel et al., 2003) und kann neben den Überschwemmungen auch mit dem Aushub der 
Entwässerungsgräben auf das Grünland verbreitet werden (Smith und Turner, 1989; Böhnel, 1999). Wird das Grünland wie im Fallbetrieb FB 2 als Weideland genutzt, ist eine direkte Aufnahme von $C$. botulinum und seinen Sporen durch das Rind möglich. Bei der Nutzung als Schnittland kann kontaminiertes Gras in das Siliergut gelangen und findet dort unter den anaeroben Verhältnissen optimale Wachstumsbedingungen, falls der $\mathrm{pH}$-Wert nicht schnell genug und ausreichend abgesenkt wird (Raatjes und Smelt, 1979). Über die Sporen als Dauerform der Clostridien wäre ein Eintrag in das Tier auch ohne eine weitere Vermehrung in der Silage möglich. Aus diesem Grund wurde das Auftreten von Überschwemmungen des Grünlandes im Rahmen dieser Studie als wahrscheinlicher Risikofaktor für das Entstehen oder das Verstärken des Krankheitsgeschehens des viszeralen Botulismus identifiziert.

Auch eine starke Maulwurfbelastung stand in dem Verdacht, das Auftreten von chronischem Botulismus zu begünstigen und begründete sich durch den aufgeworfenen Boden, der potenziell Clostridien oder deren Sporen enthalten könnte. Außerdem tragen sie zu einer zusätzlichen Verschmutzung des Schnittgutes bei einer durchschnittlichen Schnitthöhe von 5-7 cm bei. Dies ließ sich durch den mittleren Verschmutzungsgrad der Ernte im Fallbetrieb FB 1 bestätigen. Da eine starke Maulwurfbelastung ansonsten aber nur für den Kontrollbetrieb KB 2 angegeben wurde, war nicht von einem relevanten Einflussfaktor auf die Herdengesundheit in den ausgewählten Betrieben auszugehen. Das gleiche galt für die Beweidung des Grünlandes mit Schafen, die nur im Fallbetrieb FB 2 praktiziert wurde. Schafe und Ziegen gelten als ebenso empfindlich gegenüber Botulismus, können aber aus genau diesem Grund auch als Ausscheider Grünland kontaminieren (Kriek und Odendaal, 1994). Auch für Paratuberkulose ist eine wechselseitige Erregerübertragung möglich (Whittington et al., 2004) und spielte im FB 2 die wahrscheinlich größere Rolle.

Der Einfluss der Wildtierbelastung im Rahmen dieser Studie war fraglich. In der Literatur wurden bereits Fälle von akutem Botulismus bei Wildtieren beschrieben (Chamberlain und Thomas, 1995; Böhnel, 2005). Deshalb sind höchstwahrscheinlich sowohl die wiederkäuenden Wildtiere als auch das Schwarzwild wie ihre domestizierten Artgenossen in der Lage, Clostridien im Verdauungstrakt anzureichern und auszuscheiden (Yamakawa et al., 1992; Kriek und Odendaal, 1994; Dahlenborg et al., 2001). Wildvögel mit einer 
natürlichen Resistenz gegen BoNTe werden für die geografische Verbreitung von C. botulinum verantwortlich gemacht (Ohishi et al., 1979). Gelangt sporenhaltiger Kot auf die Grünflächen, sind eine Infektion der Tiere und eine Kontamination des Siliergutes denkbar. Diese These wurde durch den, während den Voruntersuchungen erfolgten, Nachweis von $C$. perfringens in einem toten Star untermauert. Da nur der Kontrollbetrieb KB 3 keine Probleme mit einem starken Wildtierbesatz hatte und alle anderen Betriebe einen Besatz mit verschiedenen Arten von Wildtieren angaben, war im Rahmen dieser Pilotstudie auch aufgrund der räumlichen Nähe zwischen den zusammengehörenden Betrieben nicht davon auszugehenden, dass das Krankheitsgeschehen durch den Wildtierbesatz verursacht wurde.

Zur Bewirtschaftung des Grünlandes und zur Erzielung optimaler Ernteerträge gehörte auch eine entsprechende Düngung des Bodens. Diese erfolgte mineralisch, organisch oder in einer Kombination aus beiden Verfahren. Die organische Düngung bestand entweder aus Gülle oder aus Kot und führte nicht verstoffwechselte Nährstoffe wieder dem Boden zu. Der Einsatz von eigener Gülle war in Betrieben mit gesundem Bestand unproblematisch. In den Betrieben FB 2 und FB 3, in denen allerdings Tiere erkrankt waren oder wahrscheinlich Krankheitserreger ohne klinische Symptome ausgeschieden wurden, drohte eine Verschleppung der Krankheit. Dies kann im Fall von gebildeten Dauerformen der Krankheitserreger eine jahrelange Verseuchung und immer wiederkehrende Rekontamination des Bodens und der Tiere bedeuten (Notermans et al., 1981; Dahlenborg et al., 2003). Bei der Herstellung von Silage aus kontaminiertem Grünland kann durch die anaeroben Bedingungen des Silierprozesses das Wachstum von pathogenen Clostridien bei zu langsamem oder nicht ausreichendem Absenken des pH-Wertes begünstigt werden. Die Verfütterung von Geflügeleinstreu ist in Deutschland verboten, da in diesem Bereich eine Übertragung von Krankheitserregern bekannt ist (Smart et al., 1987; Jean et al., 1995; Wobeser et al., 1997). Eine Düngung der Grünflächen mit Einstreu wird aber gestattet, wodurch das Risiko einer Infektion erhalten bleibt. Es wurde von akutem bzw. chronischem Botulismus in Rinderbeständen berichtet, bei denen die Düngung der Weideflächen mit Hühnergülle schon Jahre zurücklag (Impfbericht, 2008). Dadurch wurde die Problematik der Sporenbildung und Überlebensfähigkeit von $C$. botulinum besonders deutlich. Durch die Vermeidung der Düngung mit Fremdgülle konnte 
ein zusätzlicher Eintrag von pathogenen Organismen und Schadstoffen in den Bestand vermieden werden.

Theoretisch hätte die Düngung des Grünlandes mit Biokompost oder Biogasoutput im Rahmen dieser Studie völlig unberücksichtigt bleiben können, da alle teilnehmenden Betriebe angaben, nicht mit diesen Materialien zu düngen. Durch Aufzeichnungen des RGD MV war aber bekannt, dass im Fallbetrieb FB 3 noch vor zwei Jahren Gärreste einer Biogasanlage, die Schlachtabfälle verwendete, auf die Felder verbracht wurden. Ähnlich wie bei der Düngung mit Geflügelgülle wäre eine Kontamination des Grün- oder Ackerlandes mit C. botulinum und anderen Clostridien über Jahre hinweg möglich. Untersuchungen von Bagge et al. (2010) und Olsen und Larsen (1987) zeigten widersprüchliche Ergebnisse bzgl. der Sporenreduktion während des Herstellungsprozesses von Biogas. Der Verdacht, dass dieser Umstand ebenso wie die Überschwemmungen von Grünland als Risikofaktor zum Auftreten von viszeralem Botulismus beitragen würde, erhärtete sich durch das Auftreten in dem Fallbetrieb. Er müsste allerdings durch eine umfassendere Fall-KontrollStudie statistisch abgesichert und zusätzlich durch Untersuchungen von Biogasgärresten bestätigt werden. Die Frage nach der Düngung mit Biokompost oder Biogasgärresten muss bei der Weiterverwendung des Fragebogens neu formuliert werden, um auch zurückliegende Ereignisse zu erfassen. Die Dokumentation wäre aufgrund der Düngeverordnung gewährleistet.

\subsection{Bewertung der Silierung}

Im Fallbetrieb FB 2 und im Kontrollbetrieb KB 3 wurde neben einem Fahrsilo auch Ballensilage hergestellt. Da im Fallbetrieb FB 2 sehr nasses Feldgrass verwendet wurde, war aufgrund des kleinen Volumens eines Ballens eine Verdünnung der Gärsäuren möglich, die über eine langsamere Absenkung des pH-Wertes die Vermehrung von Clostridien begünstigte. Neben einer geringeren Durchmischung entsteht in den Rundballen durch die größeren Häcksellängen eine geringere Verdichtung, so dass ein größerer Gasaustausch möglich ist (ADDCON, 2010). Im Kontrollbetrieb KB 3 traten im Siliergut keine Auffälligkeiten auf. Im Zusammenhang mit der extremen Verschlechterung der 
Milchleistung, die eine Bestandserkrankung nahelegten, wäre ein Einfluss der Herstellungsart denkbar, sollte aber nicht überbewertet werden, da die weiteren Fallbetriebe FB 1 und FB 3 nur Silage aus Fahrsilo verfütterten. Eine Verschiebung der Bakterienflora im Ballensilo konnte nicht bewertet werden, da die Futtermittelproben aus dem Fahrsilo entnommen wurden. Die empfohlene Schnitthöhe wurde nur vom Kontrollbetrieb KB 2 unterschritten, hatte aber keine Auswirkungen auf den Verschmutzungsgrad der Silage. Die Fahrsilos wurden durchgängig auf einer Bodenplatte errichtet, besaßen aber größtenteils keine Seitenwände. Dies könnte, wie die Silage des Fallbetriebes FB 3 zeigte, Schwierigkeiten bei der Verdichtung fördern. Andererseits können Silowände durch den Luft- und Feuchtigkeitszutritt an diesen Stellen das Wachstum von Schimmelpilzen begünstigen (Richter et al., 2009). Die Entnahme der benötigten Silage per Blockschneider stellte die geeignetste Methode zur Verhinderung von Sauerstoffeintritt, Nacherwärmung und Schimmelbildung dar und wurde in zwei der drei Fallbetriebe und dem Kontrollbetrieb KB 3 angewandt, während in den anderen Betrieben eine Fräse oder eine Greifzange zum Einsatz kamen. Dies führte zu der Frage, ob der Einsatz eines Blockschneiders die Entstehung des Krankheitsbildes des viszeralen Botulismus begünstigen könnte. Da Blockschneider aber in keinem Zusammenhang mit einer Kontamination durch C. botulinum und dessen Sporen gebracht werden konnten, handelte es sich aller Wahrscheinlichkeit nach um eine zufällige Übereinstimmung. Die verdorbene Anschnittfläche der Grassilage des KB 3 war Folge des zu geringen Vorschubs. Obwohl die Silage hinter dem Anschnitt ohne sensorische Beanstandung war, wäre ein Eintrag von Schimmelpilzen und damit auch -toxinen in das Futter möglich, wie sich in den erhöhten Keimzahlen für Schimmelpilze und Hefen in dieser Silage bei einer gleichzeitig geringen Anzahl von Milchsäurebakterien als Konkurrenzflora zeigte.

Durch die mittlere Verschmutzung in den Fallbetrieben FB 1 und FB 3 konnte es zu einem Eintrag von Schadorganismen kommen. Diese Verschmutzung ließ sich allerdings nicht von der Schnitthöhe ableiten, sondern resultierte im Fallbetrieb FB 1 wahrscheinlich aus den Überschwemmungen und der starken Maulwurfbelastung. Im Fallbetrieb FB 3 könnte evtl. starker Niederschlag für die Verschmutzung verantwortlich sein. In der Grassilage des FB 1 zeigte sich die Verschmutzung im stark erhöhten Rohaschegehalt. Der 
schlechteren Qualität des Ausgangsmaterials wurde mit dem Einsatz von chemischen Siliermitteln begegnet. Da diese von der DLG nur für schwer silierbares Futter empfohlen werden, war auch in den Betrieben FB 2 und KB 2 von einer minderen Qualität des Siliergutes auszugehen. Trotz des Einsatzes von chemischen Hilfsmitteln im Fallbetrieb FB 1 wurden nach Öffnung des Silos Verfärbungen und ein ranziger Geruch, der bei dem Vorhandensein von Buttersäurebildnern wie den Clostridien hervorgerufen wird, festgestellt. Dieses Ergebnis konnte nicht in einen Zusammenhang mit der Schnitthöhe und der Häcksellänge gebracht werden, da diese im vorgegebenen Rahmen lagen. Durch die Silierdauer von 12 Wochen war davon auszugehen, dass das Silo durchsiliert war. Die Abweichungen schienen allein der höheren Verschmutzung und dem damit verbundenen Eintrag von schädlichen Mikroorganismen geschuldet zu sein. Den sensorischen Abweichungen und der möglichen Vermehrung von Clostridien widersprach die Ermittlung von nur $40 \mathrm{KbE} / \mathrm{mL}$ an anaeroben Sporenbildern in der LUFAUntersuchung, denen eine ausreichende Konkurrenzflora in Form von Milchsäurebakterien und ein sehr niedriger $\mathrm{pH}$-Wert gegenüber standen. Kritisch musste die sehr kurze Silierdauer im FB 3 betrachtet werden. Durch die frühzeitige Öffnung, die ungenügende Verdichtung und infolge dessen die aerobe Instabilität kam es zur Nacherwärmung der Silage. Die ermittelten Keimzahlen für diese Silage lagen allerdings im Normbereich und ließen keinen Verderb erkennen. Der sehr hohe TM-Gehalt der Silage war in der sehr kurzen Silierdauer und der damit fehlenden Fermentation begründet. Durch den Zusatz von biologischen Silierhilfsmitteln gelang trotzdem ein rasches Absenken des pH-Wertes innerhalb einer Woche. Zusätzlich wäre die Verwendung eines Blockschneiders zu empfehlen, um die Nacherwärmung im Silo zu verringern.

\subsection{Futtermitteluntersuchung der Grassilage}

Die Qualität der Silierung, der entstandenen Silage und ihr Einfluss auf die Milchleistung und die Herdengesundheit konnten durch die Bestimmung verschiedener Laborparameter bewertet werden. Alle chemischen und physikalischen Parameter wurden in Abhängigkeit von der ermittelten Trockensubstanz der jeweiligen Grassilage erhoben. Der Richtwert von 30-40 \% TM 
wurde nur vom Fallbetrieb FB 3 durch die geringe Silierdauer und die damit fehlende Fermentation deutlich überschritten. Mit Hilfe der biologischen Silierhilfsmittel wurde innerhalb dieser kurzen Zeit jedoch ein tiefer $\mathrm{pH}$-Wert erreicht, der die Vermehrung von Clostridien hemmte. Nur der pH-Wert der Silage des Kontrollbetriebes KB 2 lag mit 4,6 über dem von der DLG geforderten Wert, begünstigte aber laut den Ergebnissen der mikrobiologischen Untersuchung nicht das Wachstum von anaeroben Sporenbildern. Deren potentieller Eintrag über die Verschmutzung des Siliergutes drückte sich in den Fallbetrieben FB 1 durch einen überhöhten und in FB 3 durch einen leicht erhöhten Rohascheanteil aus. Im Kontrollbetrieb KB 3 wurde ebenfalls ein leicht erhöhter Rohaschegehalt aber ohne auffällige Verschmutzung bestimmt, so dass auch ein erhöhter Kräuter- oder Kleeanteil als Ursache in Betracht kam. Die Menge der anaeroben Sporenbildner bewegte sich in den Betrieben mit erhöhten Rohaschegehalten aber nur zwischen 5 und $40 \mathrm{KbE} / \mathrm{mL}$ und damit unterhalb des Grenzwertes.

Die Rohproteingehalte der Silagen lagen mit Ausnahme vom Kontrollbetrieb KB 1 im optimalen Bereich. Der niedrigere Wert in der Silage von KB 1 spiegelte sich aber nicht in den MLP-Daten des Betriebes wider, da sich bei der Betrachtung von Eiweiß- und Harnstoffwerten in der Milch eine gute Versorgung der Tiere ergab, die durch die Zufütterung von Kraftfutter erreicht werden konnte. Eher sollte in den Betrieben FB 2, KB 1 und KB 2 aufgrund der erhöhten Harnstoffwerte und damit des Hinweises auf Proteinüberschuss von einer Überdosierung des zusätzlichen Futters ausgegangen werden.

Aufgrund der optimalen Rohfasergehalte in den Silagen der Fallbetriebe FB 1 und FB 2 und dem erhöhten Wert im FB 3 hätten die Milchfettgehalte nicht in dem Maße absinken dürfen, wie dies in den Fallbetrieben geschah. Auch im Kontrollbetrieb KB 1 wäre ein höherer Milchfettgehalt zu erwarten gewesen. In den Kontrollbetrieben KB 2 und KB 3 passen die erniedrigten Rohfasergehalte zu den geringen Milchfettwerten. Den niedrigen Rohfasergehalten der Silage versuchte man mit einer zusätzlichen Fütterung von Stroh entgegen zu wirken.

Der Milcheiweißgehalt ist stark von der energetischen Versorgung abhängig (Lotthammer, 1999). Sinkt die Energieaufnahme gemessen an der Leistung können aufgrund des unvollständigen Körperfettabbaus Ketosen entstehen. 
Die Energiegehalte der Silagen befanden sich in den Fallbetrieben im optimalen Bereich. Aufgrund der MLP-Daten des Fallbetriebs FB 3 musste dort eher von einem Futtermangel bzw. einer Beeinträchtigung der Verdauungstätigkeit als von einem Energiemangel ausgegangen werden. Der niedrige NELWert der Silage aus dem Kontrollbetrieb KB 1 wurde anscheinend durch Ergänzungsfutter ausgeglichen, da laut MLP-Daten nur die Tendenz zum Proteinüberhang bestand. Trotz des hohen Energiegehaltes und des optimalen Rohproteingehaltes in der Silage des Kontrollbetriebes KB 3 litten die Tiere dort laut MLP unter erheblichem Protein- und Energiemangel bzw. Futtermangel. Da sowohl in den Betrieben FB 3 als auch KB 3 keine baulichen Einschränkungen zu finden waren, die die Futteraufnahme behindern konnten, musste in diesen Betrieben von einer massiven Einschränkung der Verdauungstätigkeit ausgegangen werden.

Die Bestimmung des Ammoniakanteils am Gesamtstickstoff wurde einer Bestimmung der Reineiweißgehalte der Silagen vorgezogen. $\mathrm{Da}$ die Reineiweißfraktion neben dem verdaulichen Protein auch geschädigtes, unverdauliches Protein beinhalten kann und das nach dieser Einteilung nicht erfasste Nichtreineiweiß in Form verschiedener Amine sowohl gut verwertbar als auch schädlich sein kann, lässt dieser Parameter keine Aussage über die Qualität der Silage zu. Im Gegensatz dazu werden mit der Bestimmung des Ammoniakanteils mikrobielle Abbauvorgänge und die damit verbundene Minderung des verfügbaren Proteins erfasst. Der Ammoniakanteil am Gesamtstickstoff war in den Silagen des Betriebspaares FB 1 und KB 1 zu hoch, und im Kontrollbetrieb höher als im Fallbetrieb, wodurch ein verstärkter mikrobieller Proteinabbau nachgewiesen wurde. Dafür sprachen auch die zu hohe aerobe Keimzahl in der Silage des KB 1 und die erhöhte Hefenzahl in der Silage des FB 1. Die hohe aerobe Keimzahl und hohe Zahl an Hefen im FB 2 hätte im Vergleich ebenfalls zu einer verstärkten Proteolyse in der Silage führen müssen. In fast allen Silagen bot sich den Verderbniserregern mit den Milchsäurebakterien eine ausreichend große Konkurrenzflora. Nur im Kontrollbetrieb KB 3 waren ähnliche Mengen an Verderbniserregern und Milchsäurebakterien zu finden, was zu einer Verschiebung des Gärsäuremusters führen könnte, die sich aber im sensorischen Test nicht belegen ließ. Auch die Anzahl der Schimmelpilze war ausschließlich in den Kontrollbetrieben KB 1 und KB 3 erhöht, was sich in einer erhöhten Ochratoxinbelastung der 
KB-1-Silage zeigte. Die Mykotoxingehalte in den Silagen aus FB 1 und KB 2 lagen innerhalb der Grenzwerte, auch wenn diese im Fallbetrieb FB 1 nicht mit der Anzahl der bestimmten Schimmelpilze korrelierte. Obwohl nur in drei Betrieben die Mykotoxingehalte bewertet werden konnten, war kaum von einer alleinigen Verursachung des untersuchten Krankheitsbildes auszugehen, da die nachgewiesenen Schimmelpilzgehalte in den verbleibenden Silagen gleich groß oder niedriger als die Gehalte der Silage des Kontrollbetriebes KB 2 waren und deshalb auch von gleichartigen Mykotoxinkonzentrationen im Futter ausgegangen werden konnte. Durch ruminale Mikroorganismen könnten die Toxine außerdem in unterschiedlichem Maße metabolisiert und inaktiviert werden (Hult et al., 1976; Kiessling et al., 1984; Battacone et al., 2010).

Aufgrund der Diskrepanzen zwischen MLP-Daten und der chemisch-physikalischen und mykotoxikologischen Silagebewertung konnte kein Zusammenhang zwischen der Nährstoffversorgung aus evtl. minderwertigen Grassilagen und dem Krankheitsbild des viszeralen Botulismus bzw. der „Faktorenerkrankung Milchviehherde“ hergestellt werden. Dies bestätigte sich auch in Untersuchungen zu erniedrigten Reineiweißgehalten in Grassilagen (Gresner, 2011; Theermann, 2011). Da die Silagen der Kontrollbetriebe eine vergleichbare oder schlechtere Qualität als die Silagen der Fallbetriebe aufwiesen, hätte sich im Falle eines wesentlichen Zusammenhangs mit der Entstehung des viszeralen Botulismus bzw. der Multifaktorenerkrankung auch in der Kontrollgruppe das Krankheitsbild ausbilden müssen.

Alle Grassilagen wurden im Maus-Bioassay negativ auf BoNTe getestet. Moeller et al. (2003) beschrieben, dass in Rindern trotz klinischer Symptome nach der Applikation von BoNT/C kein Toxin im Kot per Maus-Bioassay nachzuweisen war. Die Ergebnisse aus diesen in-vivo-Versuchen beschreiben sehr gut die Probleme der labordiagnostischen Bestätigung von Botulismus. Da die Sensitivität der Mäuse als natürliche Nachweisgrenze des Testes fungiert, Holstein-Friesian-Rinder aber besonders gegenüber BoNT/C zehn Mal sensitiver als die Maus reagieren (Moeller et al., 2003) und in der Mehrzahl der klinischen Botulismusfälle beim Rind keine Typbestimmung möglich war (Lindström et al., 2010), konnte eine Kontamination der Grassilagen mit BoNTen nicht ausgeschlossen werden. 


\subsection{Bewertung weiterer Futtermittel}

Neben der untersuchten Grassilage wurden in allen Betrieben auch Maissilage und Kraftfutter verfüttert, bei denen keine sensorischen Abweichungen festgestellt wurden. Da aber auch in sensorisch einwandfreien Grassilagen erhöhte Keim- und Mykotoxingehalte bestimmt wurden, wäre in Folgestudien eine eingehendere Betrachtung der Maissilage und des Kraftfutters sinnvoll, da in Maissilage bereits BoNT/B nachgewiesen wurde (Yeruham et al., 2003). Nur die Fallbetriebe verfütterten Eigengetreide in Form von Mais oder Weizen. Durch die Düngung der Felder mit der Gülle erkrankter Tiere wie in den Fallbetrieben FB 2 und FB 3 und wahrscheinlich schon durch die Verwendung derselben Maschinen im Stall und bei der Ernte im Fallbetrieb FB1 kann ein Kreislauf der Kontamination und Anreicherung geschaffen worden sein, wie er von Notermans et al. (1981) und Dahlenborg et al. (2003) beschrieben wurde. Eine mikrobiologische und toxikologische Untersuchung des verwendeten Eigengetreides sollte in Folgestudien und zur Ursachenforschung in den Fallbetrieben unbedingt geschehen. Im Rahmen dieser Pilotstudie wurde die Verfütterung von Eigengetreide als wahrscheinlicher Risikofaktor identifiziert.

\subsection{Wasserversorgung}

Die Wasserversorgung im Stall und auf der Weide konnte kaum zur Einschätzung eines möglichen Risikopotentials zum Auftreten von viszeralem Botulismus herangezogen werden. Lediglich die Kontrollbetriebe verwendeten Brunnenwasser, das durch infektiöse Tierkadaver hätte verseucht werden können. Ein Fallbetrieb nutzte auf der Weide Oberflächenwasser, das prinzipiell durch den Kot von Vögeln kontaminiert sein konnte. Da aber in den übrigen Fallbetrieben auf der Weide und im Stall nur Leitungswasser zur Versorgung der Tiere genutzt wurde, war in diesen Betrieben eine Infektion durch die Wasserversorgung auszuschließen. 


\subsection{Tiergesundheit im Bestand}

Das Krankheitsspektrum in Beständen mit Hochleistungsrindern ist weitgehend einheitlich und findet seine Ursache oft in Stoffwechselstörungen (Fürll, 2002), denen man meist durch ein entsprechendes Fütterungsmanagement oder eine kurzfristige Therapie begegnen kann. Anhaltspunkte liefern zum einen die monatlichen MLP-Daten und zum anderen die Bestandsdiagnostik mit Hilfe von Indikatortieren. Da die tierärztliche Betreuung in den ausgewählten Betrieben im wöchentlichen Rhythmus stattfand, konnten Imbalancen theoretisch sehr schnell bemerkt und korrigiert werden.

Die Laborwerte der ausgewählten Indikatortiere gestalteten sich überwiegend einheitlich und zeigten die für Hochleistungsrinder typischen Störungen, die aus Energie- oder Rohfasermangel resultierten (Lotthammer, 1999). Anhand der erhöhten Leberenzymwerte wurde die Belastung der Leber aller Tiere deutlich, die durch die Fermentationsstörungen im Pansen und die daraus resultierenden Pansenazidosen hervorgerufen wurde. Aus den Daten der Einzeltiere ließen sich Rückschlüsse auf die Stoffwechselsituation der gesamten Herde ziehen. Dabei stimmten im Fallbetrieb FB 1 die erhaltenen Erkenntnisse nicht mit den aus den MLP-Daten gezogenen Rückschlüssen überein. Die Laborparameter deuteten auf einen Energiemangel in der Frühlaktation hin, der in einem Fettmobilisationssyndrom resultierte. Aufgrund der Werte konnte keine Gebärparesegefährdung festgestellt werden. Ein Vitamin-B12Mangel war nicht ersichtlich. Im Fallbetrieb FB 2 konnte anhand der Laborparameter die Pansenazidose bestätigt werden, während durch die hohe Kaliumausscheidung und eine geringe NSBA die alkalische Stoffwechselsituation zu einem erhöhten Risiko für Gebärparese und Labmagenverlagerung führte. Der Vitamin-B12-Spiegel im Serum war während der Trockensteher- und der Hochlaktationsphase zu niedrig. Im Fallbetrieb FB 3 deutete sich anhand der Werte ebenfalls ein Fettmobilisationssyndrom an, das aber noch nicht zu ketotischen Zuständen führte. Während der I. und der II. Phase zeigte sich ein Vitamin-B12-Mangel, ebenfalls im Kontrollbetrieb KB 2. Bei allen drei Kontrollbetrieben wurde anhand der Pansen-pH-Werte ebenfalls eine Pansenazidose diagnostiziert. In den Betrieben KB 2 und KB 3 ließ sich anhand der verschiedenen Laborparameter zusätzlich ein Fettmobilisationssyndrom diagnostizieren. Ein Vitamin-B12-Mangel herrschte in den Betrieben KB 1 und KB 3 während der Hochlaktation und konnte in allen Tieren auch 
durch eine gestörte Pansenfunktion hervorgerufen worden sein. Außerdem führte die erhöhte Kaliumausscheidung im Kontrollbetrieb KB 2 zu einer Erhöhung der Gebärparesegefährdung.

$\mathrm{Da}$ in allen Beständen die Bewertung der Bestandsdiagnostik auf verschiedene Mangelerscheinungen hindeutete, die allesamt zu Entzündungen von Gebärmutter, Euter und Klauen führen konnten, diese aber nicht in allen Betrieben gleichartig auftraten, musste ein weiterer Faktor maßgeblich an der Entstehung der Bestandserkrankungen beteiligt sein. Dies galt in besonderem Maße für die verlängerten Zwischenkalbezeiten. Durch die Definition eindeutiger klinischer Symptome und deren Prävalenz konnte das Krankheitsbild des viszeralen Botulismus abgegrenzt werden.

Schon der Klauenpflegezustand ließ eine grobe Einteilung in Fall- und Kontrollbetriebe zu. Obwohl ihm in besonderem Maße eine Indikatorfunktion für Stoffwechselstörungen zugeschrieben wird (Lotthammer, 1999; Rossow, 2004; Fürll, 2005), konnte die ermittelte Herdengesundheit keine Erklärung für die gegensätzlichen Klauenpflegezustände in den Fallbetrieben FB1 und FB 2 gegenüber den Kontrollbetrieben liefern. Die anzeigepflichtigen Erkrankungen BHV-1, BVD/MD und Salmonellose wurden nicht nachgewiesen und konnten so als Ursache für plötzliche Todesfälle, Fruchtbarkeitsstörungen, Gelenksund Euterentzündungen oder zentralnervöse Störungen ausgeschlossen werden. Die meldepflichtige Paratuberkulose wurde im Fallbetrieb FB 2 festgestellt. Sie kann in ihrem Erscheinungsbild mit den Symptomen des viszeralen Botulismus, Abmagerung und Milchleistungsrückgang, übereinstimmen. Da die Auswahl der Tiere für die klinische Untersuchung nur anhand der Botulismusverdachtssymptome Lähmungen, Reaktionsmangel und schlechtem Allgemeinzustand erfolgte und die untersuchten Tiere nicht an wässrigem Durchfall litten, konnte davon ausgegangen werden, dass diese Tiere zumindest nicht akut erkrankt waren und diese Erkrankung keinen Einfluss auf die Beurteilung der Symptomatik des viszeralen Botulismus hatte. Da bereits zwei der drei Fallbetriebe auf Empfehlung des RGD MV den Clostridien-Impfstoff Covexin ${ }^{\circledR}$ einsetzten, war zum Zeitpunkt der klinischen Untersuchung im Rahmen dieser Studie eine Verbesserung des allgemeinen Gesundheitszustandes der Herde möglich. Durch die frühzeitige Verwendung des Impfstoffes konnten aber auch Symptome, die durch andere Clostridiosen hervorgerufen werden, minimiert und vernachlässigt werden. 


\subsection{Klinisches Erscheinungsbild des viszeralen Botulismus}

Betrachtete man den Anteil der Tiere mit Botulismusverdachtssymptomen an der Zahl der begutachteten Tiere, so stellte sich ein gravierender Unterschied zwischen den Fall- und Kontrollbetrieben dar. Während es in den Kontrollbetrieben nur einen geringen prozentualen Anteil an botulismusverdächtigen Tieren gab, bewegte sich deren Anteil in den Fallbetrieben zwischen 17 und $50 \%$, was die Aussage der betreuenden Tierärzte bestätigte, dass es in den Fallbetrieben kaum gesunde Tiere geben würde. Im Kontrollbetrieb KB 3 betrug der Anteil an kranken Tieren 2,5 \% und lag damit etwas über dem durchschnittlichen Wert von 0,25 \% der beiden anderen Kontrollbetriebe.

Durch die Erhebung verschiedener Auffälligkeiten im Allgemeinzustand, der Verdauung, im systemischen und neuro-motorischen Bereich ließ sich anhand der Häufigkeit der auftretenden Symptome eine Falldefinition des viszeralen Botulismus ableiten.

Die Beurteilung des Habitus eignete sich als guter Parameter zum Erkennen des Krankheitsbildes des viszeralen Botulismus, da er nur in den Fallbetrieben bei sechs der neun begutachteten Tiere auffallend abwich. Auch der Ernährungszustand war bei sechs Tieren schlecht bis sehr schlecht, allerdings war dieses auch bei vier Tieren aus den Kontrollbetrieben der Fall und konnte auf viele Erkrankungen oder auf Stoffwechselstörungen, die durch die Bestandsdiagnostik sichtbar wurden, hindeuten. Die Beurteilung des Verhaltens eignete sich, da in den Fallbetrieben drei Tiere apathisch oder gedämpft reagierten, ein viertes nervös und reizbar, was trotz der Gegensätzlichkeit schon als Symptomatik des Botulismus beim Rind beschrieben wurde (Kriek und Odendaal, 1994). Ataxien wurden bei acht der neun Tiere in den Fallbetrieben beobachtet, in den Kontrollbetrieben aber nur bei einem Tier, so dass Ataxien ebenfalls als Anhaltspunkt in der Diagnostik des viszeralen Botulismus angesehen werden konnte. Ein ebenfalls aussagekräftiger Parameter, der sich bereits ohne eingehendere klinische Untersuchung erheben ließ, war die Beobachtung der untypischen Beinstellung, die in den Fallbetrieben bei sechs Tieren vorzufinden war, bei den Kontrolltieren dagegen bei keinem Tier. 
Abweichungen von der normalen Verdauungstätigkeit waren je nach Parameter unterschiedlich stark ausgeprägt. Der Kot war bei nur einem Tier der Fallbetriebe zu fest, in einem Kontrollbetrieb bei einem Tier zu wässrig. Ansonsten waren alle begutachteten Tiere ohne besondere Beobachtungen. Die deutlichsten Unterschiede zwischen den Fall- und Kontrollbetrieben im Bereich der Verdauung ließen sich bei der Beobachtung des Pansens ausmachen. In den Fallbetrieben lag bei zwei von neun Tieren eine Pansentympanie vor, bei weiteren fünf Tieren waren nur schwache Pansenkontraktionen auszukultieren, wohingegen in den Kontrollbetrieben insgesamt bei nur einem Tier eine Pansentympanie festzustellen war. Die schwachen Pansenkontraktionen deuteten auf eine beeinträchtigte nervale Steuerung des Verdauungstraktes hin. Da dies auch als Ursache für Pansen- und Darmtympanien eine Rolle spielt, ergab sich daraus bei sieben Tieren eine massive Störung des enterischen Nervensystems, die vielfältige Ursachen und Folgen haben konnte. Durch die Aufnahme von rohfaserarmen, aber stärkeund eiweißreichem Futter oder einer unangepassten Umstellung des Futters kann es zu Störungen der Pansenfunktion in Form von Azidosen oder erhöhter Gasbildung kommen, die in ihrer chronischen Form über eine verminderte Nahrungsaufnahme und daraus folgende Stoffwechselstörungen zu Entzündungen von Gebärmutter, Klauen und Euter führen können. Lähmungen des enterischen Nervensystems infolge einer Intoxikation bzw. Toxikoinfektion mit BoNTen führen ebenfalls zu Störungen der Pansenfunktion mit den beschriebenen Folgen. Da die Rohfasergehalte in den Silagen der Fallbetriebe optimal oder erhöht waren und zusätzlich Stroh als Rauhfutter ergänzt wurde, schied dies als alleinige Ursache der Funktionsstörungen von Pansen und Darm aus, besonders im Vergleich zu den Kontrollbetrieben, die schlechtere Rohfasergehalte in ihren Silagen erreichten und trotzdem geringere klinische Störungen der Verdauungsfunktion ihrer Tiere zu verzeichnen hatten. Diese Vermutung verstärkte sich bei der Betrachtung des Pansensaftes. Die geringe Zahl der Infusorien und deren verminderte Beweglichkeit beeinträchtigten die Pansenaktivität. Damit entfiel die bereits angesprochene effektive Metabolisierung und Detoxifizierung von Mykotoxinen (Hult et al., 1976; Kiessling et al., 1984; Battacone et al., 2010), so dass eine Verstärkung toxischer Effekte in bereits kranken Tieren möglich wäre. Gleichzeitig beeinflusst die Anwesenheit von Protozoen die Anzahl und Zusammensetzung der ruminalen Bakterien (Ozutsumi et al., 2005). Bestimmte Bakterien- 
populationen stimulieren wiederum verschiedene Komponenten des enteralen Immunsystems (Umesaki und Setoyama, 2000). Pansensaft mit Bakterien besitzt ein wesentlich größeres Degradierungspotential für BoNT/C als Pansensaft mit Protozoen und wenigen Bakterien (Allison et al., 1976). Außerdem wurde in Studien im Rahmen des Verbundprojektes Botulinom festgestellt, dass Protozoen durchaus zur Degradation von vegetativen Formen von C. sporogenes fähig waren, die Zahl der Sporen im gleichen Zeitraum aber nicht reduziert wurde. In BoNT/C-positiven Rindern wurde ein signifikant höherer Anteil der Protozoengattung Epidinium und Entodinium in Kot und Pansensaft festgestellt als in BoNT/C-negativen Rindern (Krüger und Schrödl, 2010). Diese Protozoen degradieren Bakterien und nutzen deren Abbauprodukte als Nährstoffe (Coleman und Hall, 1972). Besonders im Rahmen einer Pansenazidose entsteht eine Imbalance in Richtung von sulfatreduzierenden Bakterien, die Acetat, Propionat, Laktat, Butyrat und Ethanol verwerten (Gibson et al., 1993). Durch Clostridien, Bifidobakterien und Bacteroides fragilis entsteht beim Abbau von Mucin Sulfat, das wiederum durch die sulfatreduzierenden Bakterien zu toxischem, epithelschädigendem Schwefelwasserstoff umgewandelt wird (Shirazi et al., 2000) und es auf diese Weise zu einer erheblichen Beeinträchtigung der Verdauungsfunktion kommt. Im Fall der untersuchten Betriebe wurden in allen geprüften Pansensaftproben zu niedrige $\mathrm{pH}$-Werte gemessen, die auf Pansenazidosen schließen ließen. Durch die geringen Infusorienzahlen wurden evtl. mit dem Futter oder durch die Umwelt aufgenommene vegetative Formen von $C$. botulinum und anderen Clostridien nicht mehr degradiert, sondern konnten eine für das Rind schädigende Symbiose mit sulfatreduzierenden Bakterien eingehen. Die PCR-Ergebnisse der Pansensaftproben aus den zur Bestandsdiagnostik beprobten Tieren bestätigten das Vorhandensein von C. botulinum und C.perfringens im Pansensaft, die dort durchaus physiologisch bzw. in klinisch gesunden Tieren vorhanden sein können und die Bestandteile der Nahrungsaufnahme widerspiegeln. Die Häufung von enterotoxisch wirkenden C2-positiven Pansensaftproben des Kontrollbetriebes KB 3 führte dort wahrscheinlich zu den äußerlich kaum wahrnehmbaren gesundheitlichen Veränderungen, die von den Angestellten beschrieben wurden. Da durch die Induktion der Bildung neuer Mikrotubuli-Strukturen an der Zelloberfläche die Anhaftung von Clostridien begünstigt (Schwan et al., 2009) und durch die Porenbildung der Eintritt clostridialer Toxine forciert wird 
(Simpson, 1989; Barth et al., 2000), erscheint es plausibel, dass eine Darminfektion mit C2-bildenden Clostridien den Ausgangspunkt einer Toxikoinfektion mit $C$. botulinum bildet. In den Kontrollbetrieben KB 1 und KB 2 war trotz des positiven PCR-Nachweises davon auszugehen, dass im Magen-Darm-Kanal eine starke Konkurrenzflora das Auskeimen, die Vermehrung und damit auch die Toxinbildung unterdrückte. Dadurch wurde die Entstehung von viszeralem Botulismus verhindert.

Da eine Störung der Verdauungsfunktion neben einer Intoxikation sowohl Start- als auch Endpunkt eines Kreislaufes mit unzureichender Nahrungsaufnahme, daraus resultierenden Stoffwechselstörungen und Erkrankungen sein kann, sollte das klinische Erscheinungsbild einer Dysfunktion stets durch die Untersuchung einer Pansensaftprobe untermauert werden, da eine Gegenüberstellung von Tieren eines Kontrollbetriebes mit ähnlichem Betriebsmanagement in der Praxis nicht möglich ist.

Bei der Untersuchung auf systemische Erscheinungen war bei keinem der Tiere ein tröpfelnder Harnabsatz vorzufinden. Drei der Falltiere aus dem FB 1 wiesen gestaute Venen auf, aber ebenso drei Kontrolltiere aus dem KB 2, so dass es sich hier um kein spezifisches Symptom zu handeln schien. Das Gleiche galt für Ödeme, die bei keinem Tier zu finden waren. In den Fallbetrieben wurde bei vier Tieren eine auffällige Atmung festgestellt, in den Kontrollbetrieben bei einem Tier. Weiterhin wiesen acht von neun Falltieren Entzündungen an Klauen oder Gelenken auf, in den Kontrollbetrieben waren drei Tiere betroffen, alle aus dem KB 2. Zwar sind solche Anzeichen auch grundsätzlich ein Hinweis auf Stoffwechselstörungen und können als Mangelerscheinung auftreten (Lotthammer, 1999), da aber in allen beprobten Betrieben eine ähnliche Stoffwechselsituation vorlag, wurden die unterschiedlichen Resultate wahrscheinlich durch einen weiteren Faktor hervorgerufen. Ein ebenfalls aussagekräftiger Parameter schien auch die Atrophie der Glutäenmuskulatur zu sein. Sie war bei fünf Tieren in den Fallbetrieben, aber nur bei einem Tier in den Kontrollbetrieben vorzufinden. Eine auffällige Atmung, Entzündungen an Klauen und Gelenken und die Atrophie der Glutäenmuskulatur konnten durch deren Häufung in den Fallbetrieben als Symptome für den viszeralen Botulismus betrachtet werden. 
Der Untersuchung von neuro-motorischen Symptomen kam aufgrund der Wirkung der Botulinum-Toxine als Neurotoxine eine besondere Beachtung zu. Auch wenn in den Fallbetrieben nicht alle Tiere gleich stark von allen Symptomen betroffen waren, so war doch auffällig, dass es in den Kontrollbetrieben nur bei einem Tier zu einem Ausfall des Hautreflexes kam und nur in einem weiteren Tier die Lähmung von Ischiadikus und Obturatoris zu beobachten war. Alle anderen Kontrolltiere waren unverdächtig. Aus den Fallbetrieben fielen vier Tiere durch die fehlende Abwehrbewegung bei Manipulation des Kopfes auf, bei drei Tieren war Mydriasis bei Lichteinfall zu beobachten und bei vier Tieren fehlte der Lidreflex bei Berühren des Lides, bei zwei Tieren fehlte auch der Ohrreflex. Die letztgenannten Symptome waren vorwiegend bei den Tieren aus dem FB 3 zu sehen. Schluckbeschwerden, eingeschränkter Zungen-, Anal-, Haut und Klauenreflex, muköser Speichel oder eine hängende Unterlippe wurden in den Fallbetrieben in ein bis zwei Tieren beobachtet. Keines dieser Tiere entstammte dabei dem FB 2. Die Lähmung der Fibularismuskulatur war an einem Tier zu finden, während an fünf Tieren eine partielle Ischiadikuslähmung festgestellt werden konnte. Eines davon wies zusätzlich eine Obturatorislähmung auf, ein weiteres eine Radialislähmung. Fasst man diese Symptome zusammen, waren in den Fallbetrieben sechs Tiere von Lähmungserscheinungen betroffen, in den Kontrollbetrieben dagegen nur ein Tier, wodurch sich die neuro-motorische Beeinträchtigung der erkrankten Tiere aus den Fallbetrieben bestätigte und sich als gutes Diagnostikum anbot. Da betroffene Tiere unterschiedlich sensitiv reagieren und verschieden stark und schnell Symptome ausbilden (Moeller et al., 2003), ist im Falle einer Bestandserkrankung die Beurteilung von mehr als drei Tieren ratsam.

Zusätzlich zu den klinischen Untersuchungen von drei ausgewählten Tieren pro Bestand wurden deren Kotproben mikrobiologisch untersucht. In den Fallbetrieben wurden vier von neun Tieren positiv auf $C$. perfringens und fünf positiv auf $C$. botulinum getestet. Dabei waren nur zwei der Tiere gleichzeitig positiv für beide Spezies. Von den neun Tieren aus den Kontrollbetrieben waren zwei Tiere aus dem KB 2 gleichzeitig positiv für C. perfringens und C. botulinum. Diese beiden Tiere wiesen in der klinischen Untersuchung auch Lähmungserscheinungen und gestaute Venen, sowie Entzündungen an Klauen und Gelenken auf, so dass sich hier ein Zusammenhang mit dem 
klinischen Erscheinungsbild herstellen ließ. Zusätzlich wurden zwei Tiere aus dem FB 2, wo bereits die Paratuberkulose-Problematik bekannt war, positiv auf Mykobakterien bzw. säurefeste Stäbchen getestet, aber auch ein Tier aus dem FB 3. Im Fallbetrieb FB 3 war aber der PCR-Nachweis von Mycobacterium avium ssp. paratuberculosis negativ. Da der Habitus und der Ernährungszustand der ausgewählten Tiere aus dem Fallbetrieb FB 2 ohne besondere Beobachtung blieb, war davon auszugehen, dass diese Tiere nicht klinisch erkrankt waren. Die auftretenden Lähmungen von Ischiadikus und Radialis bei diesen Tieren bestätigten die Störung der neuro-motorischen Reizleitung und damit den Einfluss von BoNTen.

\subsection{Bewertung von Maus-Bioassay und PCR anhand der Bestandsdiagnostik}

Neben den klinisch untersuchten Tieren wurde auch den zur Bestandsdiagnostik beprobten Tieren jeweils eine Kotprobe entnommen. Der BoNTNachweis mit Hilfe des Maus-Bioassays zeigte für die Fallbetriebe FB 1 und FB 2 und den Kontrollbetrieb KB 3 eine Toxikation von jeweils vier bis fünf Tieren. Da die bereits diskutierte Sensitivität des Maus-Bioassays die Nachweisfähigkeit dieses Tests limitierte, musste auch aufgrund der klinischen Symptomatik von einer höheren Zahl BoNT-positiver Tiere ausgegangen werden. Diese Vermutung wurde durch ähnliche Erfahrungen von Wilson et al. (1995) bestätigt, wo erst aus einer Kultur heraus der Nachweis von BoNT/B gelang. Der mögliche Verlust des Toxingens und des Toxinbildungsvermögens durch Kultivierung erschwert bei dem C.-botulinumTypen C und D den Nachweis zusätzlich (Oguma, 1976).

Der PCR-Nachweis von C. botulinum und C. perfringens im Kot unterschied sich wesentlich von den Ergebnissen der untersuchten Pansensaftproben, was sich aber durchaus noch im physiologischen bzw. klinisch nicht relevanten Rahmen bewegen kann. Aus den Gelbildern war für den Pansensaft in der ABEF-Multiplex-PCR ein großes Spektrum zusätzlicher Banden erkennbar, die durch die Kombination nicht zusammen gehörender Primer mit unbekannten DNA-Sequenzen entstanden (eigene Untersuchungen). Die aufgrund der 
richtigen Fragmentgrößen als positiv beurteilten Proben wurden in einer Einzel-PCR erneut getestet und ggf. korrigiert.

Da außerdem verschiedene PCR-Inhibitoren aus dem Kot die Reaktion beeinträchtigen konnten und die Nachweisgrenze der ABEF-Multiplex-PCR bei $2 \times 10^{3} \mathrm{KbE} / \mathrm{mL}$ und die der CD-Multiplex-PCR bei ca. $10^{5} \mathrm{KbE} / \mathrm{mL}$ lag, während schon eine Sporenkonzentration von 100 Sporen/g zu einem messbaren Toxinsignal führt (Schrödl et al., 2007), war unter zusätzlicher Berücksichtigung der Sensitivität des Maus-Bioassays für das letztgenannte Ergebnis von einer wesentlich höheren Infektionsrate der Tiere mit C. botulinum auszugehen. Hinzu kommt die Erkenntnis aus der Entwicklung einer eigenen CD-Multiplex-Real-time-PCR (s. Anhang), dass auch in Reinkulturen die Nachweisgrenze bei zwei Stämmen des gleichen Toxintyps erheblich schwanken kann. Dies ließ den Schluss zu, dass bei den C.-botulinum-Typen C und D während der Kultivierung ein ungleichmäßiger Verlust des Toxingens auftreten kann oder die Stämme generell unterschiedlich toxinogen sind. Auch für andere C.-botulinum-Typen wurde eine differente Sensitivität beschrieben (Lindström et al., 2001). Die im Ergebnisteil beschriebene Abnahme der BoNT/C-toxinogenen positiven Proben ist wahrscheinlich dem Verlust des Toxingens durch Kultivierung zuzuschreiben.

Mit Hilfe der verwendeten PCRs war ein Nachweis von C. botulinum bzw. C. perfringens auf Basis der im Genom enthaltenen Toxingene möglich. Zum einen wurden auf diese Weise aber auch evtl. tote Zellen und Fragmente der DNA mit erfasst, zum anderen wurde durch diese Methode keine Aussage über die tatsächliche Toxinbildung getroffen. Es musste festgestellt werden, dass ein adäquater Toxinnachweis momentan nur über den Maus-Bioassay erfolgen kann.

\subsection{Toxikologische Untersuchung von Organmaterial}

Da sowohl die Entschädigungssumme für ein Rind als auch die pathologische Untersuchung selbst für je drei Tiere aus sechs Betrieben das Budget dieser Pilotstudie überschritten hätten, konnte nur auf Ergebnisse bereits erfolgter toxikologischer Untersuchungen zurückgegriffen werden, was zu einer gerin- 
geren Aussagekraft in Bezug auf die BoNT-Gehalte einzelner Organe führte, da nicht in allen Betrieben drei Tiere untersucht wurden. Auch hier deckten sich die Ergebnisse der Kotproben nicht unbedingt mit den Ergebnissen der Pansensaftproben, schlossen sich aber nicht aus, da im Pansensaft ein anderes Milieu und damit andere Wachstumsbedingungen als im Enddarm vorzufinden sind.

Die Leber als zentrales Organ des Stoffwechsels lässt durch ihre Filterfunktion eine erhöhte Konzentration an BoNTen bei erkrankten bzw. infizierten Tieren erwarten. So gelang beispielsweise die Neutralisierung von BoNT/C aus dem Leberextrakt toter Kälber (Davies et al., 1974). Der Dünndarm als Resorptionsstelle für die BoNTe birgt ebenfalls das Potential für die Detektion von BoNT. Allerdings muss auch die schnelle und irreversible Bindung der Neurotoxine an die Nervenzellen berücksichtigt werden, die einen Nachweis unmöglich machen kann. Da im Rahmen dieser Studie für nur ein Tier eine vollständige organtoxikologische Untersuchung stattfand, war eine Bewertung der Organe Leber und Dünndarm nicht möglich. Insgesamt zeichnete sich aber durch die toxikologische Untersuchung der Kotproben ein Bild ab, das den Ergebnissen der klinischen Untersuchung Rechnung trug und auch die besondere Lage des Kontrollbetriebs KB 3 unterstrich.

Alles in allem stellte sich beim BoNT- oder C.-botulinum-Nachweis die Frage nach der geeignetsten Art der Probe. Der Pansensaft schien aufgrund des Einflusses der Pansenflora und -fauna und der aufwendigen Gewinnung kein geeignetes Mittel zu sein. Leber und Dünndarm wären geeignete Organe, da in ihnen der höchste Übertritt der BoNTe in den Organismus erfolgt. Sektionen sind aber kostenintensiv und die Tötung eines chronisch erkrankten Tieres wäre wenig sinnvoll, wenn Gegenmaßnahmen beabsichtigt werden. Aus diesem Grund bleibt für eine toxikologische Untersuchung nur der leicht zu gewinnende Kot als Alternative, obwohl aus dem Enddarm gewonnenes Toxin sehr wahrscheinlich auch erst dort gebildet wurde. Im Dünndarm vorhandenes BoNT würde auch an dieser Stelle resorbiert werden (Maksymowych et al., 1999). 


\subsection{Untersuchung auf C. perfringens}

$\mathrm{Da}$ bereits von einem gemeinsamen Auftreten von C. botulinum und C. perfringens berichtet wurde (Popoff und Lecoanet, 1987), wurden sowohl die Kotproben der klinisch untersuchten Tiere als auch die Pansensaft- und Kotproben der beprobten Tiere aus der Bestandsdiagnostik per PCR und/oder per Toxin-ELISA auf C. perfringens getestet. Besonders im Zusammenhang mit der geschädigten Pansenfauna wären bei einer gleichzeitigen Anwesenheit von mindestens zwei Toxinen, in dem Fall Botulinum-Toxinen, C.-perfringensToxinen und Mykotoxinen, additive, überadditive und potenzierende Effekte der Toxine denkbar.

Trotz der Covexin ${ }^{\circledR}$-Impfung wurde im Fallbetrieb FB 1 ein klinisch untersuchtes Tier positiv auf $C$. perfringens und $C$. botulinum getestet. Im ungeimpften Fallbetrieb FB 2 waren alle drei Tiere C.-perfringens-positiv getestet worden. Da eine Beweidung des Grünlandes mit Schafen erfolgt war, wäre es sinnvoll, diese Tiere neben Mykobakterien auf C. perfringens zu testen. Im Kontrollbetrieb KB 2 wurden zwei der klinisch untersuchten Tiere ebenfalls gleichzeitig positiv auf $C$. perfringens und $C$. botulinum im Kot getestet. In allen drei Kontrollbetrieben wurden bei den beprobten Tieren aus der Bestandsdiagnostik C.-perfringens-positive Tiere gefunden, im Kontrollbetrieb KB 3 konnte man von einer regelrechten Durchseuchung sprechen. Doch obwohl in den Proben der Kontrollbetriebe KB 1 und KB 2 gleichartige bzw. höhere Mykotoxingehalte detektiert wurden, die Pansenfauna gleichermaßen beeinträchtigt war und C. perfringens bestimmt wurde, kam es dort nicht zur Ausbildung eines vergleichbaren Krankheitsbildes wie in den Fallbetrieben, so dass der Nachweis von C. botulinum oder BoNT im Kot als ausschlaggebender Faktor für das Krankheitsbild des viszeralen Botulismus angesehen werden konnte.

Trotzdem und auch deswegen ist ein wechselnder Einfluss verschiedener Clostridien auf das Krankheitsgeschehen des viszeralen Botulismus möglich. Da die verschiedenen Toxine unterschiedliche Angriffspunkte im Organismus haben und z. B. durch ihre enterotoxische oder zytolytische Wirkung den Weg für weitere Krankheitserreger bereiten (Black und Dolly, 1987), kann man auch von einer Polyclostridiose sprechen. Das auslösende Agens ist in den wenigsten Fällen zu benennen. 


\subsection{BoNT-Antikörper}

Es ist durchaus nicht unüblich, dass auch in gesunden Tieren in geringem Maße Antikörper gegen BoNTe detektiert werden (Steinman et al., 2006; Mawhinney et al., 2011). Im Zuge einer akuten oralen Intoxikation bindet das resorbierte BoNT direkt in vollem Maße an die cholinergen Synapsen und führt in den meisten Fällen direkt zum Tod, ohne dass eine Immunreaktion zustande kommen konnte. Im Falle einer geringen, aber stetigen Absorption von im Darm gebildetem BoNT kann sich dagegen eine nachweisbare Immunantwort entwickeln und Antikörper gegen die Toxine sind nachweisbar. Diese Immunreaktion macht man sich auch bei der Entwicklung von Antikörpern zunutze, indem einem Versuchstier geringste Mengen von BoNT appliziert werden. Es wurde die Beobachtung gemacht, dass in klinisch gesunden Tieren der betroffenen Bestände höhere Titer $\mathrm{zu}$ finden waren als in sichtbar erkrankten Tieren (Schwagerick, 2010). Im Rahmen der Bestandsdiagnostik wurden allerdings nur die BoNT-Antikörpertiter klinisch gesunder Tiere analysiert. Bei Betrachtung der Einzeltiere zeigten sich in den Fallbetrieben in fast allen Tieren gleichartig hohe Antikörpertiter, während diese Titer in den Einzeltieren der Kontrollbetriebe sehr unterschiedlich ausgeprägt waren bzw. in einigen Tieren gar nicht nachweisbar waren. Durch die Impfung mit Covexin $^{\circledR}$ und die möglicherweise entstehenden Kreuzreaktionen waren die Ergebnisse der Fallbetriebe FB 1 und FB 3 nur schwer interpretierbar. Da Kreuzreaktionen mit den Antikörpern gegen C. tetani und C. novyi möglich waren, könnte dies zu falsch-positiven Signalen führen. C. novyi steht in enger Verwandtschaft zu den Stämmen der Gruppe III, C. tetani dagegen weist eine engere Verwandtschaft mit den C.-botulinum-Typen der Gruppe I auf. Da Toxoide beider Spezies im Impfstoff enthalten waren, wäre auch für BoNT/A und BoNT/B ein stärkerer und gleichartiger Anstieg der Antikörpertiter der Einzeltiere zu erwarten gewesen. Da der Gehalt an Antikörpern im Serum aber nur für BoNT/C und D stark anstieg, war dies evtl. eher auf die kreuzreaktive Boosterwirkung des Impfstoffs und eine unterschiedlich hohe Immunkompetenz der Einzeltiere zurückzuführen. Dies würde für eine vorhergehende erhöhte Exposition der Tiere gegenüber BoNT/C und D sprechen, die sich deutlich in den vielfältigen Symptomen der klinisch erkrankten Tiere dieser Betriebe zeigte. Gleichermaßen entsprachen die geringeren Antikörpertiter für BoNT/C und D im Fallbetrieb FB 2 dem 
klinischen Erscheinungsbild der dort untersuchten Tiere. Obwohl im MausBioassay und den PCR-Methoden das Vorhandensein und eine Beteiligung von anderen C.-botulinum-Typen und BoNTen am Krankheitsgeschehen nachgewiesen wurde, scheinen doch die C.-botulinum-Typen $\mathrm{C}$ und $\mathrm{D}$ mit ihren entsprechenden BoNTen, C2- und C3-Toxinen die maßgeblichen Faktoren für das Auftreten des Krankheitsbildes des viszeralen Botulismus zu sein.

Dies bestätigt sich auch durch die Anwendung des in Deutschland ausnahmegenehmigungspflichtigen Impfstoffs Botulinum Vaccine $^{\circledR}$ der südafrikanischen Firma Onderstepoort. Er enthält Toxoide der C.-botulinum-Typen $\mathrm{C}$ und D und dient sowohl zur Immunisierung gesunder Tiere und wird erstmalig eingesetzt, wenn konservative Therapieversuche der Stoffwechselstörungen ohne Erfolg bleiben. Als Folge wird von einem verbessertem Gesundheitsstatus des Betriebes, verminderten Koordinationsstörungen, Paresen und Klauenproblemen der Tiere berichtet (Impfbericht, 2008). Allerdings sind regelmäßige Nachimpfungen erforderlich, um einen ausreichenden Immunstatus zu erhalten. Da die Ausnahmegenehmigung zur Anwendung des südafrikanischen Impfstoffs nur auf Basis des Nachweises von BoNT erteilt wird, gestaltet sich eine flächendeckende langjährige Immunisierung und Bestandsaufnahme aufgrund der skizzierten Nachweisschwierigkeiten problematisch. 


\section{Schlussfolgerung}

Mit Hilfe der vorliegenden Untersuchungen im Rahmen einer Fall-KontrollStudie konnten erstmalig Aussagen über die Einflussfaktoren und klinischen Symptome beim Krankheitsbild des viszeralen Botulismus getroffen oder bestätigt werden. Des Weiteren fand eine Beurteilung der eingesetzten Methoden zur Erhebung der Daten und zur Diagnostik von C. botulinum und dessen Toxinen statt. Die Erkenntnisse dieser Arbeit können zur Planung von Prävalenzstudien und als diagnostisches Hilfsmittel zum Erkennen von viszeralem Botulismus herangezogen werden.

Das erhobene Datenmaterial war aufgrund der geringen Auswahlmöglichkeiten von Fällen und Kontrollen und der retrospektiven Erhebung teilweise unvollständig und insgesamt gering. Statt einer statistischen Auswertung war deshalb nur das Aufzeigen von Trends und Hinweisen möglich, die aufgrund der logischen Zusammenhänge aber schlüssig erschienen und deshalb als beteiligte Risikofaktoren oder klinische Symptome identifiziert wurden.

Der Fragebogen war als Instrument zur umfassenden Datenerhebung gut geeignet und deckte die Bereiche des Betriebsmanagements, der Fütterung und der Tiergesundheit hinsichtlich der vermuteten Einflussfaktoren auf das Krankheitsbild des viszeralen Botulismus umfassend ab. Im Hinblick auf die Dauerformen pathogener Mikroorganismen, die mit diesem Krankheitsbild in Verbindung gebracht werden konnten, ist eine Überarbeitung der Fragestellung in Bezug auf die Erweiterung des zeitlichen Kontextes der Düngung erforderlich.

Da die Nährstoffqualität der Grassilage in allen Betrieben ähnlich war, die mikrobiologische Qualität der Silagen in den Kontrollbetrieben schlechter als die der Fallbetriebe war und außerdem in beiden Vergleichsgruppen gleichartige Stoffwechselstörungen diagnostiziert wurden, konnte die Nährstoffversorgung als Hauptursache für das Auftreten des Krankheitsgeschehens ausgeschlossen werden. Da die Erkrankung mit dem Erscheinungsbild des viszeralen Botulismus nur in den Fallbetrieben auftrat, mussten in diesen Betrieben andern Ursachen für die Bestandserkrankung verantwortlich sein und wurden als $C$. botulinum bzw. dessen Toxine identifiziert. Eine wechselseitige Dominanz der C.-botulinum-Typen C und D mit C. perfringens bzw. additive 
Effekte einer parallelen Präsenz von Mykotoxinen, BoNTen, C2-Toxin und anderen clostridialen Toxine war wahrscheinlich.

Als Risikofaktoren für die Kontamination oder Rekontamination der Bestände mit C. botulinum kristallisierten sich Überschwemmungen des Grünlandes, die Düngung des Grünlandes mit eigener Gülle und die Verfütterung von evtl. dadurch kontaminiertem Eigengetreide heraus, bestätigten damit die Erwartungen (Böhnel et al., 2001b; Schwagerick und Böhnel, 2001; Schwagerick, 2004a; Schwagerick, 2010) und sollten näher untersucht werden. Ein Zusammenhang zwischen den zur Düngung verwendeten Gärresten einer Biogasanlage und dem Krankheitsgeschehen im Fallbetrieb FB 3 konnte aufgrund des geringen Datenmaterials im Rahmen dieser Pilotstudie nicht hergestellt werden.

Als eindeutige klinische Symptome zur Erkennung des viszeralen Botulismus konnten neben den verschiedenen neuro-motorischen Erscheinungen wie Lähmungen und Reflexausfällen auch ein schlechter Habitus, Ataxien, eine untypische Beinstellung, Tympanien und/oder schwache Pansenkontraktionen, Entzündungen an Klauen und Gelenken, eine Atrophie der Glutäenmuskulatur, eine auffällige Atmung und apathisches oder nervöses Verhalten festgestellt werden. Indizien bzw. Hinweise für eine Bestandserkrankung waren im Besonderen hohe Zwischenkalbezeiten, eine hohe Kälbermortalität und stark abfallende Fettgehalte der Rohmilch.

Der Nachweis von C. botulinum und den BoNTen im Tier und in der Grassilage wurde durch zu hohe Nachweisgrenzen, Toxingenverluste durch Kultivierung und die geringere Empfindlichkeit des Rindes im Vergleich zur Maus beeinträchtigt. Die Kombination der klinischen und labordiagnostischen Ergebnisse ermöglichte jedoch die Identifizierung von C. botulinum als auslösendem Agens. Der Maus-Bioassay wurde als Goldstandard bestätigt. 


\section{Zusammenfassung}

Botulismus ist eine akute Intoxikation von Säugetieren, Geflügel und Fischen mit Botulinum-Neurotoxinen (BoNTen), die durch C. botulinum gebildet werden. Eine seit den 1990er Jahren bisher unbekannte, chronisch verlaufende und mit erheblichen Verlusten einhergehende Bestandserkrankung bei Hochleistungsmilchrindern und Kälbern wurde 2001 von Böhnel und Schwagerick als viszeraler Botulismus beschrieben und seitdem kontrovers diskutiert.

Es galt daher, im Rahmen einer Fall-Kontroll-Studie mögliche Einflussfaktoren und typische Symptome des chronischen Krankheitsgeschehens zu identifizieren, um das Risiko einer Herdenerkrankung erkennen und senken zu können. $\mathrm{Zu}$ diesem Zweck wurde ein Fragebogen entwickelt, der die drei Bereiche Betriebsstruktur, Fütterungsbewertung und Tiergesundheit inkl. einer Bestandsdiagnostik umfasste. Zum Nachweis von C. botulinum wurden spezifische PCR-Methoden entwickelt bzw. optimiert. Daneben kamen der Maus-Bioassay zum Nachweis von BoNTen und ein ELISA zur Bestimmung des Antikörpertiters gegen BoNT/A, B, C und D zum Einsatz.

Entsprechend der geringen zur Verfügung stehenden Datenmenge konnten statt einer umfassenden statistischen Auswertung lediglich Trends und Hinweise ermittelt werden.

Es stellte sich heraus, dass die Hochleistungsrinder sowohl in den Fall- als auch in den Kontrollbetrieben in einem bedenklichen Stoffwechselzustand waren und die als Hauptursache vermutete Grassilage minderer Qualität keinen herausragenden Einfluss auf das Krankheitsgeschehen in den Fallbetrieben hatte.

Als Risikofaktoren wurden dagegen Überschwemmungen des Grünlandes, die Düngung mit Gülle kranker Tiere und die Fütterung von Eigengetreide bewertet, die durch einen Kreislauf der Re-Infektion eine Potenzierung des Krankheitsgeschehens herbeiführen könnten.

Neben verschiedenen neuro-motorischen Beeinträchtigungen konnten die klinischen Symptome eines schlechten bis sehr schlechten Habitus, Ataxien, eine untypische Beinstellung, schwache Pansenkontraktionen, Entzündungen 
an Klauen und Gelenken, die Atrophie der Glutäenmuskulatur als charakteristisch für das Krankheitsbild des chronischen Botulismus festgestellt werden. Durch den gelungene Nachweis von C. botulinum und dessen Toxinen im Kot der Tiere konnten diese als Ursache der vielfältigen Ausfallerscheinungen betrachtet werden und waren ausschlaggebend für das Krankheitsgeschehen des viszeralen Botulismus. 


\section{Summary}

Botulism generally is an acute intoxication of mammals, birds and fishes with botulinum-neurotoxins (BoNT), which are produced by $C$. botulinum. First reported in the 1990s as a so long unknown, chronic and by great losses attended lifestock disease of high performance dairy cows and calves was described as visceral botulism by Böhnel and Schwagerick in 2001 and is discussed controversially since that time.

Therefore, it was the aim to identify possible influencing factors and typical symptoms within a case-control-study in order to detect and reduce the risk of this lifestock disease. For these purposes a questionnaire was developed, which included three points of interests, lifestock management, feed assessment and animal health with lifestock diagnostics. For the detection of $C$. botulinum specific PCR methods were developed and optimized. Furthermore a mouse bioassay for the detection of BoNTs and an ELISA for the investigation of antibody titer against BoNT/A, B, C and D were used.

According to the low available amount of data instead of statistical analysis only trends and indications could be determined.

It was shown that the high performance dairy cows had a critical metabolism status in case as well as in control farms. The grass silage of low-grade quality as the suspected main cause didn't have an extraordinary effect to the disease in the case farms. Instead of it floods of the green land, the fertilisation with liquid manure of sick animals and the feeding with own crop were evaluated as risk factors, which could lead to enhancement of the sickness by a circle of re-infection.

Beside different neuro-motorical dysfunctions also clinical symptoms as a bad up to very bad habitus, ataxia, an untypical leg position, low ruminal contraction, laminitis, atrophy of the gluteal musculature were determined as characteristic for the disease pattern of visceral botulism. Due to successful detection of $C$. botulinum and its toxins in animal faeces those could be examined as the cause of the multifarious deficiencies and were the crucial factors for the disease pattern of visceral botulism. 


\section{Literaturverzeichnis}

ADDCON. (2010). Silierung - KOFASIL ULTRA, Bonn, pp. 1-8.

ADR. (2005-2010). Rinderproduktion in der Bundesrepublik Deutschland, Arbeitsgemeinschaft Deutscher Rinderzüchter e.V., Bonn, pp. http://www.adr-web.de/list_statistik.html.

Ahn-Yoon, S., DeCory, T. R. and Durst, R. A. (2004). Ganglioside-liposome immunoassay for the detection of botulinum toxin. Analytical and Bioanalytical Chemistry, 378, 68-75.

Akbulut, D., Grant, K. A. and McLauchlin, J. (2004). Development and Application of Real-Time PCR Assays to Detect Fragments of the Clostridium botulinum Types A, B, and E Neurotoxin Genes for Investigation of Human Foodborne and Infant Botulism. Foodborne Pathogens and Disease, 1, 247-257.

Aktories, K., Bärmann, M., Ohishi, I., Tsuyama, S., Jakobs, K. H. and Habermann, E. (1986). Botulinum C2 toxin ADP-ribosylates actin. Nature, 322, 390-392.

Aktories, K., Lang, A. E., Schwan, C. and Mannherz, H. G. (2011). Actin as target for modification by bacterial protein toxins. FEBS Journal, 278, $4526-4543$.

Aktories, K., Weller, U. and Chhatwal, G. S. (1987). Clostridium botulinum type C produces a novel ADP-ribosyltransferase distinct from botulinum C2 toxin. FEBS Letters, 212, 109-113.

Allison, M. J., Maloy, S. and Matson, R. (1976). Inactivation of Clostridium botulinum toxin by ruminal microbes from cattle and sheep. Applied and Environmental Microbiology, 32, 685-688.

Anniballi, F., Auricchio, B., Delibato, E., Antonacci, M., De Medici, D. and Fenicia, L. (2011). Multiplex real-time PCR SYBR Green for detection and typing of group III Clostridium botulinum. Veterinary Microbiology, doi:10.1128/AEM.02234-02206.

Anonym. (2011). Grassilage-Fibel - Leitfaden zur erfolgreichen Grassilierung, Vol. 2011, Schaumann.

AOAC. (2000). AOAC Official Method 977.26 Clostridium botulinum and Its Toxins in Foods. In: AOAC International, Vol. 977.26, AOAC International.

Appleyard, W. T. and Mollison, A. (1985). Suspected bovine botulism associated with broiler litter waste. Veterinary Record, 116, 522.

Archibald, J. G. (1953). Sugar and Acids in Grass Silage. Journal of dairy science, 36, 385-390.

Arndt, J. W., Jacobson, M. J., Abola, E. E., Forsyth, C. M., Tepp, W. H., Marks, J. D., Johnson, E. A. and Stevens, R. C. (2006). A Structural Perspective of the Sequence Variability Within Botulinum Neurotoxin Subtypes A1-A4. Journal of Molecular Biology, 362, 733-742.

Arnon, S. S. (1995). Botulism as an Intestinal Toxemia. In: Infections of the Gastrointestinal Tract, M. J. Blaser, P. D. Smith, J. I. Ravdin, H. B. Greenberg and R. L. Guerrant, Eds, Raven Press, Ltd., New York, pp. 257-271.

Arnon, S. S., Damus, K. and Chin, J. (1981). Infant Botulism: Epidemiology and Relation to Sudden Infant Death Syndrome. Epidemiologic Reviews, 3, 45-66. 
Arnon, S. S., Midura, T. F., Damus, K., Thompson, B., Wood, R. M. and Chin, J. (1979). Honey and other environmental risk factors for infant botulism. The Journal of Pediatrics, 94, 331-336.

Arnon, S. S., Midura, T. F., Damus, K., Wood, R. M. and Chin, J. (1978). Intestinal Infection and Toxin Production by Clostridium botulinum as One Cause of Sudden Infant Death Syndrome. The Lancet, 311, 12731277.

Arnon, S. S., Schechter, R., Inglesby, T. V., Henderson, D. A., Bartlett, J. G., Ascher, M. S., Eitzen, E., Fine, A. D., Hauer, J., Layton, M., Lillibridge, S., Osterholm, M. T., O'Toole, T., Parker, G., Perl, T. M., Russell, P. K., Swerdlow, D. L. and Tonat, K. (2001). Botulinum Toxin as a Biological Weapon - Medical and Public Health Management. Journal of the American Medical Association, 285, 1059-1070.

Arnon, S. S., Schechter, R., Maslanka, S. E., Jewell, N. P. and Hatheway, C. L. (2006). Human Botulism Immune Globulin for the Treatment of Infant Botulism. New England Journal of Medicine, 354, 462-471.

Artin, I., Björkman, P., Cronqvist, J., Rådstro, P. and Holst, E. (2007). First Case of Type E Wound Botulism Diagnosed Using Real-Time PCR . Journal of Clinical Microbiology, 45, 3589-3594.

Ashton, A. C., Crowther, J. S. and Dolly, J. O. (1985). A sensitive and useful radioimmunoassay for neurotoxin and its haemagglutinin complex from Clostridium botulinum. Toxicon, 23, 235-246.

Aureli, P., Fenicia, L., Pasolini, B., Gianfranceschi, M., McCroskey, L. and Hatheway, C. (1986). Two cases of type E infant botulism caused by neurotoxigenic Clostridium butyricum in Italy. Journal of Infectious Diseases, 154, 207-211.

Bagge, E., Persson, M. and Johansson, K. E. (2010). Diversity of spore-forming bacteria in cattle manure, slaughterhouse waste and samples from biogas plants. Journal of Applied Microbiology, 109, 1549-1565.

Bakheit, A. M. O., Ward, C. D. and McLellan, D. L. (1997). Generalised botulism-like syndrome after intramuscular injections of botulinum toxin type A: a report of two cases. Journal of Neurology, Neurosurgery \& Psychiatry, 62, 198.

Barash, J. R. and Arnon, S. S. (2004). Dual Toxin-Producing Strain of Clostridium botulinum Type Bf Isolated from a California Patient with Infant Botulism. Journal of Clinical Microbiology, 42, 1713-1715.

Barth, H., Blöcker, D., Behlke, J., Bergsma-Schutter, W., Brisson, A., Benz, R. and Aktories, K. (2000). Cellular Uptake of Clostridium botulinum C2 Toxin Requires Oligomerization and Acidification. Journal of Biological Chemistry, 275, 18704-18711.

Battacone, G., Nudda, A. and Pulina, G. (2010). Effects of ochratoxin a on livestock production. Toxins, 2, 1796-1824.

Bauer, J., Eckstein, B., Dänicke, S., Gropp, J., Meyer, H. D., Obst, A., Petzinger, E., Richter, W., Staudacher, W., Weinreich, O., Weiß, J. and Wolff, J. (2000). Mykotoxine vermeiden statt "bekämpfen". DLGMitteilungen, 8, 1-5.

Baums, C. G., Schotte, U., Amtsberg, G. and Goethe, R. (2004). Diagnostic multiplex PCR for toxin genotyping of Clostridium perfringens isolates. Veterinary Microbiology, 100, 11-16.

Beiers, P. R. and Simmons, G. C. (1967). Botulism in pigs. Australian Veterinary Journal, 43, 270-271.

Bengtson, I. A. (1922). Preliminary Note on a Toxin-Producing Anaerobe Isolated from the Larvae of Lucilia Caesar. Public Health Reports, 37, 164-170. 
Bengtson, I. A. (1924). Studies on organisms concerned as causative factors in botulism. Bulletin of the Hygienic Laboratory, 136, 1-101.

Berendonk, C. (2011). Ermittlung der Schnittreife im ersten Aufwuchs, Vol. 2011, Landwirtschaftskammer Nordrhein-Westfalen.

Bessetti, J. (2007). An Introduction to PCR Inhibitors. Profiles in DNA, 10, 910.

BfR. (2004). Viszeraler Botulismus - Ein neues Krankheitsbild?, Bundesinstitut für Risikobewertung, Berlin, pp. 1-8.

BfR. (2010). Viszeraler Botulismus: Sachverständigengespräch im BfR, Bundesinstitut für Risikobewertung, Berlin, pp. 1-3.

Binz, T., Blasi, J., Yamasaki, S., Baumeister, A., Link, E., Südhof, T. C., Jahn, R. and Niemann, H. (1994). Proteolysis of SNAP-25 by types E and A botulinal neurotoxins. Journal of Biological Chemistry, 269, 1617-1620.

Binz, T., Kurazono, H., Popoff, M. R., Eklund, M. W., Sakaguchi, G., Kozaki, S., Krieglstein, K., Henschen, A., Gill, D. M. and Niemann, H. (1990a). Nucleotide sequence of the gene encoding Clostridium botulinum neurotoxin type D. Nucleic Acids Research, 18, 5556.

Binz, T., Kurazono, H., Wille, M., Frevert, J., Wernars, K. and Niemann, H. (1990b). The complete sequence of botulinum neurotoxin type A and comparison with other clostridial neurotoxins. Journal of Biological Chemistry, 265, 9153-9158.

Binz, T. and Rummel, A. (2009). Cell entry strategy of clostridial neurotoxins. Journal of Neurochemistry, 109, 1584-1595.

Black, J. D. and Dolly, J. O. (1986a). Interaction of 125I-labeled botulinum neurotoxins with nerve terminals. I. Ultrastructural autoradiographic localization and quantitation of distinct membrane acceptors for types A and B on motor nerves. The Journal of Cell Biology, 103, 521-534.

Black, J. D. and Dolly, J. O. (1986b). Interaction of 125I-labeled botulinum neurotoxins with nerve terminals. II. Autoradiographic evidence for its uptake into motor nerves by acceptor-mediated endocytosis. The Journal of Cell Biology, 103, 535-544.

Black, J. D. and Dolly, J. O. (1987). Selective location of acceptors for botulinum neurotoxin a in the central and peripheral nervous systems. Neuroscience, 23, 767-779.

Black, R. E. and Gunn, R. A. (1980). Hypersensitivity reactions associated with botulinal antitoxin. The American Journal of Medicine, 69, 567570.

Blaustein, R. O., Germann, W. J., Finkelstein, A. and DasGupta, B. R. (1987). The N-terminal half of the heavy chain of botulinum type A neurotoxin forms channels in planar phospholipid bilayers. FEBS Letters, 226, 115- 120.

Blaut, M. (2002). Relationship of prebiotics and food to intestinal microflora. European Journal of Nutrition, 41, 11-17.

Böhnel, H. (1995). Botulismus. In: Handbuch der bakteriellen Infektionen bei Tieren, H. Blobel and T. Schließer, Eds, Vol. 2, Gustav Fischer Verlag Jena, Stuttgart, pp. 89-153.

Böhnel, H. (1999). Botulismus - eine vergessene Erkrankung? Berliner und Münchner Tierärztliche Wochenschrift, 112, 139-145.

Böhnel, H. (2004). Botulismus bei Rindern - Ursachen und Verbreitung. Bundesverband der beamteten Tierärzte - Kongress, Bad Steffelstein, pp. 222-229.

Böhnel, H. (2005). Akuter Botulismus bei Alpensteinböcken, Capra i. ibex, in einem Wildgehege nach Silagefütterung. - Ein Hinweis. Der zoologische Garten, 75, 116-121. 
Böhnel, H., Behrens, S., Loch, P., Lube, K. and Gessler, F. (2001a). Is there a link between infant botulism and sudden infant death? Bacteriological results obtained in Central Germany. European Journal of Pediatrics, 160, 623-628.

Böhnel, H. and Gessler, F. (2003). Botulismusdiagnose seit 1995. Ein Erfahrungsbericht. Berliner und Münchner Tierärztliche Wochenschrift, 116, 269-273.

Böhnel, H. and Gessler, F. (2004). Was ist denn nun Botulismus überhaupt? Vet-MedReport, 28, 14.

Böhnel, H. and Gessler, F. (2005). Botulinum Toxins - Cause of Botulism and Systemic Diseases? Veterinary Research Communications, 29, 313-345.

Böhnel, H. and Gessler, F. (2010). Viszeraler Botulismus ohne Ende? Großtierpraxis, 11, 402-406.

Böhnel, H., Neufeld, B. and Gessler, F. (2005). Botulinum neurotoxin type B in milk from a cow affected by visceral botulism. The Veterinary Journal, 169, 124-125.

Böhnel, H., Schwagerick, B. and Gessler, F. (2001b). Visceral Botulism - A New Form of Bovine Clostridium botulinum Toxication. Journal of Veterinary Medicine A, 48, 373-383.

Böhnel, H., Wagner, C. and Gessler, F. (2008). Tonsils - Place of botulinum toxin production: Results of routine laboratory diagnosis in farm animals. Veterinary Microbiology, 130, 403-409.

Böhnel, H., Wernery, U. and Gessler, F. (2003). Two Cases of Equine Grass Sickness with Evidence for Soil-borne Origin Involving Botulinum Neurotoxin. Journal of Veterinary Medicine B, 50, 178-182.

Boroff, D. A. and Shu-Chen, G. (1973). Radioimmunoassay for Type A Toxin of Clostridium botulinum. Applied Microbiology, 25, 545-549.

Boyer, A. E., Moura, H., Woolfitt, A. R., Kalb, S. R., McWilliams, L. G., Pavlopoulos, A., Schmidt, J. G., Ashley, D. L. and Barr, J. R. (2005). From the Mouse to the Mass Spectrometer: Detection and Differentiation of the Endoproteinase Activities of Botulinum Neurotoxins A-G by Mass Spectrometry. Analytical Chemistry, 77, 3916-3924.

Brooks, C. E., Clarke, H. J., Ardis, T. C. and Ball, H. J. (2011). Temperature dependency of Clostridium botulinum $\mathrm{C}$ and $\mathrm{D}$ toxin production from anaerobically enriched bovine gastrointestinal samples. Letters in Applied Microbiology, 53, 174-177.

Bruckstein, S. and Tromp, A. M. (2001). Food Poisoning in Three Family Dairy Herds Associated with Clostridium botulinum Type B. Israel Journal of Veterinary Medicine, 56.

Budras, K.-D., Buda, S., Berg, R., Döpfer, D., Fries, R., Glatzel, P., Mülling, C., Müller, K. and Stanek, C. (2007). Atlas der Anatomie des Rindes: Supplement Klinisch-funktionelle Anatomie. Schlütersche, Hannover, pp. 35.

Burke, G. S. (1919). Notes on Bacillus botulinus. Journal of Bacteriology, 4, 555-570.551.

Byrne, M. P. and Smith, L. A. (2000). Development of vaccines for prevention of botulism. Biochimie, 82, 955-966.

Camargo, F. C., Coleman, B. and Lawrence, L. (2008). Botulism: A deadly Disease That Can Affect Your Horse. University of Kentucky - College of Agriculture, 5, 1-4.

Campbell, K., Collins, M. D. and East, A. K. (1993a). Nucleotide sequence of the gene coding for Clostridium botulinum (Clostridium argentinense) type G neurotoxin: Genealogical comparison with other clostridial 
neurotoxins. Biochimica et Biophysica Acta (BBA) - Gene Structure and Expression, 1216, 487-491.

Campbell, K. D., Collins, M. D. and East, A. K. (1993b). Gene Probes for Identification of the Botulinal Neurotoxin Gene and Specific Identification of Neurotoxin Types B, E and F. Journal of Clinical Microbiology, 31, 2255-2262.

Cardella, M. A., Duff, J. T., Wingfield, B. H. and Gottfried, C. (1960). Studies in Immunity to Toxins of Clostridium botulinum VI.: Purification and Detoxification of Type D Toxin and the Immunological Response to Toxoid. Journal of Bacteriology, 79, 372-378.

Carter, A., Paul, C., Mason, D., Twine, S., Alston, M., Logan, S., Austin, J. and Peck, M. (2009). Independent evolution of neurotoxin and flagellar genetic loci in proteolytic Clostridium botulinum. BMC Genomics, 10, 115.

Cato. (1986). Genus I. Clostridium. In: Bergey's Manual ${ }^{\circledR}$ of Systematic Bacteriology. Volume Three:The Firmicutes, W. B. Whitman, Ed, Vol. 3, Springer, Dordrecht, Heidelberg, London, New York, pp. 736-828.

CDC. (1995). Wound botulism--California. Morbidity and mortality weekly report, 44, 889-892.

CDC. (1998). Botulism in the United States, 1899-1996. Handbook for Epidemiologists, Clinicians, and Laboratory Workers, Centers for Disease Control and Prevention, Atlanta, GA, pp. 1-42.

Chamberlain, P. and Thomas, R. J. (1995). An outbreak of botulism in a deer herd in Queensland. Australian Veterinary Journal, 72, 427-428.

Chardin, P., Boquet, P., Madaule, P., Popoff, M. R., Rubin, E. J. and Gill, D. M. (1989). The mammalian $G$ protein rhoC is ADP-ribolysated by Clostridium botulinum exoenzyme $\mathrm{C} 3$ and affects actin microfilamente in Vero cells. EMBO Journal, 8, 1087-1092.

Chen, Y., Korkeala, H., Aarnikunnas, J. and Lindström, M. (2007). Sequencing the Botulinum Neurotoxin Gene and Related Genes in Clostridium botulinum Type E Strains Reveals orfx3 and a Novel Type E Neurotoxin Subtype. Journal of Bacteriology, 189, 8643-8650.

Cherington, M. (1998). Clinical spectrum of botulism. Muscle \& Nerve, 21, 701-710.

Cobb, S. P., Hogg, R. A., Challoner, D. J., Brett, M. M., Livesey, C. T., Sharpe, R. T. and Jones, T. O. (2002). Suspected botulism in dairy cows and its implications for the safety of human food. The Veterinary Record, 150, 5-8.

Coleman, G. S. and Hall, F. J. (1972). Fine structural studies on digestion of bacterial species in the rumen ciliate, Entodinium caudatum. Tissue and Cell, 4, 37-48.

Collins, M. D. and East, A. K. (1998). Phylogeny and taxonomy of the foodborne pathogen Clostridium botulinum and its neurotoxins. Journal of Applied Microbiology, 84, 5-17.

Cottrell, D. F., McGorum, B. C. and Pearson, G. T. (1999). The neurology and enterology of equine grass sickness: a review of basic mechanisms. Neurogastroenterology \& Motility, 11, 79-92.

Curran, R. M., Fringuelli, E., Graham, D. and Elliott, C. T. (2009). Production of serotype $\mathrm{C}$ specific and serotype $\mathrm{C} / \mathrm{D}$ generic monoclonal antibodies using recombinant $\mathrm{H}_{\mathrm{C}}$ and $\mathrm{H}_{\mathrm{N}}$ fragments from Clostridium botulinum neurotoxin types $\mathrm{C}_{1}$ and $\mathrm{D}$. Veterinary Immunology and Immunopathology, 130, 1-10.

Dahlenborg, M., Borch, E. and Radstrom, P. (2001). Development of a Combined Selection and Enrichment PCR Procedure for Clostridium 
botulinum Types B, E, and F and Its Use To Determine Prevalence in Fecal Samples from Slaughtered Pigs. Applied and Environmental Microbiology, 67, 4781-4788.

Dahlenborg, M., Borch, E. and Radström, P. (2003). Prevalence of Clostridium botulinum types $\mathrm{B}, \mathrm{E}$ and $\mathrm{F}$ in faecal samples from Swedish cattle. International Journal of Food Microbiology, 82, 105-110.

DasGupta, B. R. and Sugiyama, H. (1977). Single chain and dichain forms of neurotoxin in type F Clostridium botulinum culture. Toxicon, 15, 466471.

DasGupta, B. R. and Woody, M. A. (1984). Amino acid composition of Clostridium botulinum type B neurotoxin. Toxicon, 22, 312-315.

Datta, V., Myskowski, S. M., Kwinn, L. A., Chiem, D. N., Varki, N., Kansal, R. G., Kotb, M. and Nizet, V. (2005). Mutational analysis of the group A streptococcal operon encoding streptolysin $\mathrm{S}$ and its virulence role in invasive infection. Molecular Microbiology, 56, 681-695.

Davies, A. B., Roberts, T. A., Smart, J. L. and Bradshaw, P. R. (1974). Probable botulism in calves. The Veterinary Record, 94, 412-414.

De Medici, D., Anniballi, F., Wyatt, G. M., Lindström, M., Messelhäußer, U., Aldus, C. F., Delibato, E., Korkeala, H., Peck, M. W. and Fenicia, L. (2009). Multiplex PCR for Detection of Botulinum Neurotoxin-Producing Clostridia in Clinical, Food, and Environmental Samples. Applied and Environmental Microbiology, 75, 6457-6461.

Demarchi, J., Mourgues, C., Orio, J. and Prevot, A. R. (1958). Existence du botulisme humain de type $\mathrm{D}$. Bulletin de l'Académie nationale de médecine, 142, 17-24.

Derman, Y., Lindstrom, M., Selby, K. and Korkeala, H. (2011). Growth of group II Clostridium botulinum strains at extreme temperatures. Journal of Food Protection, 74, 1797-1804.

Dezfulian, M. and Bartlett, J. G. (1984). Detection of Clostridium botulinum type A toxin by enzyme-linked immunosorbent assay with antibodies produced in immunologically tolerant animals. Journal of Clinical Microbiology, 19, 645-648.

Dezfulian, M. and Bartlett, J. G. (1985). Selective isolation and rapid identification of Clostridium botulinum types A and B by toxin detection. Journal of Clinical Microbiology, 21, 231-233.

Dezfulian, M., Hatheway, C. L., Yolken, R. H. and Bartlett, J. G. (1984). Enzyme-linked immunosorbent assay for detection of Clostridium botulinum type A and type B toxins in stool samples of infants with botulism. Journal of Clinical Microbiology, 20, 379-383.

Dezfulian, M., McCroskey, L. M., Hatheway, C. L. and Dowell, V. R., Jr. (1981). Selective medium for isolation of Clostridium botulinum from human feces. Journal of Clinical Microbiology, 13, 526-531.

DIN10102. (1988). Nachweis von Clostridium botulinum und Botulinum-Toxin. In: Mikrobiologische Untersuchung von Fleisch und Fleischerzeugnissen, Vol. DIN 10102, Normenausschuss Lebensmittel und landwirtschaftliche Produkte (NAL) im DIN Deutsches Institut für Normung e.V., Amtliche Methodensammlung.

Dineen, S. S., Bradshaw, M., Karasek, C. E. and Johnson, E. A. (2004). Nucleotide sequence and transcriptional analysis of the type A2 neurotoxin gene cluster in Clostridium botulinum. FEMS Microbiology Letters, 235, 9-16.

Dixit, A., Dhaked, R. K., Alam, S. I. and Singh, L. (2005). Characterization of Clostridium sp. RKD producing botulinum-like neurotoxin. Systematic and Applied Microbiology, 28, 405-414. 
DLG-AusschussFutterkonservierung.

(2006).

Praxishandbuch

Futterkonservierung. DLG-Verlag, Frankfurt a.M., pp. 354.

DLG. (2006). Grobfutterbewertung Teil B - DLG-Schlüssel zur Beurteilung der Gärqualität von Grünfuttersilagen auf Basis der chemischen Untersuchung. DLG-Information, 2, 1-4.

Dodds, K. L. (1994). Clostridium botulinum. In: Foodborne disease handbook, Vol. I, Diseases caused by bacteria, Y. e. a. Hui, Ed, Vol. 1, Marcel Dekker, New York, pp. 97-131.

Doellgast, G. J., Triscott, M. X., Beard, G. A., Bottoms, J. D., Cheng, T., Roh, B. H., Roman, M. G., Hall, P. A. and Brown, J. E. (1993). Sensitive enzyme-linked immunosorbent assay for detection of Clostridium botulinum neurotoxins $\mathrm{A}, \mathrm{B}$, and $\mathrm{E}$ using signal amplification via enzyme-linked coagulation assay. Journal of Clinical Microbiology, 31, 2402-2409.

Dressler, D. and Benecke, R. (2003). Autonomic side effects of botulinum toxin type $\mathrm{B}$ treatment of cervical dystonia and hyperhidrosis. European Neurology, 49, 34-38.

Dressler, D. and Saberi, F. A. (2009). Botulinum toxin: from drug to poison. Fortschritte der Neurologie-Psychatrie, 77, 49-54.

Drochner, W. (2004). Tierernährung, Fütterung und Tiergesundheit. In: Tiergesundheits- und Tierkrankheitslehre, W. Busch, W. Methling and W. M. Amselgruber, Eds, Parey Verlag, Stuttgart, pp. 20-41.

Duff, J. T., Klerer, J., Bibler, R. H., Moore, D. E., Gottfried, C. and Wright, G. G. (1957). Studies on Immunity to Toxins of Clostridium Botulinum II.: Production and Purification of Type B Toxin for Toxoid. Journal of Bacteriology, 73, 597-601.

Duff, J. T., Wright, G. G. and Yarinsky, A. (1956). Activation of Clostridium botulinum Type E Toxin by Trypsin. Journal of Bacteriology, 72, 455460.

DüV. (2006 (letzte Änderung vom 31. Juli 2009)). Verordnung über die Anwendung von Düngemitteln, Bodenhilfsstoffen, Kultursubstraten und Pflanzenhilfsmitteln nach den Grundsätzen der guten fachlichen Praxis beim Düngen (Düngeverordnung), B. d. Justiz, Ed, Bundesgesetzblatt.

East, A. K., Richardson, P. T., Allaway, D., Collins, M. D., Roberts, T. A. and Thompson, D. E. (1992). Sequence of the gene encoding type F neurotoxin of Clostridium botulinum. FEMS Microbiology Letters, 96, 225-230.

Eicken, K., Höltershinken, M. and Scholtz, H. (2010). Zusammenfassung des Vortrages " Bedingungen vor Ort und klinische Erscheinungen". Gesundheitsprobleme beim Einsatz von Grassilagen in Milchviehbeständen - Clostridium botulinum, Schloss vor Husum, pp. 24-30.

Eklund, M. W. and Poysky, F. T. (1972). Activation of a Toxic Component of Clostridium botulinum Types C and D by Trypsin. Applied Microbiology, 24, 108-113.

Eklund, M. W., Poysky, F. T., Meyers, J. A. and Pelroy, G. A. (1974). Interspecies conversion of Clostridium botulinum type $\mathrm{C}$ to Clostridium novyi type A by bacteriophage. Science, 186, 456-458.

Eklund, M. W., Poysky, F. T., Mseitif, L. M. and Strom, M. S. (1988). Evidence for plasmid-mediated toxin and bacteriocin production in Clostridium botulinum type G. Applied and Environmental Microbiology, 54, 14051408. 
Eklund, M. W., Poysky, F. T. and Reed, S. M. (1972). Bacteriophage and the toxigenicity of Clostridium botulinum type D. Nature New Biology, 235, 16-17.

Eklund, M. W., Poysky, F. T., Reed, S. M. and Smith, C. A. (1971). Bacteriophage and the Toxigenicity of Clostridium botulinum Type C. Science, 172, 480-482.

Ekong, T. A. N., Feavers, I. M. and Sesardic, D. (1997). Recombinant SNAP-25 is an effective substrate for Clostridium botulinum type A toxin endopeptidase activity in vitro. Microbiology, 143, 3337-3347.

Ekong, T. A. N., McLellan, K. and Sesardic, D. (1995). Immunological detection of Clostridium botulinum toxin type A in therapeutic preparations. Journal of Immunological Methods, 180, 181-191.

Elad, D., Yas-Natan, E., Aroch, I., Shamir, M. H., Kleinbart, S., Hadash, D., Chaffer, M., Greenberg, K. and Shlosberg, A. (2004). Natural Clostridium botulinum Type C Toxicosis in a Group of Cats. Journal of Clinical Microbiology, 42, 5406-5408.

Ermert, L., Bruckner, H., Walmrath, D., Grimminger, F., Aktories, K., Suttorp, N., Duncker, H. R. and Seeger, W. (1995). Role of endothelial cytoskeleton in high-permeability edema due to botulinum $\mathrm{C} 2$ toxin in perfused rabbit lungs. American Journal of Physiology - Lung Cellular and Molecular Physiology, 268, L753-L761.

EU-Kommission. (2006). Commission Recommendation of 17 August 2006 on the presence of deoxynivalenol, zearalenone, ochratoxin A, T-2 and HT2 and fumonisins in products intended for animal feeding (2006/576/EC)

Official Journal of the European Union, pp. 1-3.

Fach, P., Gibert, M., Griffais, R., Guillou, J. P. and Popoff, M. R. (1995). PCR and Gene Probe Identification of Botulinum Neurotoxin A-, B-, E-, F-, and G-Producing Clostridium spp. and Evaluation in Food Samples. Applied and Environmental Microbiology, 61, 389-392.

Fach, P., Gibert, M., Griffais, R. and Popoff, M. R. (1996). Investigation of animal botulism outbreaks by PCR and standard methods. FEMS Immunology and Medical Microbiology, 13, 279-285.

Fach, P., Micheau, P., Mazuet, C., Perelle, S. and Popoff, M. R. (2009). Development of real-time PCR tests for detecting botulinum neurotoxins A, B, E, F producing Clostridium botulinum, Clostridium baratii and Clostridium butyricum. Journal of Applied Microbiology, 107, 465-473.

Fenicia, L., Anniballi, F., De Medici, D., Delibato, E. and Aureli, P. (2007). SYBR Green Real-Time PCR Method To Detect Clostridium botulinum Type A . Applied and Environmental Microbiology, 73, 2891-2896.

Fenicia, L., Ferrini, A. M., Aureli, P. and Pocecco, M. (1993). A Case of Infant Botulism Associated with Honey Feeding in Italy. European Journal of Epidemiology, 9, 671-673.

Fenicia, L., Franciosa, G., Pourshaban, M. and Aureli, P. (1999). Intestinal Toxemia Botulism in Two Young People, Caused by Clostridium butyricum Type E. Clinical Infectious Diseases, 29, 1381-1387.

Ferracci, G., Miquelis, R., Kozaki, S., Seagar, M. and Lévêque, C. (2005). Synaptic vesicle chips to assay botulinum neurotoxins. Biochemical Journal, 391, 659-666.

Ferreira, J. L., Baumstark, B. R., Hamdy, M. K. and McCay, S. G. (1993). Polymerase Chain Reaction for Detection of Type A Clostridium botulinum in Foods. Journal of Food Protection, 56, 18-20.

Ferreira, J. L. and Crawford, R. G. (1998). Detection of Type A Botulinal toxinproducing Organisms Subcultured from Cheese Using an Amplified 
ELISA System. Journal of Rapid Methods \& Automation in Microbiology, 6, 289-296.

Ferreira, J. L. and Hamdy, M. K. (1995). Detection of botulinal toxin genes: types $\mathrm{A}$ and $\mathrm{E}$ or $\mathrm{B}$ and $\mathrm{F}$ using the Multiplex Polymerase Chain Reaction. Journal of Rapid Methods \& Automation in Microbiology, 3, 177-183.

Ferreira, J. L., Hamdy, M. K., Zapatka, F. A. and Hebert, W. O. (1981). Immunodiffusion method for detection of type A Clostridium botulinum. Applied and Environmental Microbiology, 42, 1057-1061.

Fischer, A. and Montal, M. (2007). Single molecule detection of intermediates during botulinum neurotoxin translocation across membranes. Proceedings of the National Academy of Sciences, 104, 10447-10452.

Franciosa, Hatheway and Aureli. (1998). The detection of a deletion in the type B neurotoxin gene of Clostridium botulinum A(B) strains by a two-step PCR. Letters in Applied Microbiology, 26, 442-446.

Franciosa, G., Fenicia, L., Caldiani, C. and Aureli, P. (1996). PCR for detection of Clostridium botulinum type $\mathrm{C}$ in avian and environmental samples. Journal of Clinical Microbiology, 34, 882-885.

Franciosa, G., Ferreira, J. L. and Hatheway, C. L. (1994). Detection of Type A, $\mathrm{B}$, and $\mathrm{E}$ Botulism Neurotoxin Genes in Clostridium botulinum and Other Clostridium Species by PCR: Evidence of Unexpressed Type B Toxin Genes in Type A Toxigenic Organisms. Journal of Clinical Microbiology, 32, 1911-1917.

Franciosa, G., Maugliani, A., Scalfaro, C. and Aureli, P. (2009). Evidence that Plasmid-Borne Botulinum Neurotoxin Type B Genes Are Widespread among Clostridium botulinum Serotype B Strains. Plos one, 4, e4829.

Fujii, N., Kubota, T., Shirakawa, S., Kimura, K., Ohishi, I., Moriishi, K., Isogai, E. and Isogai, H. (1996). Characterization of Component-I Gene of Botulinum C2 Toxin and PCR Detection of Its Gene in Clostridial Species. Biochemical and Biophysical Research Communications, 220, 353-359.

Fujinaga, Y., Inoue, K., Shimazaki, S., Tomochika, K., Tsuzuki, K., Fujii, N., Watanabe, T., Ohyama, T., Takeshi, K. and Oguma, K. (1994). Molecular Construction of Clostridium botulinum Type C Progenitor Toxin and Its Gene Organization. Biochemical and Biophysical Research Communications, 205, 1291-1298.

Fujinaga, Y., Takeshi, K., Inoue, K., Fujita, R., Ohyama, T., Moriishi, K. and Oguma, K. (1995). Type A and B Neurotoxin Genes in a Clostridium botulinum Type AB Strain. Biochemical and Biophysical Research Communications, 213, 737-745.

Fuller, R. (1989). Probiotics in man and animals. Journal of Applied Bacteriology, 66, 365-378.

Fürll, M. (2002). Stoffwechselstörungen bei Wiederkäuern: Erkennen Behandeln - Vorbeugen., Med. Tierklinik Leipzig, pp. 272.

Fürll, M. (2005). Stoffwechselüberwachung beim Rind. In: Klinische Labordiagnostik in der Tiermedizin, W. Kraft and U. M. Dürr, Eds, Schattauer Verlag, Stuttgart, pp. 459-474.

Galey, F. D. (2001). Botulism in the Horse. Veterinary Clinics of North America: Equine Practice, 17, 579-588.

Galey, F. D., Tera, R., Walker, R., Adaska, J., Etchebarne, M. A., Puschner, B., Fisher, E., Whitlock, R. H., Rocke, T. and Willoughby, D. (2000). Type C botulism in dairy cattle from feed contaminated with a dead cat. Journal of Veterinary Diagnostic Investigation, 12, 204-209. 
GENESIS-Online. (2011). Allgemeine und Repräsentative Erhebung über die Viehbestände, Statistisches Bundesamt, Wiesbaden.

Gerwing, J., Dolman, C. E. and Ko, A. (1965). Mechanism of Tryptic Activation of Clostridium botulinum Type E Toxin. Journal of Bacteriology, 89, 1176-1179.

Gessler, F. and Böhnel, H. (2004). Nachweis von Botulinum-Neurotoxinen ein methodischer Über- und Ausblick. Tierärztliche Umschau, 59, 5-9.

Gessler, F. and Böhnel, H. (2006). Persistence and mobility of a Clostridium botulinum spore population introduced to soil with spikes compost. FEMS Microbiology Ecology, 58, 384-393.

Gessler, F., Pagel-Wieder, S., Avondet, M. A. and Böhnel, H. (2007). Evaluation of lateral flow assays for the detection of botulinum neurotoxin type A and their application in laboratory diagnosis of botulism. Diagnostic Microbiology \& Infectious Disease, 57, 243-249.

Ghanem, F. M., Ridpath, A. C., Moore, W. E. and Moore, L. V. (1991). Identification of Clostridium botulinum, Clostridium argentinense, and related organisms by cellular fatty acid analysis. Journal of Clinical Microbiology, 29, 1114-1124.

Gibson, G. R., Macfarlane, G. T. and Cummings, J. H. (1993). Sulphate reducing bacteria and hydrogen metabolism in the human large intestine. GUT, 34, 437-439.

Gill, M. D. (1982). Bacterial Toxins: a Table of Lethal Amounts. Microbiological Reviews, 46, 86-94.

Giltner, L. T. and Couch, J. F. (1930). Western Duck Sickness and Botulism. Science, 72, 660.

Gimenez, D. F. and Ciccarelli, A. (1970a). Another type of Clostridium botulinum. Zentralblatt für Bakteriologie, Parasitenkunde, Infektionskrankheiten und Hygiene, Abt. I, 215, 221-224.

Gimenez, D. F. and Ciccarelli, A. S. (1970b). Studies on strain 84 of Clostridium botulinum. Zentralblatt für Bakteriologie, Parasitenkunde, Infektionskrankheiten und Hygiene, Abt. I, 215, 212-220.

Glasby, C. and Hatheway, C. L. (1985). Isolation and enumeration of Clostridium botulinum by direct inoculation of infant fecal specimens on egg yolk agar and Clostridium botulinum isolation media. Journal of Clinical Microbiology, 21, 264-266.

Gonzalez, D. J., Lee, S. W., Hensler, M. E., Markley, A. L., Dahesh, S., Mitchell, D. A., Bandeira, N., Nizet, V., Dixon, J. E. and Dorrestein, P. C. (2010). Clostridiolysin S, a Post-tranlationally Modified Biotoxin from Clostridium botulinum. Journal of Biological Chemistry, 285, 2822028228.

Gresner, N. (2011). Untersuchungen zum Einfluss von Grassilagen mit niedrigen Reineiweißgehalten auf den Eiweißstoffwechsel im Pansensaft in-vitro, Tierärztliche Hochschule, Hannover, pp. 327.

Griffin, P. M., Hatheway, C. L., Rosenbaum, R. B. and Sokolow, R. (1997). Endogenous Antibody Production to Botulinum Toxin in an Adult with Intestinal Colonization Botulism and Underlying Crohn's Disease. Journal of Infectious Diseases, 175, 633-637.

Grosse-Herrenthey, A., Maier, T., Gessler, F., Schaumann, R., Böhnel, H., Kostrzewa, M. and Krüger, M. (2008). Challenging the problem of clostridial identification with matrix-assisted laser desorption and ionization-time-of-flight mass spectrometry (MALDI-TOF MS). Anaerobe, 14, 242-249. 
Gunnison, J. B., Cummings, J. R. and Meyer, K. F. (1935). Clostridium botulinum Type E. Proceedings of the Society for Experimental Biology and Medicine, 35, 278-280.

Gutteridge, W. E., Knowler, J. and Coombes, J. D. (1969). Growth of Trypanosoma cruzi in Human Heart Tissue Cells and Effects of Aminonucleoside of Puromycin, Trypacidin and Aminopterin. Journal of Eukaryotic Microbiology, 16, 521-525.

Hall, J. D., McCroskey, L. M., Pincomb, B. J. and Hatheway, C. L. (1985). Isolation of an organism resembling Clostridium baratii which produces type $\mathrm{F}$ botulinal toxin from an infant with botulism. Journal of Clinical Microbiology, 21, 654-655.

Hallis, B., James, B. and Shone, C. (1996). Development of novel assays for botulinum type A and B neurotoxins based on their endopeptidase activities. Journal of Clinical Microbiology, 34, 1934-1938.

Halpin, B. (1981). Allgemeine Epidemiologie der Tierkrankheiten. Gustav Fischer Verlag, Jena, pp. 171.

Hannett, G. E., Stone, W. B., Davis, S. W. and Wroblewski, D. (2011). Biodiversity of Clostridium botulinum Type E Associated with a Large Outbreak of Botulism in Wildlife from Lake Erie and Lake Ontario. Applied and Environmental Microbiology, 77, 1061-1068.

Hatheway, C. L. (1992). Clostridium botulinum and other clostridia that produce botulinum neurotoxin. In: Clostridium botulinum - Ecology and Control in Foods, A. H. W. Hauschild and K. L. Dodds, Eds, Marcel Dekker, New York, pp. 3-20.

Hatheway, C. L. and McCroskey, L. M. (1987). Examination of feces and serum for diagnosis of infant botulism in 336 patients. Journal of Clinical Microbiology, 25, 2334-2338.

Hatheway, C. L., McCroskey, L. M., Lombard, G. L. and Dowell Jr., V. R. (1981). Atypical Toxin Variant of Clostridium botulinum Type B Associated with Infant Botulism. Journal of Clinical Microbiology, 14, 607-611.

Hauser, D., Eklund, M. W., Kurazono, H., Binz, T., Niemann, H., Gill, D. M., Boquet, P. and Popoff, M. R. (1990). Nucleotide sequence of Clostridium botulinum C1 neurotoxin. Nucleic Acids Research, 18, 4924.

Heid, C. A., Stevens, J., Livak, K. J. and Williams, P. M. (1996). Real time quantitative PCR. Genome Research, 6, 986-994.

Heider, L. C., McClure, J. T. and Leger, E. R. (2001). Presumptive diagnosis of Clostridium botulinum type D intoxication in a herd of feedlot cattle. Canadian Veterinary Journal, 42, 210-212.

Herrero, B. A., Ecklund, A. E., Spencer Streett, C., Ford, D. F. and King, J. K. (1967). Experimental botulism in monkeys--A clinical pathological study. Experimental and Molecular Pathology, 6, 84-95.

Higuchi, R., Dollinger, G., Walsh, P. S. and Griffith, R. (1992). Simultaneous amplification and detection of specific DNA-sequences. Biotechnology, 10, 413-417.

Hill, B. J., Skerry, J. C., Smith, T. J., Arnon, S. S. and Douek, D. C. (2010). Universal and specific quantitative detection of botulinum neurotoxin genes. BMC Microbiology, 10, 267-283.

Hill, K. K., Smith, T. J., Helma, C. H., Ticknor, L. O., Foley, B. T., Svensson, R. T., Brown, J. L., Johnson, E. A., Smith, L. A., Okinaka, R. T., Jackson, P. J. and Marks, J. D. (2007). Genetic diversity among Botulinum Neurotoxin-Producing Clostridial Strains. Journal of Bacteriology, 189, 818-832. 
Hill, K. K., Xie, G., Foley, B. T., Smith, T. J., Munk, A. C., Bruce, D. C., Smith, L. A., Brettin, T. S. and Detter, J. C. (2009). Recombination and insertion events involving the botulinum neurotoxin complex genes in Clostridium botulinum types A, B, E and F and Clostridium butyricum type E strains. BMC Biology, 7, 1-18.

Hinderink, K., Lindström, M. and Korkeala, H. (2009). Group I Clostridium botulinum strains show significant variation in growth at low and high temperatures. Journal of Food Protection, 72, 375-383.

Hoch, D. H., Romero-Mira, M., Ehrlich, B. E., Finkelstein, A., DasGupta, B. R. and Simpson, L. L. (1985). Channels Formed by Botulinum, Tetanus, and Diphtheria Toxins in Planar Lipid Bilayers: Relevance to Translocation of Proteins across Membranes. Proceedings of the National Academy of Sciences, 82, 1692-1696.

Holdeman, L. V. and Brooks, J. (1968). Variation among strains of Clostridium botulinum and related Clostridia. $1^{\text {st }}$ US-Japan Conference of Toxic Microorganisms, pp. 278-286.

Holzer, V. E. (1962). Botulismus durch Inhalation. Medizinische Klinik, 41, 1735-1738.

Höner, K. (2001). Einfluss von Silagen aus unterschiedlichen Maishybriden auf die Umsetzungen im Verdauungstrakt von Kühen. In: Klinik für Rinderkrankheiten der Tierärztlichen Hochschule Hannover und Institut für Tierernährung der Bundesforschungsanstalt für Landwirtschaft in Braunschweig, Tierärztliche Hochschule Hannover, Hannover, pp. 149.

Hörman, A., Nevas, M., Lindstrom, M., Hanninen, M.-L. and Korkeala, H. (2005). Elimination of Botulinum Neurotoxin (BoNT) Type B from Drinking Water by Small-Scale (Personal-Use) Water Purification Devices and Detection of BoNT in Water Samples. Applied and Environmental Microbiology, 71, 1941-1945.

Hubálek, Z. and Halouzka, J. (1991). Persistence of Clostridium botulinum type $\mathrm{C}$ toxin in blow fly (Calliphoridae) larvae as a possible cause of avian botulism in spring. Journal of Wildlife Diseases, 27, 81-85.

Hult, K., Teiling, A. and Gatenbeck, S. (1976). Degradation of Ochratoxin A by a Ruminant. Applied and Environmental Microbiology, 32, 443-444.

Hunter, L. C. and Poxton, I. R. (2002). Clostridium botulinum types C and D and the closely related Clostridium novyi. Reviews in Medical Microbiology, 13, 75-90.

Hutson, R. A., Collins, M. D., East, A. K. and Thompson, D. E. (1994). Nucleotide Sequence of the Gene Coding for Non-Proteolytic Clostridium botulinum Type B Neurotoxin:Comparison with Other Clostridial Neurotoxins. Current Microbiology, 28, 101-110.

Hutson, R. A., Zhou, Y., Collins, M. D., Johnson, E. A., Hatheway, C. L. and Sugiyama, H. (1996). Genetic Characterization of Clostridium botulinum Type A Containing Silent Type B Neurotoxin Gene Sequences. Journal of Biological Chemistry, 271, 10786-10792.

IfSG. (2000). Gesetz zur Verhütung und Bekämpfung von Infektionskrankheiten beim Menschen (Infektionsschutzgesetz - IfSG). In: 2126-13, B. d. Justiz, Ed, Bundesgesetzblatt.

Impfbericht. (2008). miprolab GmbH, Göttingen.

Inoue, K. and Iida, H. (1968). Bacteriophages of Clostridium botulinum. Journal of Virology, 2, 537-540.

InstitutFürTierernährungUndFutterwirtschaft. (2010). Gruber Tabelle zur Fütterung der Milchkühe, Zuchtrinder, Schafe und Ziegen. LfL FreisingWeihenstephan, pp. 86. 
Iwasaki, M., Ohishi, I. and Sakaguchi, G. (1980). Evidence that botulinum C2 toxin has two dissimilar components. Infection and Immunity, 29, 390394.

Iwasaki, M. and Sakaguchi, G. (1978). Acid precipitation of Clostridium botulinum type $\mathrm{C}$ and $\mathrm{D}$ toxins from whole culture by addition of ribonucleic acid as a precipitation aid. Infection and Immunity, 19, 749751.

Jänicke, H., Jakobs, M. and Böttcher, I. (2009). Grünlandnutzung für die Milchproduktion - Verfahren der Grünlandverbesserung und erneuerung mit nachhaltiger Tragfähigkeit, Vol. 2011, Landesforschungsanstalt für Landwirtschaft und Fischerei Mecklenburg Vorpommern.

Jansen, B. C. (1971). The toxic antigenetic factors produced by Clostridium botulinum types C and D. Onderstepoort Journal of Veterinary Research, 38, 93-98.

Jean, D., Fecteau, G., Scott, D., Higgins, R. and Quessy, S. (1995). Clostridium botulinum type $\mathrm{C}$ intoxication in feedlot steers being fed ensiled poultry litter. The Canadian veterinary journal, 36, 626-628.

Jin, Y., Takegahara, Y., Sugawara, Y., Matsumura, T. and Fujinaga, Y. (2009). Disruption of the epithelial barrier by botulinum haemagglutinin (HA) proteins - differences in cell tropism and the mechanism of action between HA proteins of types A or B, and HA proteins of type C. Microbiology, 155, 35-45.

Johnson, H. M., Brenner, K., Angelotti, R. and Hall, H. E. (1966). Serological Studies of Types A, B, and E Botulinal Toxins by Passive Hemagglutination and Bentonite Flocculation. Journal of Bacteriology, 91, 967-974.

Joshy, L., Chaudhry, R. and Chandel, D. S. (2008). Multiplex PCR for the detection of Clostridium botulinum \& $C$. perfringens toxin genes. Indian Journal of Medical Research, 128, 206-208.

Kalac, P. and Woolford, M. (1982). A review of some aspects of possible associations between the feeding of silage and animal health. British Veterinary Journal, 138, 305-320.

Kao, I., Drachman, D. B. and Price, D. L. (1976). Botulinum toxin: Mechanism of Presynaptic Blockade. Science, 193, 1256-1258.

Kerner, J. (1820). Neue Beobachtungen über die in Württemberg so häufig vorfallenden tödlichen Vergiftungen durch den Genuß geräucherter Würste. Osiander, Tübingen.

Kiessling, K. H., Pettersson, H., Sandholm, K. and Olsen, M. (1984). Metabolism of aflatoxin, ochratoxin, zearalenone, and three trichothecenes by intact rumen fluid, rumen protozoa, and rumen bacteria. Applied and Environmental Microbiology, 47, 1070-1073.

Kimura, B., Kawasaki, S., Nakano, H. and Fujii, T. (2001). Rapid, Quantitative PCR Monitoring of Growth of Clostridium botulinum Type E in ModifiedAtmosphere-Packaged Fish. Applied and Environmental Microbiology, 67, 206-216.

Kimura, K., Fujii, N., Tsuzuki, K., Murakami, T., Indoh, T., Yokosawa, N., Takeshi, K., Syuto, B. and Oguma, K. (1990). The complete nucleotide sequence of the gene coding for botulinum type $\mathrm{C} 1$ toxin in the C-ST phage genome. Biochemical and Biophysical Research Communications, 171, 1304-1311.

Kinde, H., Bettey, R. L., Ardans, A. A., Galey, F. D., Daft, B. M., Walker, R. L., Eklund, M. W. and Byrd, J. W. (1991). Clostridium botulinum type C intoxication associated with consumption of processed alfalfa hay cubes 
in horses. Journal of the American Veterinary Medical Association, 199, $742-746$.

Kirchner, S., Krämer, K. M., Schulze, M., Pauly, D., Jakob, D., Gessler, F., Nitsche, A., Dorner, B. G. and Dorner, M. B. (2010). A pentaplexed quantitative real-time PCR assay for the simultaneous detection and quantification of botulinum neurotoxin-producing clostridia in food and clinical samples. Applied and Environmental Microbiology, 76, 43874395.

Kitamura, M., Sakaguchi, S. and Sakaguchi, G. (1968). Purification and some properties of Clostridium botulinum type-E toxin. Biochimica et Biophysica Acta (BBA) - Protein Structure, 168, 207-217.

Klarmann, D. (1989). Nachweis von Clostridium botulinum in Kotproben von Rind und Schwein sowie in Rohmaterialien und Tiermehlen verschiedener Tierkörperbeseitigungsanlagen. Berliner und Münchener tierärztliche Wochenschrift, 102, 84-86.

Kleessen, B., Hartmann, L. and Blaut, M. (2001). Oligofructose and long-chain inulin: influence on the gut microbial ecology of rats associated with a human faecal flora. British Journal of Nutrition, 86, 291-300.

Kleessen, B., Hartmann, L. and Blaut, M. (2003). Fructans in the diet cause alterations of intestinal mucosal architecture, released mucins and mucosa-associated bifidobacteria in gnotobiotic rats. British Journal of Nutrition, 89, 597-606.

Koriazova, L. K. and Montal, M. (2003). Translocation of botulinum neurotoxin light chain protease through the heavy chain channel. Nature structural biology, 10, 13-18.

Kozaki, S., Dufrenne, J., Hagenaars, A. M. and Notermans, S. (1979). Enzyme linked immunosorbent assay (ELISA) for detection of Clostridium botulinum type B toxin. Japanese journal of medical science \& biology, 32, 199-205.

Kozaki, S., Nakaue, S. and Kamata, Y. (1995). Immunological Characterization of the Neurotoxin Produced by Clostridium botulinum Type A Associated with Infant Botulism in Japan. Microbiology and Immunology, 39, 767774.

Kozaki, S., Sakaguchi, S. and Sakaguchi, G. (1974). Purification and Some Properties of Progenitor Toxins of Clostridium botulinum Type B. Infection and Immunity, 10, 750-756.

Kraft, W., Dürr, U. M., Fürll, M., Bostedt, H. and Heinritzi, K. (2005). Harnapparat. In: Klinische Labordiagnostik in der Tiermedizin, W. Kraft and U. M. Dürr, Eds, Schattauer GmbH, Stuttgart, pp. 186-219.

Kreienbrock, L. and Schach, S. (2005). Epidemiologische Methoden. Elsevier, Spektrum Akademischer Verlag, München, pp. 273.

Kriek, N. P. J. and Odendaal, M. W. (1994). Botulism. In: Infectious diseases of livestock, J. A. W. Coetzer, G. R. Thomson and R. C. Tustin, Eds, Vol. 2, Oxford University Press, Kapstadt, pp. 1354-1371.

Krüger, M. and Schrödl, W. (2004). Zur Bedeutung der Magen-Darm-Flora bei landwirtschaftlichen Nutztieren, ihre Regulation und Möglichkeiten der Beeinflussung. Tierärztliche Umschau, 59, 41-46.

Krüger, M. and Schrödl, W. (2010). Abschlussbericht des Teilprojektes C8 aus dem Verbundprojekt Botulinom: Pathogenese des chronischen Botulismus - Bedeutung der gastrointestinalen Homöostase bei Kühen, Institut für Bakteriologie und Mykologie, Veterinärmedizinische Fakultät Leipzig, pp. 1-33. 
Krüger, M., Schroedl, W., Isik, W., Lange, W. and Hagemann, L. (2002). Effects of lactulose on the intestinal microflora of periparturient sows and their piglets. European Journal of Nutrition, 41, 26-31.

Kumaran, D., Eswaramoorthy, S., Furey, W., Navaza, J., Sax, M. and Swaminathan, S. (2009). Domain Organization in Clostridium botulinum Neurotoxin Type $\mathrm{E}$ Is Unique: Its Implication in Faster Translocation. Journal of Molecular Biology, 386, 233-245.

Lacy, D. B. and Stevens, R. C. (1999). Sequence homology and structural analysis of the clostridial neurotoxins. Journal of Molecular Biology, 291, 1091-1104.

Lacy, D. B., Tepp, W., Cohen, A. C., DasGupta, B. R. and Stevens, R. C. (1998). Crystal structure of botulinum neurotoxin type A and implications for toxicity. Nature structural biology, 5, 898-902.

Lamanna, C. (1959). The Most Poisonous Poison Science, 130, 763-772.

Lamanna, C. and Glassman, H. N. (1947). The Isolation of Type B Botulinum Toxin. Journal of Bacteriology, 54, 575-b-584.

Lamanna, C., McElroy, O. E. and Eklund, H. W. (1946). The purification and crystallization of Clostridium botulinum Type A toxin. Science, 103, 613614.

Lamanna, C. and Sakaguchi, G. (1971). Botulinal toxins and the problem of nomenclature of simple toxins. Bacteriological Reviews, 35, 242-249.

Landeskontrollverband, M. V. (2010). Jahresbericht 2010, Landeskontrollverband für Leistungs- und Qualitätsprüfung Mecklenburg-Vorpommern e.V., Güstrow, pp. 1-80.

Landmann, G. (1904). Über die Ursache der Darmstädter Bohnenvergiftung. Hygienische Rundschau, 10, 449-452.

Lang, A. E., Neumeyer, T., Sun, J., Collier, R. J., Benz, R. and Aktories, K. (2008). Amino Acid Residues Involved in Membrane Insertion and Pore Formation of Clostridium botulinum C2 Toxin. Biochemistry, 47, 84068413.

Lee, W. H. and Riemann, H. (1970a). Correlation of toxic and non-toxic strains of Clostridium botulinum by DNA composition and homology. Journal of General Microbiology, 60, 117-123.

Lee, W. H. and Riemann, H. (1970b). The Genetic Relatedness of Proteolytic Clostridium botulinum Strains. Journal of General Microbiology, 64, 8590.

Leuchs, J. (1910). Beiträge zur Kenntnis des Toxins und Antitoxins des Bacillus botulinus. Medical Microbiology and Immunology, 65, 55-84.

Lewis, G. E., Jr, Kulinski, S. S., Reichard, D. W. and Metzger, J. F. (1981). Detection of Clostridium botulinum type $\mathrm{G}$ toxin by enzyme-linked immunosorbent assay. Applied and Environmental Microbiology, 42, 1018-1022.

Lindberg, A., Knutsson, R., Blomqvist, G. and Baverud, V. (2010). Real-time PCR for Clostridium botulinum type $\mathrm{C}$ neurotoxin (BoNTC) gene, also covering a chimeric C/D sequence - application on outbreaks of botulism in poultry. Veterinary Microbiology, 146, 118-123.

Lindström, M., Keto, R., Markkula, A., Nevas, M., Hielm, S. and Korkeala, H. (2001). Multiplex PCR Assay for Detection and Identification of Clostridium botulinum Types A, B, E, and F in Food and Fecal Material. Applied and Environmental Microbiology, 67, 5694-5699.

Lindström, M., Myllykoski, J., Sivelä, S. and Korkeala, H. (2010). Clostridium botulinum in Cattle and Dairy Products. Critical Reviews in Food Science and Nutrition, 50, 281-304. 
Lindström, M., Nevas, M., Kurki, J., Sauna-aho, R., Latvala-Kiesila, A., Polonen, I. and Korkeala, H. (2004). Type C Botulism Due to Toxic Feed Affecting 52,000 Farmed Foxes and Minks in Finland. Journal of Clinical Microbiology, 42, 4718-4725.

Lindström, M. K., Jankola, H. M., Hielm, S., Hyytiä, E. K. and Korkeala, H. J. (1999). Identification of Clostridium botulinum with API 20 A, Rapid ID 32 A and RapID ANA II. FEMS Immunology \& Medical Microbiology, 24, 267-274.

Loch, P. (2000). Kulturell-biochemische und molekularbiologische Untersuchungen sowie Pathogenitätsprüfung von Clostridium botulinum-Stämmen - Ein Beitrag zur Taxonomie. In: Institut für Pflanzenbau und Tierproduktion in den Tropen und Subtropen / Bereich Tierhygiene der Georg-August-Universität Hannover und Institut für Mikrobiologie und Tierseuchen der Tierärztlichen Hochschule Hannover, pp. 1-222.

Lotthammer, K.-H. (1999). Beziehungen zwischen Leistungsniveau, Gesundheit, Fruchtbarkeit und Nutzungsdauer bei Milchrindern Untersuchungen in einer Hochleistungsherde. Tierärztliche Umschau, 54, 544-553.

Lowenthal, J. P. and Lamanna, C. (1951). Factors Affecting the Botulinal Hemagglutination Reaction, and the Relationship Between Hemagglutinating Activity and Toxicity of Toxin Preparations. American Journal of Epidemiology, 54, 342-353.

Lowenthal, J. P. and Lamanna, C. (1953). Characterization of Botulinal Hemagglutination. American Journal of Epidemiology, 57, 46-59.

Lúquez, C., Dykes, J. K., Yu, P. A., Raphael, B. H. and Maslanka, S. E. (2010). First Report Worldwide of an Infant Botulism Case Due to Clostridium Botulinum Type E. Journal of Clinical Microbiology, 48, 326-328.

Maksymowych, A., Reinhard, M., Malizio, C., Goodnough, M., Johnson, E. and Simpson, L. (1999). Pure botulinum neurotoxin is absorbed from the stomach and small intestine and produces peripheral neuromuscular blockade. Infection and Immunity, 67, 4708 - 4712.

Maksymowych, A. B. and Simpson, L. L. (1998). Binding and Transcytosis of Botulinum Neurotoxin by Polarized Human Colon Carcinoma Cells. Journal of Biological Chemistry, 273, $21950-21957$.

Marshall, K., Bradshaw, M. and Johnson, E. (2010). Conjugative botulinum neurotoxin-encoding plasmids in Clostridium botulinum. Plos one, 5, e 11087.

Marshall, K. M., Bradshaw, M., Pellett, S. and Johnson, E. A. (2007). Plasmid encoded neurotoxin genes in Clostridium botulinum serotype A subtypes. Biochemical and Biophysical Research Communications, 361, 49-54.

Matsumura, T., Jin, Y., Kabumoto, Y., Takegahara, Y., Oguma, K., Lencer, W. I. and Fujinaga, Y. (2008). The HA proteins of botulinum toxin disrupt intestinal epithelial intercellular junctions to increase toxin absorption. Cellular Microbiology, 10, 355-364.

Matsuoka, I., Syuto, B., Kurihara, K. and Kubo, S. (1987). ADP-ribosylation of specific membrane proteins in pheochromocytoma and primarycultured brain cells by botulinum neurotoxins type C and D. FEBS Letters, 216, 295-299.

Mauss, S., Chaponnier, C., Just, I., Aktories, K. and Gabbiani, G. (1990). ADPribosylation of actin isoforms by Clostridium botulinum $\mathrm{C} 2$ toxin and Clostridium perfringens iota toxin. European Journal of Biochemistry, 194, 237-241. 
Mawhinney, I., Palmer, D., Gessler , F., Cranwell, M., Foyle, L., Otter, A., Payne, J. and Strugnell, B. (2011). Investigation of serology for diagnosis of outbreaks of botulism in cattle. The Veterinary Journal, doi:10.1016/j.tvj1.2011.1008.1024.

McClung, L. S. and Toabe, R. (1947). The Egg Yolk Plate Reaction for the Presumptive Diagnosis of Clostridium sporogenes and Certain Species of the Gangrene and Botulinum Groups. Journal of Bacteriology, 53, 139147.

McCroskey, L. M. and Hatheway, C. L. (1988). Laboratory findings in four cases of adult botulism suggest colonization of the intestinal tract. Journal of Clinical Microbiology, 26, 1052-1054.

McCroskey, L. M., Hatheway, C. L., Fenicia, L., Pasolini, B. and Aureli, P. (1986). Characterization of an Organism That Produces Type E Botulinal Toxin But Which Resembles Clostridium butyricum from the Feces of an Infant with Type E Botulism. Journal of Clinical Microbiology, 23, 201-202.

McCroskey, L. M., Hatheway, C. L., Woodruff, B. A., Greenberg, J. A. and Jurgenson, P. (1991). Type F Botulism Due to Neurotoxigenic Clostridium baratii from an Unknown Source in an Adult. Journal of Clinical Microbiology, 29, 2618-2620.

McLoughlin, M. F., McIlroy, S. and Neill, S. (1988). A major outbreak of botulism in cattle being fed ensiled poultry litter. Veterinary Record, 579-581.

Merson, M. H. and Dowell, V. R., Jr. (1973). Epidemiologic, clinical and laboratory aspects of wound botulism. The New England journal of medicine, 289, 1005-1010.

Meyer, K. F. and Eddie, B. (1951). Perspectives concerning botulism. Zeitschrift für Hygiene und Infektionskrankheiten, 133, 255-263.

Meyer, K. F. and Gunnison, J. B. (1928). C botulinum Type D. Proceedings of the Society for Experimental Biology and Medicine, 26, 88-89.

Midura, T. F. and Arnon, S. S. (1976). Infant Botulism: Identification of Clostridium botulinum and its Toxins in Faeces. The Lancet, 308, 934936.

MilchgüteVO. (1981 (letzte Änderung 01.01.2011)). Verordnung über die Güteprüfung und Bezahlung der Anlieferungsmilch (MilchGüteverordnung), B. d. Justiz, Ed, Bundesgesetzblatt.

Miller, C. A. and Anderson, A. W. (1971). Rapid Detection and Quantitative Estimation of Type A Botulinum Toxin by Electroimmunodiffusion. Infection and Immunity, 4, 126-129.

Mills, D. C., Midura, T. F. and Arnon, S. S. (1985). Improved selective medium for the isolation of lipase-positive Clostridium botulinum from feces of human infants. Journal of Clinical Microbiology, 21, 947-950.

Miyake, M. and Ohishi, I. (1987). Response of tissue-cultured cynomolgus monkey kidney cells to botulinum C2 toxin. Microbial Pathogenesis, 3, 279-286.

Miyazaki, S., Iwasaki, M. and Sakaguchi, G. (1977). Clostridium botulinum type D toxin: purification, molecular structure, and some immunological properties. Infection and Immunity, 17, 395-401.

Möcklinghoff-Wicke, S. and Zieger, P. (2005). MLP Daten nicht nur für die Fütterungskontrolle nutzen! Nutzen Sie die umfangreichen Daten für ein zielgerichtetes Herdenmanagement!, Hessischer Bauernverband, pp. $1-23$.

Moeller, R. B., Puschner, B., Walker, R. L., Rocke, T., Galey, F. D., Cullor, J. S. and Ardans, A. A. (2003). Determination of the median toxic dose of 
type C botulinum toxin in lactating dairy cows. Journal of Veterinary Diagnostic Investigation, 15, 523-526.

Møller, V. and Scheibel, I. (1960). Preliminary report on the isolation of apparently new type of $\mathrm{Cl}$. botulinum. Acta Pathologica Microbiologica Scandinavica, 48, 80.

Montecucco, C., Papini, E. and Schiavo, G. (1994). Bacterial protein toxins penetrate cells via a four-step mechanism. FEBS Letters, 346, 92-98.

Montecucco, C. and Schiavo, G. (1994). Mechanism of action of tetanus and botulinum neurotoxins. Molecular Microbiology, 13, 1-8.

Moriishi, K., Koura, M., Abe, N., Fujii, N., Fujinaga, Y., Inoue, K. and Oguma, K. (1996a). Mosaic structures of neurotoxins produced from Clostridium botulinum types $\mathrm{C}$ and D organisms. Biochimica et Biophysica Acta, 1307, 123-126.

Moriishi, K., Koura, M., Fujii, N., Fujinaga, Y., Inoue, K., Syuto, B. and Oguma, K. (1996b). Molecular Cloning of the Gene Encoding the Mosaic Neurotoxin, Composed of Parts of Botulinum Neurotoxin Types C1 and D, and PCR Detection of This Gene from Clostridium botulinum Type C Organisms. Applied and Environmental Microbiology, 62, 662-667.

Moriishi, K., Syuto, B., Kubo, S. and Oguma, K. (1989). Molecular Diversity of Neurotoxins from Clostridium botulinum Type D Strains. Infection and Immunity, 57, 2886-2891.

Moss, C. W. and Lewis, V. J. (1967). Characterization of Clostridia by Gas Chromatography: I. Differentiation of Species by Cellular Fatty Acids. Applied and Environmental Microbiology, 15, 390-397.

Moura, H., Terilli, R. R., Woolfitt, A. R., Gallegos-Candela, M., McWilliams, L. G., Solano, M. I., Pirkle, J. L. and Barr, J. R. (2011). Studies on botulinum neurotoxins type /C1 and mosaic/DC using Endopep-MS and proteomics. FEMS Immunology \& Medical Microbiology, 61, 288300.

Myllykoski, J., Lindström, M., Keto-Timonen, R., Söderholm, H., Jakala, J., Kallio, H., Sukura, A. and Korkeala, H. (2009). Type C bovine botulism outbreak due to carcass contaminated non-acidified silage. Epidemiology and Infection, 137, 284-293.

Nakamura, S., Okado, I., Nakashio, S. and Nishida, S. (1977). Clostridium sporogenes Isolates and their Relationship to $C$. botulinum based on Deoxyribonucleic Acid Reassociation. Journal of General Microbiology, 100, 395-401.

Nevas, M., Hielm, S., Lindström, M., Horn, H., Koivuletho, K. and Korkeala, H. (2002). High prevalence of Clostridium botulinum types A and B in honey samples detected by polymerase chain reaction. International Journal of Food Microbiology, 72, 45-52.

Nevas, M., Lindström, M., Hautamäki, K., Puoskari, S. and Korkeala, H. (2005). Prevalence and diversity of Clostridium botulinum types A, B, E and $\mathrm{F}$ in honey produced in the Nordic countries. International Journal of Food Microbiology, 105, 145-151.

Noordhuizen, J. P. T. M., Frankena, K., Thrusfield, M. V. and Graat, E. A. M. (2001). Questionnaires for Field Surveys: Design and Conduct. Wageningen Press, Wageningen, pp. 429.

Notermans, S., Dufrenne, J. and Kozaki, S. (1979a). Enzyme-linked immunosorbent assay for detection of Clostridium botulinum type $\mathrm{E}$ toxin. Applied and Environmental Microbiology, 37, 1173-1175.

Notermans, S., Dufrenne, J. and Kozaki, S. (1982). The relation between toxicity and toxin-related-antigen contents of Clostridium botulinum 
types $\mathrm{C}$ and D cultures as determined by mouse bioassay and ELISA. Japanese journal of medical science \& biology, 35, 203-211.

Notermans, S., Dufrenne, J. and Oosterom, J. (1981). Persistence of Clostridium botulinum type B on a cattle farm after an outbreak of botulism. Applied and Environmental Microbiology, 41, 179-183.

Notermans, S., Dufrenne, J. and van Schothorst, M. (1978). Enzyme linked immunosorbent assay (ELISA) for detection of Clostridium botulinum toxin type A. Japanese journal of medical science \& biology, 31, 81-85.

Notermans, S., Kozaki, S. and van Schothorst, M. (1979b). Toxin production by Clostridium botulinum in grass. Applied and Environmental Microbiology, 38, 767-771.

Nowakowski, A., Wang, C., Powers, D. B., Amersdorfer, P., Smith, T. J., Montgomery, V. A., Sheridan, R., Blake, R., Smith, L. A. and Marks, J. D. (2002). Potent neutralization of botulinum neurotoxin by recombinant oligoclonal antibody. Proceedings of the National Academy of Sciences, 99, 11346-11350.

Nussbaum, H., Weißbach, F., Elsässer, M., Schenkel, H., Staudacher, W., von Borstel, U., Groß, F., Seibold, R. and Rieder, J. B. (2004). Grobfutterbewertung Teil A - DLG-Schlüssel zur Bewertung von Grünfutter, Silage und Heu mit Hilfe der Sinnenprüfung. DLGInformation, 1, 1-16.

Nussbaum, H. J. (2010). Total-Misch-Ration und Vorrats-TMR für den Milchviehbetrieb, Bildungs- und Wissenszentrum Aulendorf (LVVG), Aulendorf, pp. 2.

Obermayr, N. (2005). Milchviehfütterung, LIKRA Linzer Kraftfutter GmbH \& Co., Linz, pp. 1-13.

Oguma, K. (1976). The stability of toxigenicity in Clostridium botulinum types C and D. Journal of General Microbiology, 92, 67-75.

Oguma, K., Murayama, S., Syuto, B., Iida, H. and Kubo, S. (1984). Analysis of antigenicity of Clostridium botulinum type $\mathrm{C} 1$ and $\mathrm{D}$ toxins by polyclonal and monoclonal antibodies. Infection and Immunity, 43, 584-588.

Oguma, K., Syuto, B., Agui, T., Iida, H. and Kubo, S. (1981). Homogeneity and Heterogeneity of Toxins Produced by Clostridium botulinum Type C and D Strains. Infection and Immunity, 34, 382-388.

Oguma, K., Syuto, B., Iida, H. and Kubo, S. (1980). Antigenetic Similarity of Toxins Produced by Clostridium botulinum Type C and D Strains. Infection and Immunity, 30, 656-660.

Oguma, K., Yokota, K., Hayashi, S., Takeshi, K., Kumagai, M., Itoh, N., Tachi, N. and Chiba, S. (1990). Infant botulism due to Clostridium botulinum type C toxin. The Lancet, 336, 1449-1450.

Ohishi, I. (1983a). Lethal and vascular permeability activities of botulinum C2 toxin induced by separate injections of the two toxin components. Infection and Immunity, 40, 336-339.

Ohishi, I. (1983b). Response of mouse intestinal loop to botulinum C2 toxin: enterotoxic activity induced by cooperation of nonlinked protein components. Infection and Immunity, 40, 691-695.

Ohishi, I. (1986). NAD-Glycohydrolase Activity of Botulinum C2 Toxin: A Possible Role of Component I in the Mode of Action of the Toxin. Journal of Biochemistry, 100, 407-413.

Ohishi, I., Iwasaki, M. and Sakaguchi, G. (1980a). Purification and characterization of two components of botulinum $\mathrm{C} 2$ toxin. Infection and Immunity, 30, 668-673. 
Ohishi, I., Iwasaki, M. and Sakaguchi, G. (1980b). Vascular permeability activity of botulinum $\mathrm{C} 2$ toxin elicited by cooperation of two dissimilar protein components. Infection and Immunity, 31, 890-895.

Ohishi, I. and Okada, Y. (1986). Heterogeneities of Two Components of C2 Toxin Produced by Clostridium botulinum Types C and D. Journal of General Microbiology, 132, 125-131.

Ohishi, I. and Sakaguchi, G. (1974). Purification of Clostridium botuliunum type F progenitor toxin. Applied Microbiology, 28, 923-928.

Ohishi, I. and Sakaguchi, G. (1975). Molecular Construction of Clostridium botulinum type F Progenitor Toxin. Applied Microbiology, 29, 444-447.

Ohishi, I. and Sakaguchi, G. (1977). Activation of botulinum toxins in the absence of nicking. Infection and Immunity, 17, 402-407.

Ohishi, I. and Sakaguchi, G. (1980). Oral toxicities of Clostridium botulinum type $\mathrm{C}$ and $\mathrm{D}$ toxins of different molecular sizes. Infection and Immunity, 28, 303-309.

Ohishi, I., Sakaguchi, G., Riemann, H., Behymer, D. and Hurvell, B. (1979). Antibodies to Clostridium botulinum toxins in free-living birds and mammals. Journal of Wildlife Diseases, 15, 3-9.

Ohishi, I., Sugii, S. and Sakaguchi, G. (1977). Oral toxicities of Clostridium botulinum toxins in response to molecular size. Infection and Immunity, 16, 107-109.

Ohishi, I. and Tsuyama, S. (1986). ADP-ribosylation of nonmuscle actin with component I of C2 toxin. Biochemical and Biophysical Research Communications, 136, 802-806.

Olsen, I., Johnson, J. L., Moore, L. V. H. and Moore, W. E. C. (1995). Rejection of Clostridium putrificum and Conservation of Clostridium botulinum and Clostridium sporogenes Request for an opinion. International Journal of Systematic Bacteriology, 45, 414.

Olsen, J. E. and Larsen, H. E. (1987). Bacterial decimation times in anaerobic digestions of animal slurries. Biological Wastes, 21, 153-168.

Ozutsumi, Y., Tajima, K., Takenaka, A. and Itabashi, H. (2005). The effect of protozoa on the composition of rumen bacteria in cattle using 16S rRNA gene clone libraries. Bioscience, Biotechnology, and Biochemistry, 69, 499-506.

Paisley, J. W., Lauer, B. A. and Arnon, S. S. (1995). A Second Case of Infant Botulism Type F Caused by Clostridium baratii. The Pediatric Infectious Disease Journal, 14, 912-914.

Park, J. B. and Simpson, L. L. (2003). Inhalational poisoning by botulinum toxin and inhalation vaccination with its heavy-chain component. Infection and Immunity, 71, 1147-1154.

Poli, M. A., Rivera, V. R. and Neal, D. (2002). Development of sensitive colorimetric capture ELISAs for Clostridium botulinum neurotoxin serotypes E and F. Toxicon, 40, 797-802.

Popoff, M., Boquet, P., Gill, D. M. and Eklund, M. W. (1990). DNA sequence of exoenzyme C3, an ADP-ribosyltransferase encoded by Clostridium botulinum C and D phages. Nucleic Acids Research, 18, 1291.

Popoff, M. R. and Lecoanet, J. (1987). Botulinum type D toxin and Clostridium perfringens enterotoxin in a bull calf. The Veterinary Record, 121, 591592.

Poulet, S., Hauser, D., Quanz, M., Niemann, H. and Popoff, M. R. (1992). Sequences of the botulinal neurotoxin $\mathrm{E}$ derived from Clostridium botulinum type E (strain beluga) and Clostridium butyricum (strains ATCC 43181 and ATCC 43755). Biochemical and Biophysical Research Communications, 183, 107-113. 
Prévot, A. R. (1953). Rapport D'introduction Du President Du Souscomite Clostridium Pour L'unification De La Nomenclature Des Types Toxinogenes De C. botulinum. International Bulletin of Bacteriological Nomenclature and Taxonomy, 3, 120-123.

Prévot, A. R. and Brygoo, E. R. (1953). Nouvelle recherches sur le botulisme et ses cinq types toxigeniques. Annales de l'Institut Pasteur, 85, 544-575.

Raatjes, G. J. M. and Smelt, J. P. P. M. (1979). Clostridium botulinum can grow and form toxin at $\mathrm{pH}$ values lower than 4,6. Nature, 281, 398-399.

Raphael, B. H. and Andreadis, J. (2007). Real-time PCR detection of the nontoxic nonhemagglutinin gene as a rapid screening method for bacterial isolates harboring the botulinum neurotoxin (A-G) gene complex. Journal of Microbiological Methods, 71, 343-346.

Raphael, B. H., Choudoir, M. J., Luquez, C., Fernandez, R. and Maslanka, S. E. (2010). Sequence Diversity of Genes Encoding Botulinum Neurotoxin Type F. Applied and Environmental Microbiology, 76, 4805-4812.

Reuner, K. H., Presek, P., Boschek, B. and Aktories, K. (1987). Botulinum C2 toxin ADP-ribosylates actin and disorganizes the microfilament network in intact cells. European Journal of Cell Biology, 43, 134-140.

Richter, W., Zimmermann, N., Abriel, M., Schuster, M., Kölln-Höllrigl, K., Ostertag, J., Meyer, K., Bauer, J. and Spiekers, H. (2009). Hygiene bayerischer Silagen: Validierung einer Checkliste zum Controlling am Silo, Vol. 09, Bayerische Landesanstalt für Landwirtschaft (LfL), München, pp. 1-139.

Ricketts, S. W., Greet, T., Glyn, P., Ginnett, G., McAllister, E., McCaig, J., Skinner, P., Webbon, P., Frape, D., Smith, G. and Murray, G. (1984). Thirteen cases of botulism in horses fed big bale silage. Equine Veterinary Journal, 16, 515-518.

RKI. (2007). Falldefinitionen des Robert Koch-Instituts zur Übermittlung von Erkrankungs- oder Todesfällen und Nachweisen von Krankheitserregern, Robert Koch-Institut, Berlin, pp. 1-137.

RKI. (2011). www3.rki.de/SurvStat, Datenstand: 22.06.2011. In: SurvStat, Vol. 2011, Robert Koch-Institut.

Robertson, M. (1915). Notes upon certain anaerobes isolated from wounds. The Journal of Pathology and Bacteriology, 20, 327-349.

Rodriguez, A. and Dezfulian, M. (1997). Rapid identification of Clostridium botulinum and botulinal toxin in food. Folia Microbiologica, 42, 149-151.

Rooney, J. R. and Prickett, M. E. (1967). Shaker foal syndrome. Modern Veterinary Practice, 48, 44-45.

Rösener, S., Chhatwal, G. S. and Aktories, K. (1987). Botulinum ADPribosyltransferase $\mathrm{C} 3$ but not botulinum neurotoxins $\mathrm{C} 1$ and D ADPribosylates low molecular mass GTP-binding proteins. FEBS Letters, 224, 38-42.

Rossow, N. (2004). Die Hochleistungskuh. In: Tiergesundheits- und Tierkrankheitslehre, W. Busch, W. Methling and W. M. Amselgruber, Eds, Parey Verlag, Stuttgart, pp. 129-141.

Rubin, E. J., Gill, D. M., Boquet, P. and Popoff, M. R. (1988). Functional modification of a 21-kilodalton G protein when ADP-ribosylated by exoenzyme C3 of Clostridium botulinum. Molecular and Cellular Biology, 8, 418-426.

Saiki, R. K., Gelfand, D. H., Stoffel, S., Scharf, S. J., Higuchi, R., Horn, G. T., Mullis, K. B. and Erlich, H. A. (1988). Primer-Directed Enzymatic Amplification of DNA with a Thermostable DNA Polymerase. Science, 29, 487-491. 
Sandler, R., Rocke, T., Samuel, M. and Yuill, T. (1993). Seasonal prevalence of Clostridium botulinum type $\mathrm{C}$ in sediments of a northern California wetland. Journal of Wildlife Diseases, 29, 533-539.

Santos-Buelga, J. A., Collins, M. D. and East, A. K. (1998). Characterization of the Genes Encoding the Botulinum Neurotoxin Complex in A Strain of Clostridium botulinum Producing Type B and F Neurotoxins. Current Microbiology, 37, 312-318.

Schettler, C. H. (1979). Clostridium Botulinum Typ C - Intoxikation bei Broilern in Nordwestdeutschland. Berliner und Münchner Tierärztliche Wochenschrift, 92, 50-57.

Schiavo, G., Benfenati, F., Poulain, B., Rossetto, O., Polverino de Laurelo, P., DasGupta, B. R. and Montecucco, C. (1992a). Tetanus and botulinum$\mathrm{B}$ neurotoxins block neurotransmitter release by proteolytic cleavage of synaptobrevin. Nature, 359, 832-835.

Schiavo, G., Malizio, C., Trimble, W. S., Polverino de Laureto, P., Milan, G., Sugiyama, H., Johnson, E. A. and Montecucco, C. (1994a). Botulinum $\mathrm{G}$ neurotoxin cleaves VAMP/synaptobrevin at a single Ala-Ala peptide bond. Journal of Biological Chemistry, 269, 20213-20216.

Schiavo, G., Matteoli, M. and Montecucco, C. (2000). Neurotoxins Affecting Neuroexocytosis. Physiological Reviews, 80, 717-766.

Schiavo, G., Rossetto, O., Benfenati, F., Poulain, B. and Montecucco, C. (1994b). Tetanus and Botulinum Neurotoxins Are Zinc Proteases Specific for Components of the Neuroexocytosis Apparatus. Annals of the New York Academy of Sciences, 710, 65-75.

Schiavo, G., Rossetto, O., Catsicas, S., Polverino de Laureto, P., DasGupta, B. R., Benfenati, F. and Montecucco, C. (1993a). Identification of the nerve terminal targets of botulinum neurotoxin serotypes A, D, and E. Journal of Biological Chemistry, 268, 23784-23787.

Schiavo, G., Rossetto, O., Santucci, A., DasGupta, B. R. and Montecucco, C. (1992b). Botulinum neurotoxins are zinc proteins. Journal of Biological Chemistry, 267, 23479-23483.

Schiavo, G., Shone, C. C., Rossetto, O., Alexander, F. C. and Montecucco, C. (1993b). Botulinum neurotoxin serotype $\mathrm{F}$ is a zinc endopeptidase specific for VAMP/synaptobrevin. Journal of Biological Chemistry, 268, 11516-11519.

Schmidt, J. J., Stafford, R. G. and Millard, C. B. (2001). High-Throughput Assays for Botulinum Neurotoxin Proteolytic Activity: Serotypes A, B, D, and F. Analytical Biochemistry, 296, 130-137.

Schocken-Iturrino, R., Avila, F., Berchielli, S. and Nader Filho, A. (1990). First case of type A botulism in zebu (Bos indicus) Veterinary Record, 126, 217-218.

Scholtz, H., Eicken, K. and Höltershinken, M. (2010). Versuche zur ätiologischen Klärung der Multifaktorenerkrankung beim Milchvieh. Gesundheitsprobleme beim Einsatz von Grassilagen in Milchviehbeständen - Clostridium botulinum, Schloss vor Husum, pp. 31-33.

Schrödl, W., Kleessen, B. and Große-Herrenthey, A. (2007). Untersuchungen zu Vorkommen und Verbreitung von Clostridium botulinum in Rinderbeständen des Freistaates Sachsen. Schriftenreihe der Sächsischen Landesanstalt für Landwirtschaft, 28/2007, 14-34.

Schulze, B. (2008). Ex vivo-Veränderungen von Parametern des Stoffwechselprofils im Rinderblut - Ein Beitrag zur Entwicklung von Qualitätsstandards für die Blutentnahme beim Rind. In: Klinik für 
Klauentiere des Fachbereichs Veterinärmedizin, Freie Universität Berlin, Berlin, pp. 201.

Schwagerick, B. (2004a). Klinische Fälle von Viszeralem Botulismus bei Milchrindern in Mecklenburg-Vorpommern. Tierärztliche Umschau, 59, 25-29.

Schwagerick, B. (2004b). Leitlinien und Prüfliste für das Vorgehen in Milchviehbeständen mit dem Krankheitsbild einer Faktorenerkrankung, L. Ministerium für Ernährung, Forsten und Fischerei des Landes Mecklenburg-Vorpommern, Ed, pp. 1-36.

Schwagerick, B. (2010). Was ist vizeraler Botulismus? Erfahrungen zur Diagnostik und Bekämpfung. AVA Tagung, pp. 1-5.

Schwagerick, B. (2011a). persönliche Mitteilung - Wiederkauverhalten und Lautäußerungen der untersuchten Tiere, S. Beykirch, Ed, Köln.

Schwagerick, B. (2011b). Viszeraler Botulismus - Klinisches Bild, Nürnberg, pp. 1-3.

Schwagerick, B. and Böhnel, H. (2001). Eine chronische Erkrankung bei Milchkühen mit Nachweis von Botulinumtoxin - eine Fallstudie. Der praktische Tierarzt, 82, 516-524.

Schwan, C., Stecher, B., Tzivelekidis, T., van Ham, M., Rohde, M., Hardt, W.D., Wehland, J. and Aktories, K. (2009). Clostridium difficile Toxin CDT Induces Formation of Microtubule-Based Protrusions and Increases Adherence of Bacteria. PLoS Pathogens, 5, e1000626.

Scott, V. N. and Duncan, C. L. (1978). Cryptic plasmids in Clostridium botulinum and C. botulinum-like organisms. FEMS Microbiology Letters, 4, 55-58.

Sebaihia, M., Peck, M. W., Minton, N. P., Thomson, N. R., Holden, M. T. G., Mitchell, W. J., Carter, A. T., Bentley, S. D., Mason, D. R., Crossman, L., Paul, C. J., Ivens, A., Wells-Bennik, M. H. J., Davis, I. J., CerdeñoTárraga, A. M., Churcher, C., Quail, M. A., Chillingworth, T., Feltwell, T., Fraser, A., Goodhead, I., Hance, Z., Jagels, K., Larke, N., Maddison, M., Moule, S., Mungall, K., Norbertczak, H., Rabbinowitsch, E., Sanders, M., Simmonds, M., White, B., Whithead, S. and Parkhill, J. (2007). Genome sequence of a proteolytic (Group I) Clostridium botulinum strain Hall A and comparative analysis of the clostridial genomes Genome Research, 17, 1082-1092.

Seddon, H. R. (1922). Bulbar paralysis in cattle due to the action of a toxigenic bacillus with a discussion of the relationship of the condition to forage poisoning (botulism). Journal of comparative pathology and therapeutics, 35, 147-190.

Segner, W. P., Schmidt, C. F. and Boltz, J. K. (1971). Minimal Growth Temperature, Sodium Chloride Tolerance, $\mathrm{pH}$ Sensitivity, and Toxin Production of Marine and Terrestrial Strains of Clostridium botulinum Type C. Applied Microbiology, 22, 1025-1029.

Seifert, H. S. H., Böhnel, H., Giercke, S., Heine, A., Hoffmann, D., Sukop, U. and Boege, D. H. (1986). Routine identification of clostridia using headspace GC and integral biometric analysis. International Laboratory, 46-56.

Seyboldt, C. (2010). Clostridium botulinum, Botulismus, "viszeraler Botulismus". Gesundheitsprobleme beim Einsatz von Grassilagen in Milchviehbeständen - Clostridium botulinum, Schloss vor Husum, pp. 14.

Shapiro, R. L., Hatheway, C. and Swerdlow, D. L. (1998). Botulism in the United States: A Clinical and Epidemiologic Review. Annals of internal medicine, 129, 221-228. 
Sharma, S. K., Eblen, B. S., Bull, R. L., Burr, D. H. and Whiting, R. C. (2005). Evaluation of Lateral-Flow Clostridium botulinum Neurotoxin Detection Kits for Food Analysis. Applied and Environmental Microbiology, 71, 3935-3941.

Shiokawa, S., Sakai, K., Akimoto, Y., Suzuki, N., Hanashi, H., Nagamatsu, S., Iwashita, M., Nakamura, Y., Hirano, H. and Yoshimura, Y. (2000). Function of the Small Guanosine Triphosphate-Binding Protein RhoA in the Process of Implantation. Journal of Clinical Endocrinology \& Metabolism, 85, 4742-4749.

Shiota, M., Tanihiro, T., Nakagawa, Y., Aoki, N., Ishida, N., Miyazaki, K., Ullrich, A. and Miyazaki, H. (2003). Protein Tyrosine Phosphatase PTP20 Induces Actin Cytoskeleton Reorganization by Dephosphorylating p190 RhoGAP in Rat Ovarian Granulosa Cells Stimulated with Follicle-Stimulating Hormone. Molecular Endocrinology, 17, 534-549.

Shirazi, T., Longman, R. J., Corfield, A. P. and Probert, C. S. J. (2000). Mucins and inflammatory bowel disease. Postgraduate Medical Journal, 76, 473-478.

Shone, C., Wilton-Smith, P., Appleton, N., Hambleton, P., Modi, N., Gatley, S. and Melling, J. (1985). Monoclonal antibody-based immunoassay for type A Clostridium botulinum toxin is comparable to the mouse bioassay. Applied and Environmental Microbiology, 50, 63-67.

Siegel, L. S. (1988). Human immune response to botulinum pentavalent (ABCDE) toxoid determined by a neutralization test and by an enzymelinked immunosorbent assay. Journal of Clinical Microbiology, 26, 23512356.

Simianer, H. (1988). Zusammenhänge zwischen Krankheitsanfälligkeit und Milchleistungsmerkmalen beim Norwegischen Rotvieh. Deutsche tierärztliche Wochenschrift, 95, 165-167.

Simmons, G. C. and Tammemagi, L. (1964). Clostridium botulinum type D as a cause of bovine botulism in Queensland. Australian Veterinary Journal, 40, $123-127$.

Simpson, L. I. (1989). The binary toxin produced by Clostridium botulinum enters cells by receptor-mediated endocytosis to exert its pharmacologic effects. Journal of Pharmacology and Experimental Therapeutics, 251, 1223-1228.

Simpson, L. L. (1971). Ionic requirements for the neuromuscular blocking action of botulinum toxin: Implications with regard to synaptic transmission. Neuropharmacology, 10, 673-684.

Simpson, L. L. (1973). The interaction between divalent cations and botulinum toxin type a in the paralysis of the rat phrenic nerve-hemidiaphragm preparation. Neuropharmacology, 12, 165-176.

Simpson, L. L. (1974). Studies on the binding of botulinum toxin type a to the rat phrenic nerve-hemidiaphragm preparation. Neuropharmacology, 13, 683-691.

Simpson, L. L. (1980). Kinetic studies on the interaction between botulinum toxin type A and the cholinergic neuromuscular junction. Journal of Pharmacology and Experimental Therapeutics, 212, 16-21.

Simpson, L. L. (1982). A comparison of the pharmacological properties of Clostridium botulinum type $\mathrm{C} 1$ and $\mathrm{C} 2$ toxins. Journal of Pharmacology and Experimental Therapeutics, 223, 695-701.

Simpson, L. L. (1986). Molecular Pharmacology of Botulinum Toxin and Tetanus Toxin. Annual Review of Pharmacology and Toxicology, 26, 427-453. 
Simpson, L. L. (2004). Identification of the major steps in botulinum toxin action. Annual Review of Pharmacology and Toxicology, 44, 167-193.

SIS-OnlineMV. (2011). Landwirtschaftliche Betriebe mit Viehhaltung, S. L. Mecklenburg-Vorpommern, Ed, Statistisches Landesamt MecklenburgVorpommern, Schwerin.

Skarin, H., Hafstrom, T., Westerberg, J. and Segerman, B. (2011). Clostridium botulinum group III: a group with dual identity shaped by plasmids, phages and mobile elements. BMC Genomics, 12, 185.

Skarin, H., Lindberg, A., Aspan, A., Baverud, V. and Blomqvist, G. (2010). Molecular characterization and comparison of Clostridium botulinum type C avian strains. Avian Pathology, 39, 511-518.

Smart, J. L., Jones, T., Clegg, F. and McMurtry, M. (1987). Poultry waste associated type $\mathrm{C}$ botulism in cattle. Epidemiology and Infection, 98, 7379.

Smith, G. R. and Turner, A. (1989). The production of Clostridium botulinum toxin in mammalian, avian and piscine carrion. Epidemiology and Infection, 102, 467-471.

Smith, L. D. (1977). Botulism. The organism, its toxins, the disease.

Smith, T. J., Hill, K. K., Foley, B. T., Detter, J. C., Munk, A. C., Bruce, D. C., Doggett, N. A., Smith, L. A., Marks, J. D., Xie, G. and Brettin, T. S. (2007). Analysis of the Neurotoxin Complex Genes in Clostridium botulinum A1-A4 and B1 Strains: BoNT/A3, /Ba4 and /B1 Clusters Are Located within Plasmids. Plos one, 2, e1271 (1271-1210).

Smith, T. J., Lou, J., Geren, I. N., Forsyth, C. M., Tsai, R., LaPorte, S. L., Tepp, W. H., Bradshaw, M., Johnson, E. A., Smith, L. A. and Marks, J. D. (2005). Sequence Variation within Botulinum Neurotoxin Serotypes Impacts Antibody Binding and Neutralization. Infection and Immunity, 73, 5450-5457.

Snoeyenbos, G. H., Weinack, O. M. and Soerjadi, A. (1983). Competitive exclusion of some pathogens other than salmonella by native instestinal microflora of chickens. In: 22nd World Veterinary Congress, C. Main, Ed, Perth, Australia, pp. 191.

Sonnabend, O., Sonnabend, W., Heinzle, R., Sigrist, T., Dirnhofer, R. and Krech, U. (1981). Isolation of Clostridium botulinum type $G$ and identification of type $\mathrm{G}$ botulinal toxin in humans: Report of five sudden unexpected deaths. Journal of Infectious Diseases, 143, 22-27.

Sonnabend, W. F., O., S., Gründler, P. and Ketz, E. (1987). Intestinal toxicoinfection by Clostridium botulinum type $\mathrm{F}$ an an adult. The Lancet, 329, 357-361.

Spiekers, H. (2004). Tierphysiologische Anforderungen an die Silagequalität, Institut für Tierernährung (LfL).

Sreemannarayana, O., Frohlich, A. A., Vitti, T. G., Marquardt, R. R. and Abramson, D. (1988). Studies of the Tolerance and Disposition of Ochratoxin a in Young Calves. Journal of Animal Science, 66, 17031711.

Steinman, A., Chaffer, M., Elad, D. and Shpigel, N. Y. (2006). Quantitative Analysis of Levels of Serum Immunoglobulin G against Botulinum Neurotoxin Type D and Association with Protection in Natural Outbreaks of Cattle Botulism. Clinical and Vaccine Immunology, 13, 862-868.

Sterthoff, C. (2011). Clostridium botulinum in der Landwirtschaft und in der Biogasproduktion: Funktionale Charakterisierung eines neuen C2Toxins und Metagenomik eines Gärrestes. In: Fakultät für Biologie, Universität Bielefeld, pp. 1-96. 
Sterthoff, C., Lang, A. E., Schwan, C., Tauch, A. and Aktories, K. (2010). Functional Characterization of an Extended Binding Component of the Actin-ADP-Ribosylating C2 Toxin Detected in Clostridium botulinum Strain (C) 2300. Infection and Immunity, 78, 1468-1474.

Strom, M. S., Eklund, M. W. and Poysky, F. T. (1984). Plasmids in Clostridium botulinum and related Clostridium species. Applied and Environmental Microbiology, 48, 956-963.

Südekum, K.-H. (2010). Fettsäurezusammensetzung der Milch in Abhängigkeit von der Rationsgestaltung. DMK-Tagung Futterkonservierung und Fütterung, Grub, pp. 27-32.

Suen, J. C., Hatheway, C., Steigerwalt, A. and Brenner, D. (1988a). Genetic confirmation of identities of neurotoxigenic Clostridium baratii and Clostridium butyricum implicated as agents of infant botulism. Journal of Clinical Microbiology, 26, 2191-2192.

Suen, J. C., Hatheway, C. L., Steigerwalt, A. G. and Brenner, D. J. (1988b). Clostridium argentinense sp. nov.: A Genetically Homogeneous Group Composed of All Strains of Clostridium botulinum Toxin Type G and Some Nontoxigenic Strains Previously Identified as Clostridium subterminale or Clostridium hastiforme. International Journal of Systematic Bacteriology, 38, 375-381.

Sugii, S. and Sakaguchi, G. (1975). Molecular construction of Clostridium botulinum type A toxins. Infection and Immunity, 12, 1262-1270.

Sugii, S. and Sakaguchi, G. (1977). Botulogenic Properties of Vegetables with Special Reference to the Molecular Size of the Toxin in them. Journal of Food Safety, 1, 53-65.

Sugiyama, H. (1980). Clostridium botulinum neurotoxin. Microbiological Reviews, 44, 419-448.

Sunagawa, H., Ohyama, T., Watanabe, T. and Inoue, K. (1992). The Complete Amino Acid Sequence of the Clostridium botulinum Type D Neurotoxin, Deduced by Nucleotide Sequence Analysis of the Encoding Phage d-16 $\varphi$ Genome. Journal of Veterinary Medical Science, 54, 905-913.

Swaminathan, S. (2011). Molecular Structures and Functional Relationships in Clostridial Neurotoxins. FEBS Journal.

Swaminathan, S. and Eswaramoorthy, S. (2000). Structural analysis of the catalytic and binding sites of Clostridium botulinum neurotoxin B. Nature structural biology, 7, 693-699.

Swedberg, J., Wendel, T. H. and Deiss, F. (1987). Wound botulism. Western Journal of Medicine, 147, 335-338.

Syuto, B. and Kubo, S. (1977). Isolation and molecular size of Clostridium botulinum type C toxin. Applied and Environmental Microbiology, 33, 400-405.

Szabo, E. A., Pemberton, J. M. and Desmarchelier, P. M. (1992). Specific Detection of Clostridium botulinum Type B by Using the Polymerase Chain Reaction. Applied and Environmental Microbiology, 58, 418-420.

Szílagyi, M., Rivera, V. R., Neal, D., Merrill, G. A. and Poli, M. A. (2000). Development of sensitive colorimetric capture elisas for Clostridium botulinum neurotoxin serotypes A and B. Toxicon, 38, 381-389.

Takeda, M., Tsukamoto, K., Kohda, T., Matsui, M., Mukamoto, M. and Kozaki, S. (2005). Characterization of the neurotoxin produced by isolates associated with avian botulism. Avian Diseases, 49, 376 - 381.

Takeshi, K., Fujinaga, Y., Inoue, K., Nakajima, H., Oguma, K., Ueno, T., Sunagawa, H. and Ohyama, T. (1996). Simple Method for Detection of Clostridium botulinum Type A to F Neurotoxin Genes by Ploymerase Chain Reaction. Microbiology and Immunology, 40, 5-11. 
Thaysen, J. (2011a). Ballensilage Herstellung - Wie wird Nacherwärmung und Schimmelbildung in Ballensilage wirklich verhindert?, DOW.

Thaysen, J. (2011b). Qualitäts-Grassilage - vom Feld bis in den Trog, L. Schleswig-Holstein, Ed, aid, Bonn.

Theermann, S. (2011). Untersuchungen zum Einfluss von Grassilagen mit auffällig niedrigen Reineiweißanteilen auf Aminosäuren und Biogene Amine im Pansensaft (in vitro). In: Klinik für Rinder, Tierärztliche Hochschule, Hannover, pp. 287.

Theiler, A. and Robinson, E. M. (1927). Lamsiekte (parabotulism) in cattle in South Africa. Eleventh and Twelfth Reports of the Director of the Veterinary Education and Research, Part II, 821-1361.

TierLMHV. (2007 (letzte Änderung 12. November 2010)). Verordnung über Anforderungen an die Hygiene beim Herstellen, Behandeln und Inverkehrbringen von bestimmten Lebensmitteln tierischen Ursprungs (Tierische Lebensmittel Hygieneverordnung - Tier-LMHV), B. d. Justiz, Ed, Bundesgesetzblatt.

TierSeuchAnzV. (1991 (Neufassung vom 19.07.2011)). Verordnung über anzeigepflichtige Tierseuchen, Bundesministerium der Justiz, Bundesgesetzblatt, pp. 2.

TierSG. (2010). Tierseuchengesetz in der Fassung der Bekanntmachung vom 22. Juni 2004 (BGBl. I S.1260, 3588), das zuletzt durch Artikel 18 des Gesetzes vom 9. Dezember 2010 (BGBl. I S.1934) geändert worden ist, B. d. Justiz, Ed, Bundesgesetzblatt.

Tocher, J. F. (1924). Grass sickness in horses. Transactions of the Highland and Agricultural Society of Scotland 5th Series, 36, 65-83.

Tocher, J. F., Tocher, W., Brown, W. and Buxton, J. B. (1923). 'Grass sickness' investigation report. Veterinary Record, 3, 75-89.

Trampel, D. W., Smith, S. R. and Rocke, T. E. (2005). Toxicoinfectious Botulism in Commercial Caponized Chickens. Avian Diseases, 49, 301303.

Tsukamoto, K., Kohda, T., Mukamoto, M., Takeuchi, K., Ihara, H., Saito, M. and Kozaki, S. (2005). Binding of Clostridium botulinum Type C and D Neurotoxins to Ganglioside and Phospholipid. Journal of Biological Chemistry, 280, 35164-35171.

Tsuzuki, K., Kimura, K., Fujii, N., Yokosawa, N., Indoh, T., Murakami, T. and Oguma, K. (1990). Cloning and complete nucleotide sequence of the gene for the main component of hemagglutinin produced by Clostridium botulinum type C. Infection and Immunity, 58, 3173-3177.

Umesaki, Y. and Setoyama, H. (2000). Structure of the intestinal flora responsible for development of the gut immune systemin a rodent model. Microbes and Infection, 2, 1343-1351.

Uzal, F. A. and Robles, C. A. (1993). Mal seco, a grass sickness-like syndrome of horses in Argentina. Veterinary Research Communications, 17, 449457.

van Ermengem, E. (1897). Über einen neuen anaeroben Bacillus und seine Beziehung zum Botulismus. Zeitschrift für Hygiene und Infektionskrankheiten, 26, 1-56.

Vermilyea, B. L., Walker, H. W. and Ayres, J. C. (1968). Detection of Botulinal Toxins by Immunodiffusion. Applied Microbiology, 16, 21-24.

Vidal, D., Taggart, M. A., Badiola, I. and Mateo, R. (2011). Real-time polymerase chain reaction for the detection of toxigenic Clostridium botulinum type $\mathrm{C} 1$ in waterbird and sediment samples: comparison with other PCR techniques. Journal of Veterinary Diagnostic Investigation, 23, 942-946. 
VUW. (2006). Laborparameter für die Klauentierpraxis, Vol. 2011, Klinik für Wiederkäuer der Veterinärmedizinischen Universität Wien.

Wayne, L. G., Brenner, D. J., Colwell, R. R., Grimont, P. A. D., Kandler, O., Krichevsky, M. I., Moore, L. H., Moore, W. E. C., Murray, R. G. E., Stackebrandt, E., Starr, M. P. and Truper, H. G. (1987). Report of the Ad Hoc Committee on Reconciliation of Approaches to Bacterial Systematics. International Journal of Systematic Bacteriology, 37, 463464.

Wegner, A. and Aktories, K. (1988). ADP-ribosylated actin caps the barbed ends of actin filaments. Journal of Biological Chemistry, 263, 1373913742 .

Weickert, M. J., Chambliss, G. H. and Sugiyama, H. (1986). Production of toxin by Clostridium botulinum type A strains cured by plasmids. Applied and Environmental Microbiology, 51, 52-56.

Weingart, O. G., Schreiber, T., Mascher, C., Pauly, D., Dorner, M. B., Berger, T. F. H., Egger, C., Gessler, F., Loessner, M. J., Avondet, M.-A. and Dorner, B. G. (2010). The case of botulinum toxin in milk experimental data. Applied and Environmental Microbiology.

Weißbach, F. (2004). Analyse der Ursachen und Möglichkeiten zur Verminderung hoher Clostridien-Last im Grundfutter. Tierärztliche Umschau, 59, 32-41.

Werner, S. B., Passaro, D., McGee, J., Schechter, R. and Vugia, D. J. (2000). Wound Botulism in California, 1951-1998: Recent Epidemic in Heroin Injectors. Clinical Infectious Diseases, 31, 1018-1024.

Whelan, S. M., Elmore, M. J., Bodsworth, N. J., Brehm, J. K., Atkinson, T. and Minton, N. P. (1992). Molecular cloning of the Clostridium botulinum structural gene encoding the type B neurotoxin and determination of its entire nucleotide sequence. Applied and Environmental Microbiology, 58, 2345-2354.

Whitman, W. B. (2009). Bergey's Manual ${ }^{\circledR}$ of Systematic Bacteriology. Volume Three:The Firmicutes. Springer, Dordrecht, Heidelberg, London, New York, pp. 1422.

Whitmer, M. E. and Johnson, E. A. (1988). Development of improved defined media for Clostridium botulinum serotypes A, B, and E. Applied and Environmental Microbiology, 54, 753-759.

Whittington, R. J., Marshall, D. J., Nicholls, P. J., Marsh, I. B. and Reddacliff, L. A. (2004). Survival and Dormancy of Mycobacterium avium subsp. paratuberculosis in the Environment. Applied and Environmental Microbiology, 70, 2989-3004.

Wictome, M., Newton, K., Jameson, K., Hallis, B., Dunnigan, P., Mackay, E., Clarke, S., Taylor, R., Gaze, J., Foster, K. and Shone, C. (1999a). Development of an In Vitro Bioassay for Clostridium botulinum Type B Neurotoxin in Foods That Is More Sensitive than the Mouse Bioassay. Applied and Environmental Microbiology, 65, 3787-3792.

Wictome, M., Newton, K. A., Jameson, K., Dunnigan, P., Clarke, S., Gaze, J., Tauk, A., Foster, K. A. and Shone, C. C. (1999b). Development of in vitro assays for the detection of botulinum toxins in foods. FEMS Immunology \& Medical Microbiology, 24, 319-323.

Wilczek, C. and Merl, K. (2010). Laborwerte Rind. In: MemoVet, PraxisLeitfaden Tiermedizin, C. Wilczek and K. Merl, Eds, Schattauer GmbH, Stuttgart, pp. 424-425.

Wilde, C. and Aktories, K. (2001). The Rho-ADP-ribosylating C3 exoenzyme from Clostridium botulinum and related C3-like transferases. Toxicon, 39, 1647-1660. 
Williamson, J. L., Rocke, T. E. and Aiken, J. M. (1999). In Situ Detection of the Clostridium botulinum Type C1 Toxin Gene in Wetland Sediments with a Nested PCR Assay. Applied and Environmental Microbiology, 65, 32403243.

Wilson, R. B., Boley, M. and Corwin, B. (1995). Presumptive botulism in cattle associated with plastic-packaged hay. Journal of Veterinary Diagnostic Investigation, 7, 167-169.

Wobeser, G. (1997). Avian botulism--another perspective. Journal of Wildlife Diseases, 33, 181-186.

Wobeser, G., Baptiste, K., Clark, E. G. and Deyo, A. W. (1997). Type C botulism in cattle in association with a botulism die-off in waterfowl in Saskatchewan. The Canadian veterinary journal, 38.

Wolf, C. and Schütte, A. (2010). Vitamin B12 im Serum von Milch- und Mutterkühen. 35. Leipziger Fortbildungsveranstaltung: Labordiagnostik in der Bestandsbetreuung, Leipzig.

Xu, Q., Pichichero, M. E., Simpson, L. L., Elias, M., Smith, L. A. and Zeng, M. (2009). An adenoviral vector-based mucosal vaccine is effective in protection against botulism. Gene Therapy, 16, 367-375.

Yamakawa, K., Kamiya, S., Yoshimura, K. and Nakamura, S. (1992). Clostridium botulinum type $\mathrm{C}$ in healthy swine in Japan. Microbiology and Immunology, 36, 29-34.

Yamakawa, K. and Nakamura, S. (1992). Prevalence of Clostridium botulinum Type E and Coexistence of C. botulinum Nonproteolytic Type B in the River Soil of Japan. Microbiology and Immunology, 36, 583-591.

Yamasaki, S., Baumeister, A., Binz, T., Blasi, J., Link, E., Cornille, F., Roques, B., Fykse, E. M., Südhof, T. C. and Jahn, R. (1994). Cleavage of members of the synaptobrevin/VAMP family by types D and F botulinal neurotoxins and tetanus toxin. Journal of Biological Chemistry, 269, 12764-12772.

Yeruham, I., Elad, D., Avidar, Y., Grinberg, K., Tiomkin, D. and Monbaz, A. (2003). Outbreak of botulism type B in a dairy cattle herd: clinical and epidemiological aspects. The Veterinary Record, 153, 270-272.

Yoon, S.-Y., Chung, G. T., Kang, D.-H., Ryu, C., Yoo, C.-K. and Seong, W.-K. (2005). Application of Real-Time PCR for Quantitative Detection of Clostridium botulinum Type A Toxin Gene in Food. Microbiology and Immunology, 49, 505-511.

Zakhari, J. S., Kinoyama, I., Hixon, M. S., Di Mola, A., Globisch, D. and Janda, K. D. (2011). Formulating a new basis for the treatment against botulinum neurotoxin intoxication: 3,4-Diaminopyridine prodrug design and characterization. Bioorganic and Medicinal Chemistry, 19, 62036209. 


\section{Anhang}

\section{1 biologisches Material}

\section{Maus-Bioassay}

Für den Nachweis und die Neutralisation von BoNT im Maus-Bioassay wurden NMRI-Mäuse verwendet.

\section{Herkunft und Bezeichnung der verwendeten Referenzstämme}

Die C.-botulinum-Stämme, die in den eingesetzten Methoden zur Entwicklung oder als Positivkontrollen dienten, wurden in der institutseigenen Stammsammlung bei $-80^{\circ} \mathrm{C}$ gelagert. Sie wurden ursprünglich aus verschiedenen Quellen bezogen.

Tab. 55: Bezeichnung und Herkunft der verwendeten C.-botulinum-Stämme

\begin{tabular}{lccc}
\hline Bezeichnung & IBT-Nr. & $\begin{array}{c}\text { Ursprungs- } \\
\text { bezeichnung }\end{array}$ & Herkunft \\
\hline C.-botulinum-Typ A & 2298 & 62 A & Japan \\
C.-botulinum-Typ B & 2299 & Okra & Japan \\
C.-botulinum-Typ C1 & 3291 & C-Stockholm & unbekannt \\
C.-botulinum-Typ C1/D & 2300 & 003-9 & Japan \\
C.-botulinum-Typ D & 2301 & CB-16 & Japan \\
C.-botulinum-Typ D/C1 & 3828 & Isolat Leunig & Feldstamm \\
C.-botulinum-Typ E & 2626 & CB-K 3E & Finnland \\
C.-botulinum-Typ F & 2303 & Langeland & Japan \\
C.-botulinum-Typ G & 2270 & $46150 . G$. & Spanien \\
\hline
\end{tabular}

IBT - Institut für angewandte Biotechnologie der Tropen und Subtropen, Göttingen 


\subsection{Medien, Puffer und Lösungen}

Alle Nährmediengrundlagen und Chemikalien wurden von der Fa. Merck, Darmstadt bezogen. Auf andere Lieferanten wird gesondert hingewiesen. Die Bestellnummern sind in Klammern angegeben.

$\underline{\text { Reinforced Clostridial Medium (RCM) }}$

Hefeextrakt (1.03753)

$3,0 \mathrm{~g}$

Pepton aus Fleisch tryp.verd. (1.07214) $10,0 \mathrm{~g}$

Fleischextrakt (1.03979) $10,0 \mathrm{~g}$

D- Glukose Monohydrat (1.08342) $5,5 \mathrm{~g}$

$\mathrm{NaCl}$ (AppliChem A1371) $5,0 \mathrm{~g}$

Stärke löslich (1.01257) $1,0 \mathrm{~g}$

L- Cysteinhydrochlorid (1.02839) $0,55 \mathrm{~g}$

Natriumacetat mit $3 \mathrm{H}_{2} \mathrm{O}$ (1.06268) $4,93 \mathrm{~g}$

Agar Agar (1.01612)

$0,5 \mathrm{~g}$

$\mathrm{H}_{2} \mathrm{O}$ dest. $1000 \mathrm{~mL}$

pH 6,8

Gelatine-Phosphat-Puffer (GPP)

$\mathrm{Na}_{2} \mathrm{HPO}_{4}(1.06559)$

$50 \mathrm{mM}$

Gelatine (1.04070)

$1 \%$

$\mathrm{H}_{2} \mathrm{O}$ dest. $1000 \mathrm{~mL}$

$\mathrm{pH} 6,8$

Trypsinlösung (1:250)

Trypsin (Sigma T1426) 10.000 BAEE U/mg Protein $25 \mathrm{mg}$ $\mathrm{H}_{2} \mathrm{O}$ dest.

$10 \mathrm{~mL}$

anaerobe Atmosphäre (MART-System)

$\mathrm{N}_{2}$

$90 \%$

$\mathrm{H}_{2}$

$5 \%$

$\mathrm{CO}_{2}$ 
Enteroxämie ELISA Kit (C. perfringens)

Enterotoxaemia ELISA Kit (BioX, Belgien)

Bicarbonat-Beschichtungspuffer
$\mathrm{Na}_{2} \mathrm{CO}_{3}(1.06392)$
$40 \mathrm{mM}$
$\mathrm{NaHCO}_{3}(1.06329)$
$60 \mathrm{mM}$

Die beiden Lösungen werden gegeneinander auf den pH-Wert 9,6 titriert.

Phosphate buffered saline (PBS) -Stammlösung (10 x) 0,5 M

$\begin{array}{ll}\mathrm{Na}_{2} \mathrm{HPO}_{4} \times 2 \mathrm{H}_{2} \mathrm{O}(1.06580) & 90 \mathrm{mM} \\ \mathrm{NaH}_{2} \mathrm{PO}_{4} \times \mathrm{H}_{2} \mathrm{O}(1.06346) & 40 \mathrm{mM} \\ \mathrm{NaCl} \text { (AppliChem A1371) } & 1,45 \mathrm{M}\end{array}$

Vor dem Gebrauch wird das Konzentrat 1:10 mit $\mathrm{H}_{2} \mathrm{O}$ dest. verdünnt und mit $3 \mathrm{M} \mathrm{NaOH}$ auf einen $\mathrm{pH}-$ Wert von 7,2 eingestellt.

$\underline{\text { miproBLOCK C }}$

betriebsintern

Waschpuffer

PBS

$0,05 \mathrm{M}$

Tween $20(8.22184)$

$0,05 \%$

Substratpuffer

$\mathrm{MgCl}_{2}$ × $6 \mathrm{H}_{2} \mathrm{O}(5833)$

$500 \mathrm{mM}$

Diethanolamin (8.03116)

$97 \mathrm{~mL}$

$\mathrm{H}_{2} \mathrm{O}$ dest ad $1000 \mathrm{~mL}$

$\mathrm{NaN}_{3}$ (Serva 30175)

$200 \mathrm{mg}$

phosphatase-markierte Antikörper (Rind)

IgG (Sigma A7754)

Verdünnung 1:17.000 
Phosphatasesubstrat

p-Nitrophenylphosphat (pNPP) (Sigma S0942)

1 Tablette

Substratpuffer

$5 \mathrm{~mL}$

Schwefelsäure 25 \% (Fluka Analytical, 84736)

Tris-EDTA (TE)-Puffer

TrisBase (Sigma T1503)

$10 \mathrm{mM}$

EDTA (Sigma E5134)

$1 \mathrm{mM}$

$\mathrm{pH}$

8,0

\section{PCR-Mastermix}

SuperHOT PCR Mastermix (2 x) (BIORON 119102)

\section{Ethidiumbromid-Lösung}

Ethidiumbromid (Sigma E1510)

$100 \mathrm{mg}$

$\mathrm{H}_{2} \mathrm{O}$ dest.

$50 \mathrm{~mL}$

Tris-Borat-EDTA (TBE)-Puffer (10 x)

TrisBase (Sigma T1503)

$890 \mathrm{mM}$

EDTA (Sigma E5134)

$20 \mathrm{mM}$

$\mathrm{H}_{3} \mathrm{BO}_{3}(1.00165)$

$890 \mathrm{mM}$

Vor dem Gebrauch wird das Konzentrat 1:10 mit $\mathrm{H}_{2} \mathrm{O}$ dest. verdünnt. Der $\mathrm{pH}$ Wert sollte dann ca. 8,0 betragen.

Ladepuffer $(6 \mathrm{x})$

Bromphenolblau (8122)

$25 \mathrm{~g}$

Xylencyanol FF (Sigma X-4126)

$25 \mathrm{~g}$

Glycerol (1.04091)

$3 \mathrm{~mL}$

$\mathrm{H}_{2} \mathrm{O}$ dest.

$10 \mathrm{~mL}$ 


\subsection{Geräte}

Aufgeführt sind lediglich solche Geräte, die nicht standardmäßig in einem mikrobiologischem Labor vorhanden sind.

- Anoxomat (MART $\left.{ }^{\circledR} \mathrm{BV}\right)$

- Vakuumbrutschrank (Heraeus)

- Plattenwasher (Molecular Devices)

- Horizontalschüttler (GFL)

- Plattenphotometer Spektramax Plus 364 mit Software SoftMax Pro 5.4 (Molecular Devices)

- Kühlzentrifuge (Heraeus)

- Thermocycler TGradient (Biometra)

- Thermocycler (MWG)

- Gelelektrophorese Biorad PowerPac 200 (Biorad)

- Fotodokumentationsgerät mit Graphic Printer

\subsection{BoNT/CD-Multiplex-qPCR}

Von dem im Wasserbad bei $37^{\circ} \mathrm{C}$ aufgetauten und gevortexten DNAÜberstand werden $2,5 \mu \mathrm{L}$ in ein PCR-Reagiergefäß gegeben und mit 22,5 $\mu \mathrm{L}$ des frisch hergestellten PCR-Mastermixes versetzt. Parallel zur Probe wird eine Positivkontrolle aus den Stämmen C. botulinum C1 (IBT 3291), C. botulinum C1/D (IBT 2300), C. botulinum D (IBT 2301)und C. botulinum D/C1 (IBT 3828) als Poolprobe analysiert.

Pro Probe wurde ein $25 \mu$ L-Reaktionsansatz hergestellt. Die Einzelkomponenten wurden zu diesem Zweck bei $37^{\circ} \mathrm{C}$ im Wasserbad aufgetaut, gründlich durchmischt und bis zur Verwendung kühl gelagert. Die Primer lagen in einer Konzentration von $10 \mathrm{pmol} / \mathrm{L}$ vor. Der Reaktionsansatz wurde nach dem Pipettieren ebenfalls gründlich durchmischt und kühl gelagert.

Die Proben können anhand ihres $c_{t}$-Wertes quantitativ bestimmt werden. 
Tab. 56: Primer für die BoNT/CD-Multiplex-qPCR

\begin{tabular}{|c|c|c|c|}
\hline BoNT & Primer / Sonden & Sequenz (5'-3') & $\begin{array}{l}\text { Produktgröße } \\
\text { (bp) }\end{array}$ \\
\hline $\mathrm{C} 1$ & $\begin{array}{l}\text { qSBC } 1-\mathrm{F} \\
\text { qSBC } 1-\mathrm{R} \\
\text { qSBC1-S (FAM/BHQ1) }\end{array}$ & $\begin{array}{l}\text { tgc tcc tgg ata caa taa atg g } \\
\text { tca aac cgg tat ctg gaa ttt } \\
\text { aac aat atg atg gga aat atg aag a }\end{array}$ & 350 \\
\hline $\mathrm{C} 1 / \mathrm{D}$ & $\begin{array}{l}\text { qSBC1/D-F } \\
\text { qSBC1/D-R } \\
\text { qSBC1/D-S (Cy5/BHQ2) }\end{array}$ & $\begin{array}{l}\text { aac ctt gga gat ttt ctt ttg aa } \\
\text { cca tcc tgg atc cct aga aa } \\
\text { cat aca cgc cag ttg cag taa }\end{array}$ & 205 \\
\hline $\mathrm{D}$ & $\begin{array}{l}\text { qSBD-F } \\
\text { qSBD-R } \\
\text { qSBD-S (JOE/BHQ1) }\end{array}$ & $\begin{array}{l}\text { agt ttt agg gaa aat aca atg ctt c } \\
\text { cca tcc tgg atc cct aga aa } \\
\text { aaa tgc ata cac gcc agt tg }\end{array}$ & 389 \\
\hline $\mathrm{D} / \mathrm{C} 1$ & $\begin{array}{l}\text { qSBD/C1-F } \\
\text { qSBD/C1-R } \\
\text { qSBD/C1-S (ROX/BHQ2) }\end{array}$ & $\begin{array}{l}\text { gca aca aca aat agg ctt gg } \\
\text { ttg cag gta caa aaa ccc aat } \\
\text { ttc aaa ctt gga gat gac tat tgg }\end{array}$ & 543 \\
\hline
\end{tabular}

Tab. 57: Zusammensetzung eines 25- $\mu$ L-Reaktionsansatzes einer BoNT/CD-Multiplex-qPCR

\begin{tabular}{ll}
\hline Komponenten & Volumen \\
\hline SuperHOT Mastermix (2x) & $12,5 \mu \mathrm{L}$ \\
$\mathrm{MgCl}_{2}(100 \mathrm{mM})$ & $4 \mu \mathrm{L}$ \\
Primer & je $0,4 \mu \mathrm{L}$ qSBC1-F und qSBC1-R \\
& je $0,4 \mu \mathrm{L}$ qSBC1/D-F und qSBC1/D-R \\
& je $0,3 \mu \mathrm{L}$ qSBD-F und qSBD-R \\
Sonden & je $0,6 \mu \mathrm{L}$ qSBD/C1-F und qSBD/C1-R \\
& $0,3 \mu \mathrm{L}$ qSBC1-S \\
& $0,2 \mu \mathrm{L}$ qSBC1/D-S \\
& $0,6 \mu \mathrm{L}$ qSBD-S \\
steriles Wasser & $0,6 \mu \mathrm{L}$ qSBD/C1-S \\
\hline
\end{tabular}

Die qPCR wurde im Corbett Rotorgene 3000 (QIAGEN) durchgeführt.

Tab. 58: Thermocyclerprogramm für die BoNT/CD-Multiplex-qPCR

\begin{tabular}{ll}
\hline Programmschritt & Temperatur / Zeit \\
\hline initiale Denaturierung & $95^{\circ} \mathrm{C} / 3 \mathrm{~min}$ \\
Denaturierung & $95^{\circ} \mathrm{C} / 15 \mathrm{~s}$ \\
Annealing & $58{ }^{\circ} \mathrm{C} / 30 \mathrm{~s}$ \\
Elongation & $72{ }^{\circ} \mathrm{C} / 40 \mathrm{~s}$ \\
Zyklenanzahl & 40 \\
\hline
\end{tabular}




\subsection{Kreuzreaktionen PCR}

Tab. 59: Stämme für die Validierung der PCR-Methoden

\begin{tabular}{|c|c|c|}
\hline IBT-Stamm-Nr. & Bezeichnung & Herkunft \\
\hline 2298 & C. botulinum Typ A & 62 A, Japan \\
\hline 2299 & C. botulinum Typ B & Okra, Japan \\
\hline 2626 & C. botulinum Typ E & CB-S 3E, Finnland \\
\hline 2303 & C. botulinum Typ F & Langeland, Finnland \\
\hline 42 & C. septicum & USA \\
\hline 46 & C. sordellii & USA \\
\hline 57 & C. haemolyticum & CN 2043, Wellcome \\
\hline 76 & C. perfringens Typ E & CN 5063, Wellcome \\
\hline 934 & C. tetani & 85155, Hannover \\
\hline 1001 & C. absonum & NCTC 10984 \\
\hline 1007 & C. tertium & DSM 2485 \\
\hline 1011 & C. butyricum & NCTC 7423 \\
\hline 1014 & C. difficile & NCTC 11209 \\
\hline 1015 & C. histolyticum & NCTC 5031 \\
\hline 1025 & C. novyi $A$ & NCTC 538 \\
\hline 1027 & C. bifermentans & NCTC 1341 \\
\hline 1038 & C. perfringens Typ B & NCTC 4964 \\
\hline 1076 & C. chauvoei & ATCC 10092 \\
\hline 1078 & C. hastiforme & ATCC 33268 \\
\hline 1084 & C. baratii & ATCC 25782 \\
\hline 1085 & C. parabotulinum & ATCC 17863 \\
\hline 1087 & C. sporogenes & ATCC 3584 \\
\hline 1088 & C. subterminale & ATCC 25774 \\
\hline 1232 & Bacillus subtilis & \\
\hline 1574 & Salmonella enteritidis & Dr. Herrero \\
\hline 1629 & Salmonella typhimurium & Dr. Herrero \\
\hline 1658 & Shigella flexneri & Dr. Herrero \\
\hline 2656 & Staphylococcus aureus & DSM 20714 \\
\hline 3754 & Pseudomonas aeruginosa & DSM 288 \\
\hline \multirow[t]{6}{*}{3755} & E. coli & DSM 16263 \\
\hline & Candida albicans & DSM 10231 \\
\hline & Bacillus cereus & DSM 345 \\
\hline & E. coli & DSM 1576 \\
\hline & Pseudomonas aeruginosa & DSM 1128 \\
\hline & Saccharomyces cervisiae & DSM 1334 \\
\hline
\end{tabular}




\subsection{Laborwerte der Einzeltiere}

Tab. 60: Laborwerte der Einzeltiere aus dem Fallbetrieb FB 1

\begin{tabular}{|c|c|c|c|c|c|c|}
\hline \multicolumn{7}{|c|}{ Fallbetrieb FB 1} \\
\hline Tier & Phase & 1 & 2 & 3 & 4 & 5 \\
\hline \multicolumn{7}{|c|}{ Serum } \\
\hline \multirow[t]{3}{*}{ ASAT $[\mu \mathrm{kat} / \mathrm{L}]$} & I. & 1,72 & 1,02 & 1,18 & & \\
\hline & II. & 2,1 & 1,85 & 1,76 & & \\
\hline & III. & 2,4 & 1,34 & 1,59 & & \\
\hline \multirow[t]{3}{*}{ GLDH [nkat/L] } & I. & 434 & 115 & 351 & & \\
\hline & II. & 134 & 72 & 133 & & \\
\hline & III. & 1132 & 127 & 535 & & \\
\hline \multirow[t]{3}{*}{ Bilirubin $[\mu \mathrm{M}]$} & I. & 4,2 & 4,1 & 3,7 & & \\
\hline & II. & 21 & 11,1 & 6,4 & & \\
\hline & III. & 2,2 & 4,7 & 3,4 & & \\
\hline \multirow[t]{3}{*}{ FFS/BHB [mM] } & I. & 0,08 & 0,1 & 0,05 & & \\
\hline & II. & 1,66 & 0,85 & 1,31 & & \\
\hline & III. & 0,92 & 0,97 & 1,02 & & \\
\hline \multirow[t]{3}{*}{$\mathrm{HST}[\mathrm{mM}]$} & I. & 4,06 & 3,51 & 3,27 & & \\
\hline & II. & 5,77 & 3,57 & 4,3 & & \\
\hline & III. & 5,87 & 6,89 & 4,53 & & \\
\hline \multirow[t]{3}{*}{ Vit. B12 [ng/L] } & I. & 126 & 126 & 126 & & \\
\hline & II. & 105 & 105 & 105 & & \\
\hline & III. & 118 & 118 & 118 & & \\
\hline \multirow[t]{3}{*}{ Cholesterin $[\mathrm{mM}]$} & I. & 1,67 & 1,44 & 1,47 & & \\
\hline & II. & 3,28 & 1,83 & 2,35 & & \\
\hline & III. & 6,38 & 3,82 & 6,07 & & \\
\hline \multirow[t]{3}{*}{ Calcium $[\mathrm{mM}]$} & I. & 2,42 & 2,38 & 2,34 & & \\
\hline & II. & 2,19 & 2,35 & 2,43 & & \\
\hline & III. & 2,54 & 2,23 & 2,35 & & \\
\hline \multirow[t]{3}{*}{ Phosphor $[\mathrm{mM}]$} & I. & 2,15 & 2,47 & 1,72 & & \\
\hline & II. & 1,78 & 1,58 & 2,24 & & \\
\hline & III. & 2,46 & 1,88 & 2,23 & & \\
\hline \multicolumn{7}{|c|}{ Harn } \\
\hline \multirow[t]{3}{*}{ NSBA [mM] } & I. & & & & & \\
\hline & II. & & & & & \\
\hline & III. & & & & & \\
\hline \multirow[t]{3}{*}{ Calcium $[\mathrm{mM}]$} & I. & & & & & \\
\hline & II. & & & & & \\
\hline & III. & & & & & \\
\hline \multirow[t]{3}{*}{ Phosphor anorg. [mM] } & I. & & & & & \\
\hline & II. & & & & & \\
\hline & III. & & & & & \\
\hline \multirow[t]{3}{*}{ Kalium [mM] } & I. & & & & & \\
\hline & II. & & & & & \\
\hline & III. & & & & & \\
\hline
\end{tabular}


Tab. 61: Laborwerte der Einzeltiere aus dem Kontrollbetrieb KB 1

\begin{tabular}{|c|c|c|c|c|c|c|}
\hline \multicolumn{7}{|c|}{ Kontrollbetrieb KB 1} \\
\hline Tier & Phase & 1 & 2 & 3 & 4 & 5 \\
\hline \multicolumn{7}{|c|}{ Serum } \\
\hline \multirow[t]{3}{*}{ ASAT $[\mu \mathrm{kat} / \mathrm{L}]$} & I. & 1,17 & 1,68 & 1,91 & 2,5 & 1,34 \\
\hline & II. & 3,49 & 1,56 & 2,09 & 2,88 & 4,95 \\
\hline & III. & 1,92 & 1,42 & 1,5 & 1,34 & 2,62 \\
\hline \multirow[t]{3}{*}{ GLDH [nkat/L] } & I. & 206 & 295 & 307 & 163 & 495 \\
\hline & II. & 1759 & 371 & 423 & 562 & 1271 \\
\hline & III. & 1137 & 338 & 623 & 170 & 833 \\
\hline \multirow[t]{3}{*}{ Bilirubin $[\mu \mathrm{M}]$} & I. & 4,14 & 3,41 & 4,61 & 1,51 & 3,1 \\
\hline & II. & 6,77 & 3,41 & 4,01 & 5,66 & 4,86 \\
\hline & III. & 3,28 & 3,23 & 3,48 & 3,42 & 0,72 \\
\hline \multirow[t]{3}{*}{ FFS/BHB [mM] } & I. & 0,28 & 0,22 & 0,41 & 0,21 & 0,16 \\
\hline & II. & 1,01 & 0,66 & 0,62 & 1,42 & 1,23 \\
\hline & III. & 0,67 & 0,46 & 0,43 & 1,24 & 0,89 \\
\hline \multirow[t]{3}{*}{$\mathrm{HST}[\mathrm{mM}]$} & I. & 3,33 & 3,05 & 4,05 & 3,28 & 2,78 \\
\hline & II. & 3,09 & 3,67 & 2,89 & 2,36 & 2,88 \\
\hline & III. & 4,57 & 3,62 & 7,02 & 3,98 & 5,24 \\
\hline \multirow[t]{3}{*}{ Vit. B12 [ng/L] } & I. & 153 & 153 & 153 & 153 & 153 \\
\hline & II. & 121 & 121 & 121 & 121 & 121 \\
\hline & III. & 99 & 99 & 99 & 99 & 99 \\
\hline \multirow[t]{3}{*}{ Cholesterin [mM] } & I. & 3,2 & 3,06 & 4,48 & 4,65 & 3,13 \\
\hline & II. & 2,65 & 7,81 & 2,5 & 2,16 & 2,46 \\
\hline & III. & 5,34 & 4,19 & 7,97 & 5,64 & 6,49 \\
\hline \multirow[t]{3}{*}{ Calcium $[\mathrm{mM}]$} & I. & 2,49 & 2,41 & 2,57 & 2,44 & 2,34 \\
\hline & II. & 2,31 & 2,57 & 2,46 & 2,44 & 2,37 \\
\hline & III. & 2,22 & 2,38 & 2,64 & 2,35 & 2,39 \\
\hline \multirow[t]{3}{*}{ Phosphor $[\mathrm{mM}]$} & I. & 2,08 & 2,05 & 1,52 & 2,34 & 1,89 \\
\hline & II. & 1,57 & 2,03 & 1,95 & 1,57 & 1,43 \\
\hline & III. & 2,39 & 1,6 & 2,11 & 1,63 & 2,08 \\
\hline \multicolumn{7}{|c|}{ Harn } \\
\hline \multirow[t]{3}{*}{ NSBA [mM] } & I. & & & & & \\
\hline & II. & & & & & \\
\hline & III. & & & & & \\
\hline \multirow[t]{3}{*}{ Calcium [mM] } & I. & & & & & \\
\hline & II. & & & & & \\
\hline & III. & & & & & \\
\hline \multirow[t]{3}{*}{$\begin{array}{l}\text { Phosphor anorg. } \\
{[\mathrm{mM}]}\end{array}$} & I. & & & & & \\
\hline & II. & & & & & \\
\hline & III. & & & & & \\
\hline \multirow[t]{3}{*}{ Kalium [mM] } & I. & & & & & \\
\hline & II. & & & & & \\
\hline & III. & & & & & \\
\hline
\end{tabular}


Tab. 62: Laborwerte der Einzeltiere aus dem Fallbetrieb FB 2

\begin{tabular}{|c|c|c|c|c|c|c|}
\hline \multicolumn{7}{|c|}{ Fallbetrieb FB 2} \\
\hline \multicolumn{2}{|l|}{ Tier } & 1 & 2 & 3 & 4 & 5 \\
\hline \multicolumn{7}{|c|}{ Serum } \\
\hline \multirow[t]{3}{*}{ ASAT $[\mu$ kat $/ L]$} & I. & 1,09 & 1,19 & 1,24 & 1,14 & 0,98 \\
\hline & II. & 3,34 & 1,76 & 1,83 & 1,76 & 2,12 \\
\hline & III. & 2,68 & 1,61 & 1,41 & 1,68 & 2,44 \\
\hline \multirow[t]{3}{*}{ GLDH [nkat/L] } & I. & 85 & 119 & 117 & 82 & 45 \\
\hline & II. & 829 & 270 & 543 & 418 & 74 \\
\hline & III. & 151 & 566 & 181 & 120 & 212 \\
\hline \multirow[t]{3}{*}{ Bilirubin $[\mu \mathrm{M}]$} & I. & 1,79 & 2,53 & 1,1 & 0,96 & 0,98 \\
\hline & II. & 10,64 & 4,13 & 3,93 & 6,05 & 5,2 \\
\hline & III. & 4,39 & 3,42 & 3,88 & 3,4 & 4,34 \\
\hline \multirow[t]{3}{*}{$\mathrm{FFS} / \mathrm{BHB}[\mathrm{mM}]$} & I. & 0,31 & 0,33 & 0,17 & 0,18 & 0,34 \\
\hline & II. & 1,1 & 0,35 & 0,48 & 1,02 & 0,33 \\
\hline & III. & 0,5 & 0,41 & 0,66 & 0,71 & 0,58 \\
\hline \multirow[t]{3}{*}{$\mathrm{HST}[\mathrm{mM}]$} & I. & 4,92 & 4,01 & 5,39 & 4,47 & 4,02 \\
\hline & II. & 3,97 & 3,57 & 5,79 & 4,19 & 4,84 \\
\hline & III. & 4,32 & 6,21 & 5,16 & 5,39 & 5,43 \\
\hline \multirow[t]{3}{*}{ Vit. B12 [ng/L] } & I. & 93 & 93 & 93 & 93 & 93 \\
\hline & II. & 107 & 107 & 107 & 107 & 107 \\
\hline & III. & 81 & 81 & 81 & 81 & 81 \\
\hline \multirow[t]{3}{*}{ Cholesterin [mM] } & I. & 2,15 & 2,39 & 2,79 & 1,1 & 1,74 \\
\hline & II. & 2,14 & 2,4 & 2,43 & 3,71 & 1,95 \\
\hline & III. & 3,9 & 4,59 & 4,86 & 4,1 & 4,99 \\
\hline \multirow[t]{3}{*}{ Calcium [mM] } & I. & 2,33 & 2,36 & 2,47 & 2,25 & 2,4 \\
\hline & II. & 2,29 & 2,57 & 2,55 & 2,49 & 2,19 \\
\hline & III. & 2,34 & 2,57 & 2,52 & 2,36 & 2,52 \\
\hline \multirow[t]{3}{*}{ Phosphor[mM] } & I. & 2,31 & 2 & 2,13 & 1,74 & 2,46 \\
\hline & II. & 1,42 & 1,51 & 1,84 & 1,44 & 0,92 \\
\hline & III. & 1,62 & 1,89 & 2,03 & 1,55 & 1,67 \\
\hline \multicolumn{7}{|c|}{ Harn } \\
\hline \multirow[t]{3}{*}{$\mathrm{NSBA}[\mathrm{mM}]$} & I. & 60 & 20 & 20 & 80 & 40 \\
\hline & II. & 180 & 200 & 160 & 160 & 80 \\
\hline & III. & 180 & 180 & 180 & 200 & 200 \\
\hline \multirow[t]{3}{*}{ Calcium [mM] } & I. & 1,76 & 2,53 & 1,1 & 0,96 & 0,98 \\
\hline & II. & 0,18 & 1,07 & 1,38 & 1,44 & 0,16 \\
\hline & III. & 0,18 & 0,61 & 1,01 & 0,21 & 1,82 \\
\hline \multirow{3}{*}{$\begin{array}{l}\text { Phosphor anorg. } \\
{[\mathrm{mM}]}\end{array}$} & I. & 0,65 & 0,44 & 0,28 & 0,41 & 0,5 \\
\hline & II. & 0,33 & 0,56 & 0,47 & 0,59 & 0,54 \\
\hline & III. & 0,34 & 0,53 & 0,5 & 0,79 & 0,56 \\
\hline \multirow[t]{3}{*}{ Kalium [mM] } & I. & 323 & 240 & 197 & 205 & 289 \\
\hline & II. & 199 & 339 & 336 & 313 & 250 \\
\hline & III. & 271 & 312 & 297 & 362 & 372 \\
\hline
\end{tabular}


Tab. 63: Laborwerte der Einzeltiere aus dem Kontrollbetrieb KB 2

\begin{tabular}{|c|c|c|c|c|c|c|}
\hline \multicolumn{7}{|c|}{ Kontrollbetrieb KB 2} \\
\hline Tier & Phase & 1 & 2 & 3 & 4 & 5 \\
\hline \multicolumn{7}{|c|}{ Serum } \\
\hline \multirow[t]{3}{*}{ ASAT $[\mu \mathrm{kat} / \mathrm{L}]$} & $\mathrm{I}$. & 1,37 & 1,02 & 1,15 & 1,04 & 1,48 \\
\hline & II. & 1,83 & 1,91 & 2,44 & 1,54 & 1,36 \\
\hline & III. & 1,77 & 2,02 & 1,41 & 1,5 & \\
\hline \multirow[t]{3}{*}{ GLDH [nkat/L] } & I. & 311 & 41 & 106 & 104 & 264 \\
\hline & II. & 104 & 297 & 144 & 89 & 286 \\
\hline & III. & 346 & 416 & 190 & 322 & \\
\hline \multirow[t]{3}{*}{ Bilirubin $[\mu \mathrm{M}]$} & $\mathrm{I}$. & 2,9 & 5,9 & 4 & 8,4 & 3,9 \\
\hline & II. & 13,3 & 6,6 & 7,2 & 9,4 & 4,6 \\
\hline & III. & 5,1 & 4,8 & 4,8 & 4,6 & \\
\hline \multirow[t]{3}{*}{$\mathrm{FFS} / \mathrm{BHB}[\mathrm{mM}]$} & I. & 0,22 & 0,72 & 0,23 & 0,59 & 0,19 \\
\hline & II. & 0,72 & 0,7 & 0,55 & 0,48 & 0,31 \\
\hline & III. & 0,32 & 0,5 & 0,47 & 0,38 & \\
\hline \multirow[t]{3}{*}{ HST $[\mathrm{mM}]$} & I. & 4,35 & 4 & 5,73 & 3,7 & 3,87 \\
\hline & II. & 4,31 & 3,18 & 3,54 & 3,97 & 4,46 \\
\hline & III. & 5,02 & 5,76 & 4,71 & 3,64 & \\
\hline \multirow[t]{3}{*}{ Vit. B12 [ng/L] } & I. & 77 & 77 & 77 & 77 & 77 \\
\hline & II. & 93 & 93 & 93 & 93 & 93 \\
\hline & III. & 126 & 126 & 126 & 126 & \\
\hline \multirow[t]{3}{*}{ Cholesterin [mM] } & $\mathrm{I}$. & 1,83 & 1,87 & 2,02 & 1,79 & 1,57 \\
\hline & II. & 2,05 & 2,45 & 1,59 & 2,11 & 4,98 \\
\hline & III. & 5,16 & 5,23 & 4,01 & 5,71 & \\
\hline \multirow[t]{3}{*}{ Calcium [mM] } & I. & 2,36 & 2,34 & 2,45 & 2,51 & 2,53 \\
\hline & II. & 2,58 & 2,41 & 2,23 & 2,4 & 2,38 \\
\hline & III. & 2,5 & 2,5 & 2,61 & 2,58 & \\
\hline \multirow[t]{3}{*}{ Phosphor[mM] } & $\mathrm{I}$. & 2,29 & 1,98 & 2,59 & 2,24 & 1,81 \\
\hline & II. & 1,6 & 1,48 & 1,39 & 1,74 & 1,71 \\
\hline & III. & 1,73 & 1,68 & 1,56 & 1,96 & \\
\hline \multicolumn{7}{|c|}{ Harn } \\
\hline \multirow[t]{3}{*}{ NSBA [mM] } & I. & 40 & 180 & 100 & 140 & 80 \\
\hline & II. & 80 & 40 & 180 & 140 & 180 \\
\hline & III. & 160 & 140 & 140 & 160 & \\
\hline \multirow[t]{3}{*}{ Calcium [mM] } & I. & 1,67 & 4,23 & 8,47 & 2,34 & 5,82 \\
\hline & II. & 2,19 & 0,7 & 3,31 & 3,18 & 5,26 \\
\hline & III. & 2,19 & 0,7 & 3,31 & 3,18 & \\
\hline \multirow[t]{3}{*}{$\begin{array}{l}\text { Phosphor anorg. } \\
{[\mathrm{mM}]}\end{array}$} & I. & 1,45 & 0,97 & 1,03 & 0,89 & 0,9 \\
\hline & II. & 0,92 & 0,7 & 0,86 & 1,02 & 0,74 \\
\hline & III. & 1,22 & 0,83 & 0,91 & 0,66 & \\
\hline \multirow[t]{3}{*}{ Kalium [mM] } & I. & 359,7 & 314 & 338,7 & 313,4 & 340 \\
\hline & II. & 330,9 & 270,6 & 322,2 & 351,3 & 300 \\
\hline & III. & 309,1 & 325,3 & 249,5 & 251,6 & \\
\hline
\end{tabular}


Tab. 64: Laborwerte der Einzeltiere aus dem Fallbetrieb FB 3

\begin{tabular}{|c|c|c|c|c|c|c|}
\hline \multicolumn{7}{|c|}{ Fallbetrieb FB 3} \\
\hline \multicolumn{2}{|l|}{ Tier } & 1 & 2 & 3 & 4 & 5 \\
\hline \multicolumn{7}{|c|}{ Serum } \\
\hline \multirow[t]{3}{*}{ ASAT $[\mu \mathrm{kat} / \mathrm{L}]$} & I. & 1,33 & 1,35 & 1,4 & 1,45 & 2,64 \\
\hline & II. & 2,95 & 2 & 1,39 & 1,84 & 1,37 \\
\hline & III. & 1,04 & 1,62 & 1,88 & 1,41 & 1,44 \\
\hline \multirow[t]{3}{*}{ GLDH [nkat/L] } & I. & 219 & 168 & 217 & 141 & 218 \\
\hline & II. & 824 & 331 & 181 & 313 & 398 \\
\hline & III. & 316 & 247 & 202 & 189 & 192 \\
\hline \multirow[t]{3}{*}{ Bilirubin $[\mu \mathrm{M}]$} & I. & 3,06 & & 2,64 & 3,23 & \\
\hline & II. & 5,42 & 4,96 & 4,12 & 5,16 & 4,77 \\
\hline & III. & 3,97 & 3,96 & 3,85 & 4,1 & 3,58 \\
\hline \multirow[t]{3}{*}{$\mathrm{FFS} / \mathrm{BHB}[\mathrm{mM}]$} & I. & 0,05 & 0,03 & 0,05 & 0,09 & 0,02 \\
\hline & II. & 1,24 & 0,7 & 0,57 & 0,97 & 0,2 \\
\hline & III. & 0,45 & 0,44 & 0,69 & 0,66 & 0,6 \\
\hline \multirow[t]{3}{*}{ HST $[\mathrm{mM}]$} & I. & 6,87 & 5,88 & 7,13 & 4,25 & 6,61 \\
\hline & II. & 4,57 & 3,91 & 3,43 & 5,64 & 4,89 \\
\hline & III. & 4,73 & 5,58 & 6,37 & 3,61 & 4,58 \\
\hline \multirow[t]{3}{*}{ Vit. B12 [ng/L] } & I. & 93 & 93 & 93 & 93 & 93 \\
\hline & II. & 99 & 99 & 99 & 99 & 99 \\
\hline & III. & 105 & 105 & 105 & 105 & 105 \\
\hline \multirow[t]{3}{*}{ Cholesterin [mM] } & I. & 2,72 & 2,81 & 1,62 & 2,49 & 3,72 \\
\hline & II. & 1,72 & 2,87 & 3,08 & 2,26 & 3,58 \\
\hline & III. & 6,6 & 6,23 & 5,64 & 5,54 & 4,2 \\
\hline \multirow[t]{3}{*}{ Calcium [mM] } & I. & 2,48 & 2,4 & 2,35 & 2,54 & 2,52 \\
\hline & II. & 2,81 & 2,52 & 2,39 & 2,35 & 2,66 \\
\hline & III. & 2,49 & 2,63 & 2,54 & 2,53 & 2,43 \\
\hline \multirow[t]{3}{*}{ Phosphor $[\mathrm{mM}]$} & I. & 2,04 & 2,18 & 2,09 & 2,21 & 2,51 \\
\hline & II. & 2,35 & 1,75 & 1,74 & 1,54 & 2,34 \\
\hline & III. & 1,84 & 1,63 & 2,07 & 1,47 & 1,77 \\
\hline & & & Harn & & & \\
\hline
\end{tabular}

NSBA [mM]

Calcium [mM]

Phosphor anorg.

[mM]

Kalium [mM] 
Tab. 65: Laborwerte der Einzeltiere aus dem Kontrollbetrieb KB 3

\begin{tabular}{|c|c|c|c|c|c|c|}
\hline \multicolumn{7}{|c|}{ Kontrollbetrieb KB 3} \\
\hline \multicolumn{2}{|l|}{ Tier } & 1 & 2 & 3 & 4 & 5 \\
\hline \multicolumn{7}{|c|}{ Serum } \\
\hline \multirow[t]{3}{*}{ ASAT $[\mu \mathrm{kat} / \mathrm{L}]$} & I. & 1,23 & 1,07 & 1,43 & 2,18 & 1,23 \\
\hline & II. & 3,41 & 2,63 & 2,64 & 3,46 & 3,41 \\
\hline & III. & 1,11 & 1,71 & 3,14 & 2,87 & 1,11 \\
\hline \multirow[t]{3}{*}{ GLDH [nkat/L] } & I. & 260 & 182 & 322 & 93 & 260 \\
\hline & II. & 1124 & 92 & 231 & 149 & 1124 \\
\hline & III. & 162 & 897 & 5011 & 1430 & 162 \\
\hline \multirow[t]{3}{*}{ Bilirubin $[\mu \mathrm{M}]$} & I. & 3 & 4,1 & 8,4 & 0,6 & 3 \\
\hline & II. & 12,1 & 10,2 & 5 & 13,4 & 12,1 \\
\hline & III. & 2,9 & 2,9 & 2,9 & 3,6 & 2,9 \\
\hline \multirow[t]{3}{*}{$\mathrm{FFS} / \mathrm{BHB}[\mathrm{mM}]$} & I. & 0,08 & 0,17 & 0,84 & 0,45 & 0,08 \\
\hline & II. & 3,35 & 2,63 & 0,84 & 3,48 & 3,35 \\
\hline & III. & 1,06 & 0,63 & 0,65 & 0,62 & 1,06 \\
\hline \multirow[t]{3}{*}{ HST $[\mathrm{mM}]$} & I. & 4,67 & 4 & 5,29 & 4,1 & 4,67 \\
\hline & II. & 3,44 & 3,05 & 3,17 & 3,47 & 3,44 \\
\hline & III. & 3,72 & 3,6 & 3,38 & 3,47 & 3,72 \\
\hline \multirow[t]{3}{*}{ Vit. B12 [ng/L] } & I. & 122 & 122 & 122 & 122 & 122 \\
\hline & II. & 141 & 141 & 141 & 141 & 141 \\
\hline & III. & 88 & 88 & 88 & 88 & 88 \\
\hline \multirow[t]{3}{*}{ Cholesterin [mM] } & I. & 2,18 & 2,04 & 1,75 & 1,88 & 2,18 \\
\hline & II. & 2,43 & 1,59 & 1,52 & 1,43 & 2,43 \\
\hline & III. & 4,76 & 4,75 & 5,49 & 4,88 & 4,76 \\
\hline \multirow[t]{3}{*}{ Calcium [mM] } & I. & 2,24 & 2,37 & 1,97 & 2,08 & 2,24 \\
\hline & II. & 2,25 & 2,14 & 2,48 & 2,08 & 2,25 \\
\hline & III. & 2,27 & 2,45 & 2,37 & 2,37 & 2,27 \\
\hline \multirow[t]{3}{*}{ Phosphor[mM] } & I. & 2,01 & 2,2 & 1,61 & 1,7 & 2,01 \\
\hline & II. & 1,77 & 1,84 & 2,26 & 1,8 & 1,77 \\
\hline & III. & 2,09 & 2,34 & 2,12 & 2,12 & 2,09 \\
\hline \multicolumn{7}{|c|}{ Harn } \\
\hline \multirow[t]{3}{*}{ NSBA $[\mathrm{mM}]$} & I. & 160 & 100 & 80 & 60 & 160 \\
\hline & II. & -40 & 0 & 180 & -20 & -40 \\
\hline & III. & 120 & 100 & 120 & 140 & 120 \\
\hline \multirow[t]{3}{*}{ Calcium [mM] } & I. & 0,2 & 0,68 & 0,2 & 0,22 & 0,2 \\
\hline & II. & 21,77 & 0,74 & 3,9 & 0,23 & 21,77 \\
\hline & III. & 0,2 & 0,19 & 0,16 & 0,24 & 0,2 \\
\hline \multirow{3}{*}{$\begin{array}{l}\text { Phosphor anorg. } \\
\text { [mM] }\end{array}$} & I. & 0,57 & 0,5 & 0,61 & 2,09 & 0,57 \\
\hline & II. & 0,78 & 0,11 & 0,71 & 0,16 & 0,78 \\
\hline & III. & 0,55 & 0,47 & 0,54 & 0,4 & 0,55 \\
\hline \multirow[t]{3}{*}{ Kalium [mM] } & I. & 224,9 & 161,3 & 204 & 197,4 & 224,9 \\
\hline & II. & 161,9 & 46,2 & 325,7 & 30,2 & 161,9 \\
\hline & III. & 147,9 & 193,3 & 211,1 & 212,8 & 147,9 \\
\hline
\end{tabular}




\subsection{Anti-BoNT-Titer der Einzeltiere}

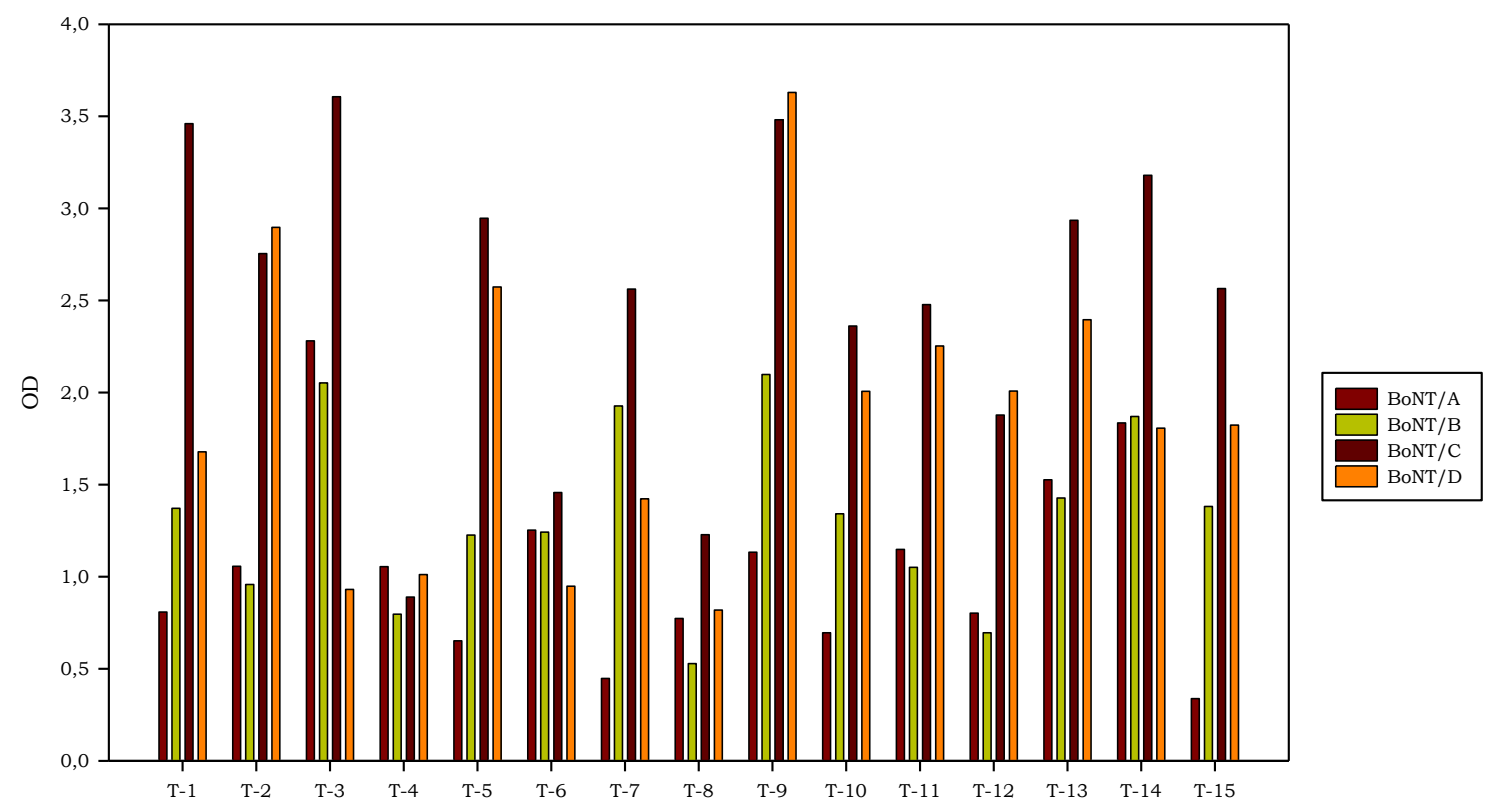

Abb. 9: Anti-BoNT-Titer der Einzeltiere im Fallbetrieb FB 1

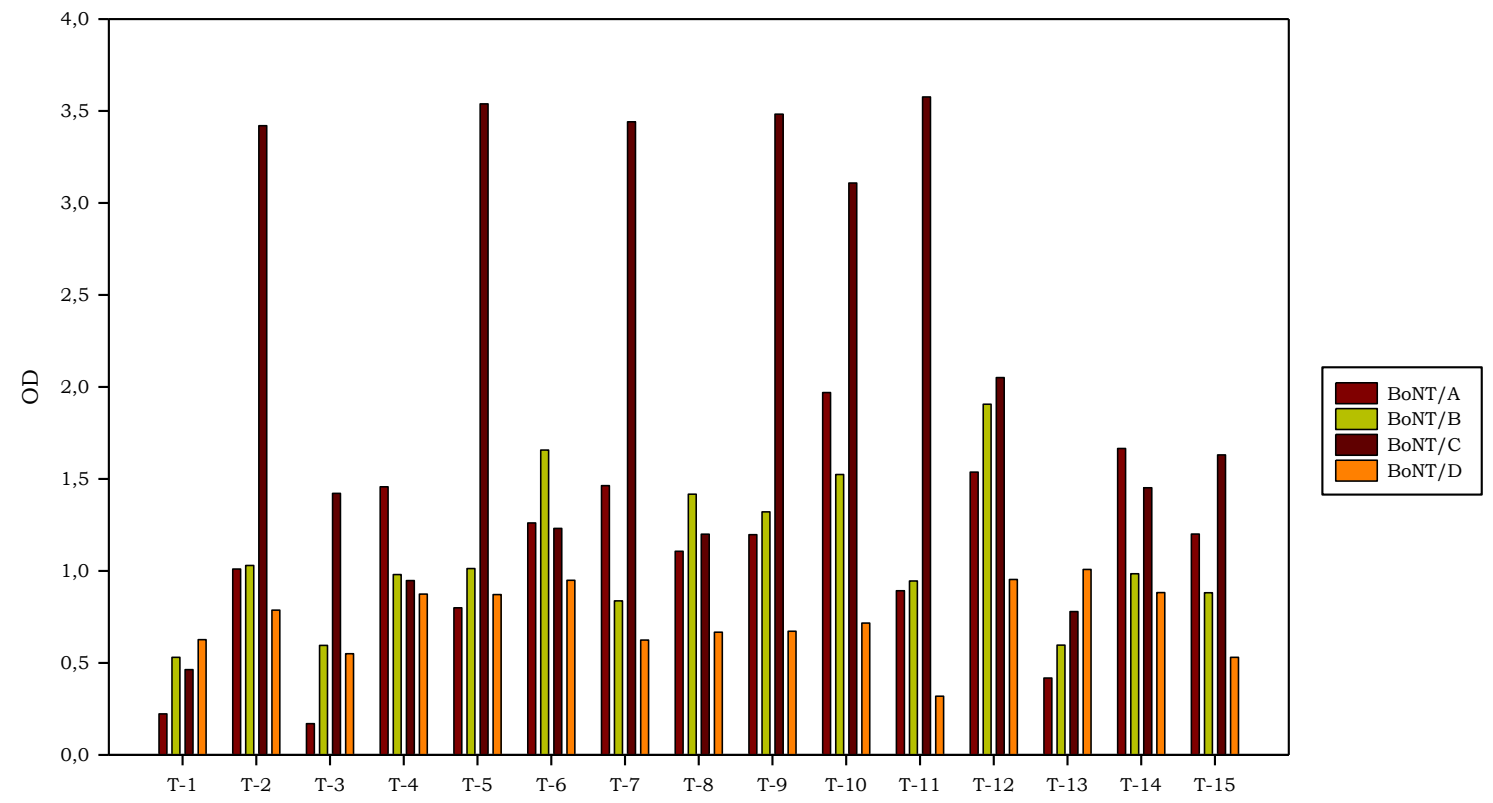

Abb. 10: Anti-BoNT-Titer der Einzeltiere im Kontrollbetrieb KB 1 


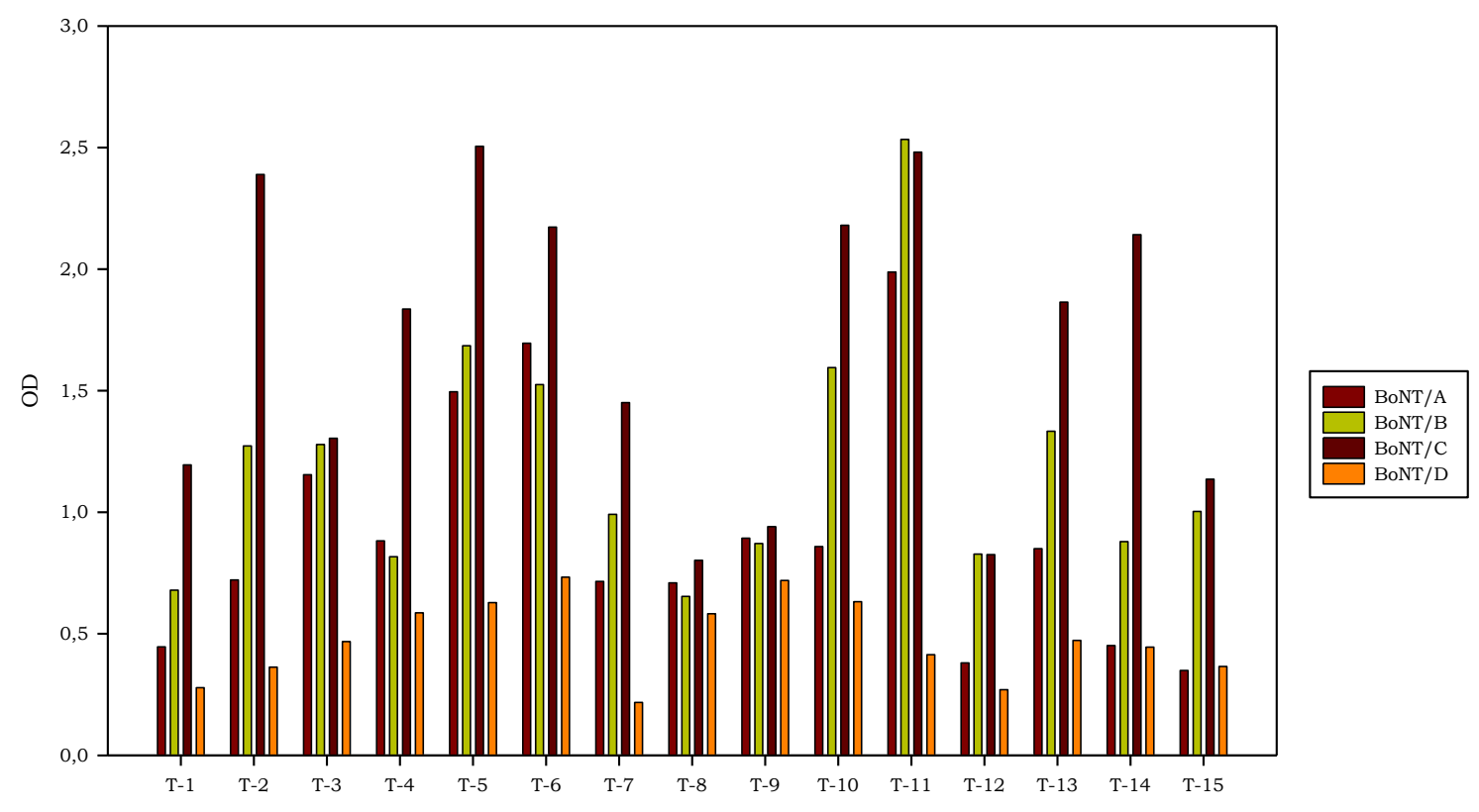

Abb. 11: Anti-BoNT-Titer der Einzeltiere im Fallbetrieb FB 2



Abb. 12: Anti-BoNT-Titer der Einzeltiere im Kontrollbetrieb KB 2 


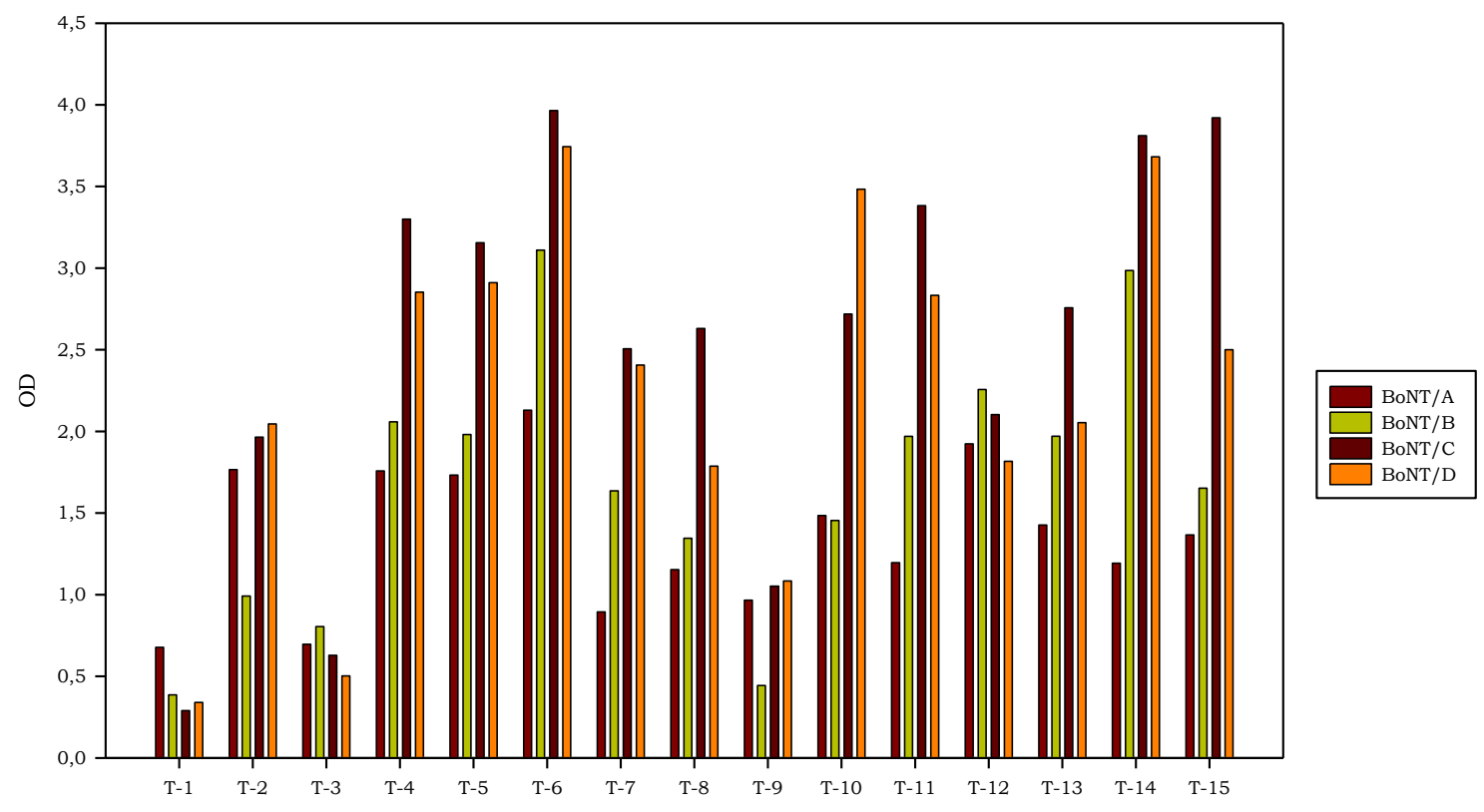

Abb. 13: Abb. 3: Anti-BoNT-Titer der Einzeltiere im Fallbetrieb FB 3

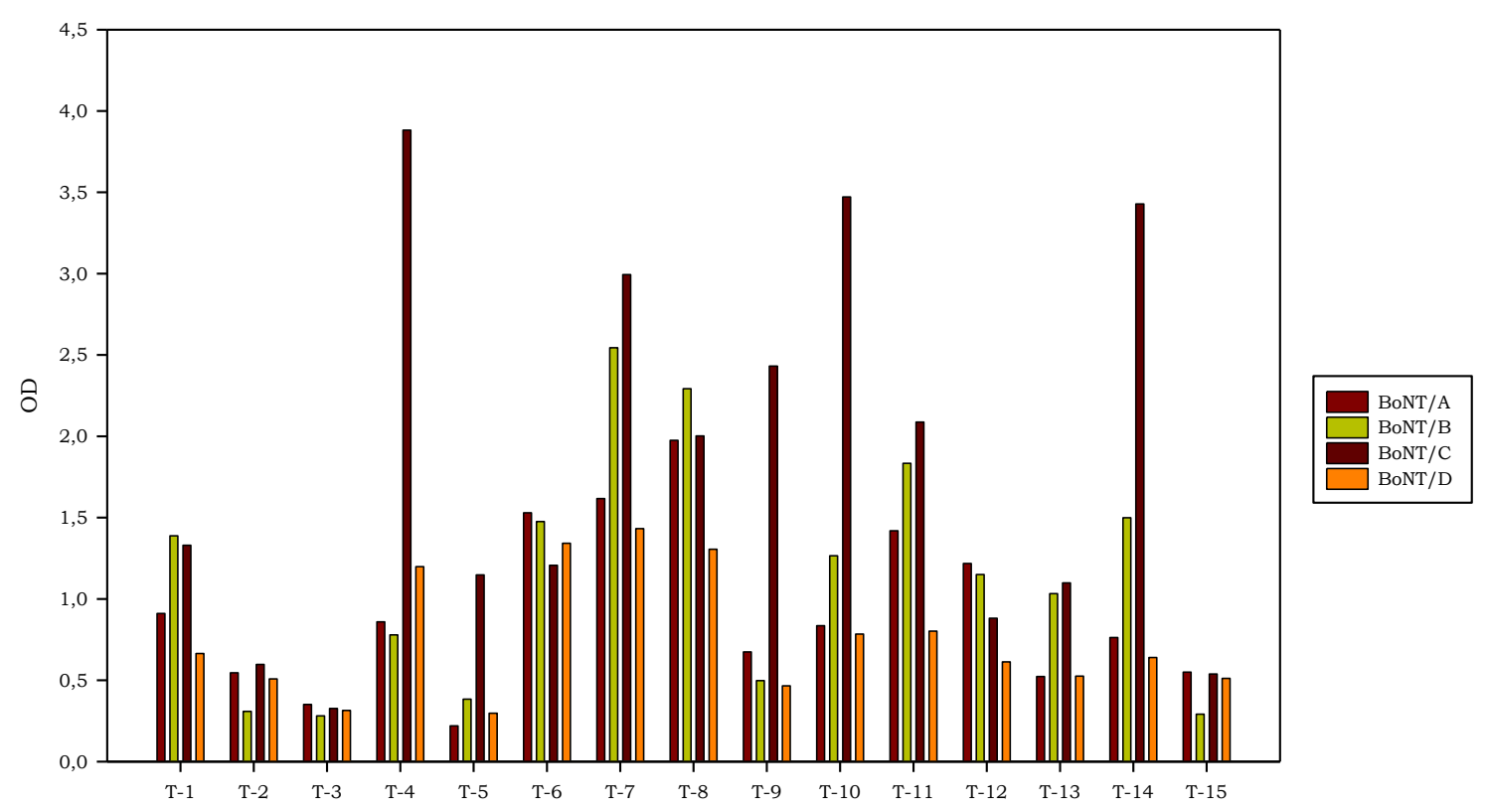

Abb. 14: Abb. 4: Anti-BoNT-Titer der Einzeltiere im Kontrollbetrieb KB 3

Alle OD (optical density)-Werte verstehen sich als arbiträre Einheiten. 


\subsection{Fragebogen}
$\square$ Fall
Kontrolle

Name des Prüfers:

Datum

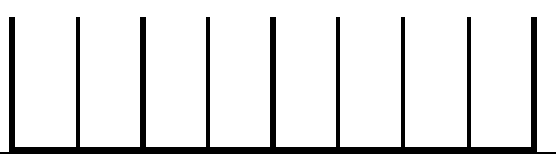

Einrichtung

des

Prüfers:

\section{Betriebsdaten}

Betriebsname:

Name verantwortliche Person:

PLZ

Ort:

Tel.:

Reg.-Nr. nach VVVO:

Hoftierarzt:

Tel.:

\section{A. BETRIEBSSTRUKTUR}

\section{A1. Bestand Milchvieh}

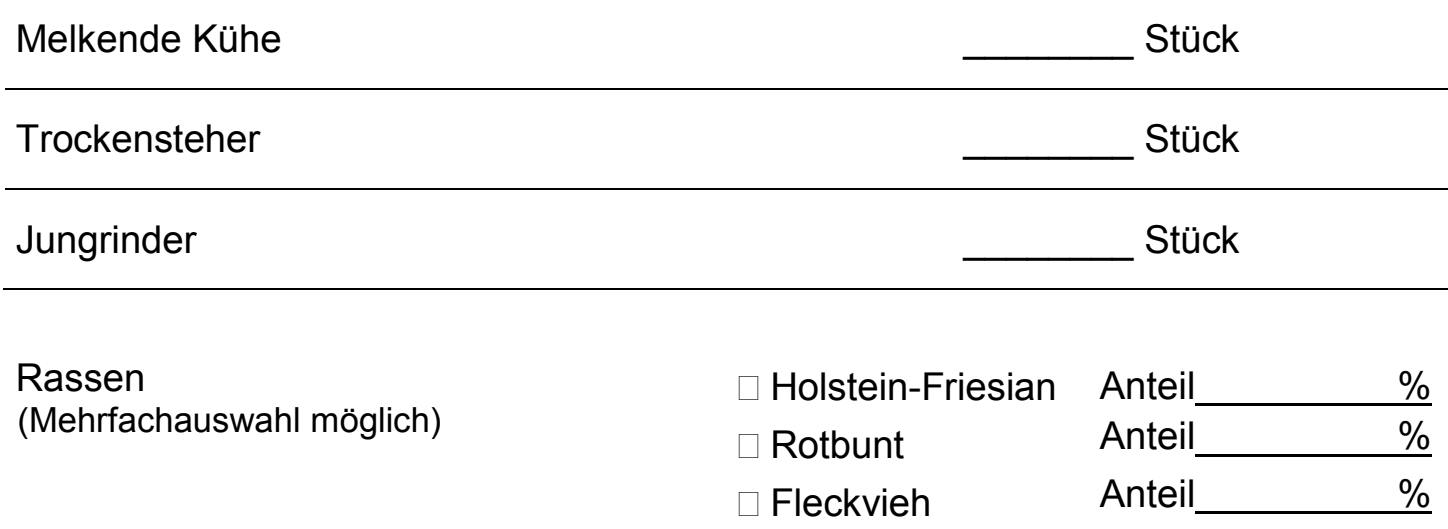


$\square$ Andere

Anteil $\%$

\section{A2. Weitere Tierhaltung}

\begin{tabular}{ll} 
Mutterkühe & Stück \\
\hline Mastrinder & Stück \\
\hline Schafe / Ziegen & Stück \\
\hline Geflügel & Stück \\
\hline Schweine & Stück \\
\hline
\end{tabular}

\section{A3. Haltung \& Reproduktion}

(Zeitraum: letzte 12 Monate)

Haltung

nur Stall

$\square$ Stall / Weide

Reproduktion

eigene Nachzucht

nur Zukauf

kombiniert

\section{A4. Leistungsdaten}

(Zeitraum: letzte 12 Monate)

\begin{tabular}{lc}
$\varnothing$ Remontierungsrate & $\%$ \\
\hline$\varnothing$ Nutzungsdauer Kühe & Jahre \\
\hline$\varnothing$ Zwischenkalbezeit aktuell & Tage \\
\hline
\end{tabular}




\section{A5. Milchleistung (monatliche Milchleistungsprüfung)}

(Zeitraum: letzte 12 Monate)

\begin{tabular}{l|l|l|l|l|}
\cline { 3 - 5 } & \multirow{2}{*}{$\begin{array}{l}\text { Aktuelle } \\
\text { Prüfung }\end{array}$} & \multicolumn{3}{c|}{ Letzte 12 Monate } \\
\cline { 3 - 5 } & & $\min$ & $\max$ & $\varnothing$ \\
\hline Melkdurchschnitt (in kg) & & & & \\
\hline Zellzahl nach MLP (in tausend) & & & & \\
\hline Fettgehalt \% & & & & \\
\hline Eiweißgehalt \% & & & & \\
\hline Harnstoffwert (in mg/l) & & & & \\
\hline
\end{tabular}

\section{A6. Jährliche Verlustdaten (Herdenprogramm)}

(Zeitraum: letzte 12 Monate)

Abortrate (Aborte/Tragende)

Aborte / Tragende

Totgeburtenrate $\%$

Kälbermortalität (<1 Mon) $\%$

Kälbermortalität (1-6 Mon) $\%$

Abgangsrate Kühe gesamt Stück

davon wegen Krankheit einschl.

Verenden, Notschlachtung

Stück

davon wegen mangelnder Leistung Stück 


\section{B. FÜTTERUNG}

\section{B1.Grünlandbewertung}

Kommt es min. 1x pro Jahr zu Überschwemmungen?

letztmalig im

(Monat / Jahr)

Nein

Keine Angabe

Ist eine starke

Maulwurfbelastung vorhanden?

$\mathrm{Ja}$

$\square$ Nein

$\square$ Nicht bekannt

Ist ein hoher Wildtierbesatz vorhanden?

Ja

$\square$ Nein

$\square$ Nicht bekannt

Wenn ja, welche Arten?

Schalenwild

Schwarzwild

Niederwild

$\checkmark$ Schadnager

$\checkmark$ Stare

$\square$ and Wildvögel

nicht bekannt

\begin{tabular}{|c|c|c|}
\hline $\begin{array}{l}\text { Nutzung des } \\
\text { Grünlandes? }\end{array}$ & $\begin{array}{l}\square \text { Schnitt: } \\
\square \text { Weide: } \\
\square \text { Schnitt \& Weide: } \\
\square \text { Keine }\end{array}$ & $\begin{array}{l}\text { Anzahl Schnitte p.a. } \\
\text { Anzahl Schnitte p.a. }\end{array}$ \\
\hline \multicolumn{2}{|c|}{ Womit erfolgt die Düngung des Grünlandes? } & $\begin{array}{l}\square \text { organisch } \\
\square \text { mineralisch } \\
\square \text { beides } \\
\square \text { keine Düngung } \\
\square \text { nicht bekannt }\end{array}$ \\
\hline
\end{tabular}


Wird Gülle oder Kot eingesetzt?

Ja, immer $\neg \mathrm{Ja}$, gelegentlich $\square$ Nie

Keine Angabe

Wenn ja, von welchen Tierarten?

Schwein

(Mehrfachauswahl möglich)

Rind

Geflügel

Nicht bekannt

Wird Fremdgülle oder Fremdkot eingesetzt?

Ja, immer

$\checkmark \mathrm{Ja}$, gelegentlich

$\square$ Nie

Keine Angabe

Wenn ja, von welchen Tierarten?

Schwein

(Mehrfachauswahl möglich)

$\square$ Rind

$\square$ Geflügel

$\square$ Nicht bekannt

Wird Biokompost zur Düngung eingesetzt?

$\square$ Ja, immer

$\checkmark \mathrm{Ja}$, gelegentlich

Nie

$\square$ Keine Angabe

Wird Biogasoutput zur Düngung verwendet?

Flüssig

Fest

Beides

Keins

Nicht bekannt

Wenn ja, woher stammen die Gärrückstände aus der Biogasanlage?
Eigen

Fremd

Beides

Nicht bekannt 
Wenn ja, welche Inputmaterialien werden bei der Biogasanlage eingesetzt? (Mehrfachauswahl möglich)

\author{
eigene Gülle \\ Schwein \\ $\square$ Rind \\ $\square$ Geflügel \\ fremde Gülle \\ Schwein \\ $\square$ Rind \\ $\square$ Geflügel \\ Maissilage \\ Grassilage \\ Schlachtabfälle
}

Anderes:

$\checkmark$ Nicht bekannt

Temperaturprofil der Biogasanlage

mesophil

thermophil

Nicht bekannt

\section{B2. Bewertung der Silierung (Grassilage)}

\begin{tabular}{|c|c|c|}
\hline $\begin{array}{l}\text { Welche Lagerungsform wird für die Silierung } \\
\text { verwendet? }\end{array}$ & $\begin{array}{l}\text { a) } \\
\text { b) }\end{array}$ & $\begin{array}{l}\square \text { Rund/Quaderballen } \\
\square \text { Fahrsilo } \\
\square \text { Beides } \\
\square \text { Nicht bekannt }\end{array}$ \\
\hline
\end{tabular}

Schnitthöhe

a) $\mathrm{cm}$

b) $\mathrm{cm}$

Häcksellänge
a) $\mathrm{cm}$
b) $\mathrm{cm}$ 
Wie hoch ist die Verschmutzung bei der Ernte?

unauffällig

mittel

stark

keine Angabe

Werden Silierzusätze beigesetzt?

biologisch

chemisch

keine

Keine Angabe

Kommt es zu einer Siloöffnung nach

Ja

Silierbeginn („Sandwichsilo“)?

Nein

Keine Angabe

Verdichtung

(„Kugelschreibertest“):

ausreichend

nicht ausreichend
Womit wird das Silo abgedeckt?

(Mehrfachnennung möglich) $\square$ Einfache Folie

$\square$ zusätzlich Unterziehfolie

Beschwerung

$\square$ Anderes:

Keine Angabe

Mindestsilierdauer in Wochen:

Wochen

Traten bei der Öffnung des Silos

Auffälligkeiten auf?

(Mehrfachnennung möglich) optische Abweichungen

$\square$ Verfärbungen
$\square$ sichtbarer Schimmelbefall

geruchliche Abweichungen

$\square$ muffig (Schimmelpilze)

$\square$ ranzig (Buttersäurebildner)

Abdeckung beschädigt

Sonstige:

$\square$ Nein

$\square$ Keine Angabe 
Silogeometrie


ohne Bodenplatte, ohne Seitenwände mit Bodenplatte, ohne Seitenwände

mit Bodenplatte, mit Seitenwänden, plane Oberfläche

mit Bodenplatte, mit Seitenwände, mit „Berg“

Sonstiges:

Keine Angabe

Silomaße

Länge: m

Breite : m

Höhe: $\mathrm{m}$

Keine Angabe

Entnahmetechnik

Greifzange

Blockschneider

Fräse

Sonstige

Keine Angabe

Vorschub $\mathrm{m} /$ Woche

\section{B3. Wasserversorgung}

Welche Wasserversorgung ist im Stall vorhanden?

(Mehrfachnennung möglich)

$\square$ Wasserleitungsnetz

$\square$ Eigener Brunnen

$\square$ Oberflächenwasser

Keine Angabe

$\square$ Wasserleitungsnetz

Eigener Brunnen

Oberflächenwasser

Keine Angabe 


\section{B4. Fütterung}

Wie findet das Fütterungsverfahren statt? (Mehrfachnennung möglich)
Einzelvorlage
Mischration
TMR
Teilmischration + Transp.
Keine Angabe

\begin{tabular}{|c|c|c|c|}
\hline Fütterung von: & Maissilage & Sensorische Abweichung: & $\begin{array}{l}\text { Ja } \\
\text { nein }\end{array}$ \\
\hline & Grassilagen & & $\begin{array}{l}\mathrm{Ja} \\
\text { nein }\end{array}$ \\
\hline & Pressschnitzel & & $\begin{array}{l}\mathrm{Ja} \\
\text { nein }\end{array}$ \\
\hline & Biertreber & & $\begin{array}{l}\mathrm{Ja} \\
\text { nein }\end{array}$ \\
\hline & Kartoffelpülpe & & $\begin{array}{l}\text { Ja } \\
\text { nein }\end{array}$ \\
\hline & Heu & & $\begin{array}{l}\text { Ja } \\
\text { nein }\end{array}$ \\
\hline & Stroh & & $\begin{array}{l}\text { Ja } \\
\text { nein }\end{array}$ \\
\hline & Eigengetreide & & $\begin{array}{l}\text { Ja } \\
\text { nein }\end{array}$ \\
\hline & $\begin{array}{l}\text { Zukauf- } \\
\text { Kraftfutter }\end{array}$ & & $\begin{array}{l}\mathrm{Ja} \\
\text { nein }\end{array}$ \\
\hline & $\begin{array}{r}\text { Sonstiges } \\
\text { Futter }\end{array}$ & & $\begin{array}{l}\mathrm{Ja} \\
\text { nein }\end{array}$ \\
\hline
\end{tabular}




\section{B5. Futtermitteluntersuchungen der Grassilage für Frischmelker / bzw. Hochleistungstiere}

\begin{tabular}{|l|l|l|l|}
\hline Parameter & $\begin{array}{c}\text { Gras- } \\
\text { silage 1 }\end{array}$ & $\begin{array}{c}\text { Gras- } \\
\text { silage 2 }\end{array}$ & Anderes: \\
\hline TS - Gehalt (g/kg) & & & \\
\hline pH-Wert & & & \\
\hline Rohasche (Sand) (g/kg TS) & & & \\
\hline Rohprotein (g/kg TS) & & & \\
\hline Rohfaser (g/kg TS) & & & \\
\hline Energiegehalt (MJ NEL / kg TS) & & & \\
\hline NH ${ }_{3}$-N \% ges-N & & & \\
\hline Keimzahlbestimmung (KbE/g) \\
(Mesophile aerobe Keimzahl)
\end{tabular}

Mikrobielle Untersuchungen: $<10^{3}, 10^{4}, 10^{5} 10^{6} \ldots>10^{10}$

\begin{tabular}{|l|l|l|l|}
\hline Deoxynivalenol & & & \\
\hline Zearalenon & & & \\
\hline Ochratoxin & & & \\
\hline Clostridium-botulinum-Toxin & & & \\
\hline
\end{tabular}

(Mykotoxine: ELISA: $\mu \mathrm{g} / \mathrm{kg} 88 \%$ TS) 


\section{TIERGESUNDHEIT}

\section{C1. Pflege der Tiere}

Tierärztl. Betreuung

$$
\begin{aligned}
& \square \text { bei Bedarf } \\
& \text { wöchentlich } \\
& \text { monatlich } \\
& 1 / 4 \text { jährlich } \\
& \text { nie } \\
& \text { keine Angabe }
\end{aligned}
$$

Klauenpflege

$$
\begin{aligned}
& \square \text { bei Bedarf } \\
& \text { wöchentlich } \\
& \text { monatlich } \\
& 1 / 4 \text { jährlich } \\
& \text { nie } \\
& \text { keine Angabe }
\end{aligned}
$$

\section{C2. Sanierungsstatus}

BHV-1-Status

$\square$ frei

nicht frei

BVD/MD-Status

unverdächtig

$\square$ nicht unverdächtig

aktuell klinische Para-Tbc im Bestand?

$\square \mathrm{Ja}$

$\square$ Nein

$\square$ Nicht bekannt

in den letzten 12 Montaten Salmonellose im

$\square \mathrm{Ja}$

Bestand?

$\square$ Nein

$\square$ Nicht bekannt 
Impfung gegen Clostridien

Nein

$\checkmark$ Ja, Name des Impfstoffes:

$\square$ Onderstepoort Bot. CD Südafrika

$\checkmark$ Bravoxin (Intervet)

$\checkmark$ Covexin (Pfizer)

$\square$ stallspezifische Vakzine

$\square$ Impferfolg

$\square$ ja

$\square$ nein

\section{C3. Klinische Untersuchung}

Herdenbeurteilung:

Welche Tiere werden im Folgenden begutachtet? alle (max. 100)

1. Leistungsgruppe

Frischmelker

Anzahl der begutachteten Tiere Stück

Anzahl derTiere mit Botulismussymptomen

- Ataxie Stück

- Reaktionsmangel

- Schlechter Allgemeinzustand 
$\rightarrow$ Auswahl von 3 Tieren den vorher definierten Tiere mit Botulismussymptomen:

Ohrmarke Tier1

Ohrmarke Tier2

Ohrmarke Tier3

\section{$\begin{array}{llll}\text { Bewertung Tier } 1 & \text { Tier } 2 & \text { Tier } 3\end{array}$}

Habitus

o.b.B.

schlecht

sehr schlecht

keine Angabe

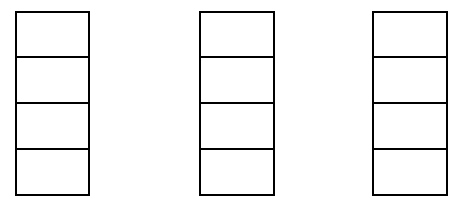

Ernährungszustand

o.b.B.

schlecht

sehr schlecht

keine Angabe

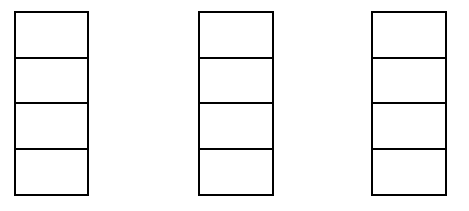

Verhalten

apathisch

gedämpft

o.b.B.

nervös, reizbar
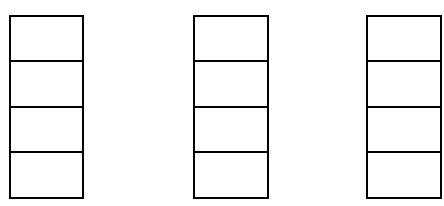

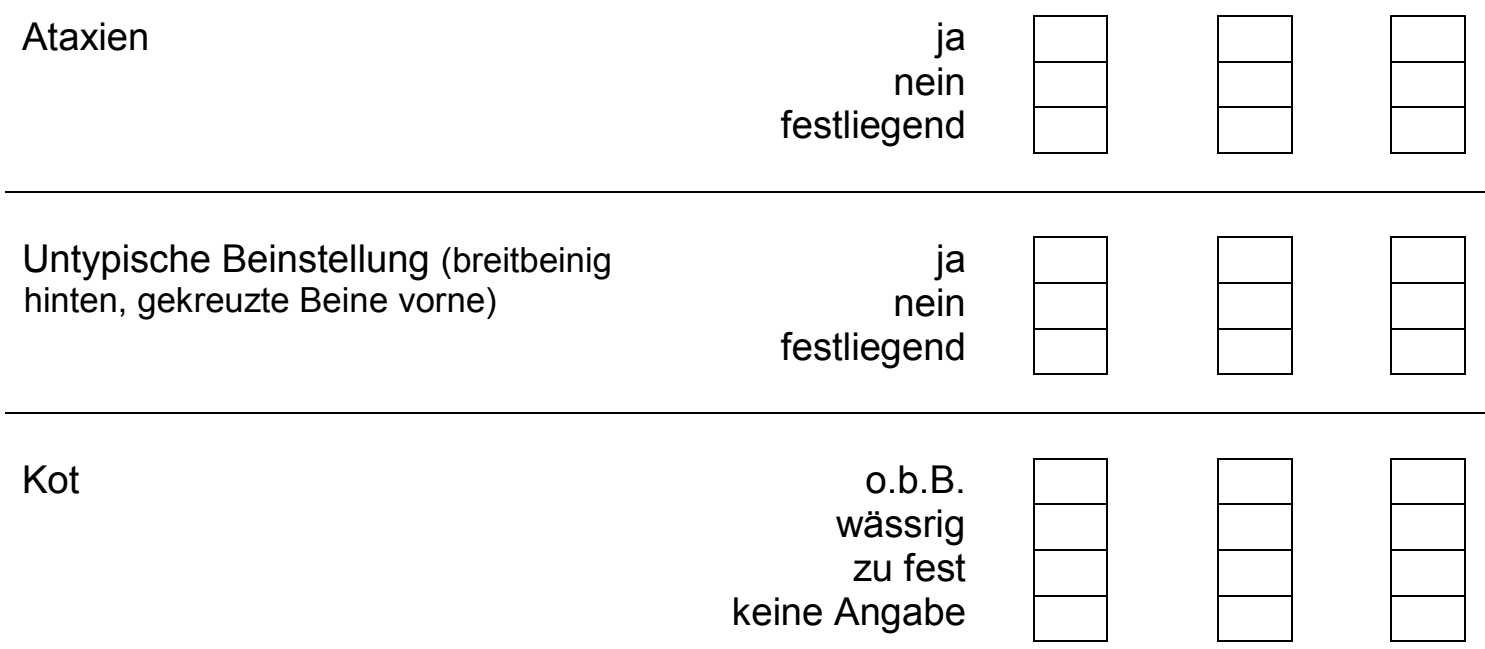


Pansen

(Mehrfachnennungen möglich)
o.b.B.

schwache

Pansenkontraktionen

Pansentympanie

keine Angabe
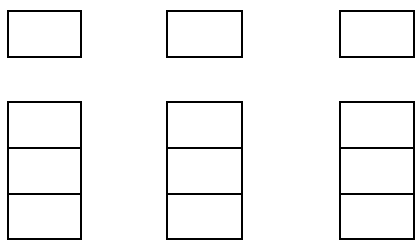

Wiederkauverhalten

o.b.B. eingeschränkt keine Angabe


Darm

o.b.B.

Dystonie Tympanie keine Angabe
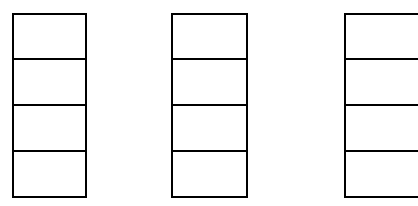

tröpfelnder Harnabsatz

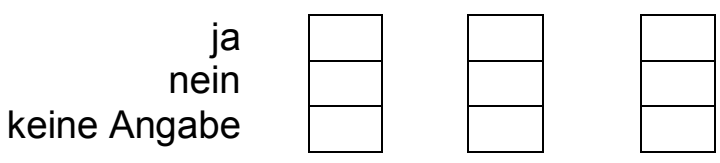

Gestaute Venen

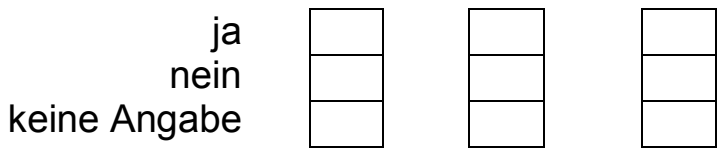

Ödeme

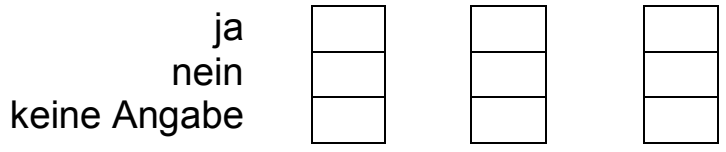

Atmung

o.b.B. auffällig keine Angabe
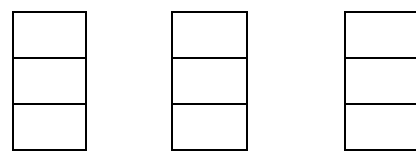

Entzündungen an Klauen oder Gelenken

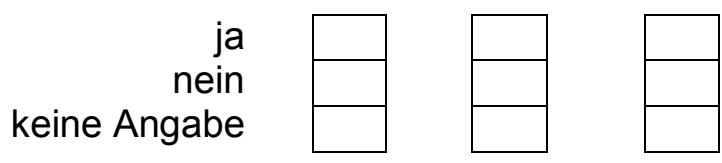

Muskelatrophie (Glutäen)

\begin{tabular}{c|c|} 
ja \\
nein \\
\end{tabular}


Keine oder schwache Abwehrbewegungen bei Manipulationen am Kopf

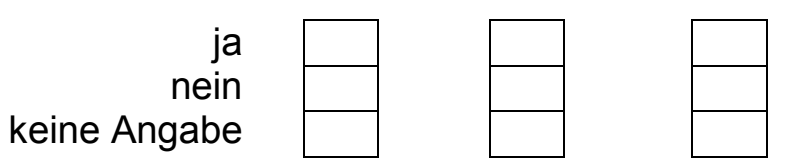

Mydriasis bei Lichteinfall;

Pupillenstarre

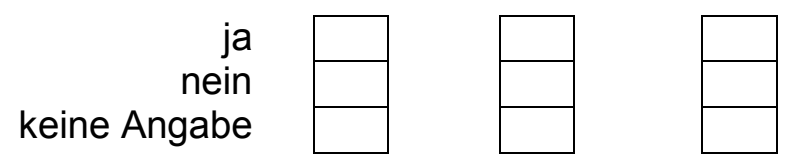

Fehlender Lidreflex

(kaum Blinzeln bei Berührung des Lides)

\begin{tabular}{c|c|} 
ja \\
nein \\
\end{tabular}

Fehlender Ohrenreflex

(Berührung innere Ohrmuschel schwache Reaktion des Ohres)

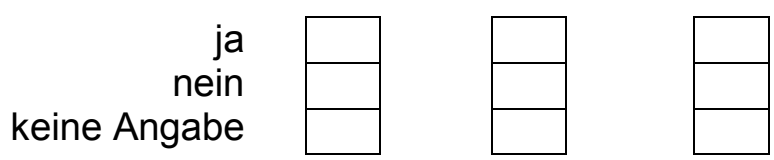

Schluckbeschwerden

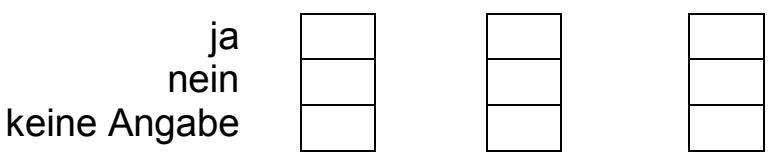

Lautäußerungen

o.b.B.

kurzes, heiseres

Anstossen

keine Angabe
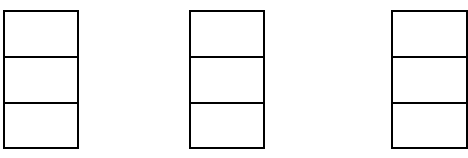

Zungenreflex eingeschränkt

(Rausziehen und langsames/ kein

Zurückziehen der Zunge)

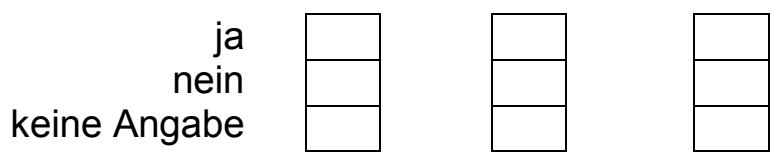

Muköser Speichel

(„fester Schaum vorm Maul“)

\begin{tabular}{c|c|} 
ja \\
nein \\
keine Angabe
\end{tabular}

Hängende Unterlippe, loser

Unterkiefer

\begin{tabular}{c|c|} 
ja & $\square$ \\
nein \\
\end{tabular}

Anal-/Schwanzreflex eingeschränkt (schwache Schwanzbewegung)

\begin{tabular}{c|c|} 
ja \\
nein \\
\end{tabular}

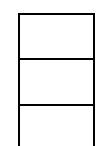


Hautreflex eingeschränkt (Berührung der Schulterregion mit Kugelschreiber o. Reaktion/ keine Fliegenabwehr)

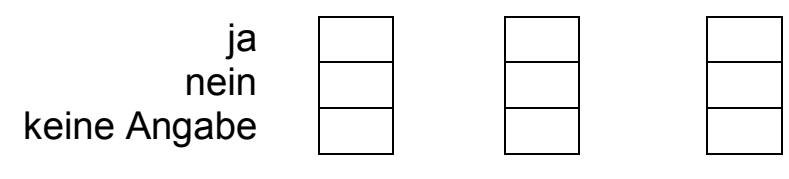

Klauen (Kronsaum)- Reflex eingeschränkt

(keine Beugung oder Wegziehen der Klaue bei Reizung)

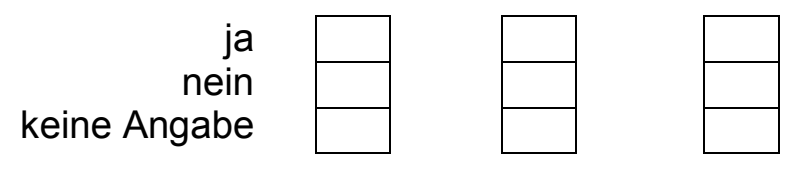

Fibularislähmung

(Einknicken in der Hinterhand, ja

Sprunggelenkstreckung eingeschränkt, keine Angabe Überköten)

Ischiadikuslähmung

(Nachschleifen des Hinterbeines,

Nachziehen der Klaue)

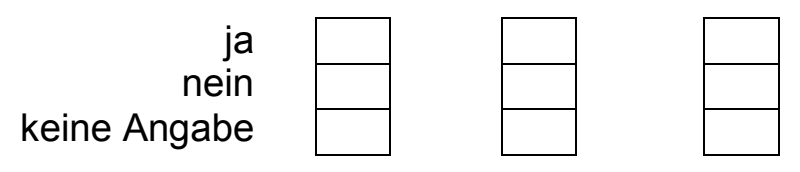

\begin{tabular}{|l|}
\hline \\
\hline
\end{tabular}
Obturatoriuslähmung

(auswärts seitliches, zitterndes, steifes Hochführen der Hinterbeine im Gehen mit verlangsamter Heranführung des

Beines = Adductorenschwäche)

Radialislähmung

(Überköten vorne)

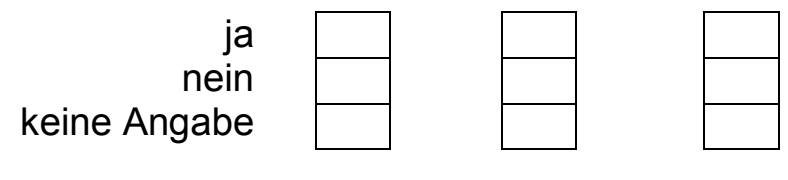

\section{ja \\ nein \\ keine Angabe
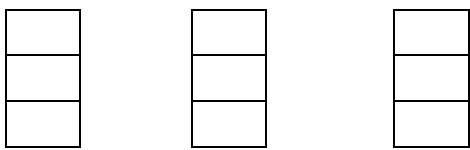

Kotuntersuchung von den 3 klinisch untersuchten Tieren

\begin{tabular}{|l|c|c|c|c|}
\cline { 2 - 4 } \multicolumn{1}{l|}{} & Ohrmarke: & & & \\
\cline { 2 - 5 } \multicolumn{1}{l|}{ C. perfringens } & Nachweis & $\square$ & & \\
\hline C. botulinum & Nachweis & $\square$ & $\square$ & \\
\hline Clostridien n. spez. & Nachweis & $\square$ & $\square$ & \\
\hline $\begin{array}{l}\text { Salmonellen } \\
\text { Mykobakterien / } \\
\text { säurefeste } \\
\text { Stäbchen }\end{array}$ & Nachweis & $\square$ & $\square$ & \\
\hline
\end{tabular}




\section{C4. Laboruntersuchung vom Bestand}

Zufällige Auswahl von $\mathbf{5}$ symptomatisch unauffälligen Tieren

Parameterbestimmung zu 3 Zeitpunkten:

I.7 -0 Tage a.p.

II. 0 - 7 Tage p.p.

III.6. -8 . Woche p.p.

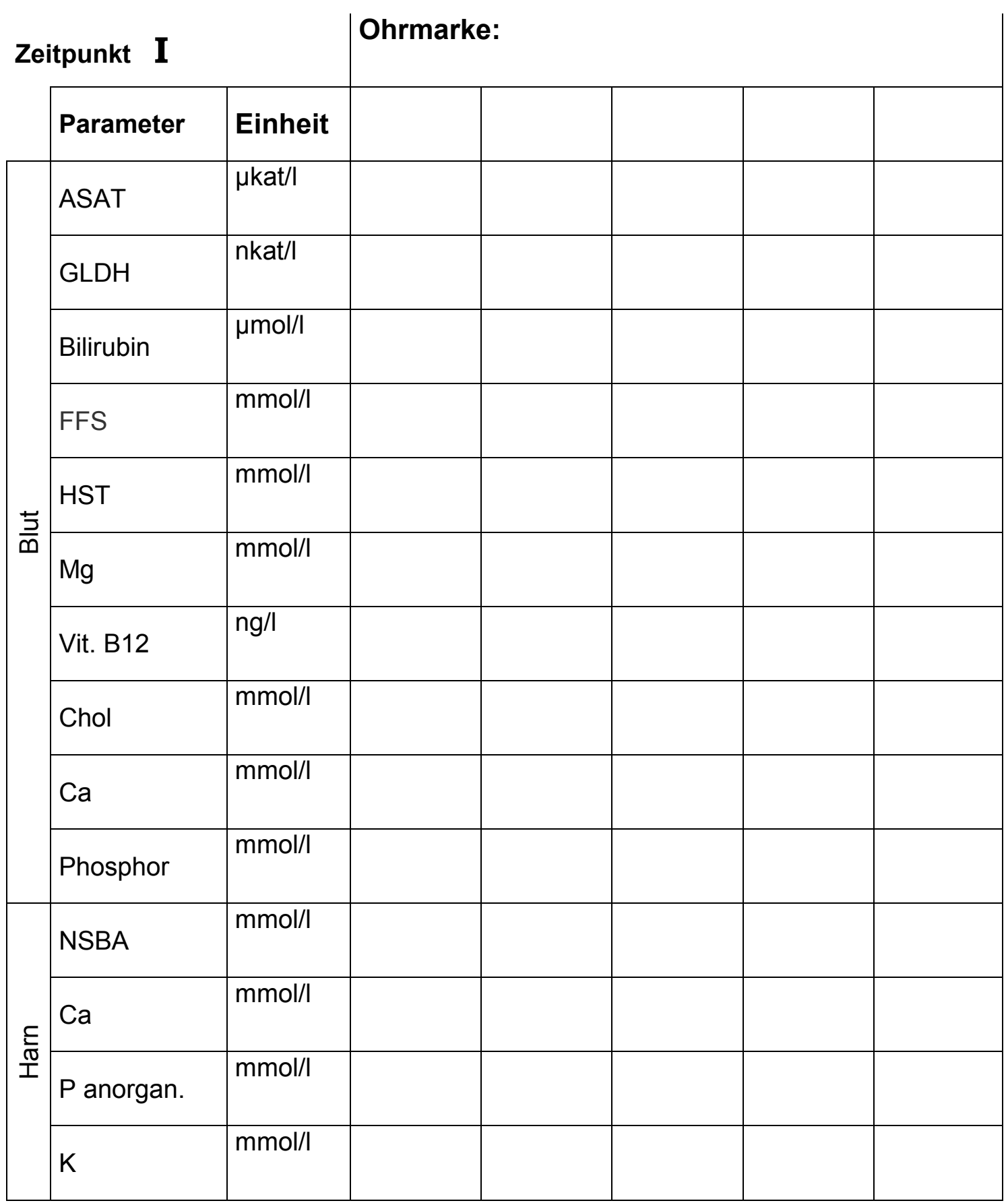




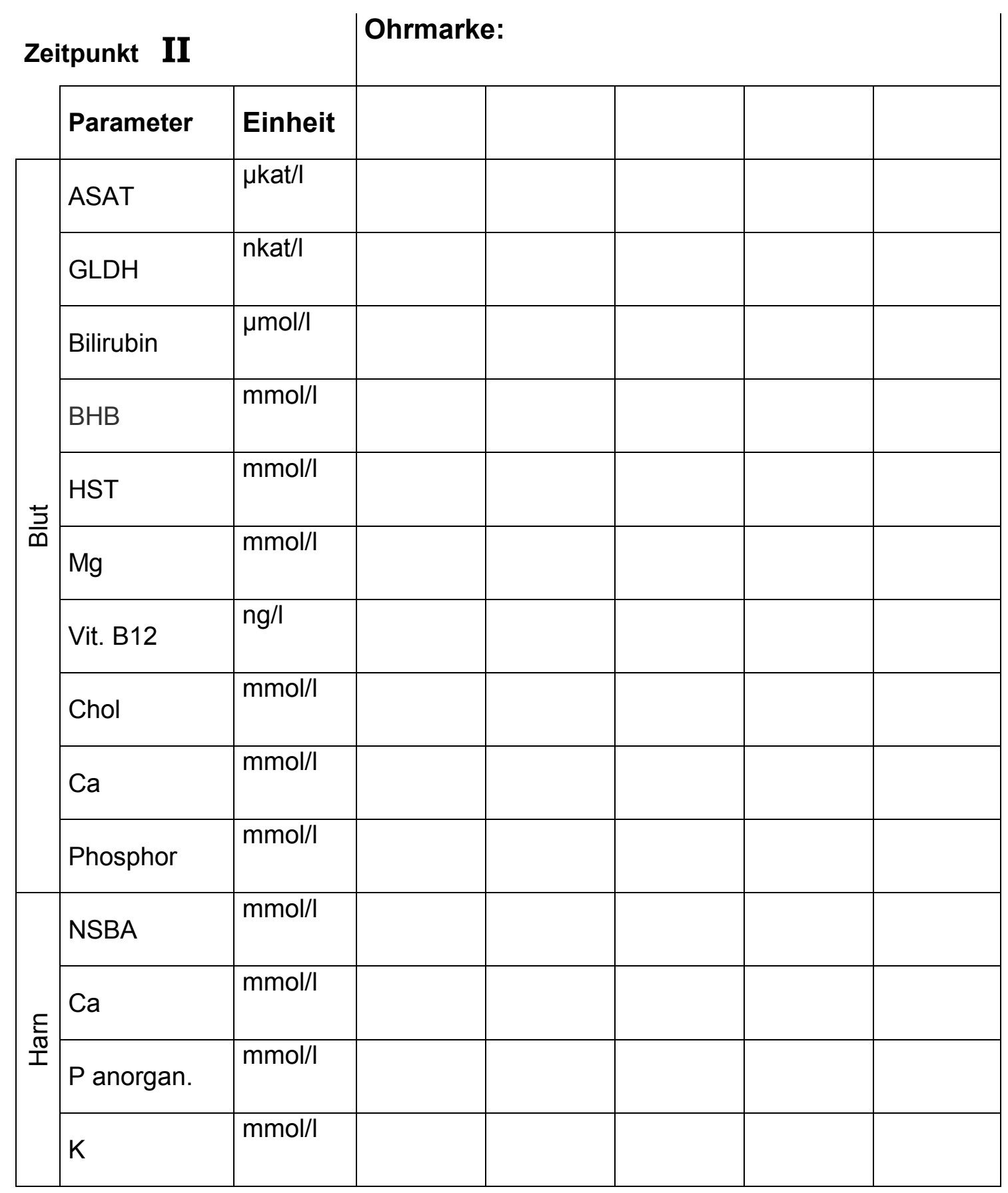




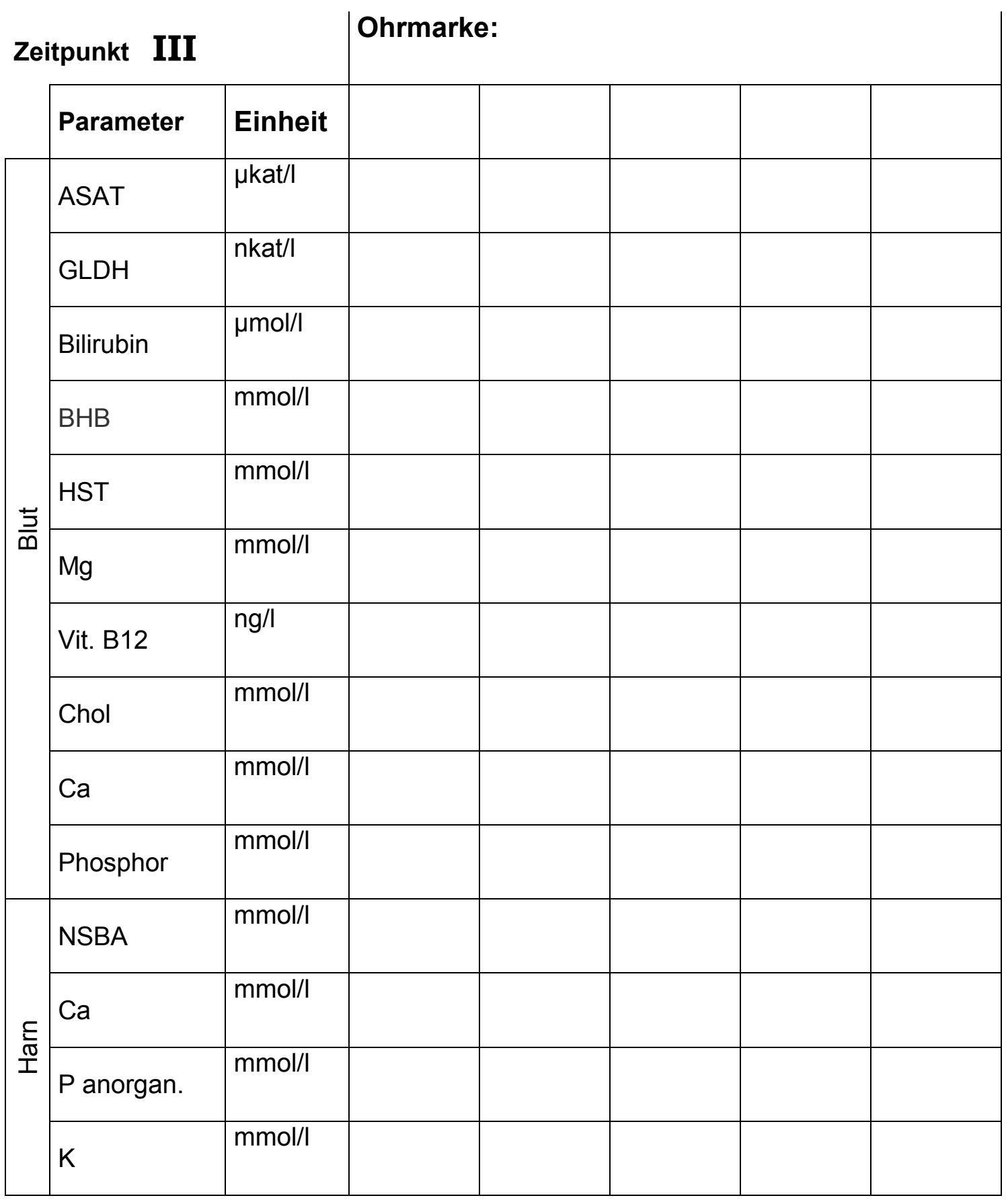


C5. Pathologische Untersuchung vom Bestand

Obligatorisch:

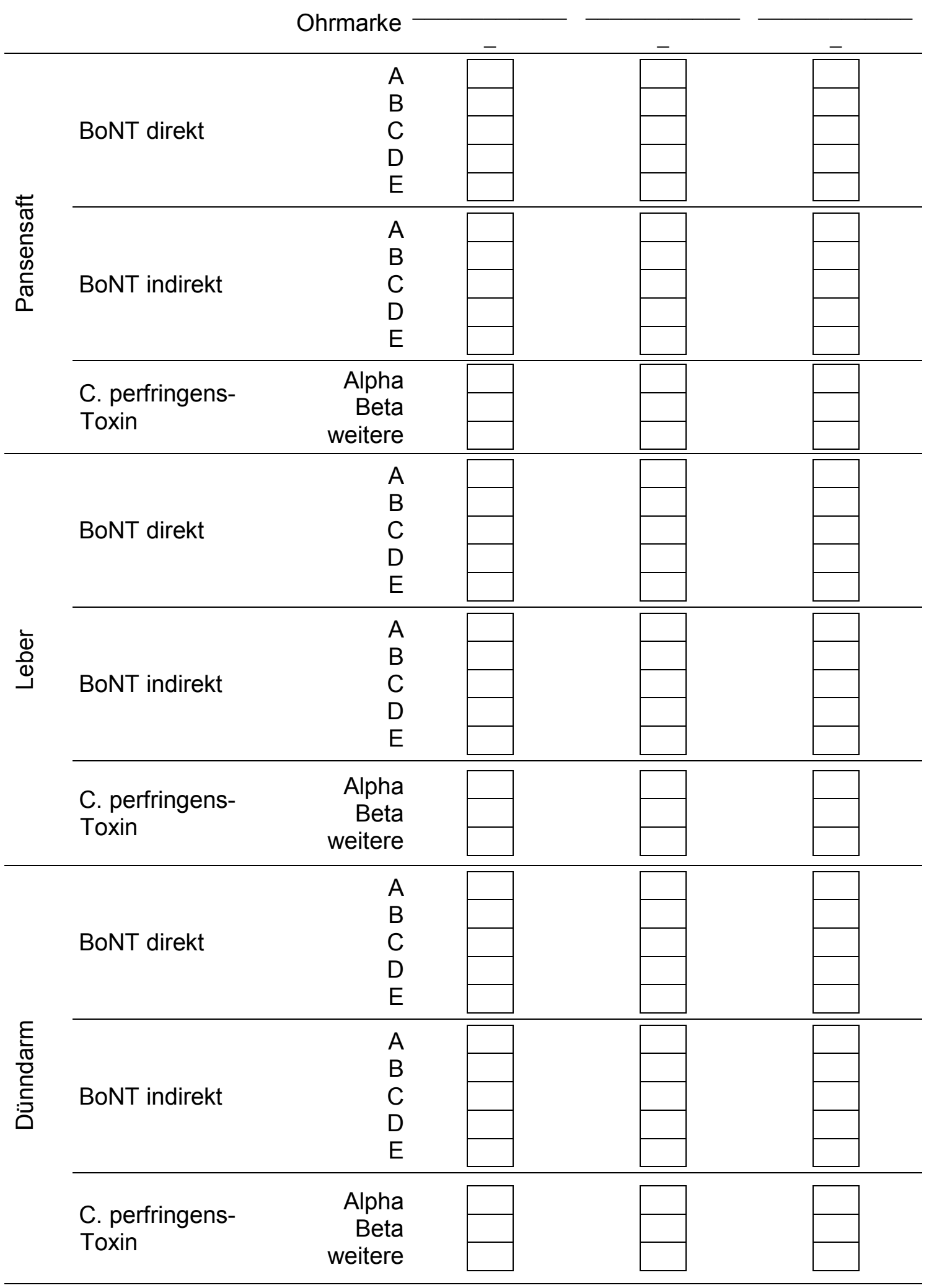









\section{Danksagung}

Herrn Prof. Dr. Dr. H. Böhnel danke ich sehr herzlich für die Aufnahme als Doktorandin und wissenschaftliche Mitarbeiterin in seine Arbeitsgruppe, für die Überlassung des Themas, für das in mich gesetzte Vertrauen sowie für die kritische Durchsicht des Manuskriptes.

Mein besonderer Dank gilt Herr PD Dr. Frank Gessler für die Betreuung meiner Arbeit und die jederzeit gewährte Unterstützung. Vielen Dank für die immer offene Tür und die Zeit, mir bei der Planung und Durchführung dieser Arbeit zur Seite zu stehen und gemeinsam Lösungsansätze zu diskutieren.

Herrn Prof. Dr. M. Gauly danke ich für die Übernahme des Korreferates.

Dem Bundesministerium für Bildung und Forschung (BMBF) sei an dieser Stelle für die Finanzierung meiner Arbeit im Rahmen des Verbundprojektes "Die Zoonose Botulismus. Der Weg des Botulinumtoxins aus dem Bakterium in die Zielzelle" (01KI0740 Project C4 und B2011-01KI0744-01F_110815) gedankt.

Frau Dr. B. Schwagerick, die die Auswahl der Betriebe und die Datenerhebung übernahm und mich an ihrem umfassenden tiermedizinischen Erfahrungsschatz teilhaben ließ, gebührt mein besonderer Dank. Weiterhin möchte ich mich bei Herrn Jongmanns für die Pansensaftentnahme und die damit verbundene Zeit recht herzlich bedanken. Ich danke auch allen teilnehmenden Landwirten für die freundliche Aufnahme und Unterstützung. Ohne ihre bereitwillige Hilfe wäre diese Studie nicht möglich gewesen.

Ich danke Frau Dr. R. Merle und Frau B. Schneider vom Institut für Biometrie, Epidemiologie und Informationsverarbeitung der Tierärztlichen Hochschule Hannover für die Erstellung der Datenbank und die Einführung in die Software, sowie für die Ratschläge für den Umgang mit dem Datenmaterial.

Allen Kollegen der miprolab GmbH, des IBT Göttingen und der AG Botulinom an der Georg-August-Universität Göttingen gilt mein allergrößter Dank für die freundliche Aufnahme in die Arbeitsgemeinschaft, die umfangreiche Einarbeitung in die verschiedensten Methoden und besonders für den gemeinsam absolvierten SchlussSprint. Vielen Dank für die schönen Stunden!

Meinen Eltern danke ich dafür, dass sie mir den gewählten Weg ermöglichten und mich in jeder Hinsicht unterstützten. Und last but not least danke ich meinem Mann von ganzem Herzen für seinen steten Zuspruch, sein Verständnis und die Unterstützung bei der Erstellung dieser Arbeit. Du bis ming Hätz, du bis ming Jlöck! 